Prepared for the U.S. Department of Energy

under Contract DE-AC05-76RL01830

\title{
300 Area Uranium Stabilization Through Polyphosphate Injection: Final Report
}
VR Vermeul
DP Mendoza
BN Bjornstad
DR Newcomer
BG Fritz
ML Rockhold
JS Fruchter
DM Wellman
RD Mackley
MD Williams

June 2009

Pacific Northwest

NATIONAL LABORATORY

Proudly Operated by Battelle Since 1965 


\title{
DISCLAIMER
}

This report was prepared as an account of work sponsored by an agency of the United States Government. Neither the United States Government nor any agency thereof, nor Battelle Memorial Institute, nor any of their employees, makes any warranty, express or implied, or assumes any legal liability or responsibility for the accuracy, completeness, or usefulness of any information, apparatus, product, or process disclosed, or represents that its use would not infringe privately owned rights. Reference herein to any specific commercial product, process, or service by trade name, trademark, manufacturer, or otherwise does not necessarily constitute or imply its endorsement, recommendation, or favoring by the United States Government or any agency thereof, or Battelle Memorial Institute. The views and opinions of authors expressed herein do not necessarily state or reflect those of the United States Government or any agency thereof.

\author{
PACIFIC NORTHWEST NATIONAL LABORATORY \\ operated by \\ BATTELLE \\ for the \\ UNITED STATES DEPARTMENT OF ENERGY \\ under Contract DE-AC05-76RL01830
}

Printed in the United States of America
Available to DOE and DOE contractors from the Office of Scientific and Technical Information,
P.O. Box 62, Oak Ridge, TN 37831-0062;
ph: (865) 576-8401
fax: $(865) 576-5728$
email: reports@adonis.osti.gov

\begin{abstract}
Available to the public from the National Technical Information Service, U.S. Department of Commerce, 5285 Port Royal Rd., Springfield, VA 22161 ph: (800) 553-6847 fax: $(703) 605-6900$

email: orders@ntis.fedworld.gov

online ordering: http://www.ntis.gov/ordering.htm
\end{abstract}




\title{
300 Area Uranium Stabilization Through Polyphosphate Injection: Final Report
}

\author{
VR Vermeul \\ DP Mendoza \\ BN Bjornstad \\ DR Newcomer \\ BG Fritz \\ ML Rockhold \\ JS Fruchter \\ DM Wellman \\ RD Mackley \\ MD Williams
}

June 2009

Prepared for

the U.S. Department of Energy

under Contract DE-AC05-76RL01830

Pacific Northwest National Laboratory

Richland, Washington 99352 



\section{Executive Summary}

For fiscal year 2006, the United States Congress authorized \$10 million dollars to Hanford for

"... analyzing contaminant migration to the Columbia River, and for the introduction of new technology approaches to solving contamination migration issues." These funds are administered through the U.S. Department of Energy Office of Environmental Management (specifically, EM-22). After a peer review and selection process, nine projects were selected to meet the objectives of the appropriation. As part of this effort, Pacific Northwest National Laboratory (PNNL) is performing bench- and field-scale treatability testing designed to evaluate the efficacy of using polyphosphate injections to reduce uranium concentrations in the groundwater to meet drinking water standards $(30 \mu \mathrm{g} / \mathrm{L})$ in situ. This technology works by forming phosphate minerals (autunite and apatite) in the aquifer, which directly sequesters the existing aqueous uranium in autunite minerals and precipitates apatite minerals for sorption and long-term treatment of uranium migrating into the treatment zone, thus reducing current and future aqueous uranium concentrations. Polyphosphate injection was selected for testing based on technology screening as part of the 300-FF-5 Phase III Feasibility Study for treatment of uranium in the 300 Area.

The objective of the treatability test was to evaluate the efficacy of using polyphosphate injections to treat uranium-contaminated groundwater in situ. A test site consisting of an injection well and 15 monitoring wells was installed in the 300 Area near the process trenches that had previously received uranium-bearing effluents. This report summarizes the work on the polyphosphate injection project, including bench-scale laboratory studies, a field injection test, and the subsequent analysis and interpretation of the results.

Previous laboratory tests have demonstrated that when a soluble form of polyphosphate is injected into uranium-bearing saturated porous media, immobilization of uranium occurs due to formation of an insoluble uranyl phosphate, autunite $\left[\mathrm{Ca}\left(\mathrm{UO}_{2}\right)_{2}\left(\mathrm{PO}_{4}\right)_{2} \cdot \mathrm{nH}_{2} \mathrm{O}\right]$. These tests were conducted at conditions expected for the aquifer and used Hanford soils and groundwater containing very low concentrations of uranium $\left(10^{-6} \mathrm{M}\right)$. Because autunite sequesters uranium in the oxidized form $\mathrm{U}(\mathrm{VI})$ rather than forcing reduction to $\mathrm{U}(\mathrm{IV})$, the possibility of re-oxidation and subsequent re-mobilization is negated. Extensive testing demonstrated the very low solubility and slow dissolution kinetics of autunite. In addition to autunite, excess phosphorous may result in apatite mineral formation, which provides a long-term source of treatment capacity. Based on results from the column transport experiments, a three-phase injection strategy was identified as an effective approach to attain both direct treatment of the uranium contamination in groundwater (i.e., autunite formation) and formation of the calcium-phosphate mineral apatite.

Amendment arrival response data from the three phases of the injection test indicate significantly lower reactive constituent retardation than was predicted based on laboratory-scale column experiments. The lower effective retardations resulted in only limited overlap between the calcium and phosphate amendments during the transition between injection phases, and thus limited calcium-phosphate mineral formation. Phosphate arrival response data indicate that, under site conditions, the polyphosphate amendment could be effectively distributed over a relatively large lateral extent, with wells located at a

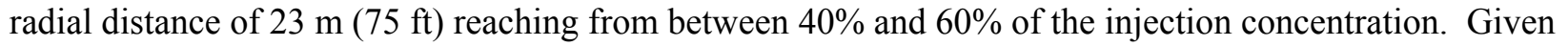
these phosphate transport characteristics, direct treatment of uranium through the formation of uranyl-phosphate mineral phases (i.e., autunite) could likely be effectively implemented at full field scale. However, formation of calcium-phosphate mineral phases using the selected three-phase approach was 
problematic. Although amendment arrival response data indicate some degree of overlap between the reactive species and thus potential for the formation of calcium-phosphate mineral phases (i.e., apatite formation), the efficiency of this treatment approach was relatively poor.

Evaluation of pressure response (both prior to and during the polyphosphate injection test) and amendment transport behavior during the three separate phases of the injection test provided evidence of both changes in the spatial distribution of aquifer permeability and an overall reduction in the bulk permeability of the aquifer materials. The results of the hydraulic analysis of the pressure recovery response in the four selected monitoring wells indicate an average hydraulic conductivity (K) estimate of $\sim 600 \mathrm{~m} /$ day $(2,000 \mathrm{ft} /$ day). The average pre-treatment $\mathrm{K}$ estimate for the aquifer was $\sim 4000 \mathrm{~m} /$ day $(13,000 \mathrm{ft} /$ day $)$, which is over six times higher than the post-treatment $\mathrm{K}$.

The baseline uranium concentration in the targeted primary treatment zone ranged from approximately 60 to $80 \mathrm{ug} / \mathrm{L}$ during the three pre-treatment monitoring events. After the injection test, aqueous uranium concentrations were routinely monitored to assess treatment performance. The initial uranium performance data indicate relatively good direct treatment of uranium through the formation of uranyl-phosphate mineral phases (i.e., autunite). Although initial post-treatment uranium concentrations decreased to below the drinking water standard of $30 \mathrm{ug} / \mathrm{L}$, a significant rebound in uranium concentration was observed approximately 2 months after treatment. In general, uranium performance monitoring results support the hypothesis that limited long-term treatment capacity (i.e., apatite formation) was established during the injection test.

Two separate overarching issues affect the efficacy of apatite remediation for uranium sequestration within the 300 Area: 1) the efficacy of apatite for sequestering uranium under the present geochemical and hydrodynamic conditions, and 2) the formation and emplacement of apatite via polyphosphate technology. In addition, the long-term stability of uranium sequestered via apatite is dependent on the chemical speciation of uranium, surface speciation of apatite, and the mechanism of retention, which is highly susceptible to dynamic geochemical conditions. It was expected that uranium sequestration in the presence of hydroxyapatite would occur by sorption and/or surface complexation until all surface sites have been depleted, but that the high carbonate concentrations in the 300 Area would act to inhibit the transformation of sorbed uranium to chernikovite and/or autunite. Adsorption of uranium by apatite was never considered a viable approach for in situ uranium sequestration in and of itself, because by definition, this is a reversible reaction. The efficacy of uranium sequestration by apatite assumes that the adsorbed uranium would subsequently convert to autunite, or other stable uranium phases. Because this appears to not be the case in the 300 Area aquifer, even in locations near the river, apatite may have limited efficacy for the retention and long-term immobilization of uranium at the 300 Area site. 


\section{Acknowledgments}

Funding for this project was provided by U.S. Department of Energy, EM-22, under the Columbia River Protection Supplementary Technologies Project. The authors would like to acknowledge the support of Jane Borghese, currently with the CH2M Hill Plateau Remediation Contractor, and Mike Thompson of the U.S. Department of Energy, Richland Office during this project. 



\section{Acronyms and Abbreviations}

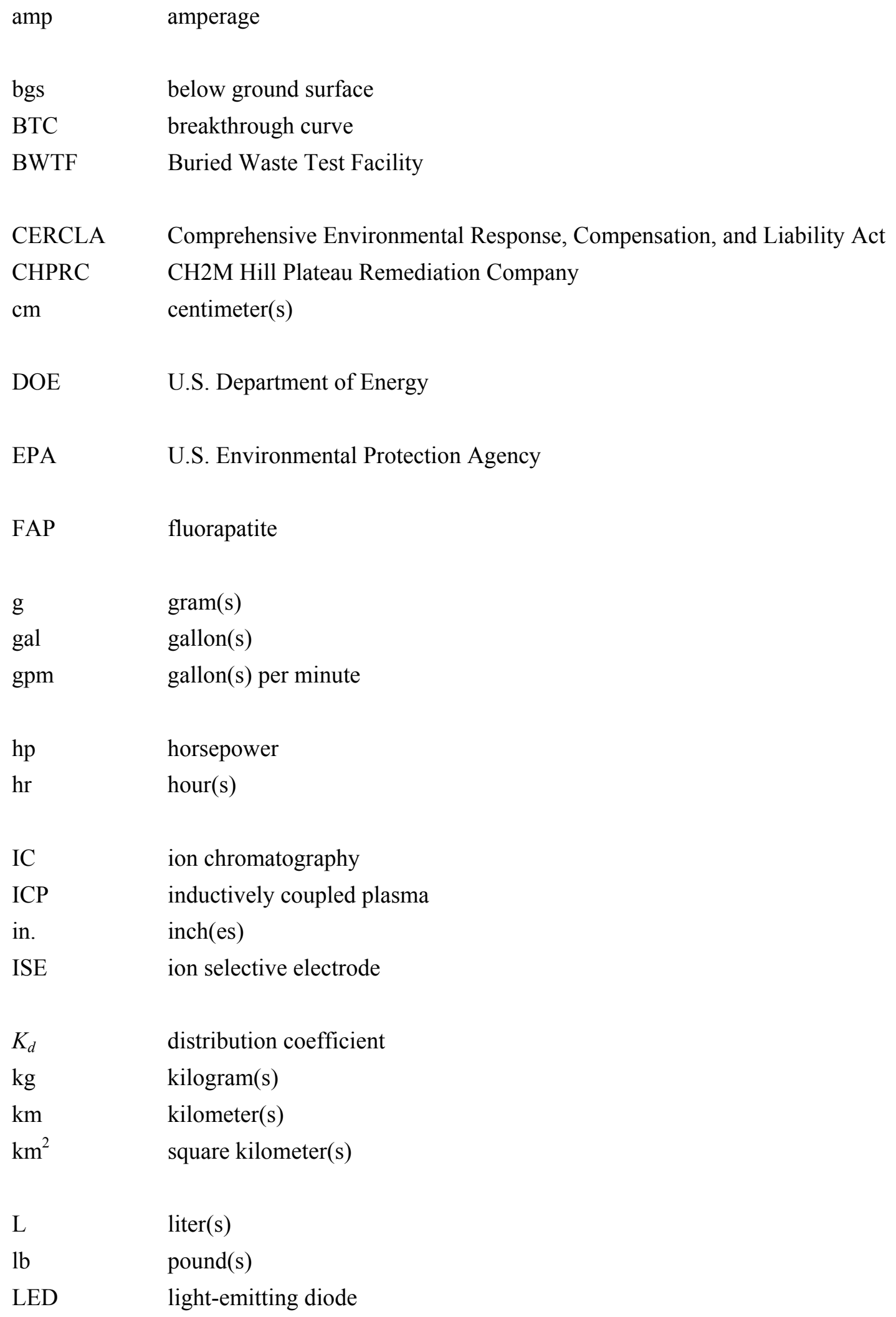




\begin{tabular}{|c|c|}
\hline LFI & limited field investigation \\
\hline Lpm & liter(s) per minute \\
\hline $\mathrm{m}$ & meter(s) \\
\hline $\mathrm{m}^{3}$ & cubic meter(s) \\
\hline MCL & maximum contaminant level \\
\hline $\mathrm{mg}$ & milligram(s) \\
\hline $\min$ & minute(s) \\
\hline MS & mass spectrometer \\
\hline $\mathrm{mV}$ & millivolt(s) \\
\hline $\mathrm{OCP}$ & octacalcium phosphate \\
\hline OES & optical emission spectrometry \\
\hline PNNL & Pacific Northwest National Laboratory \\
\hline $\mathrm{ppb}$ & parts per billion \\
\hline PV & pore volume \\
\hline PVC & polyvinyl chloride \\
\hline RCRA & Resource Conservation and Recovery Act \\
\hline SBMS & Standards-Based Management System \\
\hline$\mu \mathrm{m}$ & micrometer(s) \\
\hline$\mu \mathrm{S} / \mathrm{cm}$ & microsiemens per centimeter \\
\hline UV & ultraviolet \\
\hline $\mathrm{V}$ & velocity \\
\hline $\mathrm{yd}^{3}$ & cubic yard(s) \\
\hline
\end{tabular}




\section{Contents}

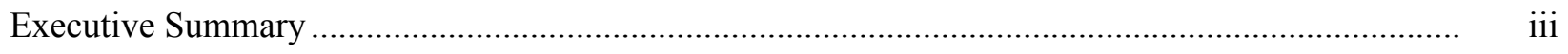

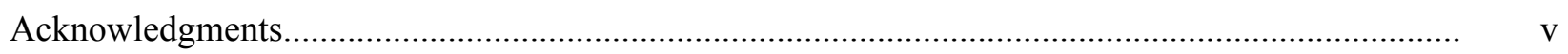

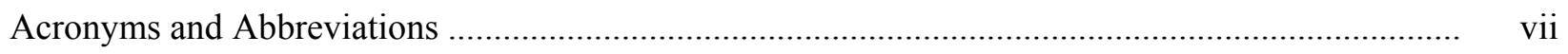

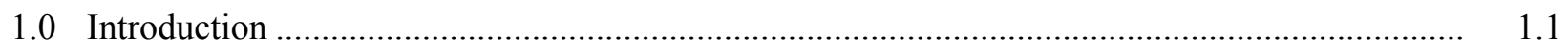

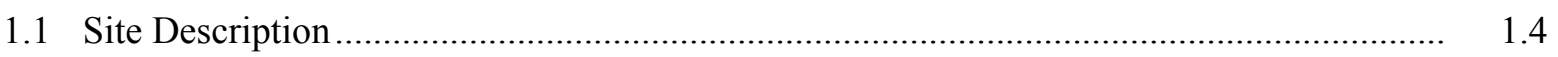

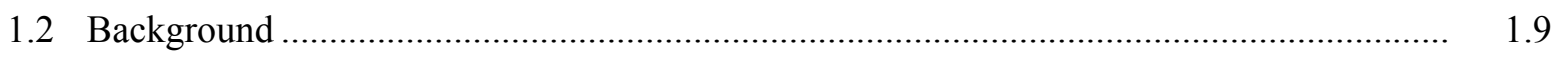

1.3 Polyphosphate Technology Description..................................................................... 1.9

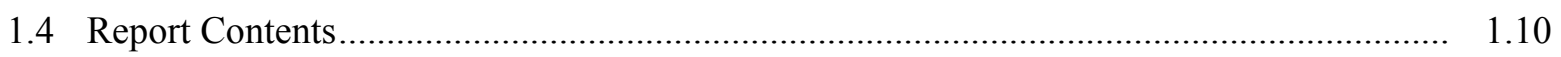

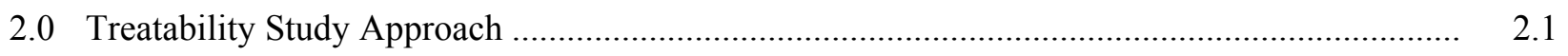

2.1 Treatability Test Objectives …................................................................................. 2.1

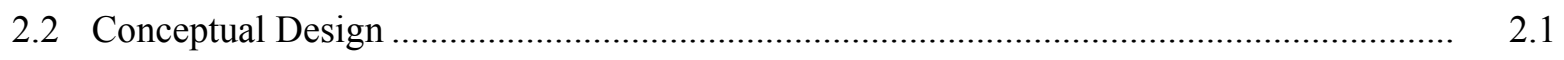

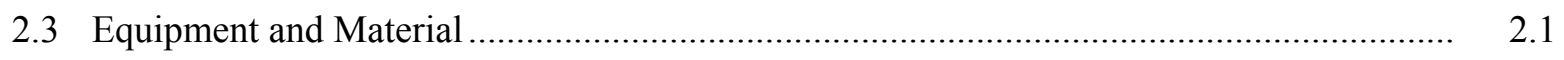

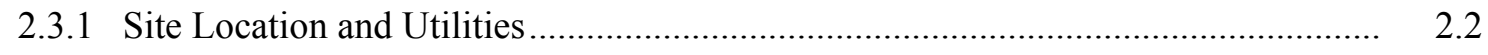

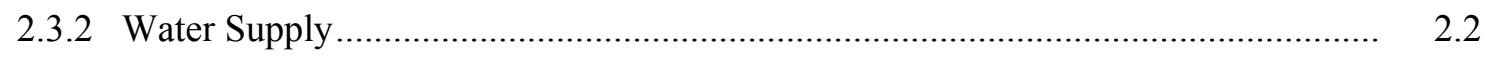

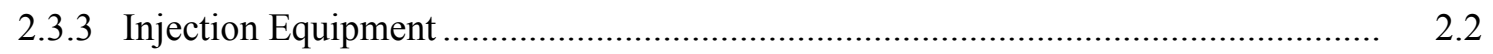

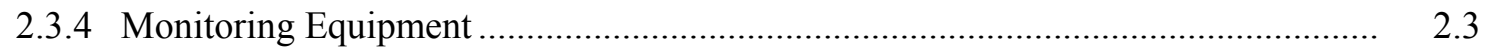

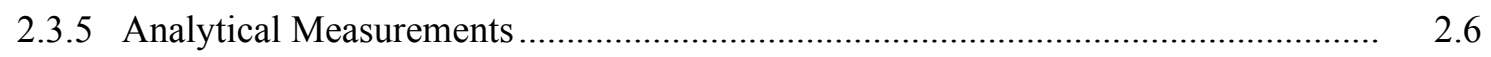

2.3.6 Water-Level/Pressure Response Measurement .................................................... 2.6

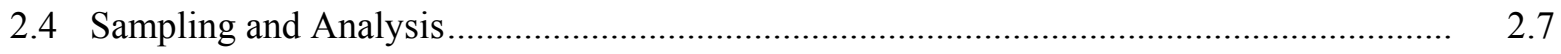

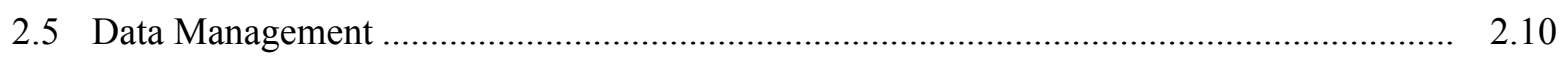

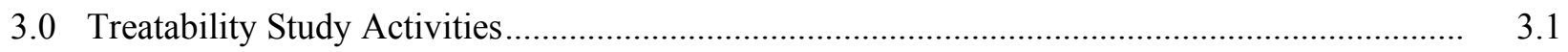

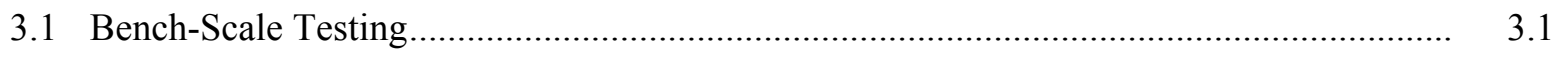

3.1.1 Polyphosphate Remediation Technology ....................................................... 3.1

3.1.2 Autunite and Apatite Formation..................................................................... 3.3

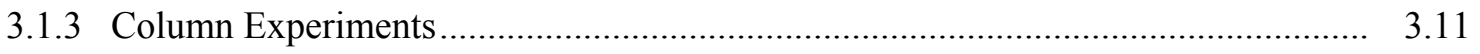

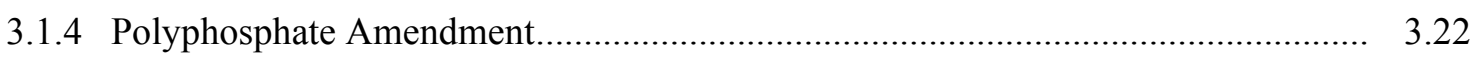

3.2 Site-Specific Characterization .............................................................................. 3.24

3.2.1 Well Installation and Geohydrologic Characterization ....................................... 3.24

3.2.2 Tracer Injection Testing .................................................................... 3.41

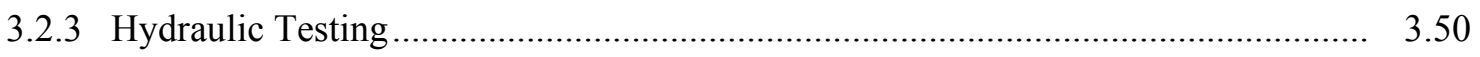

3.2.4 Baseline Groundwater Monitoring ................................................................. 3.58

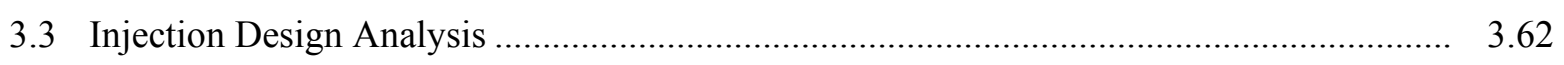

3.3.1 Injection Volume and Rates ...................................................................... 3.62

3.3.2 Treatability Test Numerical Model Description................................................. 3.67

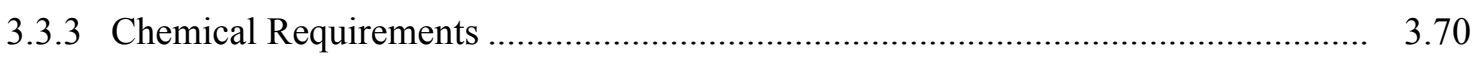

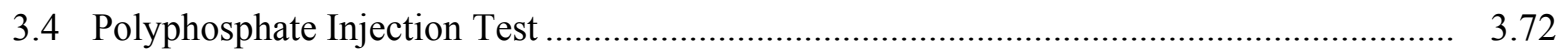




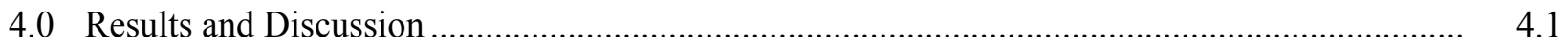

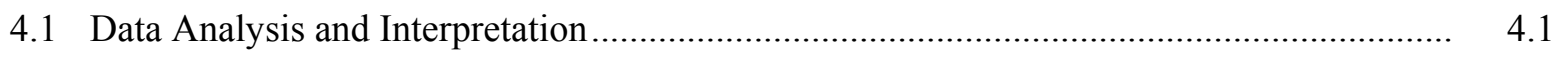

4.1.1 Assessment of Amendment Arrivals .................................................................... 4.1

4.1.2 Impacts on Formation Permeability .................................................................. 4.6

4.1.3 Uranium Treatment Performance .................................................................... 4.12

4.2 Implementation Challenges .................................................................................... 4.13

4.2.1 Effect of Hydrodynamic Conditions on the Formation of Apatite ........................... 4.14

4.2.2 Effect of 300 Area Geochemical Conditions on the Removal and Long-Term Retention of Uranium with Apatite ................................................................... 4.15

4.3 Comparison with Test Objectives ............................................................................. 4.17

4.4 Cost/Schedule for Performing Treatability Study ......................................................... 4.18

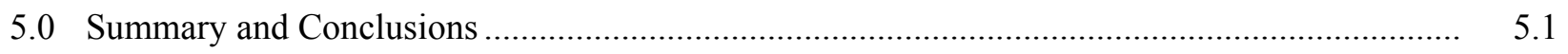

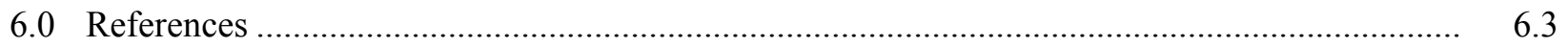

Appendix A - Hydraulic Test Results ............................................................................... A.1

Appendix B - Baseline Sampling Results ......................................................................... B. 1

Appendix C - Amendment Arrival Plots ........................................................................... C.1

Appendix D - Aqueous Uranium Performance Assessment Monitoring Data................................. D.1 


\section{Figures}

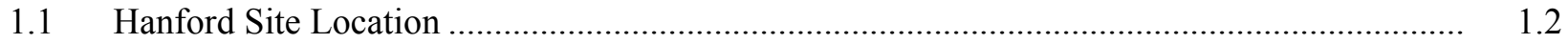

1.2 300 Area Detail Map Showing the Uranium Plume in December 2005 and Test Site

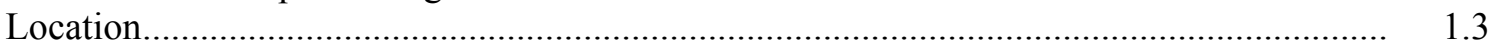

1.3 Detailed Location of the Polyphosphate Treatability Test Site .............................................. 1.4

1.4 Detail Map of the 300 Area Showing the Uranium Plume in June 2006 ............................... 1.5

1.5 Hydrogeologic Column Depicting the Hydrogeology of the 300 Area .................................. 1.7

1.6 Composite Borehole Log for Well 399-1-23 .................................................................... 1.8

$2.1 \quad$ Site Layout for the Polyphosphate Treatability Test ........................................................... 2.3

2.2 Schematic of the Injection Manifold with the Make-Up Water and all Other Necessary

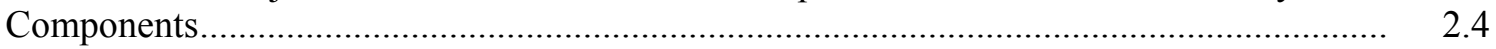

2.3 Schematic Drawing of the Groundwater Sample Acquisition System .................................... 2.5

$2.4 \quad$ Schematic Layout of Pressure Sensor Network................................................................. 2.7

3.1 Schematic Depicting the Step-Wise Hydrolysis of Sodium Tripolyphosphate ........................ 3.1

3.2 Hydrolysis Rate of Polyphosphate Molecules as a Function of $\mathrm{pH}$...................................... 3.2

3.3 Percent Removal of Calcium and Phosphorus as a Function of Calcium-to-Phosphorus Ratio

3.4 Representative Photo of Sediment Sectioned from the Effluent End of Column 1 Illustrating the Visual Identification of Uranium-Phosphate Under Short-Wave UV Radiation

3.5 Photo Showing Disperse Precipitation of Calcium-Phosphate Throughout Column 1

3.6 Graphs Depicting Aqueous Uranium Concentrations from Columns Saturated with $1000 \mu \mathrm{g} / \mathrm{L}$ Uranium as a Function of the Number of Pore Volumes of Polyphosphate Remedy Displaced through Columns a) 11, b) 12, c) 13, and d) 14

3.7 Photos of Columns Sections Taken Under Short-Wave UV Radiation.

3.8 Representative Plot Depicting the Removal of Phosphorus via Sorption and Precipitations Reactions

3.9 Graphs Depicting Aqueous Uranium Concentrations from Columns Saturated with $1000 \mu \mathrm{g} / \mathrm{L}$ Uranium as a Function of the Number of Pore Volumes of Polyphosphate Remedy Displaced Through Columns a) 15, b) 16, c) 17, and d) 18 ...

3.10 Breakthrough Curves for Sodium Ortho-, Pyro-, Tripolyphosphate, Calcium, the Phosphorus Amendment Formulation as Mixed, and the Phosphorus Amendment Formulation $\mathrm{pH}$ Adjusted to 7 .

3.11 Initial Well Layout for Polyphosphate Treatability Test Site Showing Well-Completion Depths

3.12 Ice Age Flood Deposits of the Grayish Hanford Formation Exposed at the Base of North Process Pond.

3.13 Compacted to Semi-Consolidated, Gravel-Dominated Facies of the Ringold Formation......... 3.26

3.14 Structure-Contour Map on Top of the Eroded Ringold Formation ....................................... 3.30

3.15 Saturated Thickness of the Hanford Formation............................................................. 3.31 
3.16 North-South Hydrogeologic Cross Section in the Vicinity of the Polyphosphate Injection Site

3.17 Columbia River Stage from the 300 Area Gauging Station for 2006

3.18 Water Table and Uranium Concentrations in Upper Part of the Unconfined Aquifer

Beneath the 300 Area, December 2005.

3.19 Water Table and Uranium Concentrations in Upper Part of the Unconfined Aquifer Beneath the 300 Area, June 2006.

3.20 Original 300 Area Water-Level Monitoring Network - High River Stage Example

3.21 Original 300 Area Water-Level Monitoring Network - Low River Stage Example......

3.22 Hydraulic Gradient Directions for the First Half of 2006 Calculated from 300 Area Automated Water-Level Network for Well Cluster 399-1-2, 399-1-7, and 399-1-12

3.23 Hydraulic Gradient Directions for the Second Half of 2006 Calculated from 300 Area Automated Water-Level Network for Well Cluster 399-1-2, 399-1-7, and 399-1-12

3.24 Expanded 300 Area Water-Level Monitoring Network - Low River Stage Example

3.25 Flow Rate, Duration, and Total Injection Volume for Bromide Tracer Test at Polyphosphate Treatability Test Site on December 13, 2006

3.26 Bromide Concentrations for the Tracer Injection Stream During the Injection Period of the Test and for Several Days After the Test, as Measured in the Injection Well

3.27 Breakthrough Curves Showing Bromide Concentrations Through Time for Fully Screened Wells Within the Targeted Injection Volume: a) 399-1-26, b) 399-1-29, c) 399-1-30, and d) 399-1-31

3.28 Breakthrough Curves Showing Bromide Concentrations Through Time for Wells Within the Targeted Injection Volume that Are Screened in Only the Upper or Lower Zones of the Aquifer: a) 399-1-24, b) 399-1-25, c) 399-1-27, and d) 399-1-28

3.29 Breakthrough Curves Showing Bromide Concentrations Through Time for Downgradient Wells a) 399-1-32 and b) 399-1-7

3.30 Columbia River Hydrograph and Water-Level Data for Well 399-1-23 During December 2006.

3.31 River-Well Response Function for Well 399-1-23 Based on Data Collected Between August and December 2006.

3.32 Predicted, Observed, and River-Corrected Water Levels for Well 399-1-23 Prior to the December 2006 Tracer Injection Test and Well 399-1-31 During the Test.

3.33 Composite Plot of Pressure Buildup Data for all Eight Monitoring Wells During the Tracer Injection Test

3.34 Neuman Type-Curve Analysis of Pressure Buildup Data at the Fully Screened Well 399-126 During the Tracer Injection Test

3.35 Neuman Type-Curve Analysis of Pressure Buildup Data at the Upper-Screened Well 39924 During the Tracer Injection Test

3.36 Neuman Type-Curve Analysis of Pressure Buildup Data at the Lower-Screened Well 399-1-25

3.37 Example Slug Test Responses at Three Wells Completed over the Entire Hanford Formation Thickness

3.38 Background Water-Level Gradients for Well-Well Combinations Stepping Progressively Downgradient 
3.39 Tracer Breakthrough Curves During Injection Period of the December 13, 2006, Bromide Tracer

3.40 Tracer Breakthrough Curves During Injection Period of the December 13, 2006, Bromide Tracer Test

3.41 Analytic Solution for Tracer Arrivals at Different Radial Distances Using Estimated June Conditions

3.42 Plan View of Polyphosphate Treatability Test STOMP Model Domain and Finite Difference Grid

3.43 Hydrostratigraphic Zonations in Polyphosphate Site Model at 105-m Elevation

3.44 Hydrostratigraphic Zonations in Polyphosphate Site Model at 102.5-m Elevation

3.45 Preliminary Results of Polyphosphate Site Model of Bromide Tracer Test......

3.46 Preliminary Results of Polyphosphate Site Model of Bromide Tracer Test.

3.47 Reactive and Conservative Species of Interest Measured in the Injection Solution.

4.1 Calcium/Phosphate Amendment Arrival Response for Monitoring Well 399-1-26 ................ 4.2

4.2 Calcium/Phosphate Amendment Arrival Response for Monitoring Well 399-1-24 _.............. 4.3

4.3 Calcium/Phosphate Amendment Arrival Response for Monitoring Well 399-1-38 ............... 4.5

4.4 Conservative Tracer Arrival Distribution in Site Monitoring Wells 18 Hours into Each Injection Phase

4.5 Neuman Type-Curve Analysis of Pressure Recovery Data at the Fully Screened Well 399-1-26 Following the Polyphosphate Treatability Injection Test.

4.6 Neuman Type-Curve Analysis of Pressure Recovery Data at the Upper-Screened Well 399-1-24 Following the Polyphosphate Treatability Injection Test.

4.7 Neuman Type-Curve Analysis of Pressure Recovery Data at the Lower-Screened Well 399-1-25 Following the Polyphosphate Treatability Injection Test.

4.8 Neuman Type-Curve Analysis of Pressure Recovery Data at the Lower-Screened Well 399-1-27 Following the Polyphosphate Treatability Injection Test.

4.9 Composite Plot of Pre- and Post Treatment Pressure Responses Showing Permeability Reduction in the Formation as a Result of the Polyphosphate Injection Test..

4.10 Uranium Concentration Trends in Selected Site Monitoring Wells

4.11 Normalized BTC for Calcium, Phosphorus, Chloride, and Bromide at Downgradient Well 399-1-29

4.12 Historical pH Values of Selected Near-River and Inland Wells in the 300 Area

4.13 Dependence of Uranium Uptake Expressed as Aqueous Uranium Concentration as a Function of Time in Hydroxyapatite-Equilibrated Groundwater. 



\section{Tables}

2.1 Field Parameter Monitoring Electrode Specifications.................................................... 2.6

2.2 Groundwater Chemistry Sampling Requirements ........................................................ 2.8

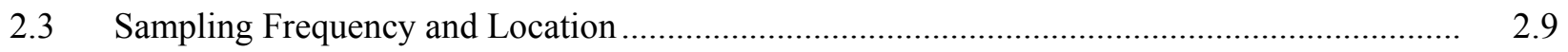

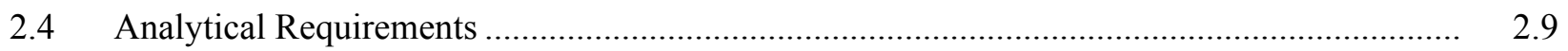

3.1 Possible Sources and Associated Solubility for Polyphosphate Amendment ........................ 3.4

3.2 Experimental Batch Conditions for Polyphosphate Amendment Optimization ....................... 3.5

3.3 Down-Selected Experimental Batch Conditions for Polyphosphate Amendment

3.4 Experimental Parameters for Polyphosphate Amendment Optimization Column Tests.......... 3.12

3.5 Transport Parameters Determined by Direct Measurement or from Laboratory-Derived Breakthrough Curves on the $<2$-mm Sediment Fraction.................................................... 3.20

3.6 Field Transport Parameters Calculated from Laboratory Derived Transport Parameters ......... 3.22

3.7 Pilot-Scale Field Test Amendment Formulation ............................................................... 3.23

3.8 Polyphosphate Treatability Well Identification and Borehole Information ............................ 3.28

3.9 Physical Property Data for Bulk Sediment Samples from Well 399-1-23 ............................ 3.29

3.10 Summary of Polyphosphate Treatability Test Site Tracer Injection Test............................... 3.42

3.11 Bromide Tracer Injection Arrival Times and Porosity Results for Targeted Injection Volume Monitoring Wells

3.12 Summary of Parameters Used to Estimate Hydraulic Conductivity Between Injection Well 399-1-23 and Downgradient Well 399-1-32 for the Main Body of Tracer ........................... 3.49

3.13 Results from Pressure Buildup During the 2006 Bromide Tracer Injection Test................... 3.54

3.14 Average Anion Concentration Results for all Site Monitoring Wells During the Three Baseline Sampling Events.

3.15 Average Trace Metals Concentration Results for all Site Monitoring Wells During the Three Baseline Sampling Events

3.16 Average Cation Concentration Results for All Site Monitoring Wells During the Three Baseline Sampling Events

3.17 Average Field Parameter Results for All Site Monitoring Wells During the Three Baseline Sampling Events.

3.18 Estimated Volumes for Tracer Arrivals for Bromide Tracer Test Conducted in December 2006

3.19 Scaled Tracer Arrivals for Wells at the Treatability Test Site to a 7.6-m Radius ................... 3.66

3.20 Summary of Injection Volumes, Flow Rates, and Test Durations for Each Phase of the

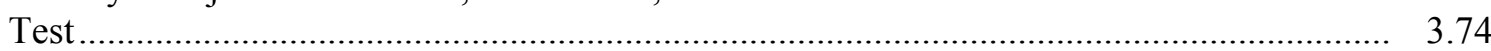

4.1 Summary of Reactive Species Arrival Concentrations and Overlap Durations ...................... 4.6

4.2 Summary of Aquifer Hydraulic Property Estimates Based on Neuman Type-Curve Analyses of Pressure Recovery Responses Following the June 2007 Polyphosphate Injection Test.

4.3 Cost and Schedule Summary for the Polyphosphate Treatability Test ................................ 4.18 



\subsection{Introduction}

For fiscal year 2006, the United States Congress authorized \$10 million dollars to Hanford for “... analyzing contaminant migration to the Columbia River, and for the introduction of new technology approaches to solving contamination migration issues." Administration of these funds through the U.S. Department of Energy (DOE) Office of Environmental Management (specifically, EM-22) involved a peer review and selection process, under which nine projects were selected to meet the objectives of the appropriation. As part of this effort, Pacific Northwest National Laboratory (PNNL) ${ }^{1}$ is performing bench- and field-scale treatability testing designed to evaluate the efficacy of using polyphosphate injections to reduce uranium concentrations in the groundwater to meet drinking water standards $(30 \mu \mathrm{g} / \mathrm{L})$ in situ. Polyphosphate injection was selected for testing based on technology screening as part of the 300-FF-5 Phase III Feasibility Study for treatment of uranium in the 300 Area.

This report describes results of the treatability test of uranium stabilization through polyphosphate injection for treatment of uranium in groundwater beneath the Hanford 300 Area (see Figure 1.1 and Figure 1.2). The treatment concept for this technology involves the formation of phosphate minerals (autunite and apatite) in situ that 1) directly sequesters the existing aqueous uranium in autunite minerals and 2) precipitates apatite minerals that could increase sorption and long-term treatment of uranium migrating into the treatment zone (Wellman et al. 2005, 2006). Polyphosphate injection was selected for testing based on previous lab-scale investigations. Evaluation of in situ treatment of uranium contamination is consistent with the results of technology screening conducted to identify a viable remedial action alternative for uranium in 300 Area groundwater, as part of the 300-FF-5 Phase III Feasibility Study (DOE 2005).

The field site for the polyphosphate treatability test, which is located in the vicinity of well 399-1-23, was selected based on hydrogeologic characterization data collected at four wells installed in fiscal year 2006 as part of the 300 Area limited field investigation (Williams et al. 2007). The polyphosphate treatability test site is comprised of a single injection well (399-1-23) surrounded by a network of monitoring wells within the targeted injection volume and downgradient monitoring wells (see Figure 1.2 and Figure 1.3). The monitoring wells were installed during two separate drilling campaigns, one in November and December 2006 to support initial site characterization activities (Vermeul et al. 2006) and a second in May 2007 to provide additional downgradient monitoring wells for monitoring amendment/tracer plume drift under a wide range of Columbia River stage conditions.

The following sections describe the site, project background, and polyphosphate technology used to conduct the treatability test of uranium stabilization.

${ }^{1}$ PNNL is operated by Battelle for DOE under Contract DE-AC05-76RLO1830. 


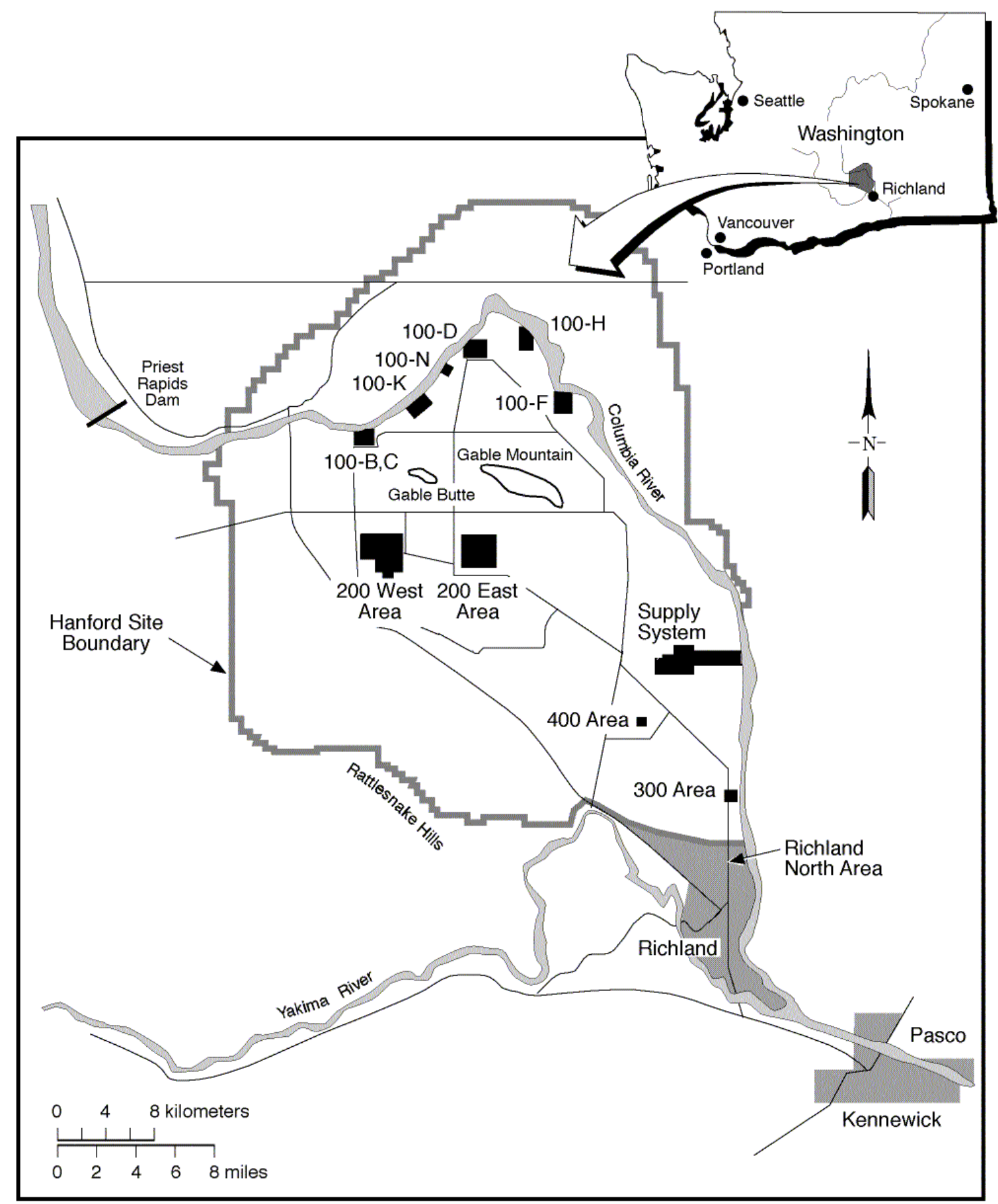

RG98120214.10

Figure 1.1. Hanford Site Location 


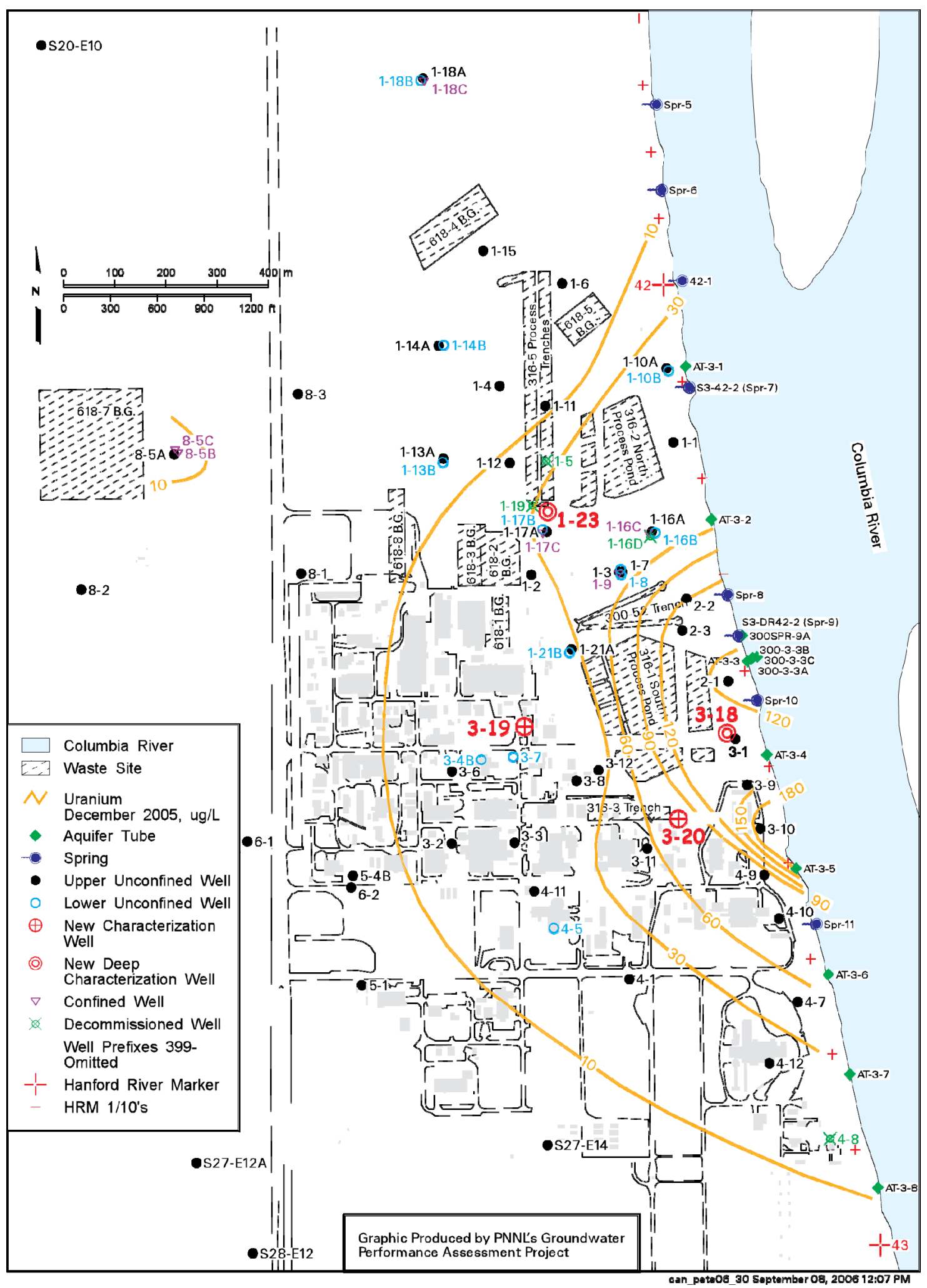

Figure 1.2. 300 Area Detail Map Showing the Uranium Plume in December 2005 and Test Site Location (around well 399-1-23) 


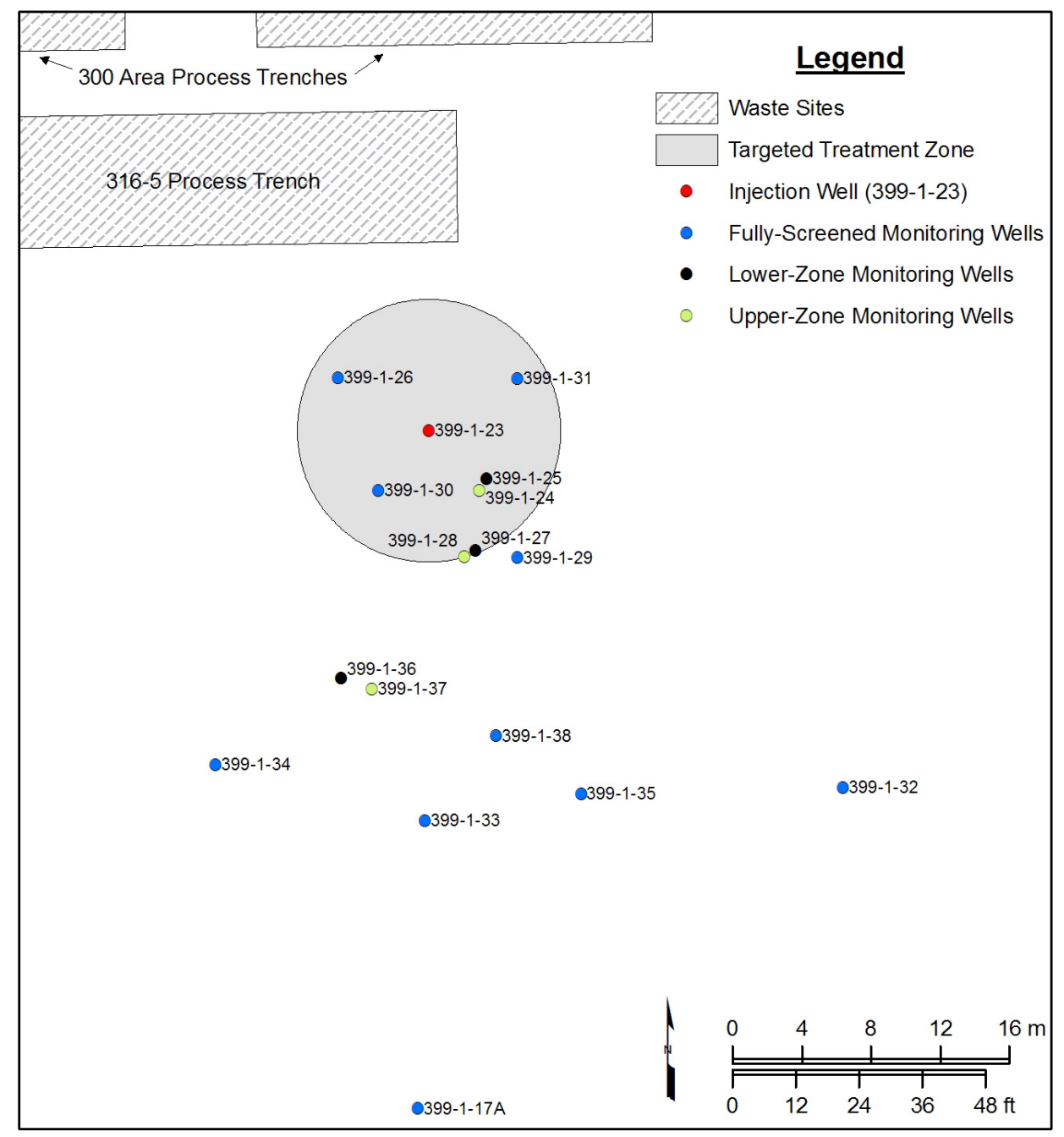

Figure 1.3. Detailed Location of the Polyphosphate Treatability Test Site

\subsection{Site Description}

A groundwater plume containing uranium from past-practice discharges of liquid waste associated with nuclear fuel fabrication activities has persisted beneath the Hanford Site 300 Area for many years (see Figure 1.2 and Figure 1.4). As indicated through comparison of these two figures, during high river stage conditions in June 2006, uranium concentrations were elevated in localized areas farther inland than indicated during December 2005. It is thought that these increases in uranium concentration are associated with contamination remaining in the deep vadose zone. Of particular interest is the zone of seasonal water-table fluctuation, or "periodically re-wetted zone." The polyphosphate treatability test site is located near one of the two delineated deep vadose sources shown in Figure 1.4. The persistence of this plume is enigmatic for several reasons, including 1) discharges containing uranium-bearing effluent to ground disposal sites ended in the mid-1980s; 2) contaminated soil associated with these waste sites was removed during the 1990s, with backfilling complete by early 2004; and 3) the aquifer is comprised of highly transmissive fluvial sediment that results in rapid movement of groundwater. Also, a water-supply well located within the plume has been in operation since 1980, with no observable effect on the plume. 


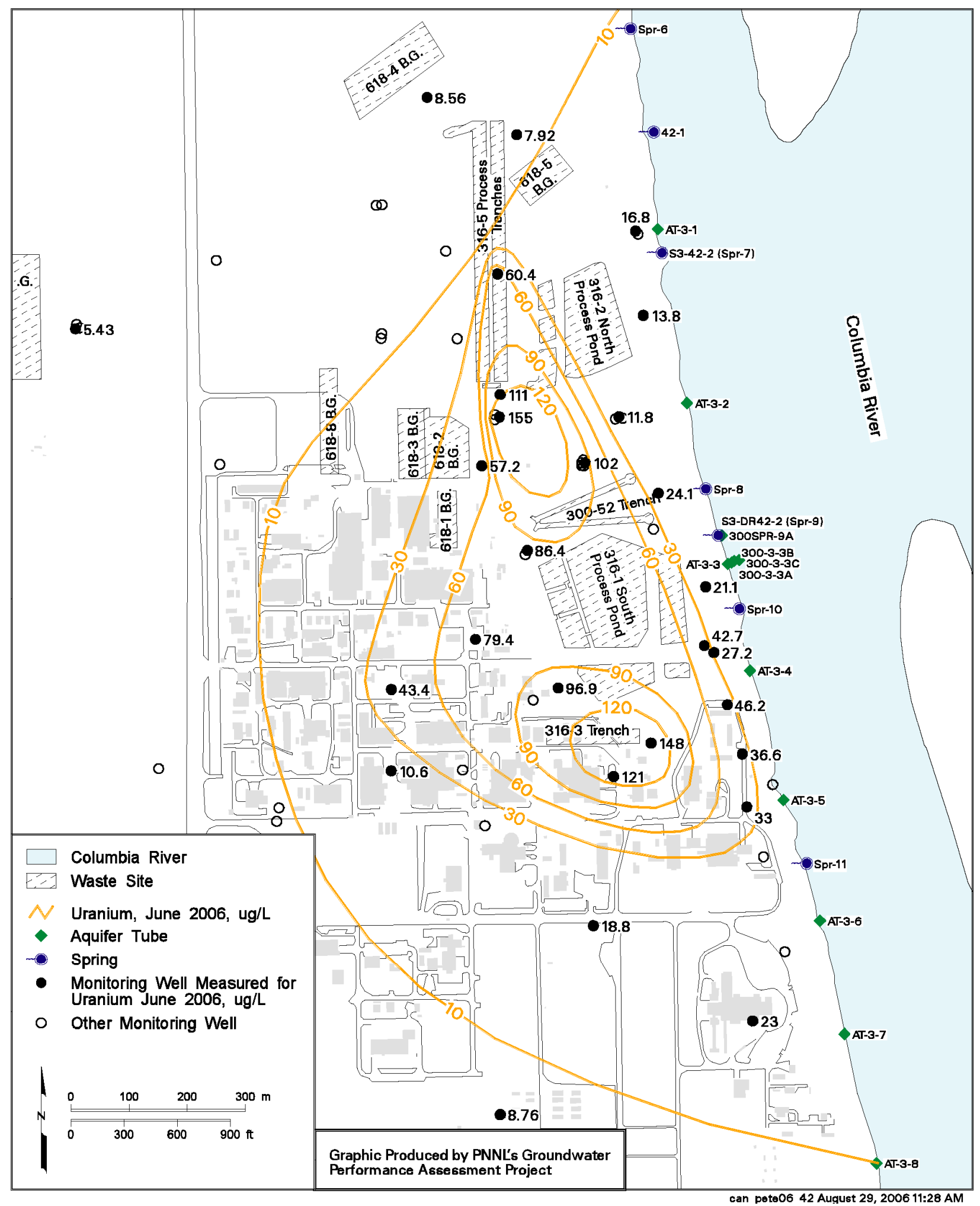

Figure 1.4. Detail Map of the 300 Area Showing the Uranium Plume in June 2006 
The current conceptual site model assumes that re-supply of the plume is occurring, with continuing release from the vadose zone beneath waste sites, the periodically re-wetted zone, and possibly from aquifer solids, as source candidates (Peterson et al. 2005). The plume ( $>30 \mu \mathrm{g} / \mathrm{L}$ ) covers an area of $\sim 0.4 \mathrm{~km}^{2}\left(0.15 \mathrm{mi}^{2}\right)$. Assuming a representative thickness of the contaminated layer of $3.3 \mathrm{~m}(10.8 \mathrm{ft})$ and $27 \%$ porosity, the volume of contaminated groundwater is $\sim 350,000 \mathrm{~m}^{3}\left(460,000 \mathrm{yd}^{3}\right)$ and the mass of dissolved uranium is $\sim 20 \mathrm{~kg}$ (44 lb). The length of Columbia River shoreline impacted is $\sim 1500 \mathrm{~m}$ (4900 ft). Uranium removal via a water-supply well for the 331 Life Sciences Building is $\sim 10 \mathrm{~kg}$ (22 lb) per year, based on monitoring data.

A remedial investigation conducted in the early 1990s, along with an expedited response action to remove contaminated soil from the most recently used disposal site, led to a 1996 record of decision (EPA 1996a) for interim remedial action that involved continued groundwater monitoring and institution controls on the use of groundwater. A computer simulation of the plume during the initial remedial investigation led to a prediction that concentrations would decrease to the proposed drinking water standard (20 $\mu \mathrm{g} / \mathrm{L}$ in 1993) in 3 to 10 years from 1993, assuming no re-supply of uranium to the plume (DOE 1995). This predicted response has not been observed in monitoring well trend data.

Principal investigations leading to the current conceptual site model for this plume include early work to describe the hydrogeology and groundwater contamination of the 300 Area (Lindberg and Bond 1979); detailed investigations to support Resource Conservation and Recovery Act (RCRA) requirements at the 300 Area Process Trenches (Schalla et al. 1988); and the initial remedial investigation under the Comprehensive Environmental Response, Compensation, and Liability Act (CERCLA) for the 300-FF-5 groundwater operable unit (DOE 1995). More recently, detailed geochemical research involving uranium in 300 Area sediment has been conducted to support decisions associated with cleanup of surface waste sites (Serne et al. 2002; Zachara et al. 2005; Brown et al. 2008) and the renewed feasibility study of potential remedial action alternatives for the plume (Nimmons 2007).

The latter investigations, which were conducted under DOE's science and technology research programs, included sampling the vadose zone beneath two major liquid waste disposal sites located near the proposed treatability test site (well 399-1-23). Samples from vertical profiles that spanned the base of the disposal site excavations down to the water table were collected, and subjected to intensive laboratory investigations to determine the geochemical and mobility characteristics of residual uranium in the lower vadose zone.

A limited field investigation (LFI) was conducted as part of the Phase III Feasibility Study (Williams et al. 2007) to reduce uncertainties in two aspects of the conceptual model for the uranium plume. The two aspects are 1) the vertical distribution of uranium in the vadose zone and uppermost aquifer at representative sites, with special emphasis on the interface between unsaturated and saturated conditions (i.e., the periodically re-wetted zone) and geochemical characteristics that influence the mobility of uranium, and 2) the vertical and lateral distribution of uranium throughout the mapped plume area where drinking water standards are exceeded (DOE 2006). 
The LFI characterization included collecting continuous core samples and depth-discrete groundwater samples, geophysical logging, and conducting aquifer tests at four sites that are representative of various combinations of proximity to waste sites and to the river, and in various hydrogeologic environments (Figure 1.2). The hydrogeologic column for the 300 Area based on all 300 Area investigations is illustrated in Figure 1.5. Figure 1.6 shows the composite borehole log for LFI well 399-1-23, which is the injection well for the polyphosphate treatability study. The entire LFI area of interest was defined by the extent of the uranium plume, i.e., the area where concentrations are above natural background levels (i.e., above $\sim 10 \mu \mathrm{g} / \mathrm{L}$ ). The extent and general shape of this area has not changed appreciably for many years (Peterson et al. 2005). The distribution pattern of the higher concentrations within this area varies significantly with time and is thought to be a consequence of liquid effluent disposal activities, source excavation activities, fluctuations in water-table elevations, and plume migration. Results from drilling and characterization in the four new wells showed that the highest groundwater and vadose concentration of uranium is in the two wells: 399-1-23 (C5000) and 399-3-18 (C4999). Results from these wells are described by Williams et al. (2007).

Hanford Site - 300 Area

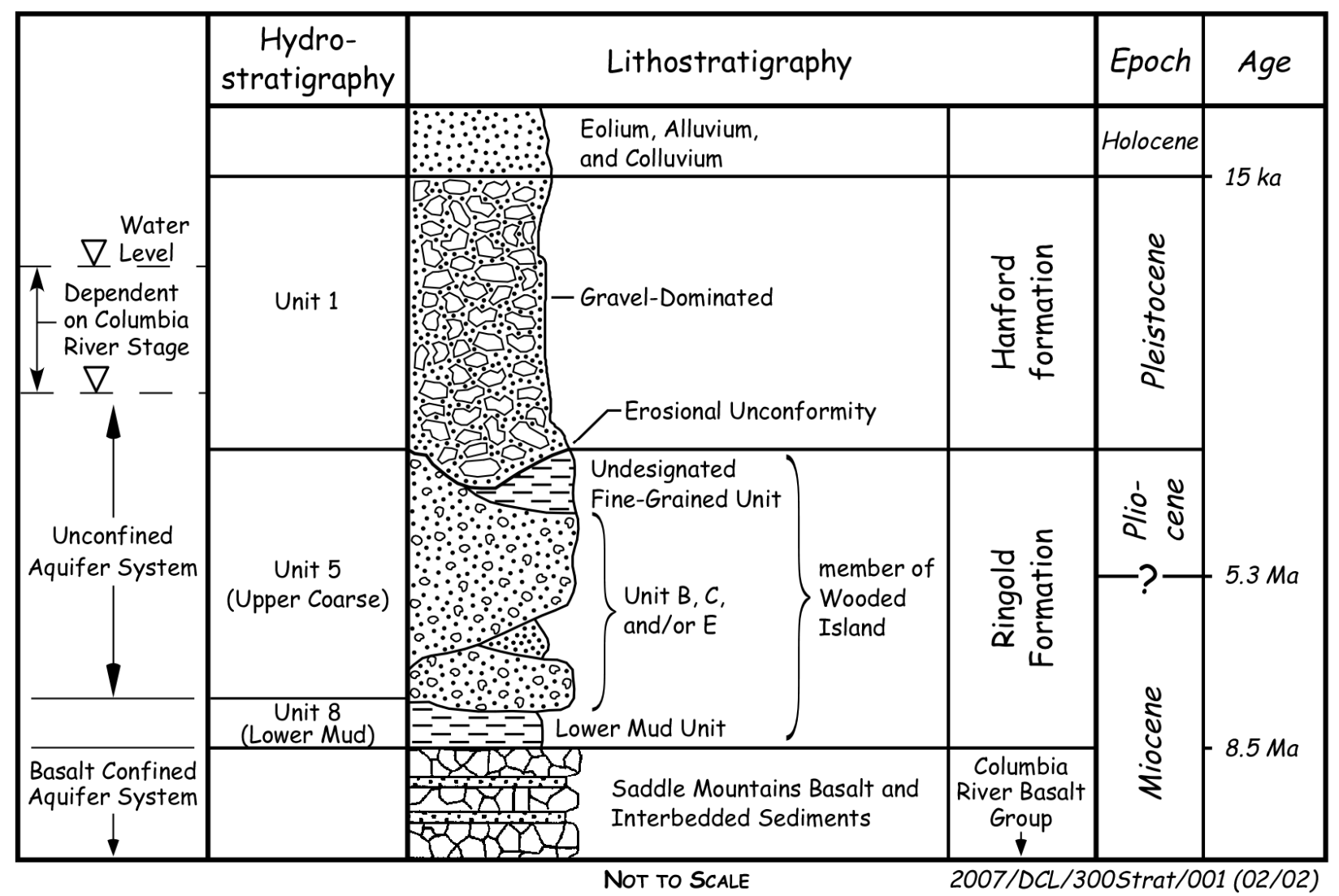

Figure 1.5. Hydrogeologic Column Depicting the Hydrogeology of the 300 Area (from Williams et al. 2007) 


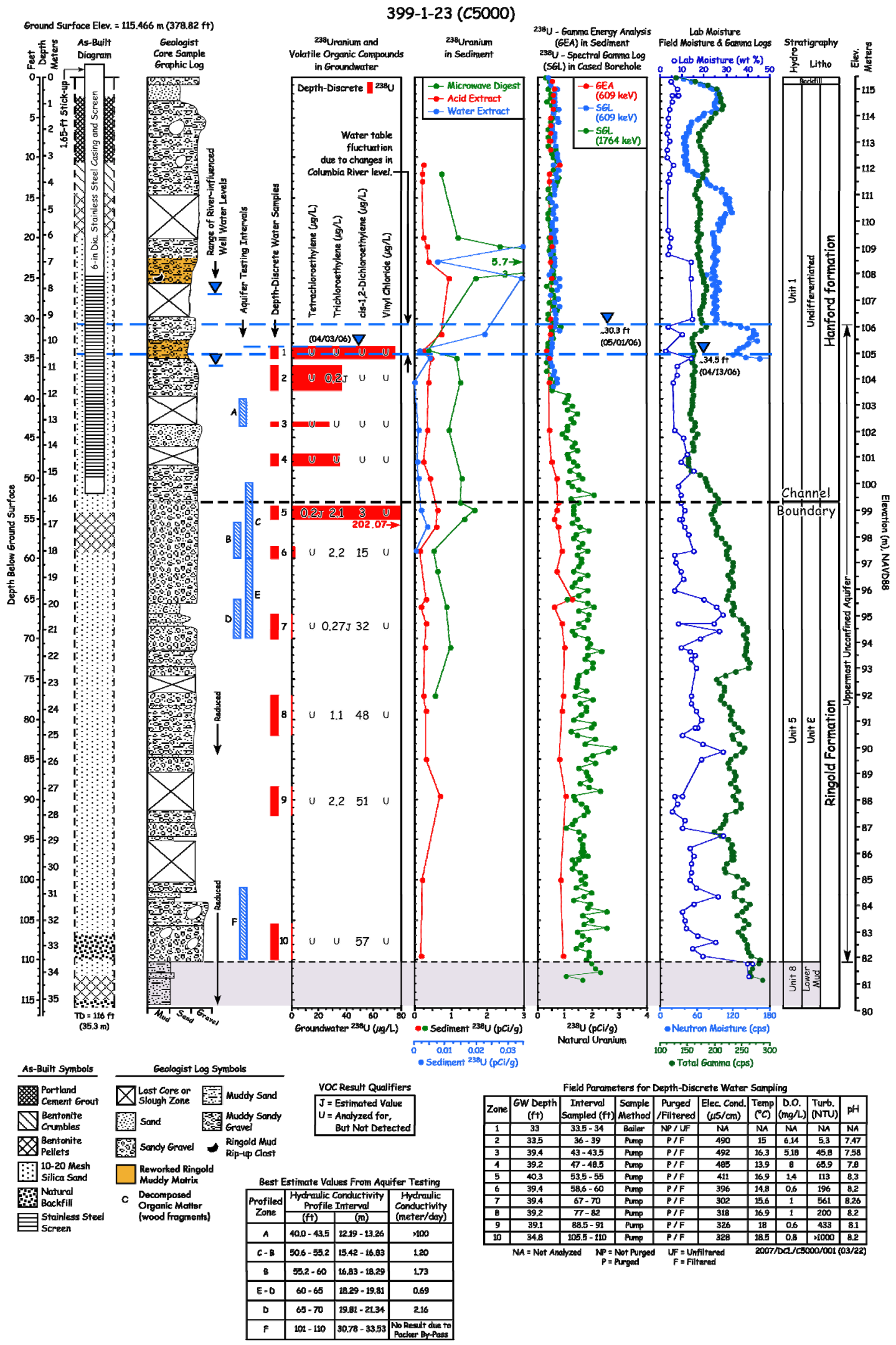

Figure 1.6. Composite Borehole Log for Well 399-1-23 (from Williams et al. 2007) 


\subsection{Background}

This section provides background information about the 300 Area uranium plume and the evolution of activities that will ultimately lead to a remedial action decision. In 1996, a record of decision (EPA 1996a) identified the following interim actions for remediation of the uranium contaminant plume beneath the site:

- Conduct continued groundwater monitoring to determine how contaminant conditions may change with time

- Implement institutional controls to limit the use of groundwater.

Analysis of the interim action results has determined that uranium concentrations in the groundwater plume have been generally declining, but still persist at concentrations above the drinking water standard (remediation goal). Therefore, re-evaluation of the remedy for uranium contamination is necessary because the rate of decrease in uranium concentrations is significantly different than the rate of decrease expected and used as a basis for the remedy selection in the current record of decision.

In the past, several public workshops were held to discuss remedial action alternatives and future land use options for the Hanford 300 Area:

1. June 2002 and May 2003: U.S. Environmental Protection Agency (EPA)-sponsored stakeholder workshops to discuss remedial action alternatives for the 300 Area uranium plume.

2. May 2004: DOE Science and Technology Program open meeting with contractors and the publicConceptual Model Development and Reactive Transport Modeling for the 300 Area Uranium Plume.

3. August 2004: DOE Headquarters review and discussion of 300 Area uranium plume - Monitoring Optimization Technical Assistance Workshop.

4. May 2005: DOE-sponsored stakeholder workshop to receive public input on remedial actions and future land use for the 300 Area - 300 Area End States Public Workshop.

5. October 2005: DOE-sponsored stakeholder involvement workshop - 300-FF-5 Workshop and Tour: Progress of the Limited Field Investigation Supporting the Phase III Feasibility Study.

Input received from these workshops supports investigating remedial action technologies that are designed to reduce the concentrations of uranium in groundwater beneath the 300 Area such that the aquifer can be restored to its maximum beneficial use, i.e., as a resource for drinking water. Reducing concentrations in the aquifer will also reduce any potential risk to ecological receptors in the Columbia River.

\subsection{Polyphosphate Technology Description}

The use of soluble long-chain polyphosphate amendments has been demonstrated to delay the precipitation of phosphate phases (Wellman et al. 2006). Precipitation of phosphate minerals occurs when phosphate compounds degrade in water, due to hydrolysis, to yield the orthophosphate molecule $\left(\mathrm{PO}_{4}{ }^{3-}\right)$. The rate of the hydrolysis reaction that leads to production of orthophosphate is related to the length of the polyphosphate chain. Accordingly, use of a long-chain polyphosphate compound does not result in a drastic change in hydraulic conductivity of the target aquifer. 
Injection of a sodium tripolyphosphate amendment into the uranium-bearing saturated porous media has been shown to immobilize uranium through the formation of an insoluble uranyl phosphate mineral, autunite $\left\{\mathrm{X}_{1-2}\left[\left(\mathrm{UO}_{2}\right)\left(\mathrm{PO}_{4}\right)\right]_{2-1} \bullet \mathrm{nH}_{2} \mathrm{O}\right\}$, where $\mathrm{X}$ is any monovalent or divalent cation. Because autunite sequesters uranium in the oxidized form $\mathrm{U}^{6+}$, rather than forcing reduction to $\mathrm{U}^{4+}$, the possibility of re-oxidation and subsequent re-mobilization of uranium is negated. Release of uranium from the autunite structure may only occur through dissolution of the autunite structure. Extensive testing demonstrates the very low solubility and slow dissolution kinetics of autunite under conditions relevant to the Hanford subsurface (Wellman et al. 2006). In addition to autunite, excess phosphorous can result in apatite mineral formation, providing a long-term source of treatment capacity.

Research beginning in the mid-1960s underscored the efficacy of using calcium and/or lime to precipitate stable calcium-phosphate solid phases including apatite for direct removal of phosphate (Ferguson et al. 1970, 1973; Jenkins et al. 1971; Schmid and McKinney 1968). By complexing calcium and sorbing to mineral surfaces, polyphosphate compounds effectively enhance the rate of calcium phosphate precipitation by reducing competing reactions, such as the formation of calcium carbonate, and "directing" calcium to participate in reactions resulting in calcium phosphate precipitation (Ferguson et al. 1973).

Fuller et al. (2003, 2002a) demonstrated the efficacy of hydroxyapatite for reducing the aqueous uranium concentration to $<0.05 \mu \mathrm{M}$ under the $\mathrm{pH}$ range of 6.3 to 6.9 in the presence of carbonate. Results suggested the binding of uranium, irrespective of dissolved carbonate concentration or aqueous uranium concentration, occurred via surface complexation; long-term retention occurs through the transformation of sorbed apatite to chernikovite. Similar evidence for the long-term retention of uranium via initial sorption and subsequent transformation to uranium mineral phases of low solubility has been observed downgradient from the uranium ore deposit at Koongarra, Australia (Murakami et al. 1996).

\subsection{Report Contents}

The ensuing sections of this report describe the treatability study approach (Section 2.0), and treatability study activities, including bench-scale testing, site-specific characterization, injection design analysis, and the polyphosphate injection test (Section 3.0). Section 4.0 discusses treatability study results; conclusions and recommendations are provided in Section 5.0. Supplemental information is included in appendices, as follows: additional results for hydraulic tests that were not included in Section 3.2.3 (Appendix A), baseline sampling results (Appendix B), amendment arrival plots (Appendix C), and aqueous uranium performance assessment monitoring data (Appendix D). 


\subsection{Treatability Study Approach}

The study approach, including treatment test objectives, conceptual design, equipment and materials, sampling and analysis, and data management, is described in the following sections.

\subsection{Treatability Test Objectives}

Uranium stabilization through polyphosphate injection was selected as a promising technology for evaluation of its ability to meet the cleanup goals for uranium in the 300 Area aquifer. The overall objectives of the treatability test included the following:

- Conduct a polyphosphate injection to evaluate reduction of aqueous uranium concentrations and to determine the longevity of the treatment zone.

- Demonstrate field-scale application of polyphosphate injections to identify implementation challenges and evaluate whether a full-scale deployment is feasible.

- Determine the number of wells, reagent concentrations, volumes, injection rates, operational strategy, and longevity for polyphosphate injections for remediating uranium such that costs for larger-scale application can be effectively estimated.

Key design parameters associated with these objectives include the radius of influence of the polyphosphate amendment injections, injection concentrations, types and amounts of phosphate minerals formed, reduction of aqueous uranium concentrations, and long-term treatment capacity of the amended zone.

\subsection{Conceptual Design}

The general treatability testing approach consisted of 1) bench-scale evaluation of the technology, 2) site-specific characterization of the field test site, 3) an injection design analysis that synthesized bench- and field-scale information, 4) a polyphosphate injection test, and 5) post-treatment performance assessment. The initial field site characterization involved well drilling, geohydrologic/geochemical characterization (hydraulic testing, tracer tests, baseline monitoring), and site setup (mobile laboratory setup, installing pumps and pressure transducers in monitoring wells, injection and sampling equipment). These activities are described in Section 3.0. In addition to these activities, bench-scale studies with site sediment were conducted to develop an effective chemicals formulation for the polyphosphate amendments and evaluate the transport properties of the amendments under site conditions (see Section 3.0).

\subsection{Equipment and Material}

This section includes a description of the site location, site utilities, injection equipment, chemical delivery, monitoring equipment, analytical equipment, and the integration of these components into the operational system required to conduct the polyphosphate injection. PNNL worked with Flour Hanford 
Inc. (now CH2M Hill Plateau Remediation Company or CHPRC) to arrange for site access, removal and installation of necessary pumps in wells, and wastewater removal. All site utilities and required operational and monitoring equipment for the testing were supplied by PNNL.

\subsubsection{Site Location and Utilities}

The polyphosphate treatability test site is located in the vicinity of well 399-1-23 (see Figure 1.2 and Figure 1.3). Figure 2.1 shows a photograph of the site setup with the wells, purgewater tanks, and laboratory and process trailers. A 30-amp electrical circuit was available at the injection test site on an existing panel. This is sufficient power to operate all of the sampling and monitoring equipment, the laboratory trailer, and the process trailer. A diesel generator was used to operate the extraction pump, the pump used for chemical injection, and flood lamps for nighttime operations.

The injection monitoring site included an exclusion zone where no unauthorized personal were allowed. The area contained sampling lines, cabling for water-level measurement, sampling pump control lines, and the make-up water feed line. The laboratory trailer was located just outside of this exclusion zone. The sampling manifold and other sampling equipment was located in the laboratory trailer. All water-level monitoring transducer cabling was routed into this trailer for real-time observations of the data during testing. An additional trailer, located in the exclusion zone, contained the make-up water injection manifold, polyphosphate injection system, and Campbell Scientific data logger readouts for flow rates through the manifold. Three 1892-L (500-gal) tanks were located outside the exclusion zone for purge water storage.

\subsubsection{Water Supply}

To accomplish a polyphosphate injection test, a substantial supply of water is needed. It was estimated that over 3,406,870 L (900,000 gal) of water would be required at a flow of $757 \mathrm{~L}$ ( $200 \mathrm{gal})$ per minute for three separate injection phases. Well 399-1-7 was chosen as the extraction well for the make-up water to be used during injection testing. This well is located $190 \mathrm{~m}(620 \mathrm{ft})$ to the southeast of well 399-1-23 (Figure 1.2). A Grundfos Model 230S150-5B stainless-steel submersible pump was installed in the extraction well and a magnetic starter (Cerus, Industrial) was used to operate the pump (15 hp, three-phase 460V).

\subsubsection{Injection Equipment}

Make-up water was routed from extraction well 399-1-7 to the site via a 7.6-cm (3-in.) lay-flat hose (Goodyear 4520, 250 psi pressure rating, wear-resistant polyvinyl chloride [PVC]). Aluminum camlock fittings were used to connect various sections of hose, which came in 15- and 30-m (50- and 100-ft) lengths. The end of the hose was reduced to 5-cm (2-in.) camlock fittings and connected to the injection manifold in the process trailer. The injection manifold (Figure 2.2) installed in the process trailer consisted of 5-cm (2-in.) stainless-steel piping, valving, a pump, and flow-rate monitoring equipment. The manifold was used for diversion/shutoff and flow control of the make-up water and for dilution of a concentrated feed stock solution to the desired injection concentration. The tracer and polyphosphate amendment solutions were fed into the manifold system using a chemical metering pump or equivalent. 
Flow rates were measured continuously with an inline Omega ${ }^{\circledR}$ turbine flow meter and the total injection rate was checked manually with a variable area meter (King Instrument Company model 7500Rotameter). All Omega ${ }^{\circledR}$ turbine flow meters were logged using a Campbell CR10X data logger.

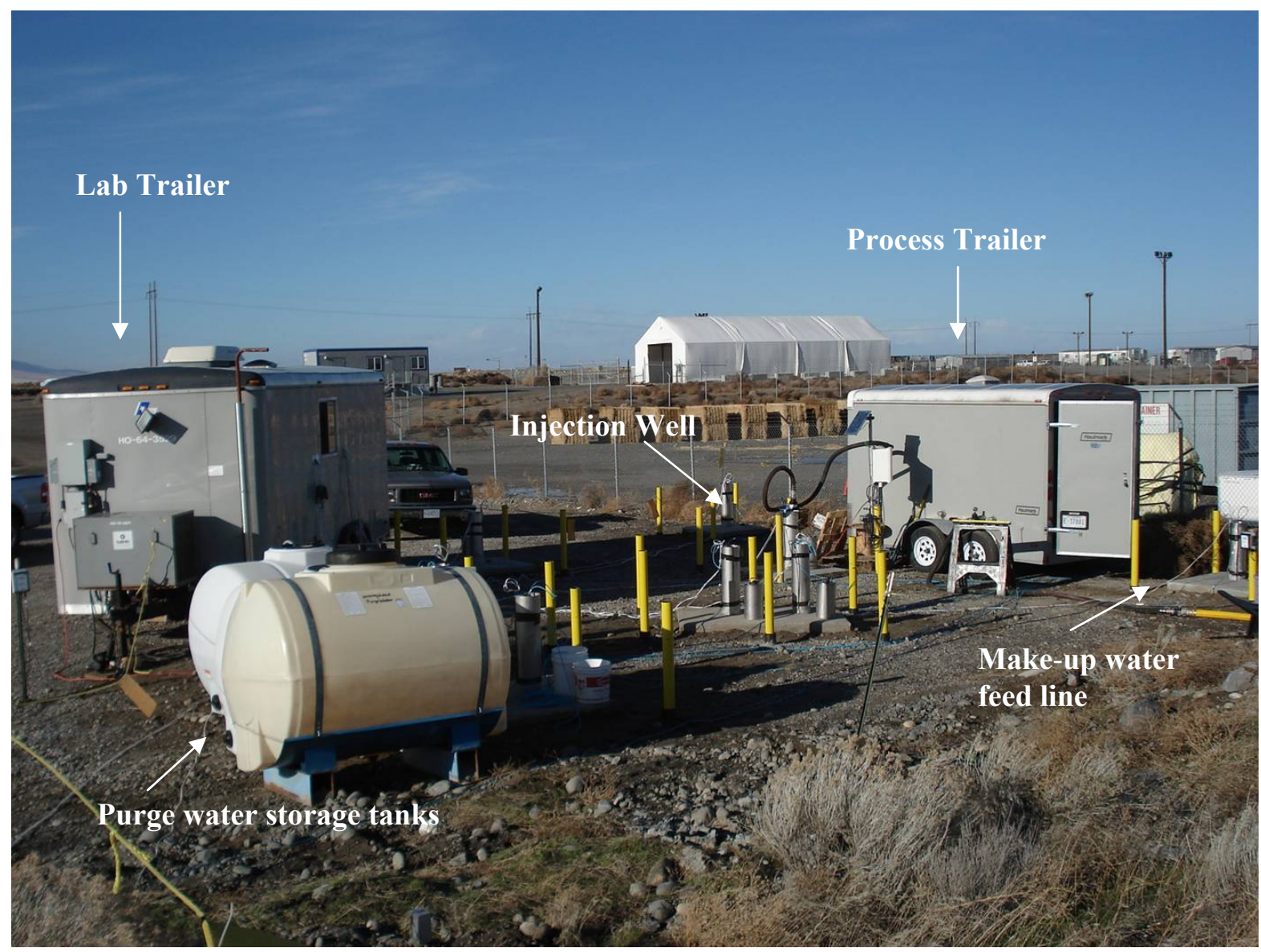

Figure 2.1. Site Layout for the Polyphosphate Treatability Test

Two pressure gauges were located in the system; one each at the inlet and at the outlet of the injection manifold (Figure 2.2). The injection well was outfitted with $15 \mathrm{~m}(50 \mathrm{ft})$ of 7.6-cm (3-in.) schedule 40 PVC pipe with the bottom section capped. A total of 15 rows of $0.6-\mathrm{cm}(0.25-\mathrm{in}$.) holes (four holes per row) were drilled into the PVC, which corresponds to approximately one half of the open area of the 7.6-cm (3-in.) pipe. The holes were drilled into the pipe at 16-in. intervals starting at $8.8 \mathrm{~m} \mathrm{(29} \mathrm{ft})$ to $14.9 \mathrm{~m}(49 \mathrm{ft})$ below ground surface.

\subsubsection{Monitoring Equipment}

Dedicated "Mega Typhoon" sampling pumps (Proactive Pumps, Trenton NJ), capable of delivering flows up to $7.57 \mathrm{~L}$ ( 2 gal) per minute, were installed in all site monitoring wells. The sample tubing ( $0.95 \mathrm{~cm}$ [0.375 in.] polyethylene) from each of these sampling pumps was routed inside a mobile laboratory and connected to a sampling manifold. A single direct-current power supply (model 1688A) from $\mathrm{B}+\mathrm{K}$ Precision Corp. (Yorba Linda, $\mathrm{CA}$ ) provided power for the sampling pumps. The power to the sampling pumps was regulated by a manufacturer-recommended pump controller that increased the operating voltage of the pumps to 19 volts (and subsequently a lower current demand). A project- 
developed multi-channel interface (pump switch box) was used to allow a single power supply/controller arrangement to provide power to all 10 sampling pumps. A multi-position rotary switch on the switch box eliminated the possibility of powering more than one pump at a time.

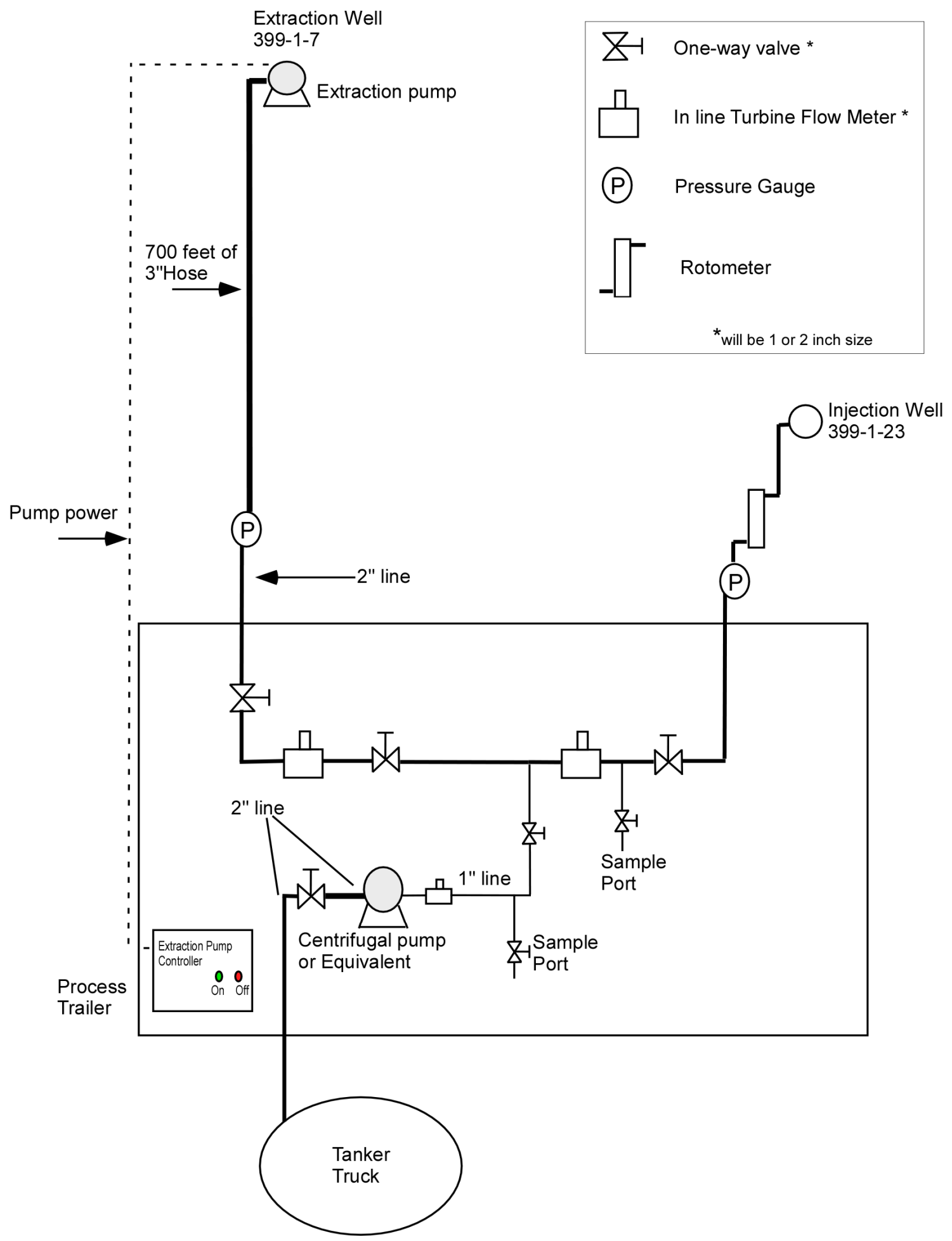

Figure 2.2. Schematic of the Injection Manifold with the Make-Up Water and all Other Necessary Components 
A project-developed sampling manifold was used to collect samples from the various monitoring wells. This approach routes all sample streams into a central manifold for monitoring field parameters (in a flow-through monitoring assembly) and collecting groundwater samples (Figure 2.3). The advantage of this type of system is that all field parameter measurements are made using a single set of electrodes, which improves data quality and comparability of spatially distributed measurements. Consistent labeling between the sampling manifold and pump switch box simplified selection of the well to be sampled and reduced the chance of operator error during the frequent sampling associated with the injection tests. To further help reduce the potential for collecting sample from the wrong well, the pump switch box was wired to a series of low-voltage light-emitting diode (LED) indicator lights on the sample manifold. When a pump was turned on, a light came on to indicate which pump was operating, and which valve on the manifold should be opened.

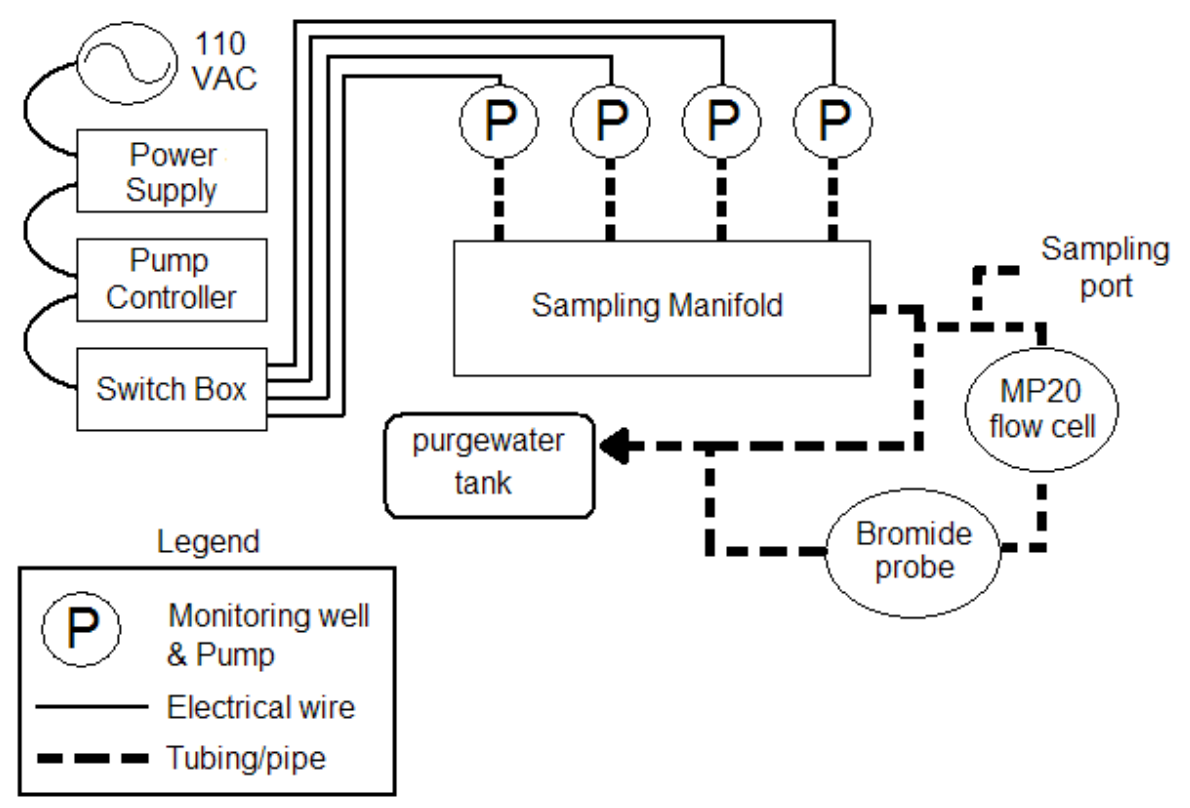

Figure 2.3. Schematic Drawing of the Groundwater Sample Acquisition System

Field parameters (specific conductance, temperature, dissolved oxygen, $\mathrm{pH}$, and oxidation reduction potential) were monitored using an MP20 flow cell (QED Environmental Systems, Ann Arbor MI). The flow-through nature of the flow-cell assembly minimizes the amount of dead space within the monitoring chamber.

To monitor real-time tracer arrivals, bromide ion selective electrodes (ISE) were used in a flow-through assembly for pumped samples and in selected monitoring wells for downhole measurements. The ISE probe (TempHion, Instrumentation Northwest Inc.) was plumbed in series with the MP20 flow cell, providing real-time estimates of bromide concentration in the field. Prior to sampling, it was determined that the housing for the bromide probe required a 3.78-L (1-gal) purge volume for readings to stabilize. ISE measurements were logged using a Campbell Scientific CR10X data logger programmed to record data at a frequency ranging from 5 to 30 minutes.

Purge rates during groundwater sampling were maintained at $3.78 \mathrm{~L}$ ( 1 gal) per minute to minimize drawdown in the monitoring wells and, based on volumetric calculations and field observations, it was determined that a 2-minute purge time was sufficient to assure adequate purging of the sample lines, 
manifold, and flow cells. During field operations, flow-cell readings generally stabilized in less than a minute, indicating that the 2-minute purge time was adequate. The sensors used to measure field parameters during this test meet the specifications listed in Table 2.1.

Table 2.1. Field Parameter Monitoring Electrode Specifications

\begin{tabular}{lccc}
\hline \multicolumn{1}{c}{ Parameter } & Manufacturer/Model \# & Range & Accuracy \\
\hline $\mathrm{pH}$ & QED/MP20 & 2 to $12 \mathrm{pH}$ units & $\pm 0.2 \mathrm{pH}$ \\
$\begin{array}{l}\text { Oxidation Reduction } \\
\text { Potential }\end{array}$ & QED/MP20 & -999 to $999 \mathrm{mV}$ & $\pm 25 \mathrm{mV}$ \\
Temperature & QED/MP20 & 5 to $50^{\circ} \mathrm{C}$ & $\pm 0.2^{\circ} \mathrm{C}$ \\
Specific Conductance & QED/MP20 & 0 to $100 \mathrm{mS} / \mathrm{cm}$ & $\pm 1 \%$ \\
Dissolved Oxygen & QED/MP20 & 0 to $50 \mathrm{mg} / \mathrm{L}$ & $\pm 0.2 \mathrm{mg} / \mathrm{L}$ \\
Bromide or Chloride & Instrumentation NW TempHion & Calibrate to specified range & $\pm 5 \%$ of range \\
\hline
\end{tabular}

\subsubsection{Analytical Measurements}

Prior to the polyphosphate injection test, three rounds of baseline samples were collected and analyzed for a variety of metals, cations, and anions. The analytes and sample-handling specifics are outlined in Section 2.4. For all samples collected, field parameters were measured in the flow-through cells. Samples were selected for analysis based on the results of the field parameter measurements. All analyses were conducted by a PNNL-operated analytical laboratory according to PNNL-developed procedures (PNL-MA-567, PNNL 1994).

\subsubsection{Water-Level/Pressure Response Measurement}

A network of submersible pressure sensors was used to monitor pre-test baseline water levels, pressure responses during the test, and post-test water levels. Sensors were installed in the water-supply well (399-1-7), the injection well (399-1-23), and in each of the nine monitoring wells (Figure 2.4). The pressure sensors are digitally networked using cables for the 10 proximal wells and radio transceivers for the distant water-source well. The radios consist of a pair of Instrumentation Northwest (INW, Kirkland, WA) WaveData short-haul radio-frequency modems. The sensor network terminated in a single-drop access point to the field computer located inside the sample trailer.

Integrated data logger pressure sensors (INW model PT2X) with a $0-15$ psig range and $0.1 \%$ full-scale accuracy were used. The sensors are vented at the ground surface with vented cables to allow for compensation with barometric pressure changes. Pressure response measurements were continuously recorded to an internal memory logger on each sensor and periodically downloaded to a field computer through the single-point connection in the sensor network. In addition to the continuous internal data logging, pressure measurements were recorded to a separate data file located on a field computer during the injection phase of the test to ensure data redundancy and backup. This was made possible by having all 11 sensors serially networked to a field computer running INW's Aqua4Push software. The software automatically polls each sensor in the digital network at a user-defined interval and appends these values 
to a single data file. This is similar to traditional analog systems (e.g., Campbell Scientific, Inc. data logger) except for the ability to simultaneously log data to two separate recording systems rather than a single one.

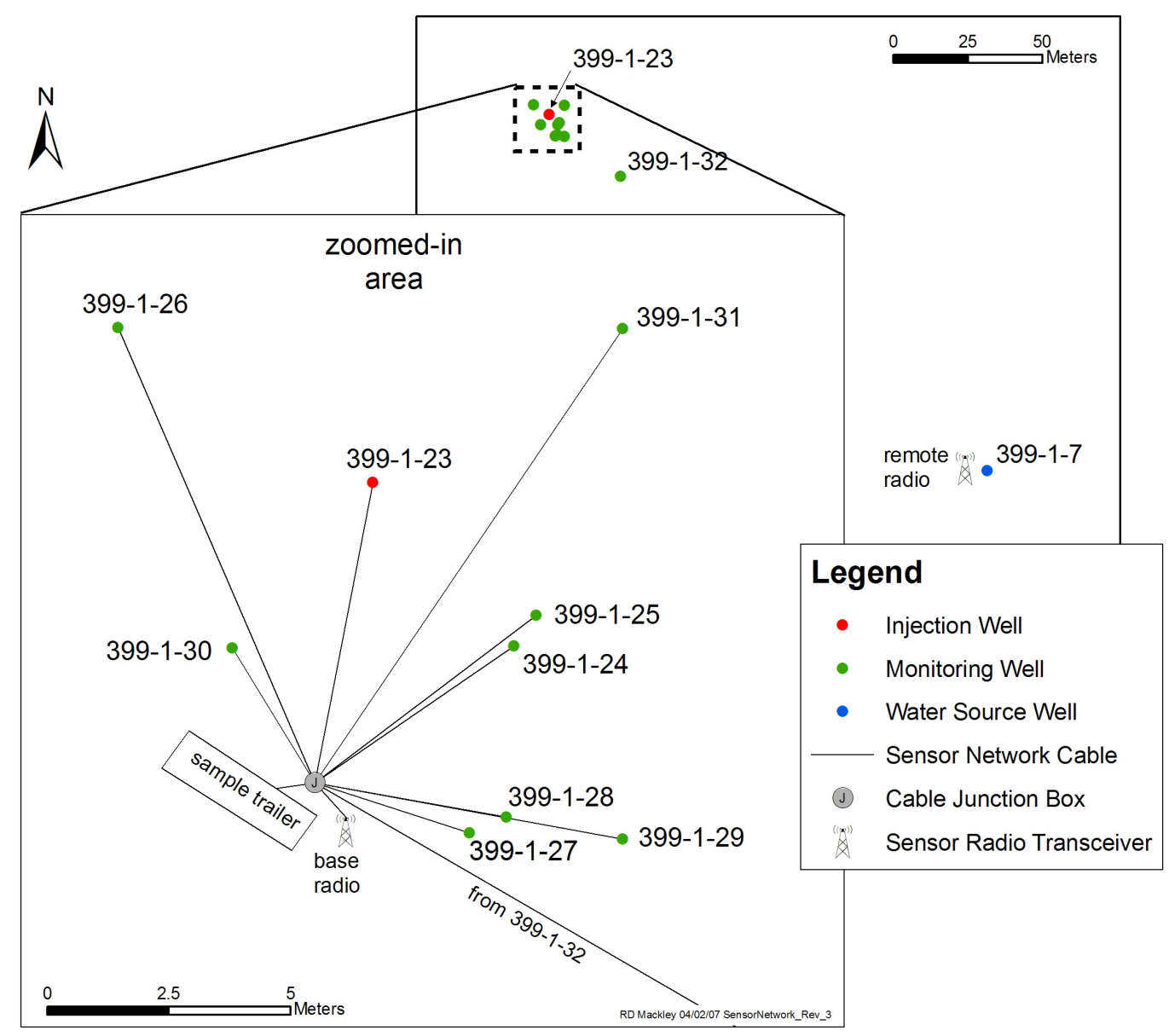

Figure 2.4. Schematic Layout of Pressure Sensor Network

Water levels were measured using a high-accuracy, non-stretch, metal-taped, water-level meter traceable to the National Institute of Standards and Technology and marked in 0.003-m (0.01-ft) gradations. The north side of the top of casing was used as the vertical reference point for all water levels.

\subsection{Sampling and Analysis}

The treatability test plan originally called for the collection of both aqueous and sediment samples from the site to assess treatment performance. However, because aqueous monitoring data indicated limited potential for calcium-phosphate mineral formation, post-treatment sediment core collection was not performed. The equipment used to conduct the sampling is described in Section 2.3. All sampling activities complied with applicable subject areas of PNNL's Standards-Based Management System (SBMS) located at https://sbms.pnl.gov and PNL-MA 567, Procedures for Groundwater Investigations. SBMS is a web-based system for communicating PNNL's management systems and procedures through subject areas. Investigation-derived waste was handled in accordance with Hanford Site requirements. 
During all groundwater sampling, field parameters $(\mathrm{pH}$, specific conductance, dissolved oxygen, oxidation reduction potential, and temperature) were measured and recorded manually on data sheets, which were copied for distribution. Calibration of field probes followed the manufacturer's instructions and recommendations using standard calibration solutions. Detailed sampling instructions, including which wells to sample and at what frequency, were posted in the field site trailer prior to initiation of the test. Groundwater sample collection requirements and location and frequency of sampling are provided in Table 2.2 and Table 2.3, respectively. All analyses were performed in accordance analytical requirements listed in Table 2.4 .

Table 2.2. Groundwater Chemistry Sampling Requirements

\begin{tabular}{|c|c|c|c|c|c|}
\hline Parameter & $\begin{array}{l}\text { Media/ } \\
\text { Matrix }\end{array}$ & Monitoring Phase & $\begin{array}{l}\text { Volume/ } \\
\text { Container }\end{array}$ & Preservation & $\begin{array}{l}\text { Holding } \\
\text { Time }\end{array}$ \\
\hline \multicolumn{6}{|c|}{ Water Quality Parameters } \\
\hline $\begin{array}{l}\text { Major cations: } \\
\mathrm{Al}, \mathrm{As}, \mathrm{B}, \mathrm{Ba}, \mathrm{Bi}, \mathrm{Ca} \text {, } \\
\mathrm{Co}, \mathrm{Fe}, \mathrm{K}, \mathrm{Mg}, \mathrm{Mn}, \mathrm{Ni} \\
\mathrm{Zn}, \mathrm{Zr}, \mathrm{P}, \mathrm{Sr}, \mathrm{Na}, \mathrm{Si}, \mathrm{S} \text {, } \\
\mathrm{Sb}\end{array}$ & Water & $\begin{array}{l}\text { Pre-Test Monitoring, } \\
\text { Injection Monitoring, } \\
\text { Performance Monitoring }\end{array}$ & $\begin{array}{l}\text { 20-ml plastic } \\
\text { vial }\end{array}$ & $\begin{array}{l}\text { Filtered } \\
(0.45 \mu \mathrm{m}), \\
\text { unfiltered dup. } \\
\text { at } 20 \% \text { level } \\
\mathrm{HNO}_{3} \text { to pH } \\
<2\end{array}$ & 60 Days \\
\hline $\begin{array}{l}\text { RCRA/trace metals: } \\
\mathrm{Cr}, \mathrm{Cu}, \mathrm{As}, \mathrm{Se}, \mathrm{Mo}, \mathrm{Ag} \text {, } \\
\mathrm{Cd}, \mathrm{Pb}, \mathrm{U}\end{array}$ & Water & $\begin{array}{l}\text { Pre-Test Monitoring, } \\
\text { Performance Monitoring }\end{array}$ & $\begin{array}{l}\text { 20-ml plastic } \\
\text { vial }\end{array}$ & $\begin{array}{l}\text { Filtered } \\
(0.45 \mu \mathrm{m}) \\
\mathrm{HNO}_{3} \text { to } \mathrm{pH} \\
<2\end{array}$ & 60 Days \\
\hline $\begin{array}{l}\text { Anions: } \\
\mathrm{Cl}^{-}, \mathrm{Br}^{-}, \mathrm{SO}_{4}{ }^{2-}, \mathrm{PO}_{4}{ }^{3-}, \\
\mathrm{NO}_{2}{ }^{-}, \mathrm{NO}_{3}{ }^{-}\end{array}$ & Water & $\begin{array}{l}\text { Pre-Test Monitoring, } \\
\text { Injection Monitoring, } \\
\text { Performance Monitoring }\end{array}$ & $\begin{array}{l}\text { 20-ml plastic } \\
\text { vial }\end{array}$ & $\mathrm{Cool} 4^{\circ} \mathrm{C}$ & 45 Days \\
\hline \multicolumn{6}{|c|}{ Parameters Measured with Field Probes } \\
\hline Bromide or chloride & Water & $\begin{array}{l}\text { Monitored during each } \\
\text { sampling event }\end{array}$ & $\begin{array}{c}\text { Field } \\
\text { Measurement }\end{array}$ & None & NA \\
\hline $\mathrm{pH}$ & Water & $\begin{array}{l}\text { Monitored during each } \\
\text { sampling event }\end{array}$ & $\begin{array}{c}\text { Field } \\
\text { Measurement }\end{array}$ & None & NA \\
\hline Specific conductance & Water & $\begin{array}{l}\text { Monitored during each } \\
\text { sampling event }\end{array}$ & $\begin{array}{c}\text { Field } \\
\text { Measurement }\end{array}$ & None & NA \\
\hline Dissolved oxygen & Water & $\begin{array}{l}\text { Monitored during each } \\
\text { sampling event }\end{array}$ & $\begin{array}{c}\text { Field } \\
\text { Measurement }\end{array}$ & None & NA \\
\hline $\begin{array}{l}\text { Oxidation-reduction } \\
\text { potential }\end{array}$ & Water & $\begin{array}{l}\text { Monitored during each } \\
\text { sampling event }\end{array}$ & $\begin{array}{c}\text { Field } \\
\text { Measurement }\end{array}$ & None & NA \\
\hline Temperature & Water & $\begin{array}{l}\text { Monitored during each } \\
\text { sampling event }\end{array}$ & $\begin{array}{c}\text { Field } \\
\text { Measurement }\end{array}$ & None & NA \\
\hline $\mathrm{NA}=$ not applicable & & & & & \\
\hline
\end{tabular}


Table 2.3. Sampling Frequency and Location

\begin{tabular}{|c|c|c|c|}
\hline Parameter & Monitoring Phase & Sampling Location & Sampling Frequency \\
\hline \multirow{3}{*}{$\begin{array}{l}\text { Major cations: } \\
\mathrm{Al}, \mathrm{As}, \mathrm{B}, \mathrm{Ba}, \mathrm{Bi} \text {, } \\
\mathrm{Ca}, \mathrm{Co}, \mathrm{Fe}, \mathrm{K}, \mathrm{Mg} \text {, } \\
\mathrm{Mn}, \mathrm{Ni}, \mathrm{Zn}, \mathrm{Zr}, \mathrm{P}, \\
\mathrm{Sr}, \mathrm{Na}, \mathrm{Si}, \mathrm{S}, \mathrm{Sb}\end{array}$} & $\begin{array}{l}\text { Pre-Test } \\
\text { Monitoring }\end{array}$ & $\begin{array}{l}\text { All available monitoring } \\
\text { wells }\end{array}$ & 3 times prior to injection \\
\hline & $\begin{array}{l}\text { Injection } \\
\text { Monitoring }\end{array}$ & $\begin{array}{l}\text { All available monitoring } \\
\text { wells }\end{array}$ & $\begin{array}{l}\text { Sufficient frequency to adequately describe } \\
\text { amendment arrival and transport response }\end{array}$ \\
\hline & $\begin{array}{l}\text { Performance } \\
\text { Monitoring }\end{array}$ & $\begin{array}{l}\text { Selected wells (see above } \\
\text { list) }\end{array}$ & $\begin{array}{l}\text { A minimum of } 3 \text { post-injection sampling } \\
\text { events }\end{array}$ \\
\hline \multirow{2}{*}{$\begin{array}{l}\text { RCRA/trace } \\
\text { metals: } \\
\mathrm{Cr}, \mathrm{Cu}, \mathrm{As}, \mathrm{Se}, \\
\mathrm{Mo}, \mathrm{Ag}, \mathrm{Cd}, \mathrm{Pb}, \mathrm{U}\end{array}$} & $\begin{array}{l}\text { Pre-Test } \\
\text { Monitoring }\end{array}$ & $\begin{array}{l}\text { All available monitoring } \\
\text { wells }\end{array}$ & 3 times prior to injection \\
\hline & $\begin{array}{l}\text { Performance } \\
\text { Monitoring }\end{array}$ & $\begin{array}{l}\text { Selected wells (see above } \\
\text { list) }\end{array}$ & $\begin{array}{l}\text { A minimum of } 3 \text { post-injection sampling } \\
\text { events }\end{array}$ \\
\hline \multirow{3}{*}{$\begin{array}{l}\text { Anions: } \mathrm{Cl}^{-}, \mathrm{Br}^{-} \\
\mathrm{SO}_{4}{ }^{2-}, \mathrm{PO}_{4}{ }^{-3}, \mathrm{NO}_{2}^{-}\end{array}$} & $\begin{array}{l}\text { Pre-Test } \\
\text { Monitoring }\end{array}$ & $\begin{array}{l}\text { All available monitoring } \\
\text { wells }\end{array}$ & 3 times prior to injection \\
\hline & $\begin{array}{l}\text { Injection } \\
\text { Monitoring }\end{array}$ & $\begin{array}{l}\text { All available monitoring } \\
\text { wells }\end{array}$ & $\begin{array}{l}\text { Sufficient frequency to adequately describe } \\
\text { amendment arrival and transport response }\end{array}$ \\
\hline & $\begin{array}{l}\text { Performance } \\
\text { Monitoring }\end{array}$ & $\begin{array}{l}\text { Selected wells (see above } \\
\text { list) }\end{array}$ & $\begin{array}{l}\text { A minimum of } 3 \text { post-injection sampling } \\
\text { events }\end{array}$ \\
\hline Field parameters & $\begin{array}{l}\text { Each Sampling } \\
\text { Event }\end{array}$ & $\begin{array}{l}\text { All available monitoring } \\
\text { wells }\end{array}$ & $\begin{array}{l}\text { Collected for each sample, and more } \\
\text { frequently if necessary, to characterize arrival } \\
\text { curves and monitor injection performance }\end{array}$ \\
\hline
\end{tabular}

Table 2.4. Analytical Requirements

\begin{tabular}{|c|c|c|c|c|}
\hline Parameter & Analysis Method & $\begin{array}{l}\text { Detection Limit } \\
\text { or (Range) }\end{array}$ & $\begin{array}{l}\text { Typical } \\
\text { Precision/ } \\
\text { Accuracy }\end{array}$ & QC Requirements \\
\hline $\begin{array}{l}\text { Major cations/metals: } \\
\mathrm{Ca}, \mathrm{Fe}, \mathrm{K}, \mathrm{Mg}, \mathrm{P}, \mathrm{Na} \text {, } \\
\mathrm{Si}, \mathrm{S}, \mathrm{Al}, \mathrm{B}, \mathrm{Ba}, \mathrm{Bi}, \mathrm{Ni} \text {, } \\
\mathrm{Zn}, \mathrm{Zr}, \mathrm{Sr}\end{array}$ & $\begin{array}{l}\text { ICP-OES, PNNL- } \\
\text { AGG-ICP-AES } \\
\text { (similar to EPA } \\
\text { Method 6010B [EPA } \\
\text { 1996b]) }\end{array}$ & $\begin{array}{c}1 \mathrm{mg} / \mathrm{L} \\
0.1 \mathrm{mg} / \mathrm{L}\end{array}$ & $\pm 10 \%$ & $\begin{array}{l}\text { Daily calibration; blanks } \\
\text { and duplicates and matrix } \\
\text { spikes at } 10 \% \text { level per } \\
\text { batch of } 20 .\end{array}$ \\
\hline $\begin{array}{l}\text { RCRA/trace metals: } \\
\mathrm{Cr}, \mathrm{Cu}, \mathrm{As}, \mathrm{Se}, \mathrm{Mo}, \mathrm{Ag} \text {, } \\
\mathrm{Cd}, \mathrm{Pb}, \mathrm{U}\end{array}$ & $\begin{array}{l}\text { ICP-MS, PNNL-AGG- } \\
415 \text { (similar to EPA } \\
\text { Method } 6020 \text { [EPA } \\
\text { 2000]) }\end{array}$ & $\begin{array}{c}1 \mu \mathrm{g} / \mathrm{L} \text { for trace } \\
\text { elements }\end{array}$ & $\pm 10 \%$ & $\begin{array}{l}\text { Daily calibration; blanks } \\
\text { and duplicates and matrix } \\
\text { spikes at } 10 \% \text { level per } \\
\text { batch of } 20 .\end{array}$ \\
\hline $\begin{array}{l}\text { Anions: } \mathrm{Cl}^{-}, \mathrm{Br}^{-}, \mathrm{SO}_{4}{ }^{2-} \text {, } \\
\mathrm{PO}_{4}^{3-}, \mathrm{NO}_{2}^{-}, \mathrm{NO}_{3}^{-}\end{array}$ & $\begin{array}{l}\text { Ion Chromatography, } \\
\text { AGG-IC-001 (based } \\
\text { on EPA Method } \\
\text { 300.0A [EPA 1991]) }\end{array}$ & $1 \mathrm{mg} / \mathrm{L}$ & $\pm 15 \%$ & $\begin{array}{l}\text { Daily calibration; blanks } \\
\text { and duplicates at } 10 \% \\
\text { level per batch of } 20 .\end{array}$ \\
\hline Bromide and chloride & Ion selective electrode & $\begin{array}{c}0.4 \text { to } \\
79,900 \mathrm{mg} / \mathrm{L}\end{array}$ & $\begin{array}{c} \pm 5 \% \\
\text { For indication } \\
\quad \text { only }\end{array}$ & $\begin{array}{l}\text { Follow manufacturer } \\
\text { recommendations }\end{array}$ \\
\hline
\end{tabular}


Table 2.4. (contd)

\begin{tabular}{|c|c|c|c|c|}
\hline Parameter & Analysis Method & $\begin{array}{l}\text { Detection Limit } \\
\text { or (Range) }\end{array}$ & $\begin{array}{l}\text { Typical } \\
\text { Precision/ } \\
\text { Accuracy }\end{array}$ & QC Requirements \\
\hline $\mathrm{pH}$ & pH electrode & 2 to $12 \mathrm{pH}$ units & $\begin{array}{l} \pm 0.2 \mathrm{pH} \text { unit } \\
\text { For indication } \\
\text { only }\end{array}$ & $\begin{array}{l}\text { User calibrate, follow } \\
\text { manufacturer } \\
\text { recommendations }\end{array}$ \\
\hline Specific conductance & Electrode & 0 to $100 \mathrm{mS} / \mathrm{cm}$ & $\begin{array}{l} \pm 1 \% \text { of reading } \\
\text { For indication } \\
\text { only }\end{array}$ & $\begin{array}{l}\text { User calibrate, follow } \\
\text { manufacturer } \\
\text { recommendations }\end{array}$ \\
\hline Dissolved oxygen & Membrane electrode & 0 to $20 \mathrm{mg} / \mathrm{L}$ & $\begin{array}{l} \pm 0.2 \mathrm{mg} / \mathrm{L} \\
\text { For indication } \\
\quad \text { only }\end{array}$ & $\begin{array}{l}\text { User calibrate, follow } \\
\text { manufacturer } \\
\text { recommendations }\end{array}$ \\
\hline $\begin{array}{l}\text { Oxidation-reduction } \\
\text { potential }\end{array}$ & Electrode & -999 to $999 \mathrm{mV}$ & $\begin{array}{l} \pm 25 \mathrm{mV} \\
\text { For indication } \\
\quad \text { only }\end{array}$ & $\begin{array}{l}\text { User calibrate, follow } \\
\text { manufacturer } \\
\text { recommendations }\end{array}$ \\
\hline Temperature & Thermocouple & 5 to $50^{\circ} \mathrm{C}$ & $\begin{array}{c} \pm 0.2^{\circ} \mathrm{C} \\
\text { For indication } \\
\text { only }\end{array}$ & Factory calibration \\
\hline \multicolumn{5}{|c|}{$\begin{array}{l}\mathrm{ICP}=\text { inductively coupled plasma } \\
\mathrm{MS}=\text { mass spectrometry } \\
\mathrm{OES}=\text { optical emission spectrometry }\end{array}$} \\
\hline
\end{tabular}

\subsection{Data Management}

A project-specific database was developed and maintained to collect, organize, store, verify/validate, and manage analytical laboratory data and/or field measurements for environmental samples. The data were stored electronically in Microsoft Excel spreadsheets and paper copies were maintained in the project files. A project data custodian was designated to control and maintain the data. The following data were contained, at a minimum, as part of the database:

- sample identifier

- sample location

- sample medium type

- sampling date

- analysis date

- laboratory name

- analyte name

- concentration value

- measurement unit.

Data were managed in accordance with the EM-20 project quality assurance project plan (PNNL 2007). 


\subsection{Treatability Study Activities}

Bench-scale testing, site-specific characterization, injection design analysis, and polyphosphate injection testing comprised the activities conducted under the treatment study.

\subsection{Bench-Scale Testing}

This section describes bench-scale experiments that were conducted in support of developing a field-scale injection design for the polyphosphate treatability test. A detailed description of these experiments and other supporting information is provided by Wellman et al. (2007).

\subsubsection{Polyphosphate Remediation Technology}

Numerous proposals have been made to sequester uranium, in situ, with solid-phase hydroxyapatite (Arey et al. 1999; Conca 1996; Gauglitz and Holterdorf 1992; Moore et al. 2001; Seaman et al. 2001; Wright et al. 1995), and water-soluble phosphate compounds, such as tribasic sodium phosphate $\left[\mathrm{Na}_{3}\left(\mathrm{PO}_{4}\right) \cdot \mathrm{nH}_{2} \mathrm{O}\right]$ (Lee et al. (1995) or phytic acid (Jensen et al. 1996; Nash et al. 1998a; Nash et al. 1998b; Nash et al. 1999). These compounds can be injected into contaminant plumes from strategically placed wells as a chemical stabilizer for uranium and other radionuclides and heavy metals. The advantages of soluble amendments is that they allow for treatment of plumes situated deep within the subsurface and act to sequester uranium by precipitating insoluble uranium minerals rather than by reversible sorption mechanisms. However, Wellman et al. (2005) demonstrated that compounds including tribasic sodium phosphate and phytic acid result in the rapid formation of phosphate phases. Formation of these phases occludes $\sim 30 \%$ of the fluid-filled pore space within the sedimentary formation. Rapid reduction in the hydraulic conductivity will have a significant effect on subsequently injected amendment solutions, the targeted groundwater plume, or both, by deflecting flow from the natural path.

Conversely, the use of soluble long-chain polyphosphate materials has been demonstrated to delay the precipitation of phosphate phases (Wellman et al. 2005) (Figure 3.1). Precipitation of phosphate minerals occurs when phosphate compounds degrade in water, due to hydrolysis, to yield orthophosphate molecules $\left(\mathrm{PO}_{4}{ }^{3-}\right)$. The longer the polyphosphate chain, the slower the hydrolysis reaction, which leads to orthophosphate production (Figure 3.2). Accordingly, use of a long-chain polyphosphate compound does not result in a drastic change in hydraulic conductivity of the target aquifer.

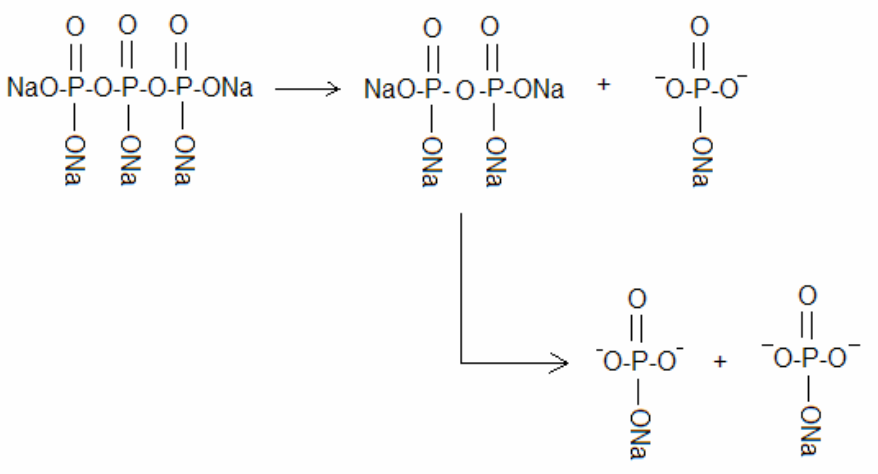

Figure 3.1. Schematic Depicting the Step-Wise Hydrolysis of Sodium Tripolyphosphate 
Previous laboratory tests have demonstrated that when a soluble form of polyphosphate is injected into uranium-bearing saturated porous media, immobilization of uranium occurs due to formation of an insoluble uranyl phosphate, autunite $\left[\mathrm{Ca}\left(\mathrm{UO}_{2}\right)_{2}\left(\mathrm{PO}_{4}\right)_{2} \cdot \mathrm{nH}_{2} \mathrm{O}\right]$. These tests were conducted at conditions expected for the aquifer and used Hanford soils and groundwater containing very low concentrations of uranium $\left(10^{-6} \mathrm{M}\right)$. Because autunite sequesters uranium in the oxidized form $\mathrm{U}(\mathrm{VI})$ rather than forcing reduction to $\mathrm{U}(\mathrm{IV})$, the possibility of re-oxidation and subsequent re-mobilization is negated. Extensive testing demonstrated the very low solubility and slow dissolution kinetics of autunite. In addition to autunite, excess phosphorous may result in apatite mineral formation, which provides a long-term source of treatment capacity. Uranium transport studies in columns packed with contaminated sediment from the Hanford 300 Area indicated that a polyphosphate solution reduces the concentration of uranium in groundwater to approximately $7 \mathrm{ppb}$, which is less than the drinking water standard (30 ppb).

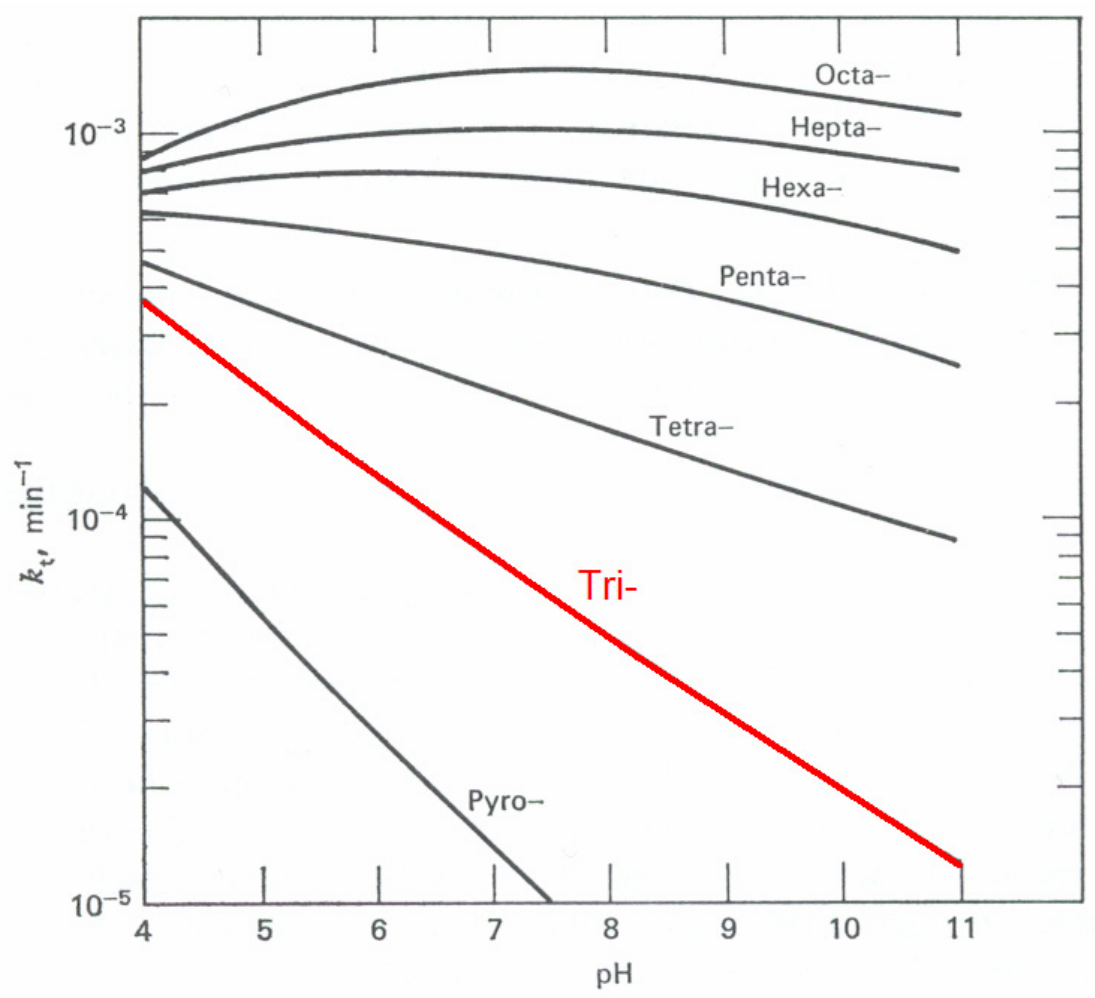

Figure 3.2. Hydrolysis Rate of Polyphosphate Molecules as a Function of pH (Shen and Morgan 1973)

Extensive laboratory tests were conducted to evaluate the following technical issues:

- formation rate of autunite/apatite for various polyphosphate formulations

- polyphosphate treatment efficiency - amount of polyphosphate required to treat a pore volume of uranium contaminated groundwater

- polyphosphate treatment emplacement efficiency - evaluate mixing problem (i.e., effective contact or tendency for the reagent to push contaminated groundwater ahead of the treatment volume).

All experiments were conducted with sediments from the 300 Area to ensure that testing conditions were representative of the remediation area. 


\subsubsection{Autunite and Apatite Formation}

In homogeneous systems the precipitating phase first forms stable nuclei and then grows via crystallization to a macroscopic size. The nucleation rate can be expressed as follows:

$$
B=\beta \exp \left(\frac{-A}{\ln ^{2} S}\right)
$$

where $B=$ the rate

$\beta=$ the frequency factor

$A=$ a parameter that depends on interfacial energy

$s=$ the degree of supersaturation of the solution.

However, heterogeneous nucleation on foreign or heterogeneous surfaces lowers the interfacial energy, $A$. Equation (3.2) can be used to understand the increase in precipitation rates due to heterogeneous nucleation (Avrami 1939, 1940). The rate of heterogeneous nucleation can be expressed as follows:

$$
B(t)=k N(t)=k N \text { exp }(-k t)
$$

in which the nucleation rate as a function of time, $B(t)$, is equivalent to the product of a constant times the nucleation density as a function of time, $k N(t)$, and is equal to the product of a constant, $k$, the number of heterogeneous germ nuclei, $N_{o}$, and exponentially to the negative product of the constant, $k$, and time, $t$. Note the degree of supersaturation of the solution is still important and is accounted for in the parameter $k$. The nucleation rate is directly proportional to the number of nucleation sites available, a number that should be large for a solution percolating through porous media. This equation also suggests that nucleation rates should be fastest at early times and diminish exponentially.

These equations are relevant to the understanding of surface-mediated catalysis of autunite and apatite precipitation kinetics. Rapid initial rates are critical for the successful deployment of a soluble polyphosphate amendment. The above equations imply that catalysis of polyphosphate hydrolysis and solid-phase precipitation should be immediate after orthophosphate contacts porous media. Furthermore, these rate equations highlight the importance of quantifying kinetic precipitation data for systems in more realistic column experiments containing actual 300 Area sediments coupled with knowledge regarding the degradation of proposed polyphosphates.

Preliminary field tracer investigations indicated a field flow rate of $\sim 15.2 \mathrm{~m} \mathrm{(50} \mathrm{ft)} \mathrm{per} \mathrm{day} \mathrm{(see}$ Section 6.0), suggesting that rapid formation of autunite and apatite is required within the 300 Area subsurface for remediation. Therefore, nine potential phosphate compounds were selected for investigation as possible components to the polyphosphate amendment formulation (Table 3.1). Selection of the amendment sources was based on the solubility, hydrolysis rate, and amount of phosphorus and/or calcium provided by the respective compounds. Prior to conducting column tests, heterogeneous batch experiments were conducted in the presence of 300-Area sediment over a range of polyphosphate sources and concentrations to identify the optimum source of phosphorus and calcium in order to obtain maximum precipitation of autunite and/or apatite. Batch experiments evaluated the potential composition of the polyphosphate amendment based on the extreme (i.e., 10 to $1000 \mathrm{ppb}$ ) uranium concentration range 
measured within the 300-Area aquifer. The use of multi-length polyphosphate chain amendments was evaluated to afford rapid precipitation of autunite and/or apatite. All experiments were conducted in Hanford groundwater and in the presence of 300-Area sediments for 1 week at room temperature. Aqueous concentrations were monitored via inductively couple plasma-mass spectrometry (ICP-MS) and inductively couple plasma-optical emission spectrometry (ICP-OES). The exact details constituting the multiple nucleation and growth process, which may occur during the formation of calcium phosphate or the assignment of absolute limits of mineralization potential for any given set of reaction conditions, was beyond the scope of this investigation. Rather, the intent was to identify the optimum sources of calcium and phosphorous to precipitate autunite and apatite within a saturated sedimentary matrix through static batch tests.

Table 3.1. Possible Sources and Associated Solubility for Polyphosphate Amendment

\begin{tabular}{lc}
\hline \multicolumn{1}{c}{ Amendment Source } & Formula \\
\hline Sodium Orthophosphate & $\mathrm{Na}_{3} \mathrm{PO}_{4} \cdot 12 \mathrm{H}_{2} \mathrm{O}$ \\
\hline Sodium Pyrophosphate & $\mathrm{Na}_{4} \mathrm{P}_{2} \mathrm{O}_{7} \cdot 10 \mathrm{H}_{2} \mathrm{O}$ \\
\hline Sodium Tripolyphosphate & $\mathrm{Na}_{5} \mathrm{P}_{3} \mathrm{O}_{10}$ \\
\hline Sodium Trimetaphosphate & $\left(\mathrm{NaPO}_{3}\right)_{3} \cdot 6 \mathrm{H}_{2} \mathrm{O}$ \\
\hline Sodium Hexametaphosphate & $\left(\mathrm{NaPO}_{3}\right)_{6} \cdot n \mathrm{H}_{2} \mathrm{O}$ \\
Calcium Dihydrogen Phosphate & $\mathrm{Ca}\left(\mathrm{H}_{2} \mathrm{PO}_{4}\right)_{2} \cdot \mathrm{H}_{2} \mathrm{O}$ \\
Calcium Hydrogen Phosphate & $\mathrm{CaHPO}_{4} \cdot 2 \mathrm{H}_{2} \mathrm{O}$ \\
Calcium Pyrophosphate & $\mathrm{Ca}_{2} \mathrm{P}_{2} \mathrm{O}_{7} \cdot 5 \mathrm{H}_{2} \mathrm{O}$ \\
Calcium Hypophosphite & ${\mathrm{Ca}\left(\mathrm{H}_{2} \mathrm{PO}_{2}\right)_{2}}_{\text {Calcium Chloride }}^{\mathrm{CaCl}_{2}}$ \\
\hline
\end{tabular}

Initial batch tests were conducted based on the minimum amendment concentration as defined by previously conducted preliminary column tests, which indicated a 1000-ppm sodium tripolyphosphate solution would reduce the aqueous concentration of uranium to near the maximum contaminant level (MCL) in $\sim 12$ pore volumes. The initial upper limit for the concentration of phosphorus was set to $1000 \mathrm{ppm}$. Additionally, lower concentrations of 100, 250, and $500 \mathrm{ppm}$ were investigated in an effort to ensure the amendment did not contain excessive phosphorus, which may not be used in remediation efforts. Results further indicated the availability of calcium from Hanford 300 Area sediments and groundwater was insufficient to precipitate calcium-phosphate solid phases, because the use of a sodium phosphate compounds as the source of phosphorus requires the addition of a calcium source. The initial matrix of batch tests is given in Table 3.2. 
Table 3.2. Experimental Batch Conditions for Polyphosphate Amendment Optimization

\begin{tabular}{|c|c|c|c|c|c|}
\hline & $\begin{array}{l}\text { Phosphorus } \\
\text { Conc. (ppm) }\end{array}$ & Calcium Source & $\begin{array}{c}\text { Calcium } \\
\text { Conc. (ppm) }\end{array}$ & \multicolumn{2}{|c|}{$\begin{array}{l}\text { Uranium Conc. } \\
\qquad(\mu \mathrm{g} / \mathrm{L})\end{array}$} \\
\hline \multirow{2}{*}{ Sodium Orthophosphate } & \multirow{2}{*}{1000} & & & 10 & 1000 \\
\hline & & & & \multicolumn{2}{|c|}{0.00} \\
\hline \multirow{2}{*}{ Sodium Pyrophosphate } & \multirow{2}{*}{1000} & & & 10 & 1000 \\
\hline & & & & \multicolumn{2}{|c|}{0.00} \\
\hline \multirow{2}{*}{ Sodium Tripolyphosphate } & \multirow{2}{*}{1000} & & & 10 & 1000 \\
\hline & & & & \multicolumn{2}{|c|}{0.00} \\
\hline \multirow{2}{*}{ Sodium Orthophosphate } & \multirow{2}{*}{500} & & & 10 & 1000 \\
\hline & & & & \multicolumn{2}{|c|}{0.00} \\
\hline \multirow{2}{*}{ Sodium Pyrophosphate } & \multirow{2}{*}{500} & & & 10 & 1000 \\
\hline & & & & \multicolumn{2}{|c|}{0.00} \\
\hline \multirow{2}{*}{ Sodium Tripolyphosphate } & \multirow{2}{*}{500} & & & 10 & 1000 \\
\hline & & & & \multicolumn{2}{|c|}{0.00} \\
\hline \multirow{2}{*}{ Sodium Trimetaphosphate } & \multirow{2}{*}{1000} & & & 10 & 1000 \\
\hline & & & & \multicolumn{2}{|c|}{0.00} \\
\hline \multirow{2}{*}{ Sodium Trimetaphosphate } & \multirow{2}{*}{500} & & & 10 & 1000 \\
\hline & & & & \multicolumn{2}{|c|}{0.00} \\
\hline \multirow{2}{*}{ Sodium Hexametaphosphate } & \multirow{2}{*}{1000} & & & 10 & 1000 \\
\hline & & & & \multicolumn{2}{|c|}{0.00} \\
\hline \multirow{2}{*}{ Sodium Hexametaphosphate } & 500 & & & 10 & 1000 \\
\hline & 300 & & & & \\
\hline Calcium Hynonhosphite & 1000 & & & 10 & 1000 \\
\hline 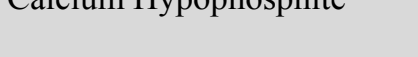 & 1000 & & & & \\
\hline Colcium Hunephesphite & 500 & & & 10 & 1000 \\
\hline Calcium пурорпоspminte & 500 & & & & \\
\hline Colcium Hunophenhitt & 250 & & & 10 & 1000 \\
\hline Calcium нурорпоspnite & 250 & & & & \\
\hline C 1. & 1000 & Coloium Cblorid & 500 & 10 & 1000 \\
\hline 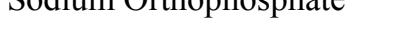 & 1000 & - & 300 & & \\
\hline Sodium Orthonhosnhate & 500 & Calcium Chloride & 500 & 10 & 1000 \\
\hline 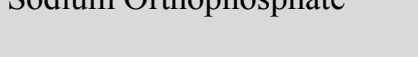 & 500 & - & 300 & & \\
\hline Sodium Pyronhosnhate & 1000 & Colcium Cbloride & 500 & 10 & 1000 \\
\hline 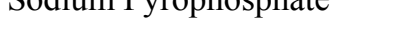 & 1000 & - & 300 & & \\
\hline Sodium Dyronhecuhat & 500 & Colcium Cblorid & 500 & 10 & 1000 \\
\hline & & & & & \\
\hline
\end{tabular}


Table 3.2. (contd)

\begin{tabular}{|c|c|c|c|c|c|}
\hline & $\begin{array}{l}\text { Phosphorus } \\
\text { Conc. (ppm) }\end{array}$ & Calcium Source & $\begin{array}{c}\text { Calcium } \\
\text { Conc. (ppm) }\end{array}$ & \multicolumn{2}{|c|}{$\begin{array}{l}\text { Uranium Conc. } \\
\qquad(\mu \mathrm{g} / \mathrm{L})\end{array}$} \\
\hline \multirow{2}{*}{ Sodium Tripolyphosphate } & \multirow{2}{*}{1000} & \multirow{2}{*}{ Calcium Chloride } & \multirow{2}{*}{500} & 10 & 1000 \\
\hline & & & & \multicolumn{2}{|c|}{0.00} \\
\hline \multirow{2}{*}{ Sodium Tripolyphosphate } & \multirow{2}{*}{500} & \multirow{2}{*}{ Calcium Chloride } & \multirow{2}{*}{500} & 10 & 1000 \\
\hline & & & & & \\
\hline \multirow{2}{*}{ Sodium Trimetaphosphate } & \multirow{2}{*}{1000} & \multirow{2}{*}{$\begin{array}{c}\text { Calcium } \\
\text { Hypophosphite }\end{array}$} & \multirow{2}{*}{500} & 10 & 1000 \\
\hline & & & & & \\
\hline \multirow{2}{*}{ Sodium Trimetaphosphate } & \multirow{2}{*}{1000} & \multirow{2}{*}{ Calcium Chloride } & \multirow{2}{*}{500} & 10 & 1000 \\
\hline & & & & & \\
\hline \multirow{2}{*}{ Sodium Trimetaphosphate } & \multirow{2}{*}{500} & \multirow{2}{*}{ Calcium Chloride } & \multirow{2}{*}{500} & 10 & 1000 \\
\hline & & & & & \\
\hline \multirow{2}{*}{ Sodium Hexametaphosphate } & \multirow{2}{*}{1000} & \multirow{2}{*}{$\begin{array}{c}\text { Calcium } \\
\text { Hypophosphite }\end{array}$} & \multirow{2}{*}{500} & 10 & 1000 \\
\hline & & & & & \\
\hline \multirow{2}{*}{ Sodium Hexametaphosphate } & \multirow{2}{*}{1000} & \multirow{2}{*}{ Calcium Chloride } & \multirow{2}{*}{500} & 10 & 1000 \\
\hline & & & & & \\
\hline \multirow{2}{*}{ Sodium Hexametaphosphate } & \multirow{2}{*}{500} & Coloium Cblorid & 500 & 10 & 1000 \\
\hline & & Calcium Cnioride & 500 & & \\
\hline Colcium Hunophonhite & 1000 & Coloium Cbloride & 1000 & 10 & 1000 \\
\hline - arc & 1000 & 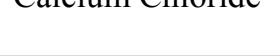 & 1,000 & & \\
\hline Coloinm Uun & 1000 & Calcium Chloride & 500 & 10 & 1000 \\
\hline 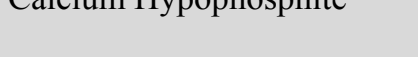 & 1000 & e alcium & 300 & & \\
\hline Colcium Hunphombito & 500 & Colcium Chlorid & 1000 & 10 & 1000 \\
\hline Calcium пурорпоspnte & 500 & - & 1,000 & & \\
\hline Coloium Uunonbenhit & 500 & Coloium Cblorid & 500 & 10 & 1000 \\
\hline 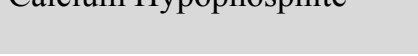 & 00 & 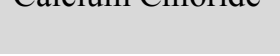 & 500 & & \\
\hline Calcium Hynonhosphite & 250 & Calcium Chloride & 1000 & 10 & 1000 \\
\hline 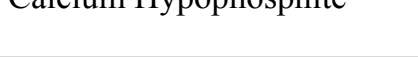 & 200 & cartium & 1,000 & & \\
\hline Colcium Hunonhonhit & 250 & Col: & 500 & 10 & 1000 \\
\hline Calcium пурорпоspntе & 250 & 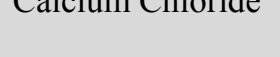 & 500 & & \\
\hline
\end{tabular}

All potential calcium phosphate sources were eliminated from further consideration during the initial round of batch testing. Results indicated that the solubility limits of calcium dihydrogen phosphate, calcium hydrogen phosphate, and calcium pyrophosphate did not provide a sufficient source of phosphate or calcium to be included in the amendment formulation. Although calcium hypophosphite provides a sufficient source of calcium and phosphorus, rather than forming discrete precipitates this amendment formulation produces fine floccules. The formation of fine floccules as a result of phytic acid remediation 
has been previously shown to provide sorption sites for uranium (Nash 2000; Nash et al. 1997, 1998a, 1998b,1999). However, fine floccules may be highly mobile in the 300-Area subsurface under high flow conditions. Alternatively, it has also been previously shown that rapid flocculation due to heterogeneous nucleation in regions of moderate to low hydraulic conductivity may occlude pore space (Wellman et al. 2006). Either of these results is potentially detrimental and serves to eliminate calcium hypophosphite from further consideration as a component of the amendment formulation.

A second set of batch tests was conducted to further develop the amendment formulation using the remaining sodium phosphate compounds under consideration and calcium chloride as the soluble source for calcium (Table 3.3). As discussed above, results from initial batch tests established that phosphorus solutions $>1,000 \mathrm{ppm}$ were required to achieve $>50 \%$ removal of aqueous uranium. Results from the second set of batch tests indicated that concentrations greater than $1000 \mathrm{ppm}$ of sodium trimetaphosphate produced fine floccules, which eliminated it from further consideration for reasons previously noted. Although sodium hexametaphosphate produced discrete precipitates, the extent of precipitation was significantly less than for sodium ortho-, pyro-, or tripolyphosphate under equivalent conditions (Figure 3.3). Additionally, sodium hexametaphosphate reduced the $\mathrm{pH}$ of the groundwater by one to two $\mathrm{pH}$ units. Therefore, sodium hexametaphosphate was eliminated from further consideration for the amendment formulation.

Figure 3.3 displays the percent of calcium and phosphorus removed from solution as a function of the calcium-to-phosphorus ratio in the presence of 10 and 1,000 ppb uranium. The objective of these tests was to identify the calcium-to-phosphorus ratio for maximum removal from the aqueous phase. The mechanisms of removal may include sorption and precipitation; however, no attempt was made to discern the degree of removal based on these respective mechanisms. Greater than $90 \%$ removal of calcium and phosphorus from solution was achieved in the presence of sodium orthophosphate, sodium pyrophos-phate, and sodium tripolyphosphate, respectively, with calcium chloride (Figure 3.3). The optimum ratio of calcium to phosphorus for sodium orthophosphate and sodium pyrophosphate is 1.5; whereas, the optimum calcium-to-phosphorus ratio for sodium tripolyphosphate is $\sim 2.4$. Moreover, the uptake of uranium was rapid ( $<2 \mathrm{~min}$ ) and complete, $\sim 100 \%$, which is discussed in detail below.

Tripolyphosphate is a primary ingredient in detergents; however, as illustrated above, tripolyphosphate degrades to pyro- and orthophosphate. As such, the removal of these phosphate compounds from wastewater has been the subject of several investigations conducted for over five decades. Research beginning in the mid-1960s demonstrated the efficacy of using calcium and/or lime to precipitate stable calcium-phosphate solid phases, including apatite for direct removal of phosphate (Ferguson et al. 1970, 1973; Jenkins et al. 1971; Schmid and McKinney 1968).

However, the results of these early investigations underscore the importance of conducting site-specific tests to optimize the formation of apatite based on environmental parameters including $\mathrm{pH}$, carbonate concentration, etc. 
Table 3.3. Down-Selected Experimental Batch Conditions for Polyphosphate Amendment Optimization

\begin{tabular}{|c|c|c|c|c|c|}
\hline Phosphate Source & $\begin{array}{l}\text { Phosphorus } \\
\text { Conc. (ppm) }\end{array}$ & Calcium Source & $\begin{array}{l}\text { Calcium Conc. } \\
\text { (ppm) }\end{array}$ & \multicolumn{2}{|c|}{$\begin{array}{l}\text { Uranium Conc., } \\
\qquad(\mu \mathrm{g} / \mathrm{L})\end{array}$} \\
\hline \multirow{2}{*}{ Sodium Orthophosphate } & \multirow{2}{*}{1500} & & & 10 & 1000 \\
\hline & & & & \multicolumn{2}{|c|}{0.00} \\
\hline \multirow{2}{*}{ Sodium Orthophosphate } & \multirow{2}{*}{2000} & & & 10 & 1000 \\
\hline & & & & \multicolumn{2}{|c|}{0.00} \\
\hline \multirow{2}{*}{ Sodium Orthophosphate } & \multirow{2}{*}{2500} & & & 10 & 1000 \\
\hline & & & & \multicolumn{2}{|c|}{0.00} \\
\hline \multirow{2}{*}{ Sodium Pyrophosphate } & \multirow{2}{*}{1500} & & & 10 & 1000 \\
\hline & & & & \multicolumn{2}{|c|}{0.00} \\
\hline \multirow{2}{*}{ Sodium Pyrophosphate } & \multirow{2}{*}{2000} & & & 10 & 1000 \\
\hline & & & & \multicolumn{2}{|c|}{0.00} \\
\hline \multirow{2}{*}{ Sodium Pyrophosphate } & \multirow{2}{*}{2500} & & & 10 & 1000 \\
\hline & & & & \multicolumn{2}{|c|}{0.00} \\
\hline \multirow{2}{*}{ Sodium Tripolyphosphate } & \multirow{2}{*}{1500} & & & 10 & 1000 \\
\hline & & & & \multicolumn{2}{|c|}{0.00} \\
\hline \multirow{2}{*}{ Sodium Tripolyphosphate } & \multirow{2}{*}{2000} & & & 10 & 1000 \\
\hline & & & & \multicolumn{2}{|c|}{0.00} \\
\hline \multirow{2}{*}{ Sodium Tripolyphosphate } & \multirow{2}{*}{2500} & & & 10 & 1000 \\
\hline & & & & \multicolumn{2}{|c|}{0.00} \\
\hline \multirow{2}{*}{ Sodium Trimetaphosphate } & 1500 & & & 10 & 1000 \\
\hline & 1000 & & & & \\
\hline Sodium Trimetanhosnhate & 2000 & & & 10 & 1000 \\
\hline 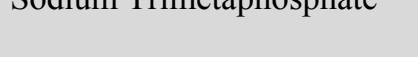 & 2000 & & & & \\
\hline Sodium Trimetanhosnhate & 2500 & & & 10 & 1000 \\
\hline 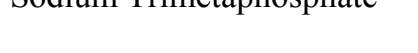 & 2000 & & & & \\
\hline Sodium Heyometonhecnhot & 1500 & & & 10 & 1000 \\
\hline sodium Hexamelapnospnate & 1500 & & & & \\
\hline Sodium Hexametanhosnhate & 2000 & & & 10 & 1000 \\
\hline & & & & & \\
\hline Sodium Heyometanhronhate & 2500 & & & 10 & 1000 \\
\hline sodium nexamietapiospiate & 2500 & & & & \\
\hline Sodium Orthonbosnhate & 1500 & Calcium & 1000 & 10 & 1000 \\
\hline 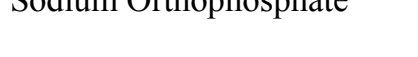 & 1000 & Chloride & 1000 & & \\
\hline Sodium Orthophosphate & 1500 & $\begin{array}{l}\text { Calcium } \\
\text { Chloride }\end{array}$ & 1500 & 10 & 1000 \\
\hline
\end{tabular}


Table 3.3. (contd)

\begin{tabular}{|c|c|c|c|c|c|}
\hline Phosphate Source & $\begin{array}{l}\text { Phosphorus } \\
\text { Conc. (ppm) }\end{array}$ & Calcium Source & $\begin{array}{l}\text { Calcium Conc. } \\
\text { (ppm) }\end{array}$ & \multicolumn{2}{|c|}{$\begin{array}{l}\text { Uranium Conc., } \\
(\mu \mathrm{g} / \mathrm{L})\end{array}$} \\
\hline \multirow{2}{*}{ Sodium Orthophosphate } & \multirow{2}{*}{2000} & Calcium & \multirow{2}{*}{1000} & 10 & 1000 \\
\hline & & Chloride & & & \\
\hline \multirow{2}{*}{ Sodium Orthophosphate } & \multirow{2}{*}{2000} & Calcium & \multirow{2}{*}{1500} & 10 & 1000 \\
\hline & & Chloride & & & \\
\hline \multirow{2}{*}{ Sodium Orthophosphate } & \multirow{2}{*}{2500} & Calcium & \multirow{2}{*}{1000} & 10 & 1000 \\
\hline & & Chloride & & & \\
\hline \multirow{2}{*}{ Sodium Orthophosphate } & \multirow{2}{*}{2500} & Calcium & \multirow{2}{*}{1500} & 10 & 1000 \\
\hline & & Chloride & & & \\
\hline \multirow{2}{*}{ Sodium Pyrophosphate } & \multirow{2}{*}{1500} & Calcium & \multirow{2}{*}{1000} & 10 & 1000 \\
\hline & & Chloride & & & \\
\hline \multirow{2}{*}{ Sodium Pyrophosphate } & \multirow{2}{*}{1500} & Calcium & \multirow{2}{*}{1500} & 10 & 1000 \\
\hline & & Chloride & & & \\
\hline \multirow{2}{*}{ Sodium Pyrophosphate } & \multirow{2}{*}{2000} & Calcium & \multirow{2}{*}{1000} & 10 & 1000 \\
\hline & & Chloride & & & \\
\hline \multirow{2}{*}{ Sodium Pyrophosphate } & \multirow{2}{*}{2000} & Calcium & \multirow{2}{*}{1500} & 10 & 1000 \\
\hline & & Chloride & & & \\
\hline \multirow{2}{*}{ Sodium Pyrophosphate } & \multirow{2}{*}{2500} & Calcium & \multirow{2}{*}{1000} & 10 & 1000 \\
\hline & & Chloride & & & \\
\hline \multirow{2}{*}{ Sodium Pyrophosphate } & 2500 & Calcium & 1500 & 10 & 1000 \\
\hline & & Chloride & & & \\
\hline Sodium Trinolyphosphate & 1500 & Calcium & 1000 & 10 & 1000 \\
\hline socium inporypnospnate & 1300 & Chloride & 1000 & & \\
\hline Sodium Trinolyphosphate & 1500 & Calcium & 1500 & 10 & 1000 \\
\hline Sodium Iriporyphosphate & 1500 & Chloride & 1500 & & \\
\hline Sodium Tringlunbenhat & 2000 & Calcium & 1000 & 10 & 1000 \\
\hline 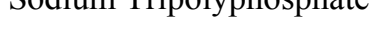 & 2000 & Chloride & 1000 & & \\
\hline Sodium Tringlumbonth & 0000 & Calcium & $1500+2+2+3$ & 10 & 1000 \\
\hline Sodium Iriporyphosphate & 2000 & Chloride & 1500 & & \\
\hline Sodium Trinolyphosnhate & 2500 & Calcium & 1000 & 10 & 1000 \\
\hline Sodium Iripolyphosphate & 2500 & Chloride & 1000 & & \\
\hline Sodium Tripolyphosphate & 2500 & Calcium & 1500 & 10 & 1000 \\
\hline & & Chloride & & & \\
\hline Sodium Trimetanhosnhate & 1500 & Calcium & 1000 & 10 & 1000 \\
\hline sodium I rimetaphosphate & 1500 & Chloride & 1000 & & \\
\hline
\end{tabular}


Table 3.3. (contd)

\begin{tabular}{|c|c|c|c|c|c|}
\hline Phosphate Source & $\begin{array}{l}\text { Phosphorus } \\
\text { Conc. (ppm) }\end{array}$ & Calcium Source & $\begin{array}{l}\text { Calcium Conc. } \\
\quad(\mathrm{ppm})\end{array}$ & \multicolumn{2}{|c|}{$\begin{array}{l}\text { Uranium Conc., } \\
\qquad(\mu \mathrm{g} / \mathrm{L})\end{array}$} \\
\hline \multirow{2}{*}{ Sodium Trimetaphosphate } & \multirow{2}{*}{1500} & Calcium & \multirow{2}{*}{1500} & 10 & 1000 \\
\hline & & Chloride & & \multicolumn{2}{|c|}{0.00} \\
\hline \multirow{2}{*}{ Sodium Trimetaphosphate } & \multirow{2}{*}{2000} & Calcium & \multirow{2}{*}{1000} & 10 & 1000 \\
\hline & & Chloride & & & \\
\hline \multirow{2}{*}{ Sodium Trimetaphosphate } & \multirow{2}{*}{2000} & Calcium & \multirow{2}{*}{1500} & 10 & 1000 \\
\hline & & Chloride & & & \\
\hline \multirow{2}{*}{ Sodium Trimetaphosphate } & \multirow{2}{*}{2500} & Calcium & \multirow{2}{*}{1000} & 10 & 1000 \\
\hline & & Chloride & & \multicolumn{2}{|c|}{0.00} \\
\hline Sodium Trimetaphosphate & 2500 & Calcium & 1500 & 10 & 1000 \\
\hline \multirow{3}{*}{ Sodium Hexametaphosphate } & \multirow{3}{*}{1500} & & \multirow{3}{*}{1000} & 10 & 1000 \\
\hline & & Chloride & & & \\
\hline & & & & & \\
\hline \multirow{2}{*}{ Sodium Hexametaphosphate } & \multirow{2}{*}{1500} & Calcium & \multirow{2}{*}{1500} & 10 & 1000 \\
\hline & & Chloride & & & \\
\hline \multirow{2}{*}{ Sodium Hexametaphosphate } & \multirow{2}{*}{2000} & Calcium & \multirow{2}{*}{1000} & 10 & 1000 \\
\hline & & Chloride & & & \\
\hline \multirow{2}{*}{ Sodium Hexametaphosphate } & \multirow{2}{*}{2000} & Calcium & \multirow{2}{*}{1500} & 10 & 1000 \\
\hline & & Chloride & & & \\
\hline \multirow{2}{*}{ Sodium Hexametaphosphate } & \multirow{2}{*}{2500} & Calcium & \multirow{2}{*}{1000} & 10 & 1000 \\
\hline & & Chloride & & & \\
\hline \multirow{2}{*}{ Sodium Hexametaphosphate } & \multirow{2}{*}{2500} & Calcium & 1500 & 10 & 1000 \\
\hline & & Chloride & 1500 & & \\
\hline
\end{tabular}



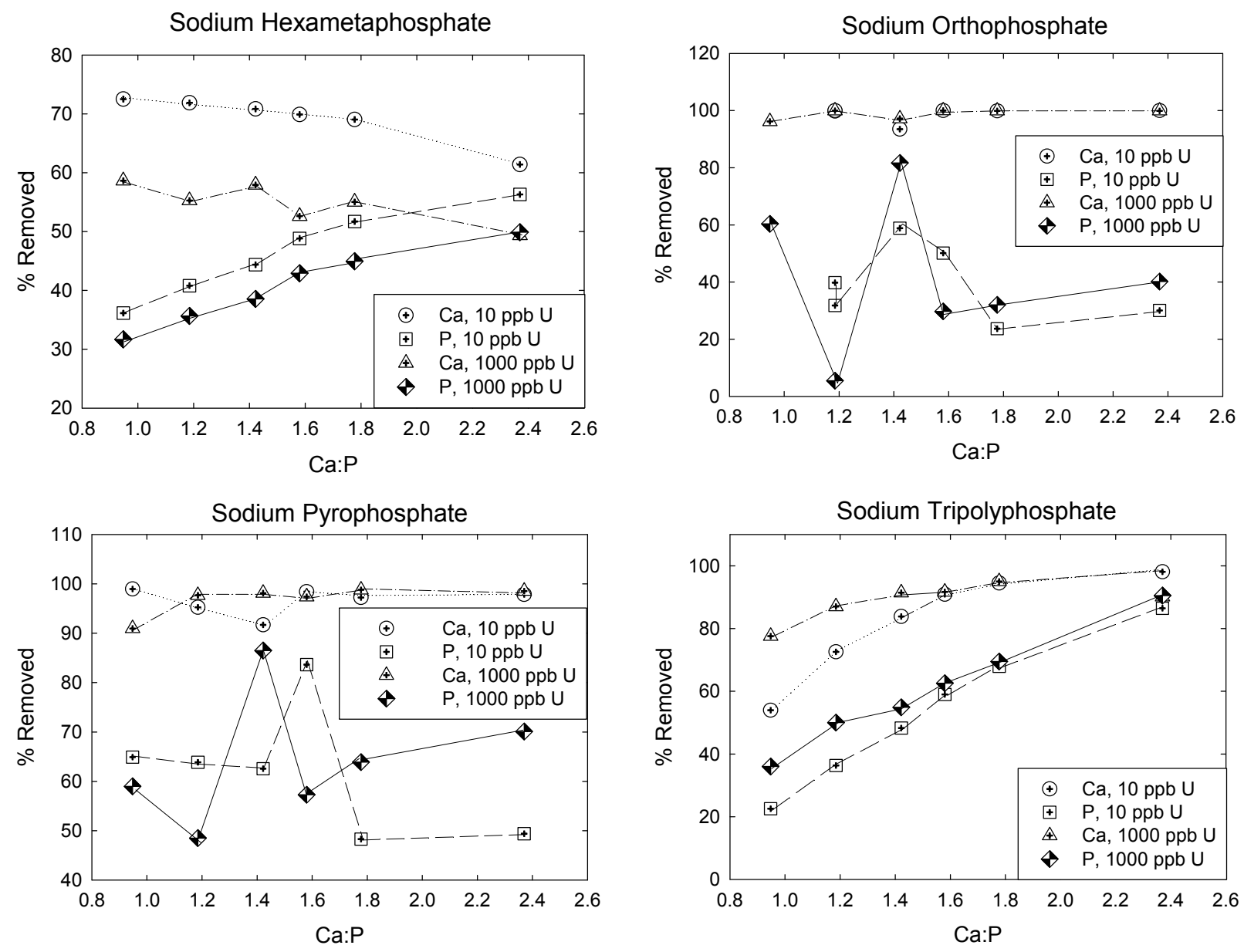

Figure 3.3. Percent Removal of Calcium and Phosphorus as a Function of Calcium-to-Phosphorus Ratio

\subsubsection{Column Experiments}

Column experiments were conducted to accomplish the following (as described below):

- Optimize the amendment formulation based on results of batch tests for amendment emplacement and the formation of autunite and apatite.

- Quantify the mobility of ortho-, pyro-, and tripolyphosphate individually as well as a mixed formulation to evaluate the differences in retardation due to the interaction between the various phosphate compounds.

- Evaluate the mobility of calcium.

\subsubsection{Amendment Formulation}

Saturated column tests were conducted to evaluate the concentration of total phosphorus and calcium; the ratio of ortho-, pyro-, and tripolyphosphate; the ratio of calcium to phosphorus; $\mathrm{pH}$; the injection order to optimize emplacement of the amendment and the extent of treatment; reduction in aqueous uranium concentration; and the formation of autunite and apatite. PVC columns (length, $L=30.48 \mathrm{~cm}$; radius, $r=2.54 \mathrm{~cm}$; and bulk volume, $V_{b}=194.04-202.20 \mathrm{~cm}^{3}$ ) were packed uniformly with sediment 
from 300 Area cores and were saturated with Hanford groundwater to ensure chemical equilibrium. Preliminary characterization results indicated the uranium concentration within the aqueous and solid matrix of the sediment cores is below the MCL for uranium. As such, to effectively evaluate polyphosphate amendments for uranium remediation, it was necessary to use a solution of Hanford groundwater spiked with aqueous uranium as the influent solution. The uranium concentration in the pore fluid was $1000 \mathrm{ppb}$. This allowed the efficacy of the polyphosphate amendment to be evaluated under maximum uranium concentrations.

Several injection scheme variations were investigated and are discussed in further detail below; however, in general, following saturation and attainment of chemical equilibrium with uranium-spiked groundwater, the influent solution was changed to Hanford groundwater containing the polyphosphate amendment or calcium followed by the other respective solution. Aqueous concentrations were monitored using ICP-MS and ICP-OES; solid-phase formation was evaluated via fluorescence spectroscopy using short-wave ultraviolet (UV) radiation, $254 \mathrm{~nm}$.

Sodium orthophosphate $\left(\mathrm{Na}_{3} \mathrm{PO}_{4} \bullet 12 \mathrm{H}_{2} \mathrm{O}\right)$, sodium pyrophosphate $\left(\mathrm{Na}_{4} \mathrm{P}_{2} \mathrm{O}_{7} \bullet 10 \mathrm{H}_{2} \mathrm{O}\right)$, and sodium tripolyphosphate $\left(\mathrm{Na}_{5} \mathrm{P}_{3} \mathrm{O}_{10}\right)$ provided the source of each respective phosphate for all phosphorus amendment formulations and calcium chloride $\left(\mathrm{CaCl}_{2}\right)$ was used as the source of calcium. Calcium rapidly precipitates with orthophosphate; therefore, all injections were conducted in two phases by injecting either the calcium solution followed by the phosphorus solution or vice versa. Details regarding the amendment formulation, injection order, calcium to total phosphorus ratio, and amendment $\mathrm{pH}$ and concentrations are summarized in Table 3.4. The $\mathrm{pH}$ of the amendment solutions was as mixed, unless specified as $\mathrm{pH} 7$, which was attained by adjustment with nitric acid.

Table 3.4. Experimental Parameters for Polyphosphate Amendment Optimization Column Tests

\begin{tabular}{|c|c|c|c|c|c|c|}
\hline $\begin{array}{l}\text { Column } \\
\text { No. }\end{array}$ & Amendment Source & $\begin{array}{l}\mathrm{Wt} \% \text { Phosphate } \\
\text { Source }\end{array}$ & $\begin{array}{l}\text { Injection } \\
\text { Order }\end{array}$ & $\mathrm{Ca}: \mathrm{P}_{\text {total }}$ & $\mathrm{pH}$ & Conc., $\mathrm{M}$ \\
\hline \multirow[t]{4}{*}{1} & Ortho $[\mathrm{P}]_{\mathrm{aq}}$ & 0.25 & 1 & 2.2 & 7 & $1.32 \times 10^{-3}$ \\
\hline & Pyro $[\mathrm{P}]_{\mathrm{aq}}$ & 0.25 & & & & $6.58 \times 10^{-4}$ \\
\hline & Tripoly $[\mathrm{P}]_{\mathrm{aq}}$ & 0.5 & & & & $8.77 \times 10^{-4}$ \\
\hline & Calcium & & 2 & & & $1.15 \times 10^{-2}$ \\
\hline \multirow[t]{4}{*}{2} & Ortho $[\mathrm{P}]_{\mathrm{aq}}$ & 0.25 & 1 & 2.2 & 7 & $1.97 \times 10^{-3}$ \\
\hline & Pyro $[\mathrm{P}]_{\mathrm{aq}}$ & 0.25 & & & & $9.87 \times 10^{-4}$ \\
\hline & Tripoly $[\mathrm{P}]_{\mathrm{aq}}$ & 0.5 & & & & $1.32 \times 10^{-3}$ \\
\hline & Calcium & & 2 & & & $1.74 \times 10^{-2}$ \\
\hline \multirow[t]{4}{*}{3} & Ortho $[\mathrm{P}]_{\mathrm{aq}}$ & 0.25 & 1 & 2.2 & No adj. & $1.97 \times 10^{-3}$ \\
\hline & Pyro $[\mathrm{P}]_{\mathrm{aq}}$ & 0.25 & & & & $9.87 \times 10^{-4}$ \\
\hline & Tripoly $[\mathrm{P}]_{\mathrm{aq}}$ & 0.5 & & & & $1.32 \times 10^{-3}$ \\
\hline & Calcium & & 2 & & & $1.74 \times 10^{-2}$ \\
\hline
\end{tabular}


Table 3.4. (contd)

\begin{tabular}{|c|c|c|c|c|c|c|}
\hline $\begin{array}{l}\text { Column } \\
\text { No. }\end{array}$ & Amendment Source & $\begin{array}{l}\mathrm{Wt} \% \text { Phosphate } \\
\text { Source }\end{array}$ & $\begin{array}{l}\text { Injection } \\
\text { Order }\end{array}$ & $\mathrm{Ca}: \mathrm{P}_{\text {total }}$ & $\mathrm{pH}$ & Conc., $\mathrm{M}$ \\
\hline \multirow[t]{4}{*}{4} & Ortho $[\mathrm{P}]_{\mathrm{aq}}$ & 0.375 & 1 & 2.2 & No adj. & $2.63 \times 10^{-3}$ \\
\hline & Pyro $[\mathrm{P}]_{\mathrm{aq}}$ & 0.25 & & & & $1.32 \times 10^{-3}$ \\
\hline & Tripoly $[\mathrm{P}]_{\mathrm{aq}}$ & 0.375 & & & & $1.75 \times 10^{-3}$ \\
\hline & Calcium & & 2 & & & $2.32 \times 10^{-2}$ \\
\hline \multirow[t]{4}{*}{5} & Ortho $[\mathrm{P}]_{\mathrm{aq}}$ & 0.25 & 1 & 1.67 & No adj. & $3.47 \times 10^{-3}$ \\
\hline & Pyro $[\mathrm{P}]_{\mathrm{aq}}$ & 0.25 & & & & $1.74 \times 10^{-3}$ \\
\hline & Tripoly $[\mathrm{P}]_{\mathrm{aq}}$ & 0.5 & & & & $2.32 \times 10^{-3}$ \\
\hline & Calcium & & 2 & & & $2.32 \times 10^{-2}$ \\
\hline \multirow[t]{4}{*}{6} & Ortho $[\mathrm{P}]_{\mathrm{aq}}$ & 0.25 & 1 & 1.67 & 7 & $3.47 \times 10^{-3}$ \\
\hline & Pyro $[\mathrm{P}]_{\mathrm{aq}}$ & 0.25 & & & & $1.74 \times 10^{-3}$ \\
\hline & Tripoly $[\mathrm{P}]_{\mathrm{aq}}$ & 0.5 & & & & $2.32 \times 10^{-3}$ \\
\hline & Calcium & & 2 & & & $2.32 \times 10^{-2}$ \\
\hline \multirow[t]{4}{*}{$7 / 11$} & Ortho $[\mathrm{P}]_{\mathrm{aq}}$ & 0.25 & 1 & 2.2 & No adj./7 & $2.63 \times 10^{-3}$ \\
\hline & Pyro $[\mathrm{P}]_{\mathrm{aq}}$ & 0.25 & & & & $1.32 \times 10^{-3}$ \\
\hline & Tripoly $[\mathrm{P}]_{\mathrm{aq}}$ & 0.5 & & & & $1.75 \times 10^{-3}$ \\
\hline & Calcium & & 2 & & & $2.32 \times 10^{-2}$ \\
\hline \multirow[t]{4}{*}{$8 / 12$} & Ortho $[\mathrm{P}]_{\mathrm{aq}}$ & 0.25 & 1 & 2.2 & No adj./7 & $6.58 \times 10^{-3}$ \\
\hline & Pyro $[\mathrm{P}]_{\mathrm{aq}}$ & 0.25 & & & & $3.29 \times 10^{-3}$ \\
\hline & Tripoly $[\mathrm{P}]_{\mathrm{aq}}$ & 0.5 & & & & $4.39 \times 10^{-3}$ \\
\hline & Calcium & & 2 & & & $5.79 \times 10^{-2}$ \\
\hline \multirow[t]{4}{*}{$9 / 13$} & Ortho $[\mathrm{P}]_{\mathrm{aq}}$ & 0.25 & 1 & 2.2 & No. $\operatorname{Adj} / 7$ & $9.21 \times 10^{-3}$ \\
\hline & Pyro $[\mathrm{P}]_{\mathrm{aq}}$ & 0.25 & & & & $4.61 \times 10^{-3}$ \\
\hline & Tripoly $[\mathrm{P}]_{\mathrm{aq}}$ & 0.5 & & & & $6.14 \times 10^{-3}$ \\
\hline & Calcium & & 2 & & & $8.10 \times 10^{-2}$ \\
\hline \multirow[t]{4}{*}{$10 / 14$} & Ortho $[\mathrm{P}]_{\mathrm{aq}}$ & 0.25 & 1 & 2.2 & No Adj./7 & $1.32 \times 10^{-2}$ \\
\hline & Pyro $[\mathrm{P}]_{\mathrm{aq}}$ & 0.25 & & & & $6.58 \times 10^{-3}$ \\
\hline & Tripoly $[\mathrm{P}]_{\mathrm{aq}}$ & 0.5 & & & & $8.77 \times 10^{-3}$ \\
\hline & Calcium & & 2 & & & $1.16 \times 10^{-1}$ \\
\hline \multirow[t]{4}{*}{15} & Ortho $[\mathrm{P}]_{\mathrm{aq}}$ & 0.25 & 2 & 1.9 & No Adj. & $1.32 \times 10^{-2}$ \\
\hline & Pyro $[\mathrm{P}]_{\mathrm{aq}}$ & 0.25 & & & & $6.58 \times 10^{-3}$ \\
\hline & Tripoly $[\mathrm{P}]_{\mathrm{aq}}$ & 0.5 & & & & $8.77 \times 10^{-3}$ \\
\hline & Calcium & & 1 & & & $9.98 \times 10^{-2}$ \\
\hline
\end{tabular}


Table 3.4. (contd)

\begin{tabular}{|c|c|c|c|c|c|c|}
\hline $\begin{array}{l}\text { Column } \\
\text { No. }\end{array}$ & Amendment Source & $\begin{array}{l}\mathrm{Wt} \% \text { Phosphate } \\
\text { Source }\end{array}$ & $\begin{array}{l}\text { Injection } \\
\text { Order }\end{array}$ & $\mathrm{Ca}: \mathrm{P}_{\text {total }}$ & $\mathrm{pH}$ & Conc., M \\
\hline \multirow[t]{4}{*}{16} & Ortho $[\mathrm{P}]_{\mathrm{aq}}$ & 0.25 & 2 & 1.9 & 7 & $1.32 \times 10^{-2}$ \\
\hline & Pyro $[\mathrm{P}]_{\mathrm{aq}}$ & 0.25 & & & & $6.58 \times 10^{-3}$ \\
\hline & Tripoly $[\mathrm{P}]_{\mathrm{aq}}$ & 0.5 & & & & $8.77 \times 10^{-3}$ \\
\hline & Calcium & & 1 & & & $9.98 \times 10^{-2}$ \\
\hline \multirow[t]{4}{*}{17} & Ortho $[\mathrm{P}]_{\mathrm{aq}}$ & 0.25 & 2 & 2.2 & 7 & $9.21 \times 10^{-3}$ \\
\hline & Pyro $[\mathrm{P}]_{\mathrm{aq}}$ & 0.25 & & & & $4.61 \times 10^{-3}$ \\
\hline & Tripoly $[\mathrm{P}]_{\mathrm{aq}}$ & 0.5 & & & & $6.14 \times 10^{-3}$ \\
\hline & Calcium & & 1 & & & $8.10 \times 10^{-2}$ \\
\hline \multirow[t]{4}{*}{18} & Ortho $[\mathrm{P}]_{\mathrm{aq}}$ & 0.25 & 2 & 2.2 & 7 & $1.32 \times 10^{-2}$ \\
\hline & Pyro $[\mathrm{P}]_{\mathrm{aq}}$ & 0.25 & & & & $6.58 \times 10^{-3}$ \\
\hline & Tripoly $[\mathrm{P}]_{\mathrm{aq}}$ & 0.5 & & & & $8.77 \times 10^{-3}$ \\
\hline & Calcium & & 1 & & & $1.16 \times 10^{-1}$ \\
\hline
\end{tabular}

Visual inspection of sediment removed from columns 1 through 4 after application of the associated amendment formulations illustrated the formation of fluorescent green precipitates under short-wave UV radiation, $254 \mathrm{~nm}$, indicative of uranium-phosphate phases (Figure 3.4).

Qualitatively, the precipitate appeared to be within or coating $\sim 50 \%$ of the sedimentary matrix. ICP-MS results from columns 1 through 4 demonstrated $\sim 50 \%$ reduction in the aqueous uranium concentration, suggesting a higher concentration of phosphorus and calcium in the amendment formulation was necessary. Comparison of columns 2 and 3 suggested there was little effect of $\mathrm{pH}$ in reducing the aqueous uranium concentration; however, precipitation of calcium-phosphate was more significant under $\mathrm{pH}$ conditions $\sim 7$.

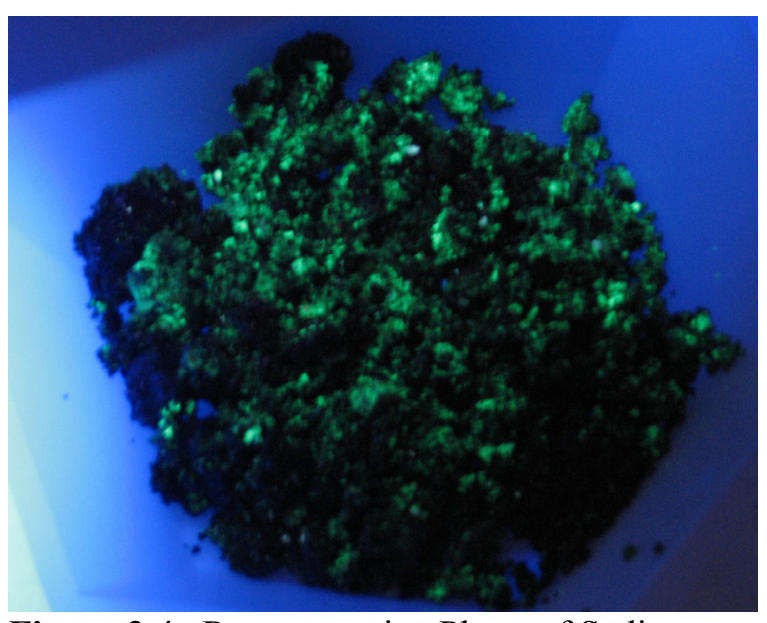

Figure 3.4. Representative Photo of Sediment Sectioned from the Effluent End of Column 1 Illustrating the Visual Identification of UraniumPhosphate Under Short-Wave UV Radiation

Precipitation of apatite from homogeneous matrices has been suggested to proceed through initial precipitation of amorphous calcium phosphate, which serves as a template for the heterogeneous nucleation of octacalcium phosphate (OCP) (Feenstra and de Bruyn 1979). In turn, OCP serves as a template for epitaxial growth of hydroxyapatite (Brown et al. 1962; Eanes et al. 1965; Eanes and Meyer 1977; Eanes and Posner 1965; Feenstra and de Bruyn 1979). The conversion of amorphous to crystalline phases involving an epitaxial matching of the depositing phase onto the hydroxyapatite crystalline substrate is consistent with a hypothesized autocatalytic conversion mechanism (Boskey and Posner 1973; Boskey and Posner 1976; Eanes and Posner 1965). This explains the significance of apatite 
seed crystals for accelerated precipitation of hydroxyapatite from solution (Amjad et al. 1981; Boskey and Posner 1973; Brown 1980, 1981a, 1981b; Inskeep and Silvertooth 1988; Nancollas and Mohan 1970; Nancollas and Tomazic 1974). Once the reservoir of non-apatitic calcium-phosphate is depleted during the conversion process, the increase in size of apatite crystals proceeds by Ostwald ripening in which the overall number of apatite crystals in reduced by consolidation and recrystalization (Eanes and Posner 1970). The Gibbs-Kelvin effect states the thermodynamic driving force for this mechanism is that the equilibrium solubility of small particles decreases with increasing size. Therefore, in a suspension of heterogeneous particles, the smaller particles have a higher solubility than larger particles. The smaller particles dissolve and the larger particles continue to grow (Eanes et al. 1965; Eanes and Posner 1970). However, the growth rate of apatite is controlled by surface nucleation and/or dislocation mechanisms (Eanes and Posner 1970). As such, hydroxyapatite growth is limited by a process occurring at the crystal interface (Nancollas and Mohan 1970) and therefore is dependent on the surface area (Inskeep and Silvertooth 1988). (Christoffersen and Christoffersen 1982) proposed that protonation of phosphate groups at the crystal surface catalyzes the exchange of phosphate between the apatite surface and the bulk solution, thereby accelerating growth. At $\mathrm{pH} 7.4$, hydroxyapatite is the least soluble phase and most thermodynamically stable, in the absence of kinetic complications (Nancollas and Tomazic 1974). This is consistent with findings regarding the growth of fluorapatite (FAP) wherein a direct relationship exists between the growth rate of FAP and $\mathrm{pH}$ (van Cappellen and Berner 1991). For a given degree of supersaturation, the growth rate of FAP at $\mathrm{pH} 7$ was twice that when measured at $\mathrm{pH} 8$.

This underscores the complex series of elementary reactions in the precipitation of hydroxyapatite, which suggests either direct precipitation from solution on the surface of hydroxyapatite seed crystals, precipitation from surface or absorbed calcium and phosphate whose concentrations are dependent on solution of calcium and phosphate (Inskeep and Silvertooth 1988). The compactness of the heterogeneous nucleus is more conducive to formation of hydroxyapatite than the diffuse homogeneous ionic nucleus (Garten and Head 1966). However, macromolecules can influence both the initial formation of amorphous calcium phosphate and conversion to apatite (Termine et al. 1970; Termine and Posner 1970). Macromolecules contain sites within their internal or solvation shell favoring both nucleation and growth (Termine et al. 1970; Termine and Posner 1970). Additionally, a decreased dielectric constant enhances initial mineral phase separation and amorphous-crystalline conversion. Thus, a partially non-polar region within a macromolecule, as well as more polar regions, may provide a local milieu favorable for amorphous calcium phosphate formation or crystal conversion (Termine et al. 1970). Sodium tripolyphosphate serves as a favorable nucleating surface toward initial mineral phase separation and formation of amorphous calcium-phosphate with orthophosphate. When mineralization nucleation is considered relative to initial mineral phase depositions, pyrophosphate is a strong nucleating agent (Termine and Posner 1970).

Schmid and McKinney (1968) identified key processes involved in the formation of apatite from mixtures of ortho-, pyro-, and tripolyphosphate. Results of sorption studies illustrated that orthophosphate sorbs onto polyphosphate near $\mathrm{pH} \sim 7$ to 9 . Although, tripolyphosphate does not readily precipitate in the absence of orthophosphate, sorption of orthophosphate onto tripolyphosphate serves as a heterogeneous nucleating surface to promote precipitation. As orthophosphate begins to precipitate, the $\mathrm{pH}$ of the solution increases slightly, and as this occurs, the degradation of tripolyphosphate is accelerated to form ortho- and pyrophosphate. This further enhances precipitation by providing additional orthophosphate. Furthermore, pyrophosphate produces a heavy, fast-settling precipitate with calcium, which increases the settling rate of the finer precipitates formed from tripolyphosphate. In the absence of 
orthophosphate, precipitation from tripolyphosphate is only $\sim 50 \%$ of that under the same conditions in the presence of both ortho- and tripolyphosphate.

A key additional consideration regarding the use of a polyphosphate amendment in the precipitation of calcium phosphate under conditions present within the 300 Area is the effect of carbonate. Precipitation of calcium phosphate from monophosphate solutions is strongly influenced by competing reactions to produce calcium carbonates (Diaz et al. 1994; Lindsay and Moreno 1960). Jenkins et al. (1971) demonstrate that in $\mathrm{Ca}-\mathrm{PO}_{4}-\mathrm{CO}_{3}-\mathrm{H}^{+}-\mathrm{H}_{2} \mathrm{O}$ system precipitation of calcium carbonate competes with the precipitation of calcium phosphate under the $\mathrm{pH}$ range of 9 to 10.5 . Between $\mathrm{pH} 7.5$ to 8.5 and above $\mathrm{pH} 10.5$, calcium phosphate precipitation controls the phosphorus concentration. Increases in the bicarbonate concentration increased the initial induction period required for precipitation of calcium phosphate and also decreased the subsequent rate of removal as a function of bicarbonate concentration.

By complexing calcium and sorbing to mineral surfaces, polyphosphate compounds effectively reduce both the rate and extent of calcium carbonate precipitation, simultaneously enhancing the rate of calcium phosphate precipitation by reducing the competing reaction and essentially "directing" calcium to participate in reactions resulting in calcium phosphate precipitation (Ferguson et al. 1973).

Column 4 highlighted the significance of the complex relationship between ortho-, pyro-, and tripolyphosphate. Although the concentration of aqueous uranium was decreased $\sim 50 \%$, the formation of calcium-phosphate was restricted to a discrete region within the sediment matrix (Figure 3.5).

Columns 5 and 6, in comparison to columns 3 and 2, respectively, illustrated the significance of the calcium-to-phosphorus ratio. Qualitatively, the calcium-to-phosphorus ratio of 2.2 afforded more precipitation than a calcium-to-phosphorus ratio of 1.67, which gave no visual indication of calciumphosphate precipitation. Although batch testing indicated that the optimal calcium-to-phosphorus ratio for removal of calcium and phosphorus in the presence of both ortho-, and pyrophosphate was $\sim 1.5$, columns 1 through 4 illustrate the significance of the calcium-to-phosphorus ratio of 2.4 indicated by tripolyphosphate batch testing. This supports batch test results, which indicated that a total calcium-to-phosphorus ratio of $\geq 1.9$ was optimal.

The calcium and phosphorus formulations were conducted in duplicate using columns 7 through 14 at $\mathrm{pH} 7$ and at the unadjusted $\mathrm{pH}$ of the solutions as measured, $\sim 10$ and 11. The calcium-to-phosphorus ratio for all columns was 2.2. The concentration of calcium varied from $2.32 \times 10^{-2} \mathrm{M}$ to $1.16 \times 10^{-1} \mathrm{M}$ and the phosphorus concentrations ranged from $1.05 \times 10^{-2} \mathrm{M}$ to $5.26 \times 10^{-2} \mathrm{M}$. Precipitation of calcium-phosphate in columns 7 through 10 was limited, eliminating consideration of non-adjusted amendment solutions. Alternatively, columns 11 through 14 demonstrated an increase in the degree of calcium-phosphate precipitation using the same amendment formulation adjusted to $\mathrm{pH} \sim 7$. In columns 
11 and 12 the concentration of aqueous uranium in the effluent solution increased over the first 0.5 to 1 pore volumes during remedy injection to concentrations 1.2 to 3 times the influent uranium concentration. However, increasing the concentration of phosphorus and calcium in the amendment formulation precluded this phenomenon. Additionally, the concentration of aqueous uranium was reduced to below the $\mathrm{MCL}, 30 \mu \mathrm{g} / \mathrm{L}$, within 0.5 to 1 pore volumes of treatment and remained well below $30 \mu \mathrm{g} / \mathrm{L}$ thereafter (Figure 3.6).

Columns 15 through 18 used the optimum formulations identified through previous tests (columns 13 and 14), as well as two additional formulations that contained equivalent total phosphorus concentrations but maintained total calcium to phosphorus ratios of 1.9 (columns 17 and 18). The order of injection was altered for all columns (15 through 18), such that calcium was injected prior to phosphorus. Qualitative visual inspection of the columns following treatment suggests the most complete distribution within the column and removal of uranium occurred in column 16, which used a calcium-to-phosphorus ratio of 1.9 and $\mathrm{pH} 7$ (Figure 3.7). However, with the exception of column 17, quantitative analysis of effluent uranium concentrations did not decline as rapidly as those measured in the previous set of columns, 11 through 14, wherein phosphorus was injected first followed by calcium (Figure 3.9). Additionally, the efficacy and long-term performance of columns 15 through 18 is less than that of columns 11 through 14 Remedy Displaced through Columns a) 11, b) 12, c) 13, and d) 14 (Table 3.4). Remedy injection order was phosphorus followed by calcium.

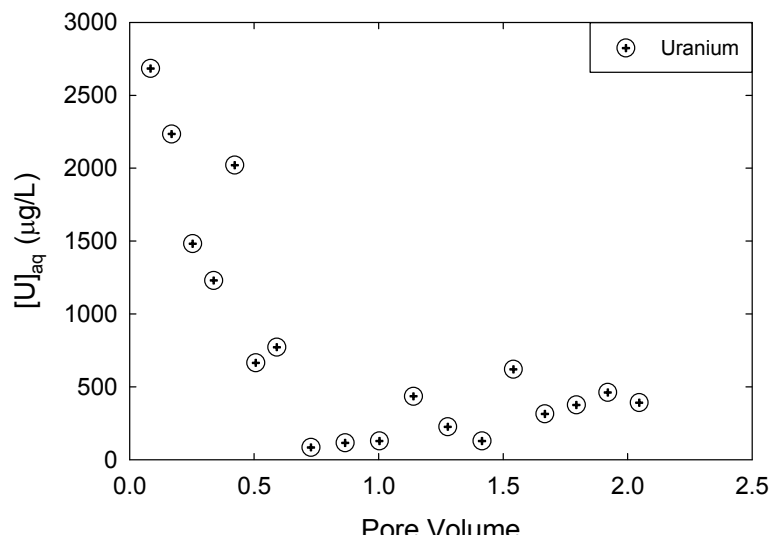

a.
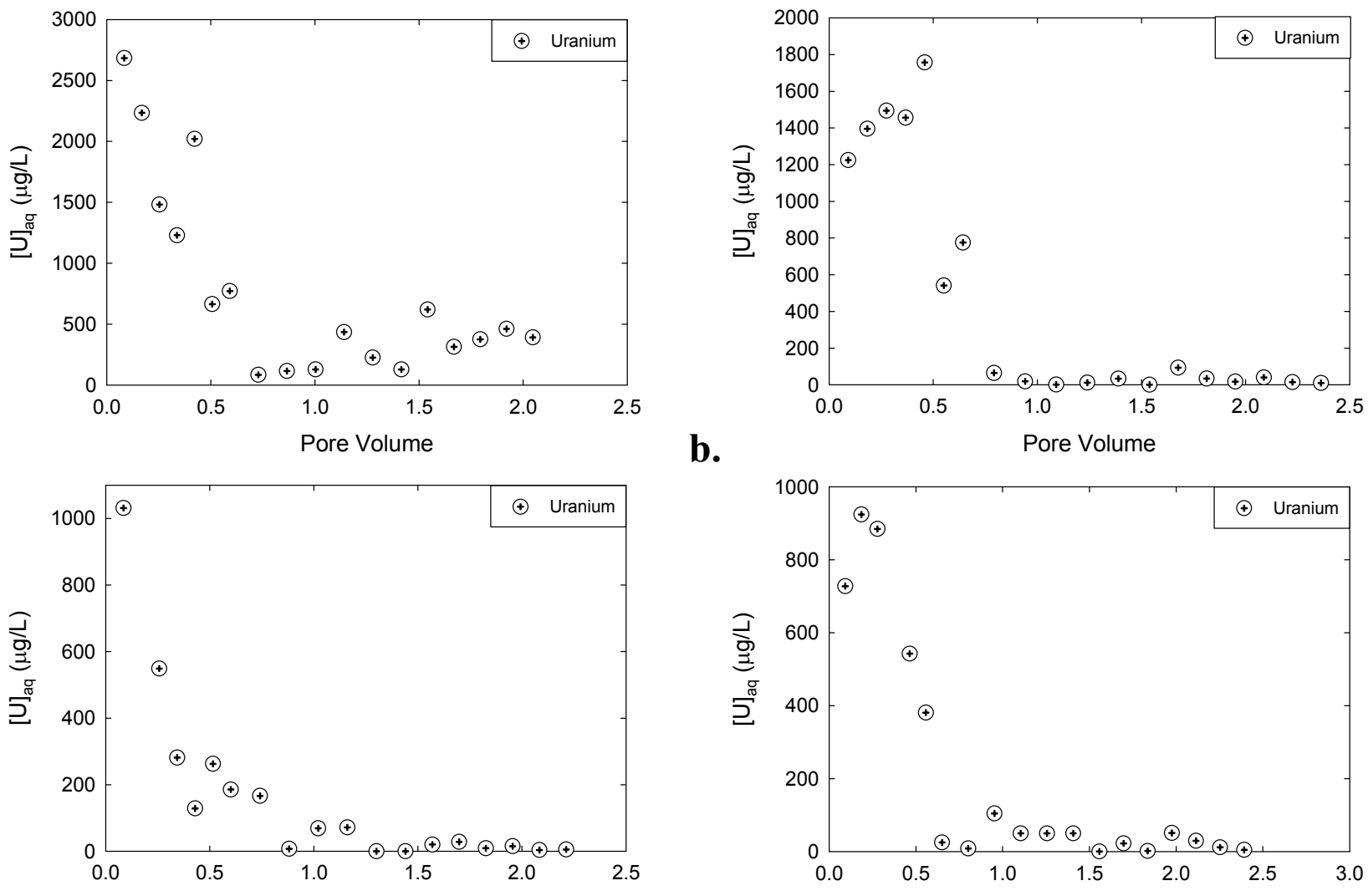

c.

Pore Volume

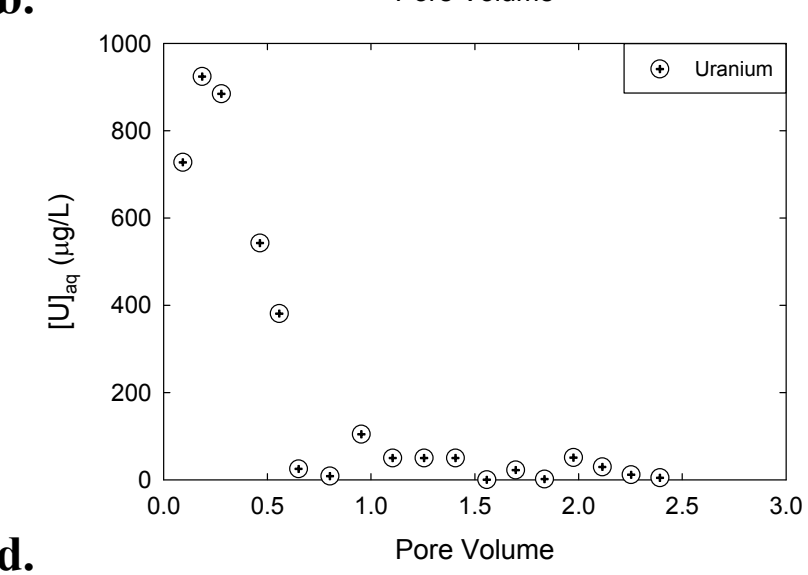

Figure 3.6. Graphs Depicting Aqueous Uranium Concentrations from Columns Saturated with $1000 \mu \mathrm{g} / \mathrm{L}$ Uranium as a Function of the Number of Pore Volumes of Polyphosphate 


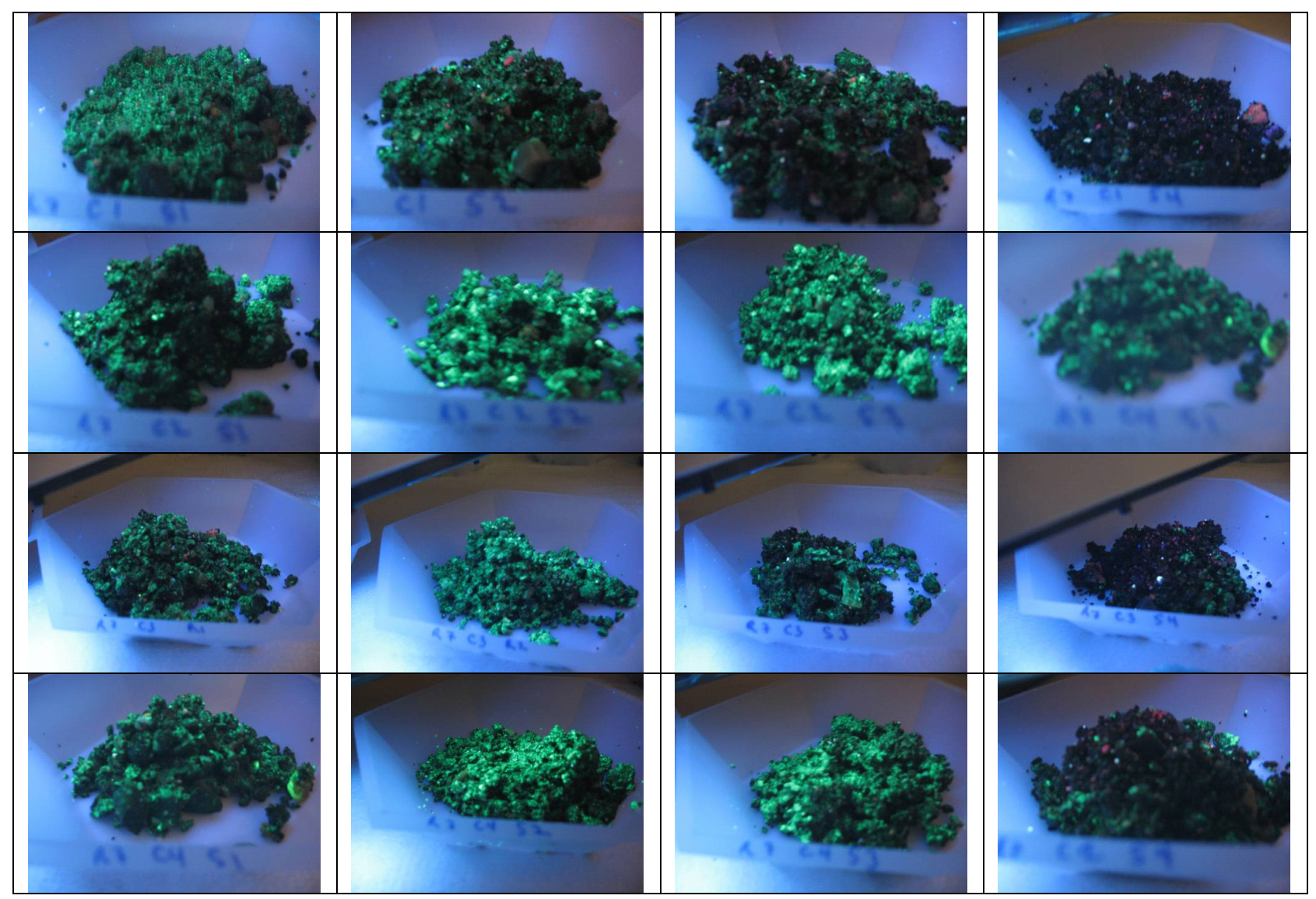

Figure 3.7. Photos of Columns Sections Taken Under Short-Wave UV Radiation (orientation: top-down, columns 15 through 18; left to right, influent to effluent)

Effluent concentrations of phosphorus are at or below background groundwater concentrations. Thus, the potential for downgradient transport and potential migration to the river is minimal. Additionally, phosphate readily precipitates cationic species as highly insoluble phases (Griffith et al. 1973; Lindsay 1979; Lindsay and Moreno 1960; Nriagu and Moore 1984; Sparks and Hunger 2002). As such, there is minimal concern regarding mobilization of sedimentary components during treatment. Moreover, use of the polyphosphate amendment to control precipitation kinetics afforded no effect on the hydraulic conductivity of the sediment during column testing; therefore, no significant impact on the hydraulic conductivity of the aquifer is anticipated.

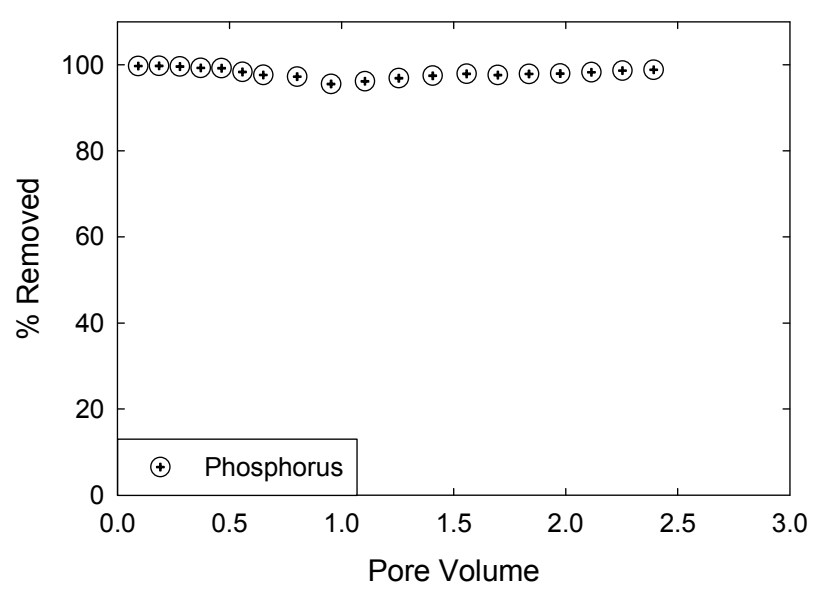

Figure 3.8. Representative Plot Depicting the Removal of Phosphorus via Sorption and Precipitations Reactions 

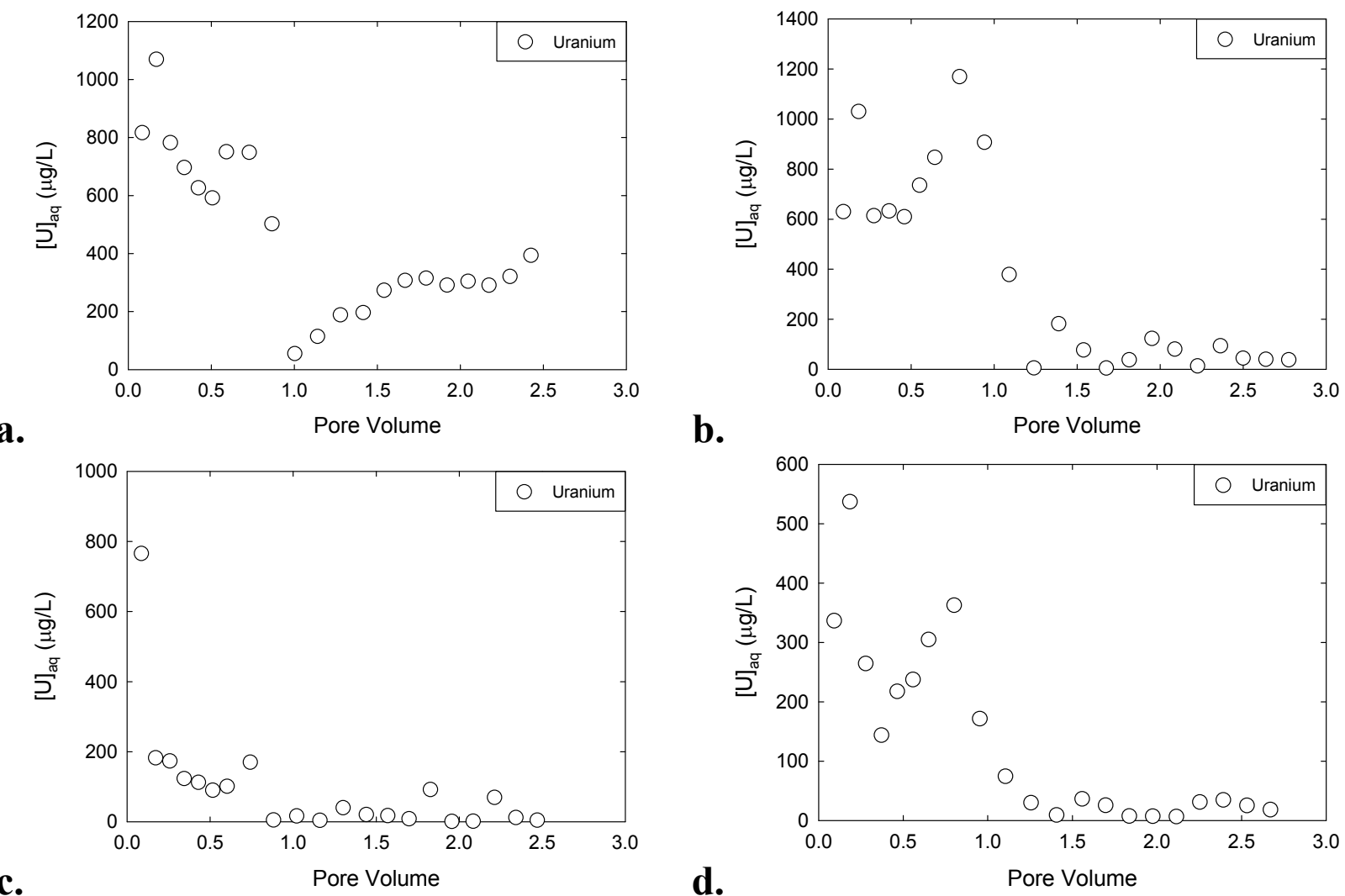

b.

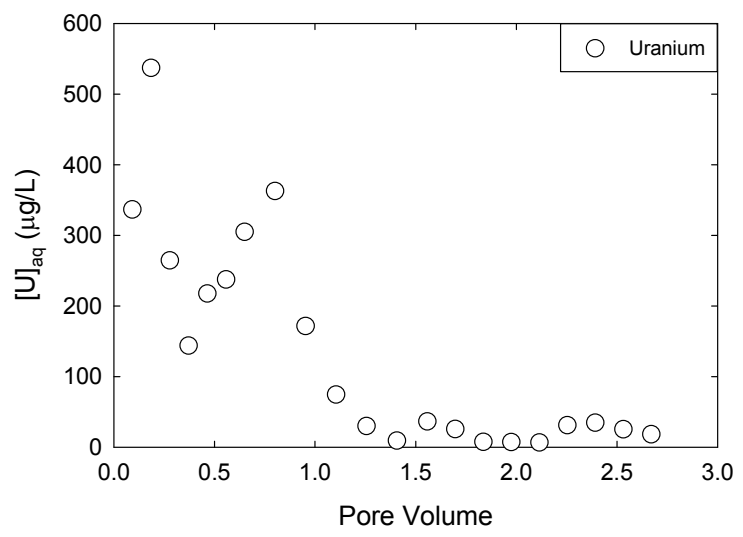

Figure 3.9. Graphs Depicting Aqueous Uranium Concentrations from Columns Saturated with $1000 \mu \mathrm{g} / \mathrm{L}$ Uranium as a Function of the Number of Pore Volumes of Polyphosphate Remedy Displaced Through Columns a) 15, b) 16, c) 17, and d) 18 (Table 3.4). Remedy injection order was calcium followed by phosphorus.

\subsubsection{Amendment Transport}

Column experiments were conducted to quantify the mobility of ortho-, pyro-, and tripolyphosphate, individually and as a mixed formulation, to evaluate differences in retardation due to interaction between the various phosphate compounds and evaluate the mobility of calcium to determine the volume of amendment necessary to treat the desired zone. Saturated column tests were conducted with the $<2-\mathrm{mm}$ sediment fraction from 300 Area cores. The conditions and measured parameters for all of the transport experiments are summarized in Table 3.5. Recovery (\%) reflects the percentage of solute recovered in the effluent. $R$ is the retardation factor analysis and $K_{d}$ is the apparent distribution coefficient calculated from $R$. Transport experiments were conducted at a $v$ of $\sim 20 \mathrm{~cm} \mathrm{~h}^{-1}$.

The saturated column technique that was used here has been described elsewhere (Gamerdinger et al. 1994, 2001a, 2001b). Briefly, borosilicate glass columns (length, $L=10.5 \mathrm{~cm}$, radius, $r=1.25 \mathrm{~cm}$; and bulk volume, $V_{b}=53.71 \mathrm{~cm}^{3}$ ) were packed uniformly with the $<2$-mm fraction of sediment from cores collected from the 300 Area. The columns were saturated with Hanford groundwater until stable water content was attained; syringe pumps were used to control the flow rate. Sediment bulk density, $\rho_{b}$ $\left(\mathrm{g} \mathrm{cm}^{-3}\right)$, and volumetric water content, $\theta\left(\mathrm{cm}^{3} \mathrm{~cm}^{-3}\right)$, were determined from the mass of the sediment and/or water. The percent saturation was calculated from the ratio of $\theta$ (water-filled porosity), to the total porosity, $\phi$, which was calculated from the bulk density and particle density. 
Table 3.5. Transport Parameters Determined by Direct Measurement or from Laboratory-Derived Breakthrough Curves on the $<2$-mm Sediment Fraction

\begin{tabular}{lcccccccc}
\hline Expt. $^{(\mathrm{a})}$ & $\begin{array}{c}F \\
\left(\mathrm{~cm}^{3} / \mathrm{hr}\right)\end{array}$ & $\begin{array}{c}\rho_{b} \\
\left(\mathrm{~g} / \mathrm{cm}^{3}\right)\end{array}$ & $\theta$ & $\begin{array}{c}V_{w} \\
(\mathrm{~mL})\end{array}$ & $\begin{array}{c}v \\
(\mathrm{~cm} / \mathrm{hr})\end{array}$ & $\begin{array}{c}t_{o} \\
\left(\mathrm{~V}_{\mathrm{w}}\right)\end{array}$ & $R$ & $\begin{array}{c}K_{d} \\
(\mathrm{~mL} / \mathrm{g})\end{array}$ \\
\hline Ortho & 30.37 & 1.478 & 0.386 & 20.89 & 16.01 & 11.22 & 5.54 & 1.19 \\
Pyro & 41.93 & 1.444 & 0.385 & 20.33 & 22.18 & 15.90 & 7.61 & 1.76 \\
Tripoly & 40.80 & 1.460 & 0.392 & 21.27 & 21.22 & 14.70 & 5.17 & 1.12 \\
\hline Calcium & 31.41 & 1.478 & 0.386 & 20.89 & 16.57 & 11.95 & 14.14 & 3.44 \\
Amend7 & 30.61 & 1.444 & 0.385 & 20.33 & 16.19 & 12.26 & 5.83 & 1.29 \\
\hline Amend & 30.88 & 1.460 & 0.392 & 21.27 & 16.05 & 11.82 & 5.23 & 1.13 \\
\hline
\end{tabular}

$F=$ flow rate; $\rho_{b}=$ bulk density; $\theta=$ average volumetric water content (standard deviation); $V_{w}=$ average pore volume; $v=$ average pore water velocity; $t_{o}=$ step input; $R=$ retardation factor; $K_{d}=$ sediment water distribution coefficient based on $R$.

(a) Columns appeared saturated and had reached a stable water content.

The results of transport in near-saturated columns for sodium ortho-, pyro-, tripolyphosphate, calcium, the phosphorus amendment formulation as mixed, and the phosphorus amendment formulation $\mathrm{pH}$ adjusted to $\sim 7$ are shown in Figure 3.10. Note that columns were saturated until a stable water content was attained. Calculation of the percent saturation based on total porosity indicated that the conventional columns were approximately $90 \%$ saturated. A full breakthrough curve for sodium orthophosphate was attained and recovery of phosphorus in the effluent was $\sim 100 \%$ (Figure 3.10 ). Breakthrough curves (BTCs) for sodium pyro- and tripolyphosphate, conducted under the same conditions as sodium orthophosphate, only afforded $\sim 75 \%$ recovery of the influent pulse (Figure 3.10 ). Possible mechanisms that may have resulted in increased sorption are 1) sorption of degradation products onto sediment bound polymerized phosphate molecules, and/or 2) degradation of polymerized phosphate compounds and subsequent sorption to the sediment matrix. This suggests the significance of reactions occurring between sodium ortho-, pyro-, and tripolyphosphate. In the absence of precipitation reactions (i.e., formation of calcium- and uranium-phosphate phases), the mobility of the phosphorus amendment is comparable to that of the individual phosphate compounds. The apparent retardation factor within the $<2-\mathrm{mm}$ sediment fraction is 5.23 for the non-pH-adjusted amendment and 5.83 for the $\mathrm{pH}$-adjusted amendment (Table 3.5). Correcting these values for field conditions assumed retardation was due to the $<2-\mathrm{mm}$ fraction which comprised $\sim 10 \%$ of the total sediment matrix. Using a porosity value of 0.2 and a bulk density of 2.19 , the calculated field $K_{d}$ and retardation values are given in Table 3.6.

Figure 3.10 also displays the result of calcium transport under saturated conditions. Unlike the anionic phosphate species, calcium is cationic and strongly retarded within the anionic sedimentary and aqueous conditions present within the Hanford 300 Area subsurface (Table 3.5). Injection of a calcium pulse required a greater number of pore volumes to be delivered in order to afford a $C / C_{o}=1$. Moreover, the desorption, or later, half of the calcium BTC, displayed prolonged tailing for more than 40 pore volumes without reaching zero. Correcting the retardation value for field conditions again assumed retardation was due to the $<2-\mathrm{mm}$ fraction, which comprised $\sim 10 \%$ of the total sediment matrix. Using a porosity value of 0.2 , the calculated field $K_{d}$ and retardation values are given in Table 3.6. 

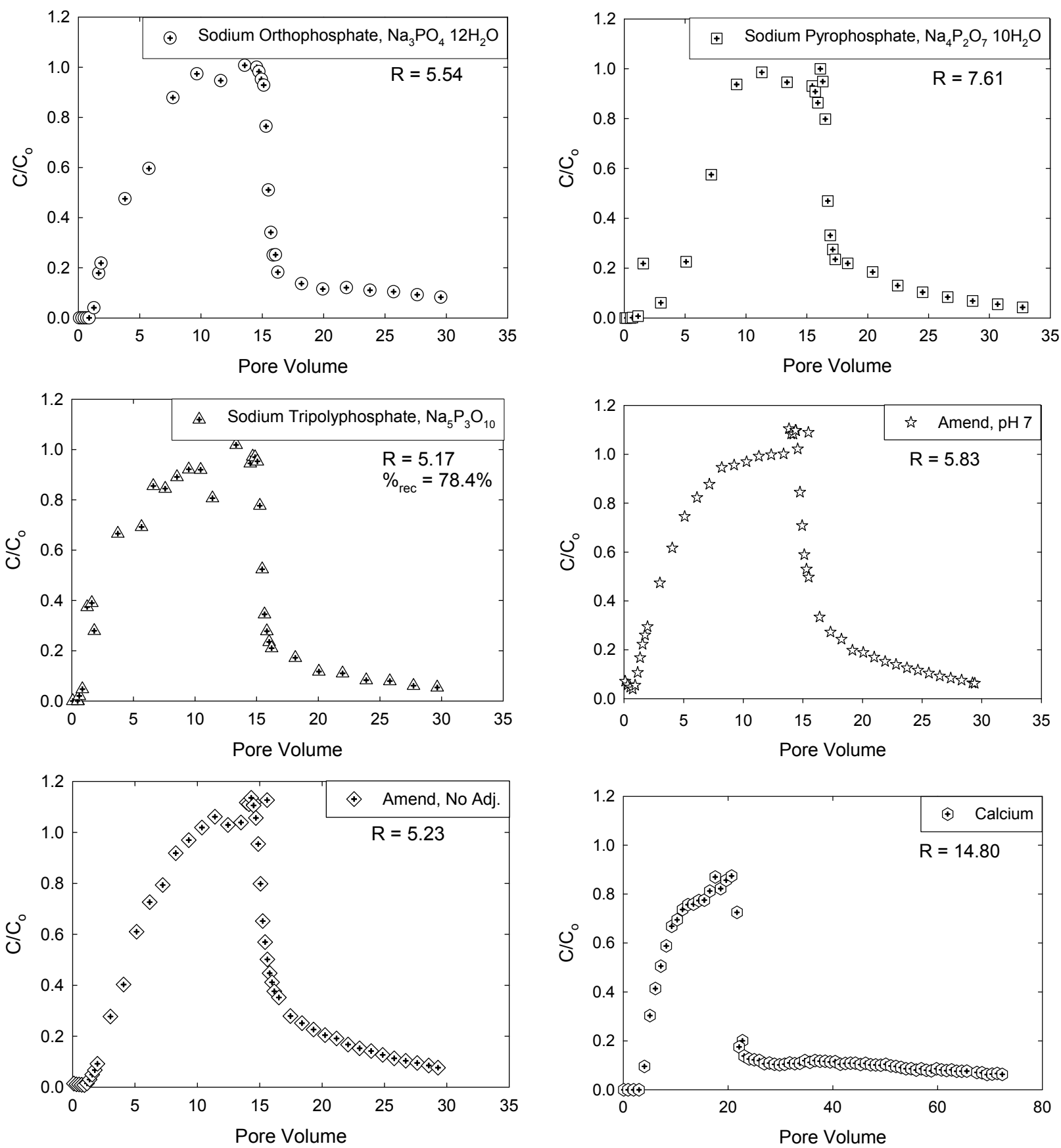

Figure 3.10. Breakthrough Curves for Sodium Ortho-, Pyro-, Tripolyphosphate, Calcium, the Phosphorus Amendment Formulation as Mixed, and the Phosphorus Amendment Formulation $\mathrm{pH}$ Adjusted to $\sim 7$ 
Table 3.6. Field Transport Parameters Calculated from Laboratory Derived Transport Parameters

\begin{tabular}{lccc}
\hline \multicolumn{1}{c}{ Compound } & $\begin{array}{c}v \\
(\mathrm{ft} / \mathrm{d})\end{array}$ & $R$ & $\begin{array}{c}K_{d} \\
(\mathrm{~mL} / \mathrm{g})\end{array}$ \\
\hline Sodium Orthophosphate & 24.3 & 2.30 & 0.12 \\
Sodium Pyrophosphate & 35.4 & 2.93 & 0.18 \\
Sodium Tripolyphosphate & 34.5 & 2.23 & 0.11 \\
Calcium & 26.5 & 4.76 & 0.34 \\
Amendment, pH 7 & 25.8 & 2.41 & 0.13 \\
Amendment, no pH Adjustment & 26.1 & 2.24 & 0.11 \\
\hline
\end{tabular}

\subsubsection{Potential Adverse Impacts}

As described in the preceding paragraphs, irrespective of the injection order or concentration of phosphorus and calcium used in the amendment formulation, all phosphorus, including degradation products, was removed via sorption and precipitation reactions (Figure 3.8); effluent concentrations of phosphorus are at or below background groundwater concentrations. Additionally, phosphate readily precipitates cationic species as highly insoluble phases (Cotter-Howells and Caporn 1996; Griffith et al. 1973; Lindsay 1979; Lindsay and Moreno 1960; Nriagu and Moore 1984; Sparks and Hunger 2002). Thus, the potential for downgradient transport and potential migration to the river is minimal; there is minimal concern regarding mobilization of sedimentary components during treatment. Moreover, use of the polyphosphate amendment to control precipitation kinetics afforded no effect on the hydraulic conductivity of the sediment during column testing; therefore, no significant impact on the hydraulic conductivity of the aquifer is anticipated.

\subsubsection{Polyphosphate Amendment}

Based on results from the column transport experiments discussed in Section 3.1.3, a three-phase injection strategy was identified as an effective approach to obtain both direct treatment of the uranium contamination in groundwater (i.e., autunite formation) and formation of the calcium-phosphate mineral apatite. The objective of apatite formation was to provide long-term treatment capacity within the amended zone to address uranium solubilized and released from the periodically re-wetted zone during future high water table conditions. The three-part injection strategy consisted of the following:

- An initial polyphosphate amendment injection was conducted to precipitate aqueous uranium within the treatment zone as autunite.

- The initial polyphosphate injection was directly followed by injection of a calcium chloride $(\mathrm{CaCl})$ solution to provide a sufficient calcium source for apatite formation during a subsequent polyphosphate injection. Due to the higher $K_{d}$ of the $\mathrm{CaCl}$ solution as measured in bench-scale experiments with site-specific sediments, it was anticipated that a larger injection volume would be required to reach the full radial extent of the targeted treatment zone for this component of the 
amendment formulation. However, this same increased retardation would also help to facilitate mixing between the calcium and polyphosphate amendments during the third and final injection phase.

- The $\mathrm{CaCl}$ injection was directly followed by a final polyphosphate injection.

Table 3.7 presents the final polyphosphate amendment formulation (Wellman et al. 2007). The solubility values listed in Table 3.7 were experimentally determined in tap water, filtered through a $0.45-\mu \mathrm{m}$ filter, at room temperature. Moreover, the values are not independent solubility values; rather, they are the maximum solubility within the total polyphosphate formulation. Results of batch and column tests demonstrated that optimum performance is achieved using a formulation in which the contribution of phosphorus is $25 \%$ orthophosphate, $25 \%$ pyrophosphate, and $50 \%$ tripolyphosphate. The mixture of the various components of the polyphosphate solution will achieve a solution $\mathrm{pH}$ of $\sim 7$. The amendment solution was prepared by mixing, in order, the sodium orthophosphate, sodium pyrophosphate, and sodium tripolyphosphate to achieve a $\mathrm{pH}$ of 7 and prevent degradation of polymerized phosphate molecules during preparation.

Table 3.7. Pilot-Scale Field Test Amendment Formulation

\begin{tabular}{|c|c|c|c|c|c|c|c|c|}
\hline Injection & Amendment & Formula & CAS \# & $\begin{array}{c}\text { Formula } \\
\mathrm{Wt} \\
(\mathrm{g} / \mathrm{mol})\end{array}$ & $\begin{array}{c}\text { Solubility, } \\
\mathrm{g} / \mathrm{L} 23^{\circ} \mathrm{C} \\
\mathrm{H}_{2} \mathrm{O}\end{array}$ & $\begin{array}{l}\text { Density, } \\
\mathrm{g} / \mathrm{cm}^{3} \\
\left(25^{\circ} \mathrm{C}\right)\end{array}$ & $\begin{array}{l}\text { Conc. } \\
(\mathrm{g} / \mathrm{L})\end{array}$ & $\begin{array}{l}\text { Conc. } \\
\text { (M) }\end{array}$ \\
\hline \multirow{4}{*}{1} & $\begin{array}{l}\text { Sodium Phosphate, } \\
\text { monobasic }\end{array}$ & $\mathrm{NaH}_{2} \mathrm{PO}_{4}$ & $7558-80-7$ & 119.98 & 29.63 & \multirow{4}{*}{1.002} & 0.59 & $\begin{array}{c}4.94 \mathrm{x} \\
10^{-3}\end{array}$ \\
\hline & $\begin{array}{l}\text { Sodium } \\
\text { Pyrophosphate }\end{array}$ & $\mathrm{Na}_{4} \mathrm{P}_{2} \mathrm{O}_{7}$ & $7722-88-5$ & 265.9 & 32.81 & & 0.66 & $\begin{array}{c}2.47 \mathrm{x} \\
10^{-3}\end{array}$ \\
\hline & $\begin{array}{l}\text { Sodium } \\
\text { Tripolyphosphate }\end{array}$ & $\mathrm{Na}_{5} \mathrm{P}_{3} \mathrm{O}_{10}$ & $7758-29-4$ & 367.86 & 60.40 & & 1.21 & $\begin{array}{c}3.29 \mathrm{x} \\
10^{-3}\end{array}$ \\
\hline & Sodium Bromide & $\mathrm{NaBr}$ & & 102.90 & & & 0.103 & $\begin{array}{c}1.00 \mathrm{x} \\
10^{-3}\end{array}$ \\
\hline 2 & Calcium Chloride & $\mathrm{CaCl}_{2}$ & $10043-52-4$ & 110.98 & 800 & 1.003 & 3.41 & $\begin{array}{c}3.07 \times 1 \\
0^{-2}\end{array}$ \\
\hline \multirow{4}{*}{3} & $\begin{array}{l}\text { Sodium Phosphate, } \\
\text { monobasic }\end{array}$ & $\mathrm{NaH}_{2} \mathrm{PO}_{4}$ & $7558-80-7$ & 119.98 & 29.63 & \multirow{4}{*}{1.002} & 0.59 & $\begin{array}{c}4.94 \mathrm{x} \\
10^{-3}\end{array}$ \\
\hline & $\begin{array}{l}\text { Sodium } \\
\text { Pyrophosphate }\end{array}$ & $\mathrm{Na}_{4} \mathrm{P}_{2} \mathrm{O}_{7}$ & $7722-88-5$ & 265.9 & 32.81 & & 0.66 & $\begin{array}{c}2.47 \mathrm{x} \\
10^{-3}\end{array}$ \\
\hline & $\begin{array}{l}\text { Sodium } \\
\text { Tripolyphosphate }\end{array}$ & $\mathrm{Na}_{5} \mathrm{P}_{3} \mathrm{O}_{10}$ & $7758-29-4$ & 367.86 & 60.40 & & 1.21 & $\begin{array}{c}3.29 \mathrm{x} \\
10^{-3}\end{array}$ \\
\hline & Sodium Bromide & $\mathrm{NaBr}$ & & 102.90 & & & 0.103 & $\begin{array}{l}1.00 \mathrm{x} \\
10^{-3}\end{array}$ \\
\hline
\end{tabular}




\subsection{Site-Specific Characterization}

This section describes the site-specific characterization activities that were conducted in support of the polyphosphate treatability test, including well installation and geohydrologic characterization, tracer injection testing, hydraulic testing, and baseline groundwater chemistry monitoring.

\subsubsection{Well Installation and Geohydrologic Characterization}

Monitoring wells were installed during two separate drilling campaigns: one in November and December 2006 to support initial site characterization activities (Vermeul et al. 2006) and a second in May 2007 to provide additional downgradient monitoring wells for monitoring amendment/tracer plume drift under a wide range of Columbia River stage conditions. The relative location of targeted treatment zone wells is shown on the location map in Figure 3.11 along with a schematic of well-completion depths, and downgradient well locations are shown in Figure 1.3. Two pre-existing wells include 1) the injection well (399-1-23), which was drilled earlier in 2006 as part of a limited field examination for uranium contamination in the 300 Area (Williams et al. 2007), and 2) 399-1-17A, drilled in 1986, to monitor the top of the unconfined aquifer. As-built summaries and geologist logs for all wells are available on the Hanford Well Information Interface (http://www7.rl.gov/hwisweb/).

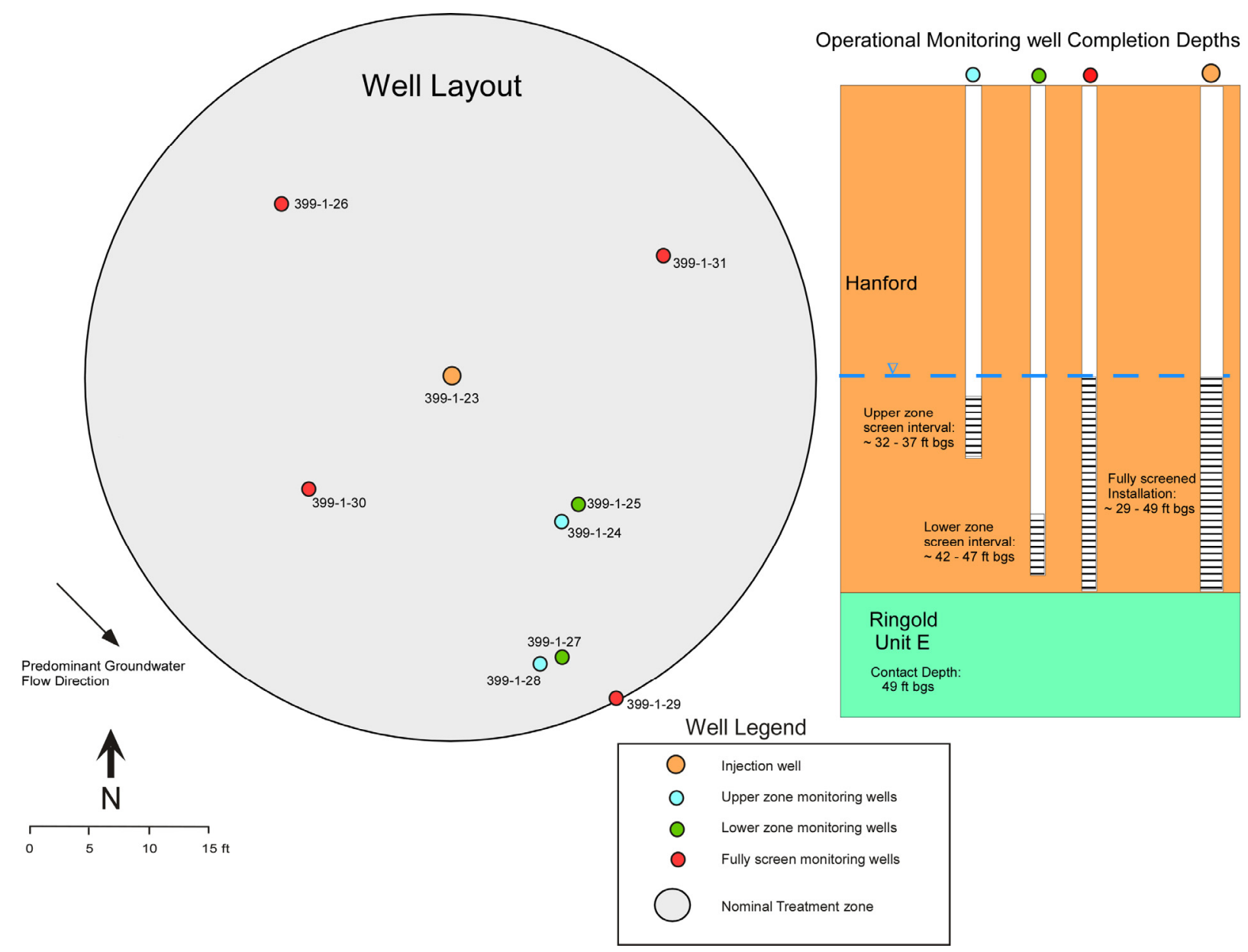

Figure 3.11. Initial Well Layout for Polyphosphate Treatability Test Site Showing Well-Completion Depths 
Treatability test site wells were constructed to the specifications and requirements described in Washington Administrative Code 173-160, the Site Characterization Plan: Uranium Stabilization through Polyphosphate Injection (Vermeul et al. 2006), and specifications provided by Fluor Hanford, Inc. (now CHPRC), Richland, Washington. During drilling and construction of the wells, sampling and analysis activities were conducted to support field screening for radiological and chemical contaminants and to collect nearly continuous sediment samples for geologic description. The borehole logs for these new wells were evaluated to determine the stratigraphic contacts and key lithologic changes where possible. These results were compared to borehole investigation results from well 399-1-23 contained in the report by Williams et al. (2007).

Two suprabasalt stratigraphic units are present in the 300 Area, namely the Hanford and Ringold formations (Bjornstad et al. 2009). The Hanford formation consists of mostly angular, gravel-dominated deposits of Pleistocene Ice Age floods (Figure 3.12). Although predominantly coarse-grained, these deposits are poorly sorted with a wide range of grain sizes from boulders to fine sand, silt, and clay. Hanford formation sediments are gray colored due to their high basalt content and very permeable because of their generally loose nature with high porosity. The polyphosphate injection took place entirely within the Hanford formation.

The underlying Ringold Formation represents coarse-grained Miocene- to Pliocene-age deposits of the ancestral Columbia and Snake rivers within the Pasco Basin. The Ringold Formation in the 300 Area is typically a bimodal, clast-supported, rounded, pebble-cobble gravel in a matrix of reddish-brown (oxidized) fine to coarse sand (Figure 3.13). Massive beds of gravel-dominated facies are sometimes separated by beds or lenses of sand, silt, and/or clay. Because the Ringold Formation is much older it is more altered and compacted compared to the Hanford Formation. As a result, its permeability may be up to several orders of magnitude less than the overlying Hanford Formation, and may act somewhat as a hydrologic boundary.

\section{North Process Pond - Pit \#2}

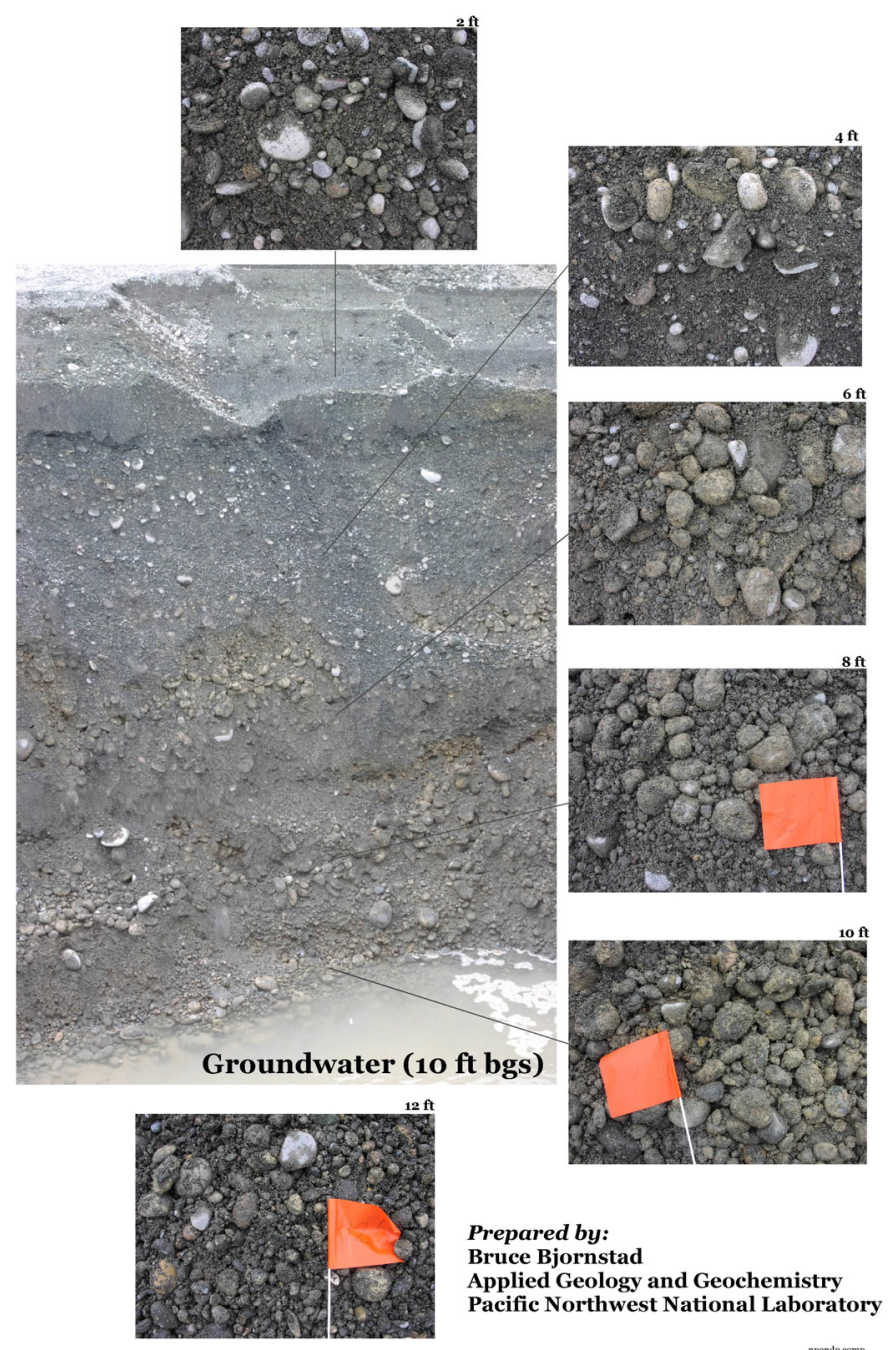

Figure 3.12. Ice Age Flood Deposits of the Grayish Hanford Formation Exposed at the Base of North Process Pond (located just north of the polyphosphate-injection site; Bjornstad 2004). 
Beneath the polyphosphate treatability test site, the Hanford-Ringold contact boundary ranged in depth between approximately 11.9 and $15.5 \mathrm{~m}$ (39 and $51 \mathrm{ft}$ ) bgs in the new boreholes (Table 3.8). Typical depths to water range from $10.6 \mathrm{~m}(35 \mathrm{ft})$ bgs during low river stage conditions to $9.1 \mathrm{~m}(30 \mathrm{ft})$ bgs during spring/summer high water conditions, resulting in a Hanford aquifer thickness of 4.5 to $6 \mathrm{~m}$ (15 to $20 \mathrm{ft}$ ). In all of the wells, from $\sim 10.9 \mathrm{~m}$ (36 ft) bgs to the Ringold Formation contact, the Hanford formation consists predominantly of coarse sandy gravel to gravel. A more open framework, i.e., clast-supported structure, composed of predominantly gravel to slightly sandy gravel is reported in wells 399-1-24, 399-1-26, 399-1-30, and 399-1-31 in the lower Hanford formation from approximately $10.9 \mathrm{~m}$ (36 ft) bgs down to the Hanford-Ringold contact; where present, the matrix sand is composed of medium to coarse sand.

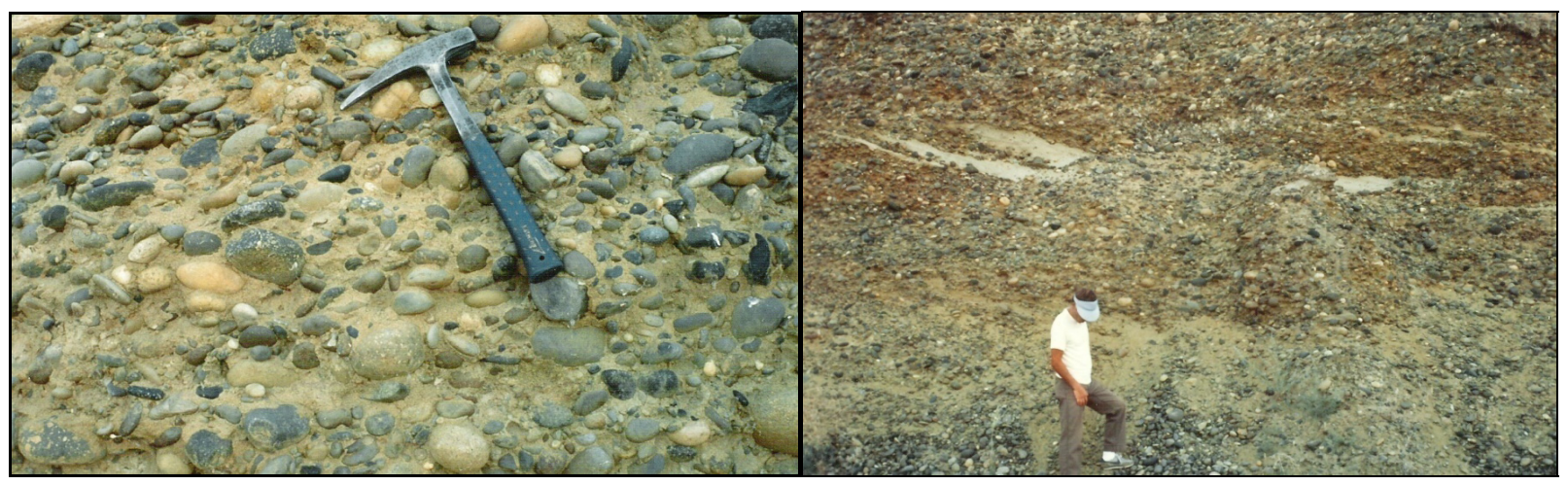

Figure 3.13. Compacted to Semi-Consolidated, Gravel-Dominated Facies of the Ringold Formation (exposed in the White Bluffs across the Columbia River from the 300 Area). Notice: clean sand lenses within the clast-supported, fluvial gravel in the left image; clean sand lenses within the clast-supported, fluvial gravel in the left image; and the distinct color change, degree of sorting, and lithification, compared to the gravel-dominated facies of the Hanford formation.

The Ringold Formation unit 5 that lies beneath the Hanford formation is composed of mostly gravelly silty sand to sand. With the exception of two shallow well pairs and the earlier LFI well 399-1-23 (which was drilled down to the lower mud unit), the wells were drilled a few feet into the Ringold Formation to a total depth of $\sim 15.5 \mathrm{~m}(51 \mathrm{ft})$ bgs (Table 3.8); therefore, only the upper few feet of Ringold Formation sediments were encountered. At all locations, the Hanford-Ringold contact was distinguished by a distinct color change, decrease in gravel size and content, and a significant increase in fine sand.

As part of the LFI effort, particle size analysis was performed on depth-discrete sediment core samples (Gee and Or 2002) for well 399-1-23. A summary of physical and hydraulic property data for the selected samples for which particle-size distributions were measured on the whole (bulk) sample for this well is presented in Table 3.9. Over $90 \%$ of the sediments from the borehole were dominated by gravel and sand sized particles. Higher silt/clay contents (29.7-31.6\%) were found at a depth between 6.4 and $7.6 \mathrm{~m} \mathrm{(21} \mathrm{and} 25 \mathrm{ft}) \mathrm{bgs}$, which is consistent with the high moisture contents measured over this depth zone.

Depth-discrete hydraulic tests were also conducted as part of the LFI effort to provide an assessment of the variation and vertical distribution of hydraulic conductivity with depth within the unconfined aquifer at these specific locations (Williams et al. 2007). Aquifer hydraulic testing was generally planned to coincide with selective depth-discrete water sampling, which could then use a common, temporary 
well-screen installation during the sampling/characterization process. After collection of the water sample, the temporary casing was pulled back to expose $\sim 1.5 \mathrm{~m}(5 \mathrm{ft})$ of screen, and the packer that was attached to the top of the well-screen assembly was then inflated to isolate the test interval. The aquifer hydraulic tests were initiated mechanically by rapidly removing a slugging rod of known volume from the well-screen section. A detailed discussion of these tests, along with the analysis methods and results, are included in the report by Williams et al. (2007).

Hydraulic conductivity estimates for the Ringold Formation ranged from 0.69 to $2.16 \mathrm{~m}$ ( 2.26 to $7 \mathrm{ft})$ per day, while estimates for the Hanford formation were reported as being $>100 \mathrm{~m}(328 \mathrm{ft})$ per day. It should be noted that, because of test limitations for the Hanford test intervals, no quantitative test analysis was possible; however, the observed test response indicates a high permeability condition. The actual hydraulic conductivity value for this test interval, therefore, is likely to be significantly higher than this assigned minimum value, as confirmed by the hydraulic testing conducted to support this treatability study (see discussion in Section 3.2.3). These hydraulic testing results, which are representative of baseline (i.e., pre-polyphosphate injection) conditions, will be compared to post-injection values to assess whether any aquifer plugging occurred during treatment.

The upper surface of the Ringold Formation represents an erosional unconformity, created when Ice Age floods scoured into the Ringold Formation and backfilled with flood deposits of the Hanford formation. The eroded surface of the Ringold Formation is shown in Figure 3.14. The polyphosphate injection well (399-1-23) appears to lie along a topographic low in the Ringold Formation, which may coincide with a flood paleochannel. Accordingly, the Hanford formation would be thickest along the paleochannel (Figure 3.14), thus resulting in more permeable Hanford formation materials over this portion of the unconfined aquifer (Figure 3.15). A hydrogeologic cross section (A-A') of the polyphosphate-injection site is represented in Figure 3.16. Illustrated are the uneven eroded surface and the location of discontinuous finer-grained lenses within the Ringold Formation. Also illustrated are the minimum and maximum groundwater levels for the unconfined aquifer and the water level observed at the time of injection. 
Table 3.8. Polyphosphate Treatability Well Identification and Borehole Information

\begin{tabular}{|c|c|c|c|c|c|c|c|c|c|c|c|c|c|c|c|c|}
\hline $\begin{array}{l}\text { Well } \\
\text { Name }\end{array}$ & Well ID & $\begin{array}{l}\text { SURVEY } \\
\text { DATE }\end{array}$ & $\begin{array}{l}\text { EASTING } \\
(\mathrm{m})\end{array}$ & $\begin{array}{l}\text { NORTHING } \\
(\mathrm{m})\end{array}$ & $\begin{array}{l}\text { Total } \\
\text { Depth } \\
\text { (ft) }\end{array}$ & $\begin{array}{c}\text { Ground } \\
\text { Surface } \\
\text { Elevation } \\
\text { (ft) }\end{array}$ & $\begin{array}{l}\text { Screen } \\
\text { Length } \\
(\mathrm{ft})\end{array}$ & $\begin{array}{l}\text { Screen } \\
\text { Depth } \\
(\mathrm{ft})\end{array}$ & $\begin{array}{c}\mathrm{H} / \mathrm{R} \\
\text { Contact } \\
\text { Depth } \\
\text { (ft) }\end{array}$ & $\begin{array}{l}\text { Top } \\
\text { Ringold } \\
\text { Fine } \\
\text { Sand } \\
\text { Depth } \\
\text { (ft) }\end{array}$ & $\begin{array}{l}\text { Elev. } \\
\text { Top } \\
\text { Ringold } \\
\text { (ft) }\end{array}$ & $\begin{array}{l}\text { Elev. } \\
\text { Top } \\
\text { Ringold } \\
\text { (m) }\end{array}$ & $\begin{array}{l}\text { Depth } \\
\text { to } \\
\text { Water } \\
(\mathrm{ft})\end{array}$ & Date & $\begin{array}{l}\text { Water } \\
\text { Table } \\
\text { Elev } \\
(\mathrm{ft})\end{array}$ & $\begin{array}{c}\text { Saturated } \\
\text { Hanford } \\
\text { fm } \\
\text { thickness } \\
(\mathrm{ft})^{*}\end{array}$ \\
\hline 399-1-17A & A5028 & $10 / 28 / 1992$ & 594112.87 & 116413.79 & 41 & 378.5 & 5 & $25-40$ & $50 *$ & $\mathbf{N P}$ & $328.5^{*}$ & $100.1^{*}$ & & & & $16.5^{*}$ \\
\hline $399-1-23$ & C5000 & $2 / 16 / 2007$ & 594113.51 & 116453.15 & 116 & 378.8 & 25 & $25-50$ & 51 & NP & 327.8 & 99.9 & 34.5 & & 344.3 & 17.2 \\
\hline $399-1-24$ & C5351 & 2/16/2007 & 594116.45 & 116449.68 & 42 & 379.3 & 5 & $32-37$ & $>42$ & NP & $<337.3$ & $<102.8$ & 33.8 & $11 / 30 / 2006$ & 345.5 & $>7.7$ \\
\hline $399-1-25$ & C5352 & $2 / 16 / 2007$ & 594116.88 & 116450.35 & 50 & 379.2 & 5 & $42-47$ & 48.2 & $\mathbf{N P}$ & 331.0 & 100.9 & 34.3 & $11 / 30 / 2006$ & 344.9 & 14.0 \\
\hline $399-1-26$ & C5353 & $2 / 16 / 2007$ & 594108.27 & 116456.21 & 50.5 & 378.8 & 20 & $29-49$ & 48.5 & NP & 330.3 & 100.7 & 33.8 & $11 / 30 / 2006$ & 345.0 & 14.7 \\
\hline $399-1-27$ & C5354 & $2 / 16 / 2007$ & 594116.23 & 116446.18 & 50 & 379.6 & 5 & $42-47$ & 48 & $\mathbf{N P}$ & 331.6 & 101.1 & 34.9 & $11 / 29 / 2006$ & 344.7 & 13.4 \\
\hline $399-1-28$ & C5355 & $2 / 16 / 2007$ & 594115.57 & 116445.84 & 40.5 & 379.6 & 5 & $32-37$ & $>40.5$ & NP & $<339.1$ & $<103.4$ & 34 & $11 / 30 / 2006$ & 345.6 & $>5.9$ \\
\hline $399-1-29$ & C5356 & $2 / 16 / 2007$ & 594118.67 & 116445.75 & 51 & 379.6 & 20 & $29-49$ & 49 & NP & 330.6 & 100.8 & 35 & $12 / 1 / 2006$ & 344.6 & 14.4 \\
\hline 399-1-30 & C5357 & $2 / 16 / 2007$ & 594110.62 & 116449.68 & 50.5 & 379.4 & 20 & $29-49$ & 49.8 & NP & 329.6 & 100.4 & 33.6 & $11 / 28 / 2006$ & 345.8 & 15.4 \\
\hline 399-1-31 & C5358 & $2 / 16 / 2007$ & 594118.66 & 116456.15 & 51 & 379.0 & 20 & $29-49$ & 48.5 & NP & 330.5 & 100.7 & 33.7 & $11 / 20 / 2006$ & 345.3 & 14.5 \\
\hline $399-1-32$ & C5359 & $2 / 16 / 2007$ & 594137.47 & 116432.44 & 50.5 & 378.2 & 15 & $29-44$ & 43 & 43 & 335.2 & 102.2 & 32.5 & $12 / 8 / 2006$ & 345.7 & 9.8 \\
\hline 399-1-33 & C5626 & 6/30/2007 & 594113.28 & 116430.5 & 46 & 379.7 & 20 & $24.3-44.3$ & 39 & 45.5 & 340.7 & 103.8 & 30.5 & 6/1/2007 & 349.2 & 4.3 \\
\hline $399-1-34$ & C5627 & $6 / 30 / 2007$ & 594101.2 & 116433.75 & 50.5 & 380.1 & 20 & $29.1-49.1$ & 39 & NP & 341.1 & 104.0 & 30.8 & $6 / 1 / 2007$ & 349.3 & 3.9 \\
\hline $399-1-35$ & C5628 & $6 / 30 / 2007$ & 594122.33 & 116432.05 & 49 & 379.3 & 20 & $28.1-48.1$ & 47.5 & NP & 331.8 & 101.1 & 30.5 & $5 / 30 / 2007$ & 348.8 & 13.2 \\
\hline $399-1-36$ & C5629 & $6 / 30 / 2007$ & 594108.45 & 116438.76 & 50 & 380.0 & 5 & $41-46$ & 45.5 & 45.5 & 334.5 & 102.0 & 30.7 & $5 / 9 / 2007$ & 349.3 & 10.5 \\
\hline $399-1-37$ & C5630 & $6 / 30 / 2007$ & 594110.22 & 116438.15 & 37.9 & 380.0 & 5 & $31.1-36.1$ & $>37.9$ & NP & $<342.1$ & $<104.3$ & 31.2 & $5 / 15 / 2007$ & 348.8 & $>2.9$ \\
\hline 399-1-38 & C5631 & 6/30/2007 & 594117.42 & 116435.42 & 48.7 & 379.8 & 20 & $26.6-46.6$ & 47 & 47 & 332.8 & 101.4 & 30.6 & 5/31/2007 & 349.2 & 12.2 \\
\hline
\end{tabular}


Table 3.9. Physical Property Data for Bulk Sediment Samples from Well 399-1-23 (from Williams et al. 2007)

\begin{tabular}{cccccccccc}
\hline $\begin{array}{c}\text { Well } \\
\text { Name }\end{array}$ & Sample & $\begin{array}{c}\text { Elevation } \\
\text { Mid-pt (m) }\end{array}$ & Unit & $\begin{array}{c}\text { Bulk } \\
\text { Density } \\
\left(\mathrm{g} / \mathrm{cm}^{3}\right)\end{array}$ & $\begin{array}{c}\text { Total } \\
\text { Porosity }\end{array}$ & $\begin{array}{c}\text { \% } \\
\text { \% Grav }\end{array}$ & $\begin{array}{c}\text { Sand } \\
\text { Silt }\end{array}$ & $\begin{array}{c}\text { \% } \\
\text { Clay }\end{array}$ \\
\hline 399-1-23 & C5000-39D & 107.83 & $\mathrm{H}$ & 1.95 & 0.293 & 71.78 & 21.15 & 4.16 & 2.92 \\
\hline $399-1-23$ & C5000-40C & 105.69 & $\mathrm{H}$ & 2.34 & 0.152 & 76.18 & 19.43 & 3.02 & 1.37 \\
\hline $399-1-23$ & C5000-40E & 105.08 & H & 2.31 & 0.165 & 70.59 & 22.12 & 5.34 & 1.95 \\
\hline $399-1-23$ & C5000-41C & 104.47 & H & 2.34 & 0.153 & 76.45 & 19.73 & 2.55 & 1.26 \\
$399-1-23$ & C5000-45C & 98.99 & R & 2.26 & 0.182 & 82.77 & 13.18 & 3.03 & 1.02 \\
\hline
\end{tabular}

(a) Particle density was not measured, so an average particle density $=2.76 \mathrm{~g} / \mathrm{cm}^{3}$ (see Williams et al. 2006, Table 3) was used to calculate porosities.

\subsubsection{Water Table and Groundwater Flow Directions}

The water table at the 300 Area is very dynamic due to fluctuations in the Columbia River stage (see Figure 3.17) and the very high permeability of the Hanford formation sediments comprising the uppermost part of the unconfined aquifer. Large daily, weekly, and seasonal fluctuations in the Columbia River stage are caused by the operation of hydroelectric dams on the river and seasonal trends (i.e., spring freshet). The dynamics of river stage fluctuations and the water table elevation cause a mixing zone of river and groundwater within the aquifer. During relatively high river stage periods river water enters the aquifer. Measurements of specific conductance and temperature in wells in the 300 Area, where the groundwater and river water have a large contrast in values, show that river water can encroach more than $190 \mathrm{~m}$ inland in the aquifer during a high river stage period. During relatively low river stage periods, groundwater discharges to the river, as indicated by specific conductance measurements (and other analytes) in aquifer tubes installed below the river bed and in springs along the shoreline (Patton et al. 2003). 


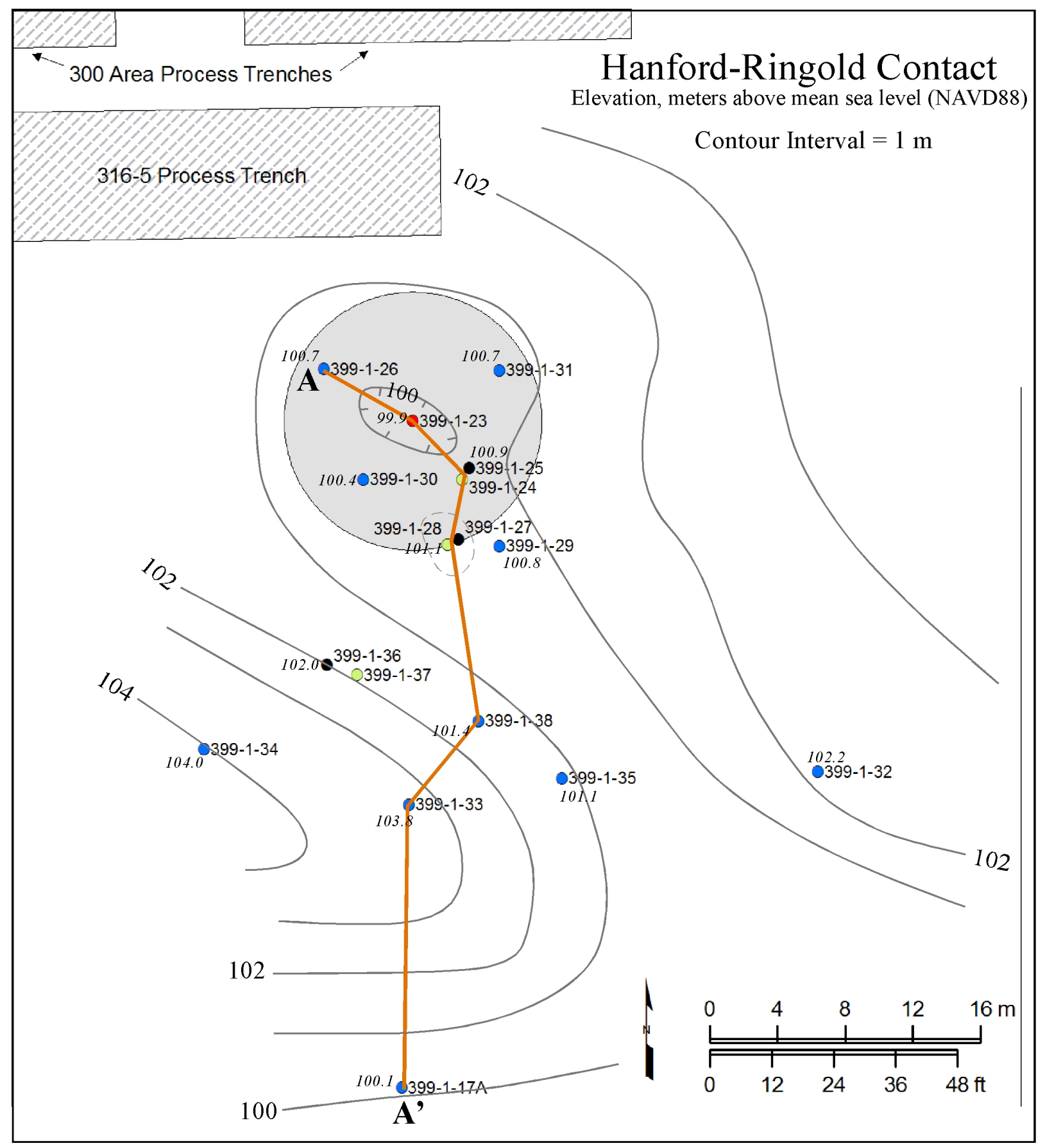

Figure 3.14. Structure-Contour Map on Top of the Eroded Ringold Formation. Cross section A-A' is shown in Figure 3.16. 


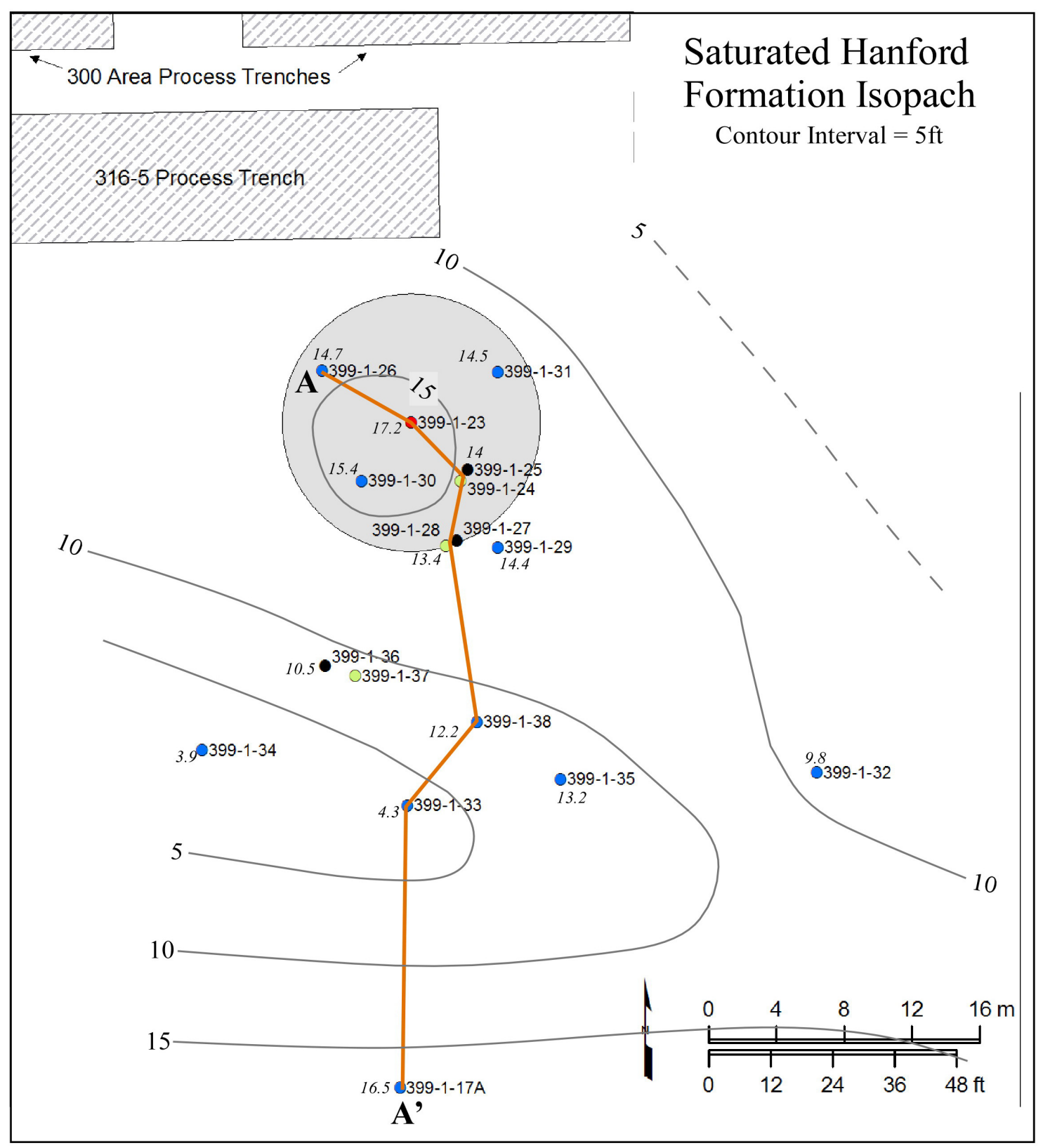

Figure 3.15. Saturated Thickness of the Hanford Formation. Cross section A-A' is shown in Figure 3.16. 


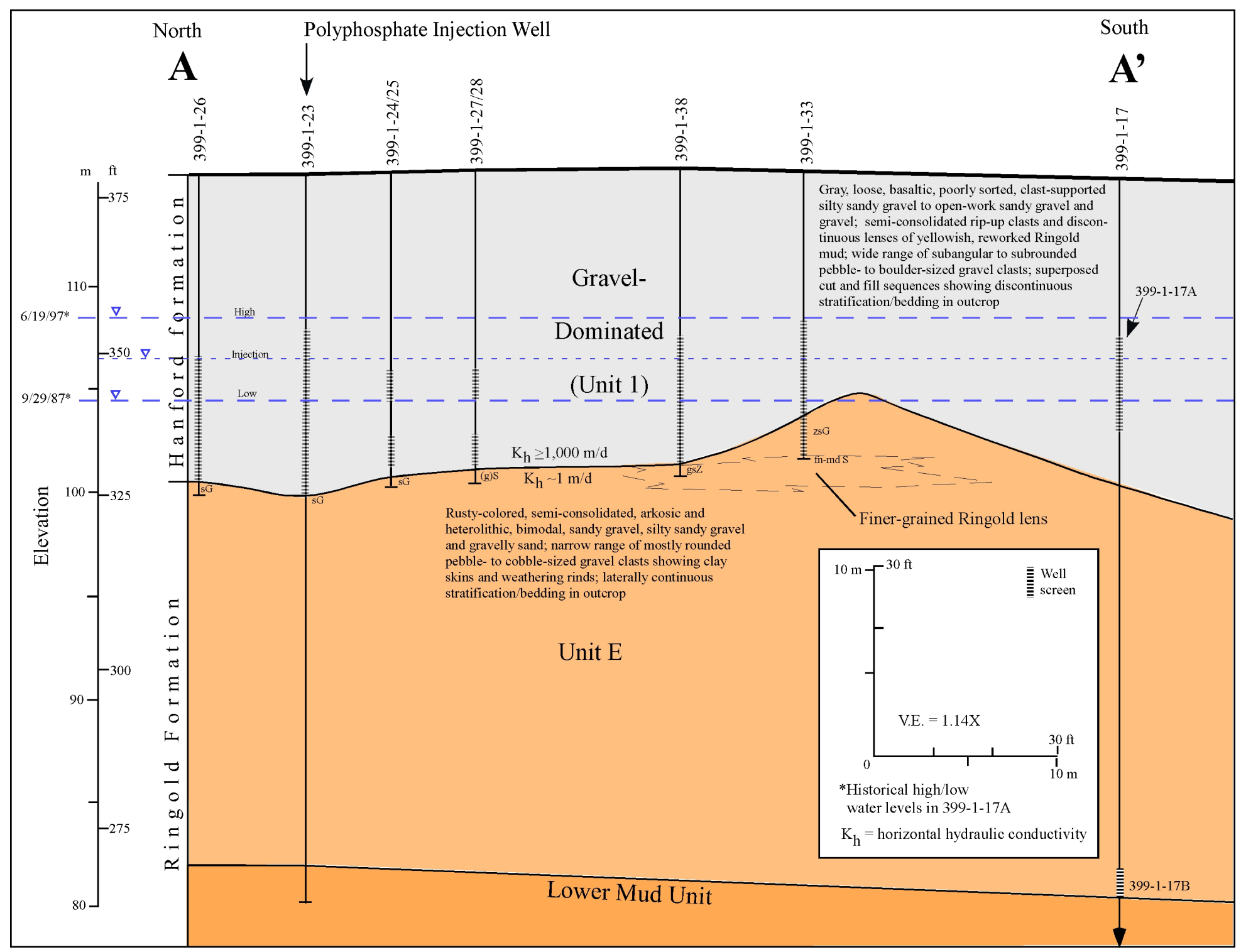

Figure 3.16. North-South Hydrogeologic Cross Section in the Vicinity of the Polyphosphate Injection Site. 


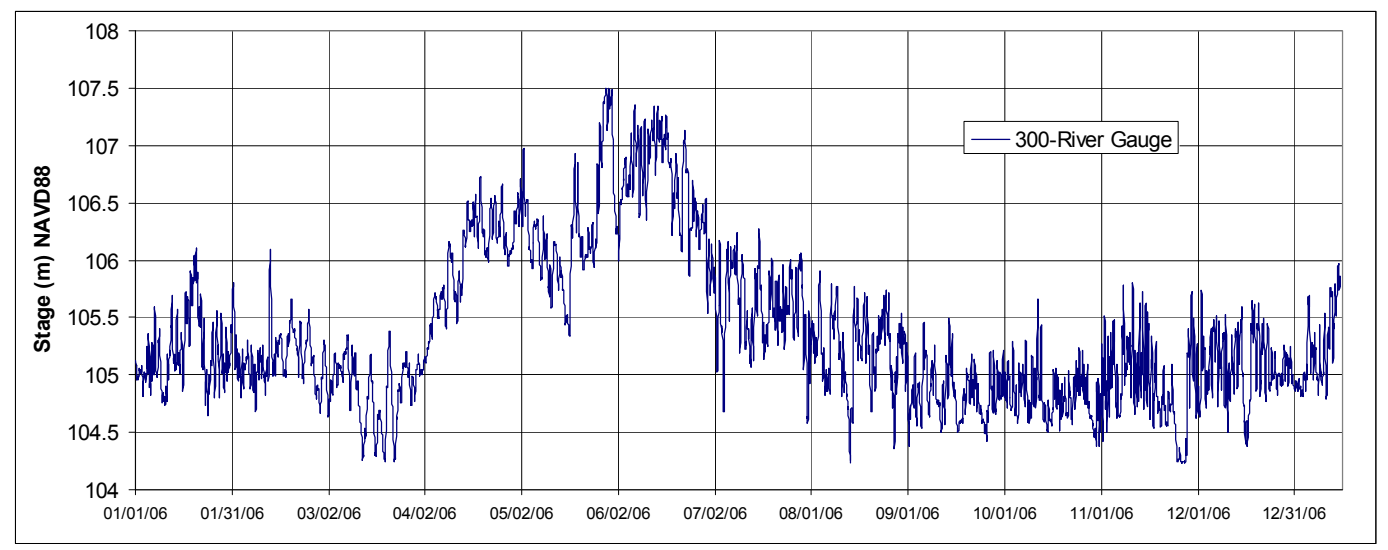

Figure 3.17. Columbia River Stage from the 300 Area Gauging Station for 2006

The water table for a low (December) and high river stage period (June) and are shown in Figure 3.18 and Figure 3.19, respectively. The water table, along with the uranium concentrations, is distinctly different during these periods as shown in the figures. Additionally, the water table is relatively flat in the 300 Area (i.e., very small hydraulic gradients) due to the extremely high permeability of the Hanford formation comprising the uppermost portion of the unconfined aquifer.

An automated water-level monitoring network was installed by the Remediation and Closure Science project in the 300 Area in 2004. Nine wells were initially included in this network that collected water levels on hourly and sub-hourly intervals in the area between the North and South Process Ponds and extending westward past the southern portion of the North Process Trenches (see Figure 3.20). Six of these wells also monitored groundwater temperature and electrical conductivity. Contoured hydraulic head data and calculated hydraulic gradients for two selected time periods, high and low river stage for 2006, are shown in Figure 3.20 and Figure 3.21, respectively. As shown by these figures, groundwater flow directions are inland during the June high river stage period and toward the river during the December low river stage period. Monthly rose diagrams showing the groundwater flow direction from this network using measurements every 2 hours are shown in Figure 3.22 and Figure 3.23.

The 300 Area water-level monitoring network was supplemented in July 2006 with the addition of the polyphosphate injection well (399-1-23) and well 399-1-16A to refine the well coverage from the original network. Two additional wells, 399-1-11 and 399-1-10A, were also added in October 2006 to increase the northern extent of the well coverage (see Figure 3.24). The addition of the polyphosphate injection well to this network shows significant variations in the gradient direction compared to the results from the coarser water-level network (compare Figure 3.21 and Figure 3.24). 


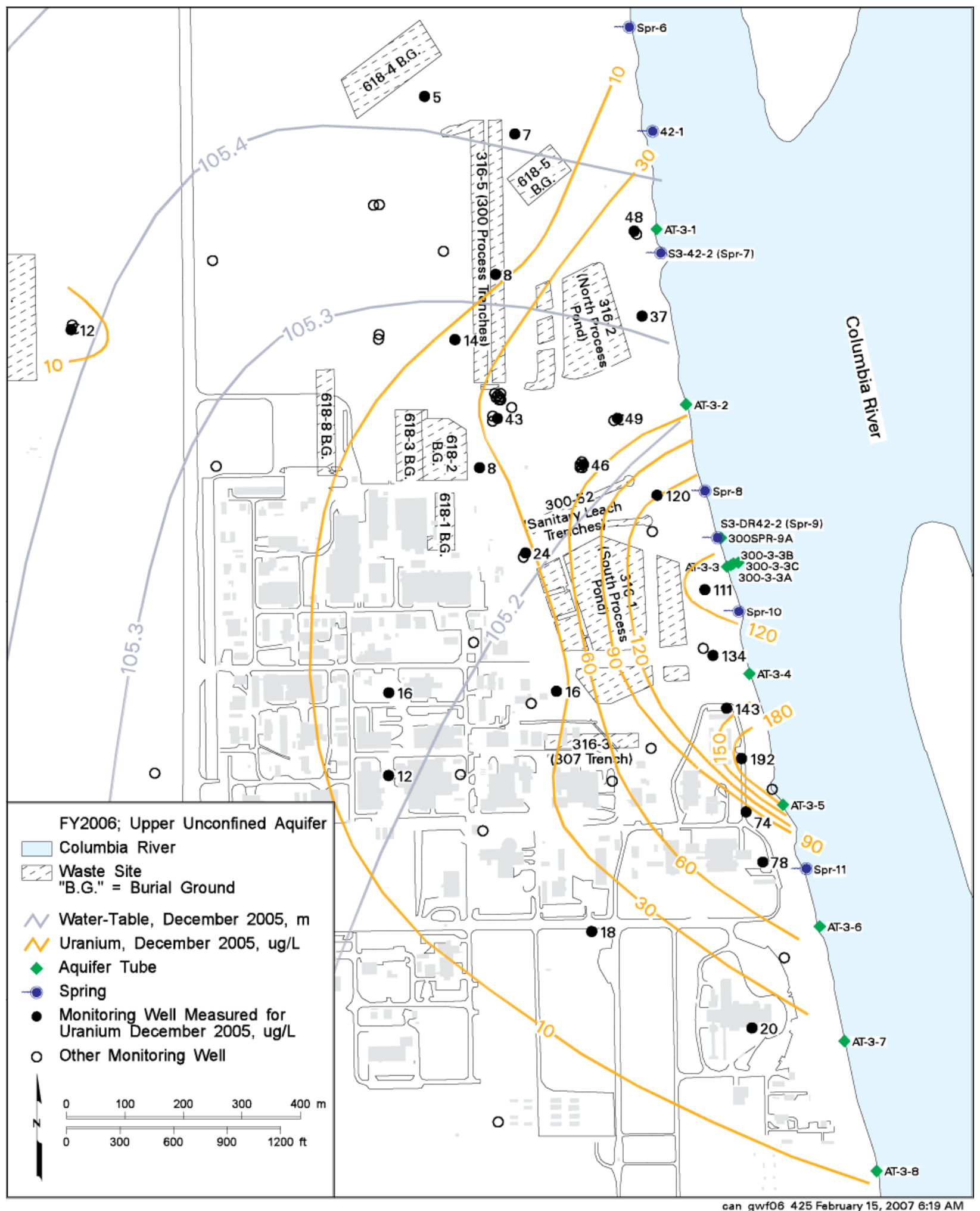

Figure 3.18. Water Table and Uranium Concentrations in Upper Part of the Unconfined Aquifer Beneath the 300 Area, December 2005 (from Hartman et al. 2007) 


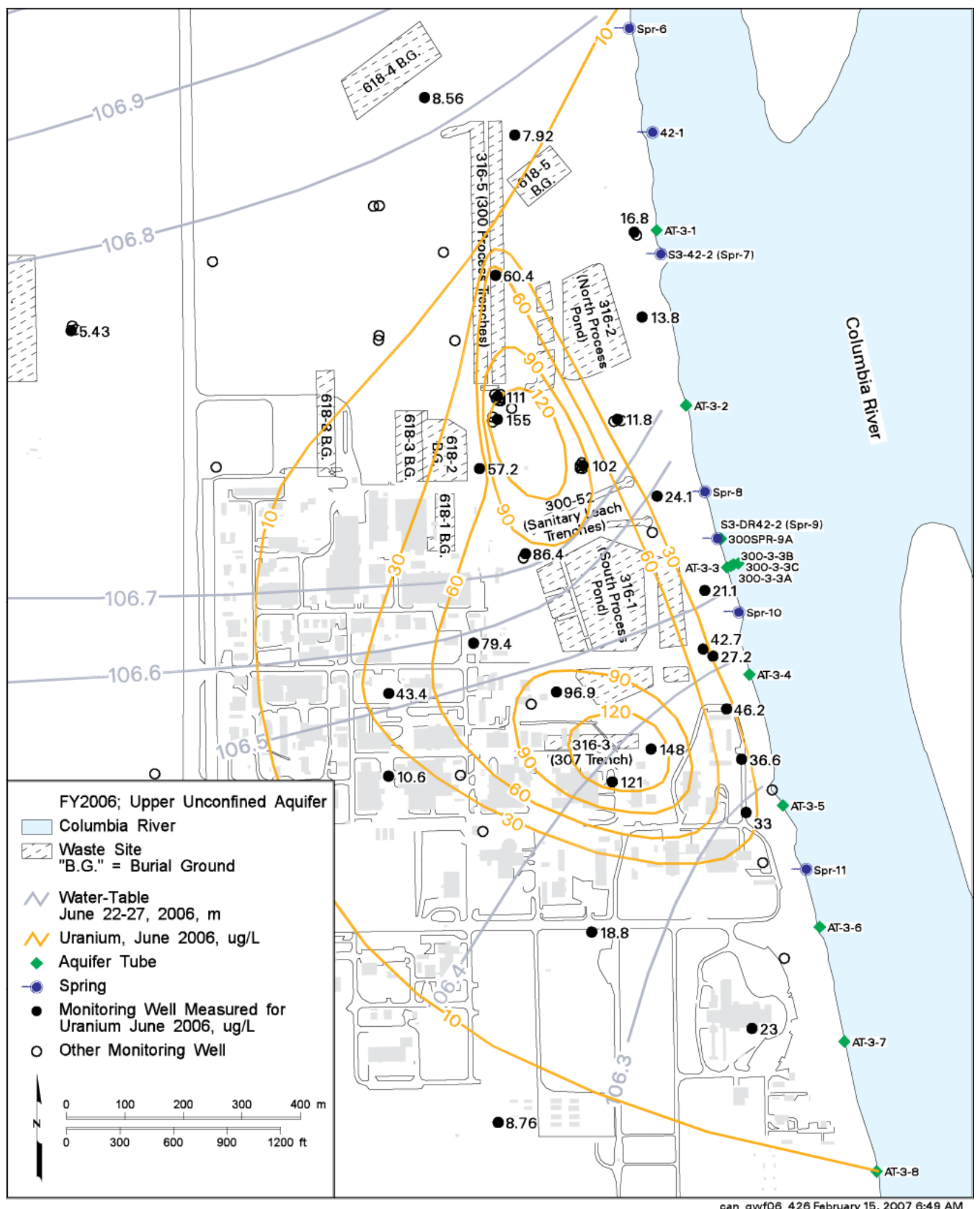

Figure 3.19. Water Table and Uranium Concentrations in Upper Part of the Unconfined Aquifer Beneath the 300 Area, June 2006 (from Hartman et al. 2007) 


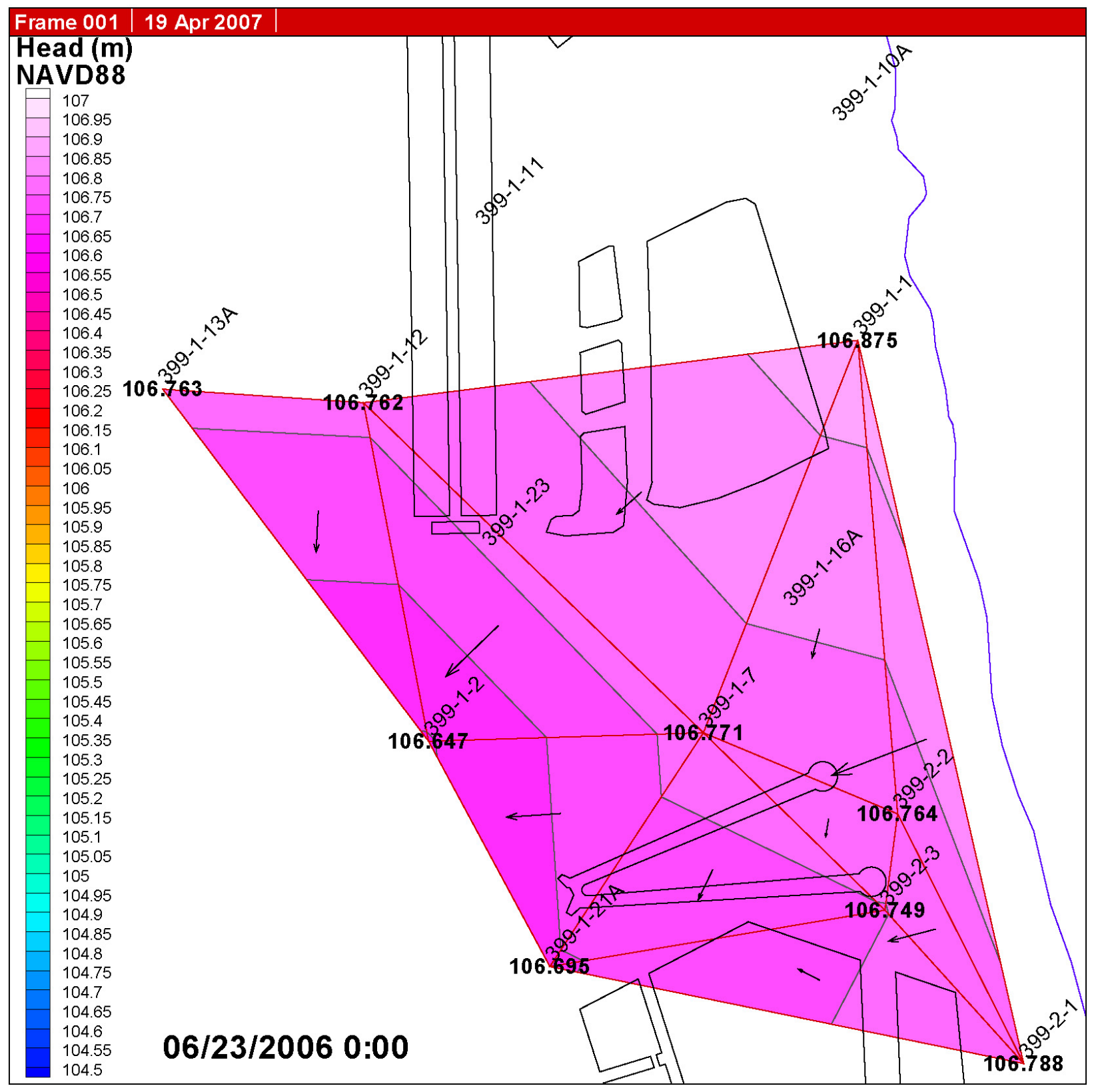

Figure 3.20. Original 300 Area Water-Level Monitoring Network - High River Stage Example 


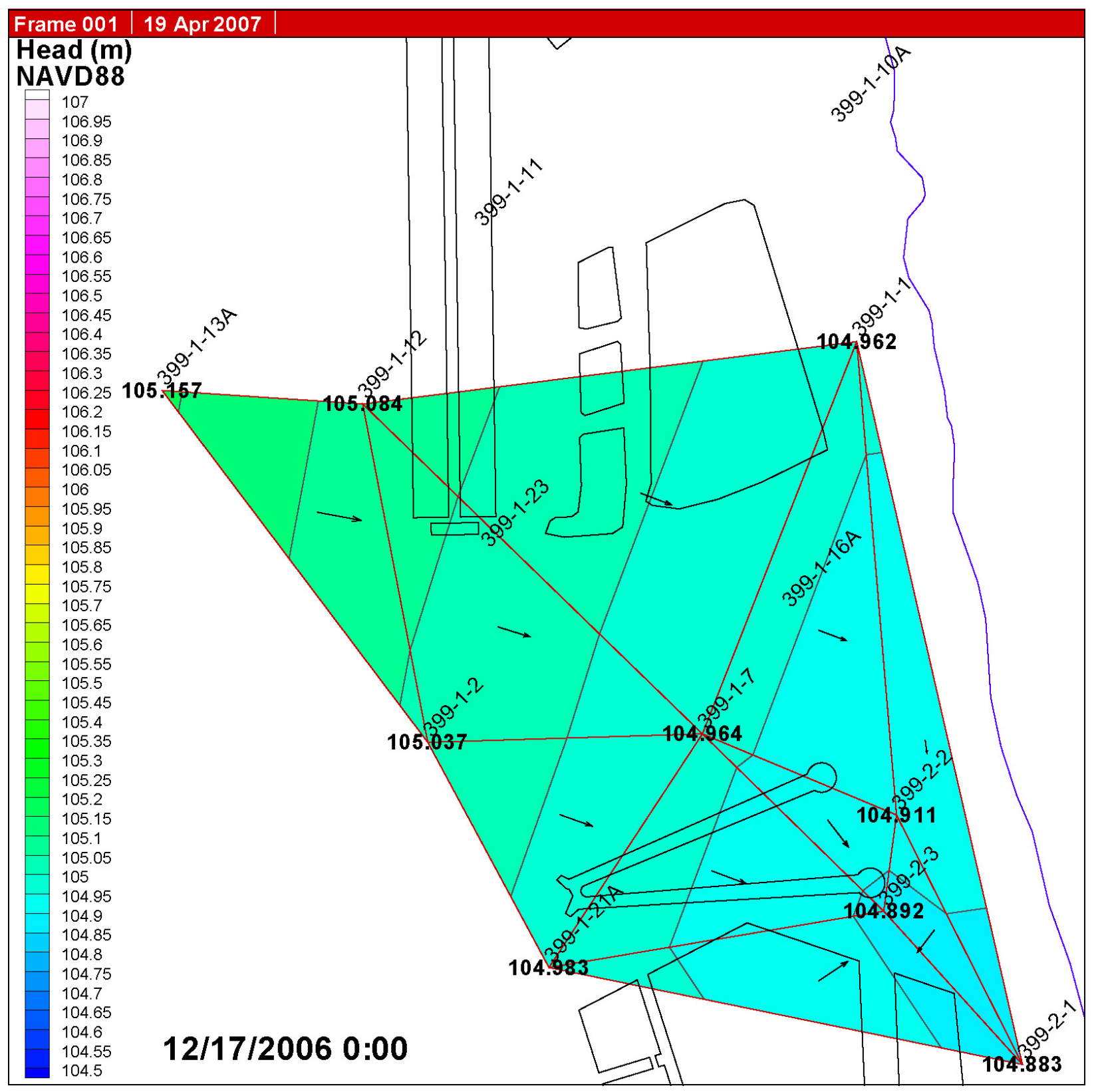

Figure 3.21. Original 300 Area Water-Level Monitoring Network - Low River Stage Example 


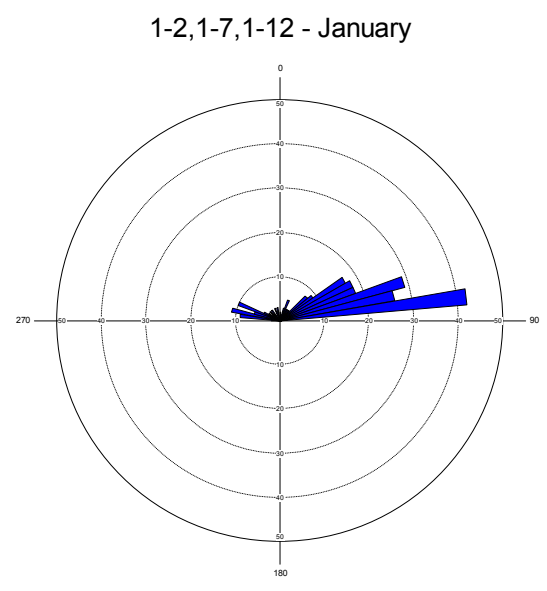

1-2,1-7,1-12 - March

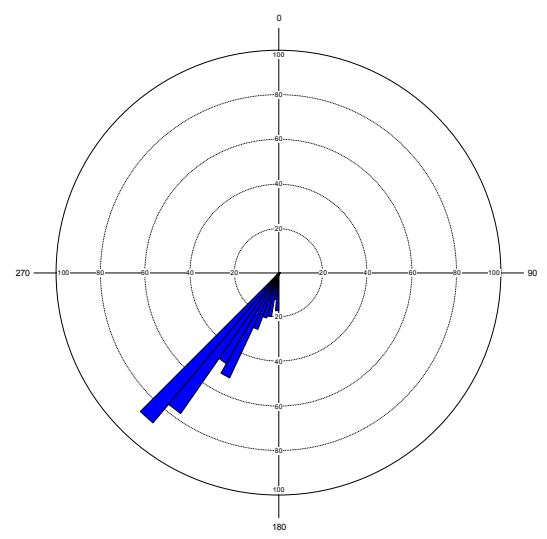

1-2,1-7,1-12 - May

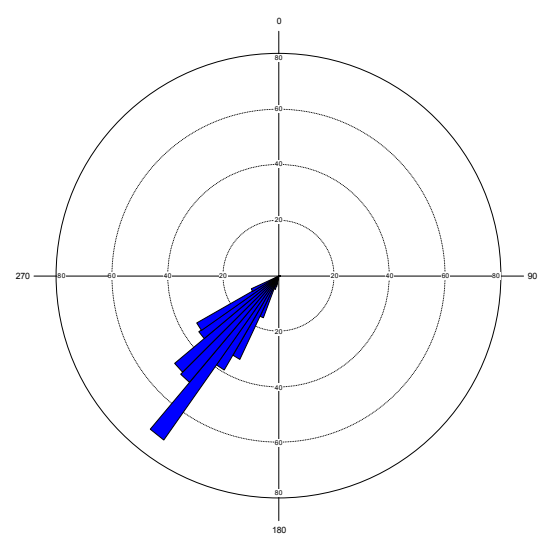

1-2,1-7,1-12 - February

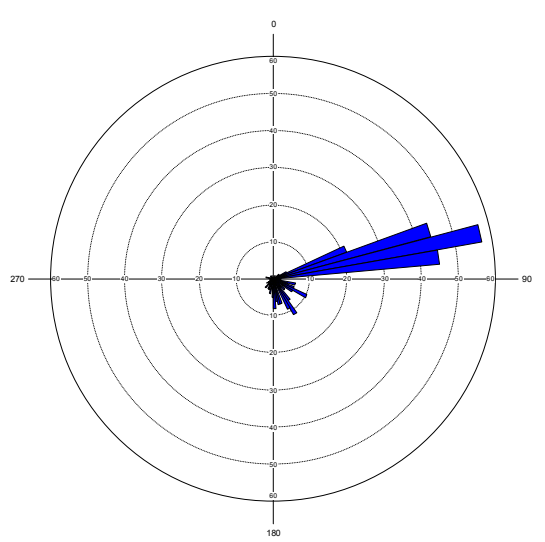

1-2,1-7,1-12 - April

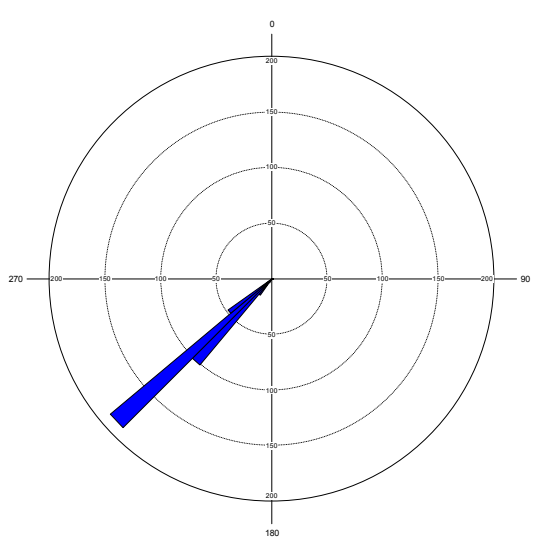

1-2,1-7,1-12 - June

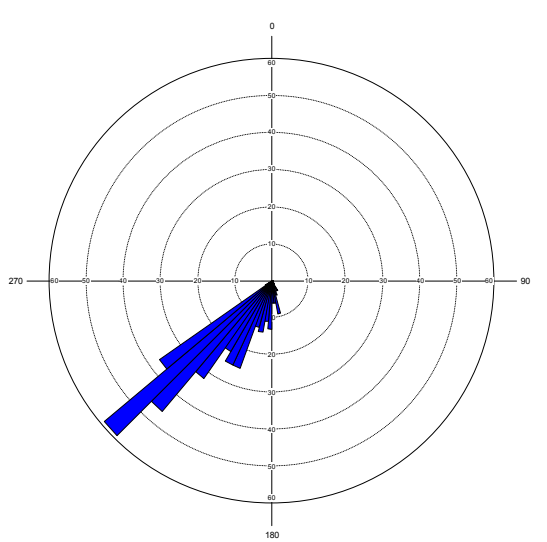

Figure 3.22. Hydraulic Gradient Directions for the First Half of 2006 Calculated from 300 Area Automated Water-Level Network (2-hour data intervals used) for Well Cluster 399-1-2, 399-1-7, and 399-1-12. Azimuth shows direction towards flow (March 16, 2007 data). 


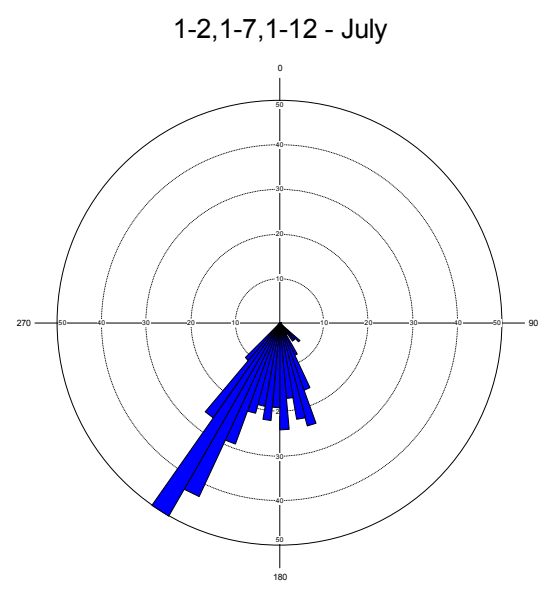

1-2,1-7,1-12 - September
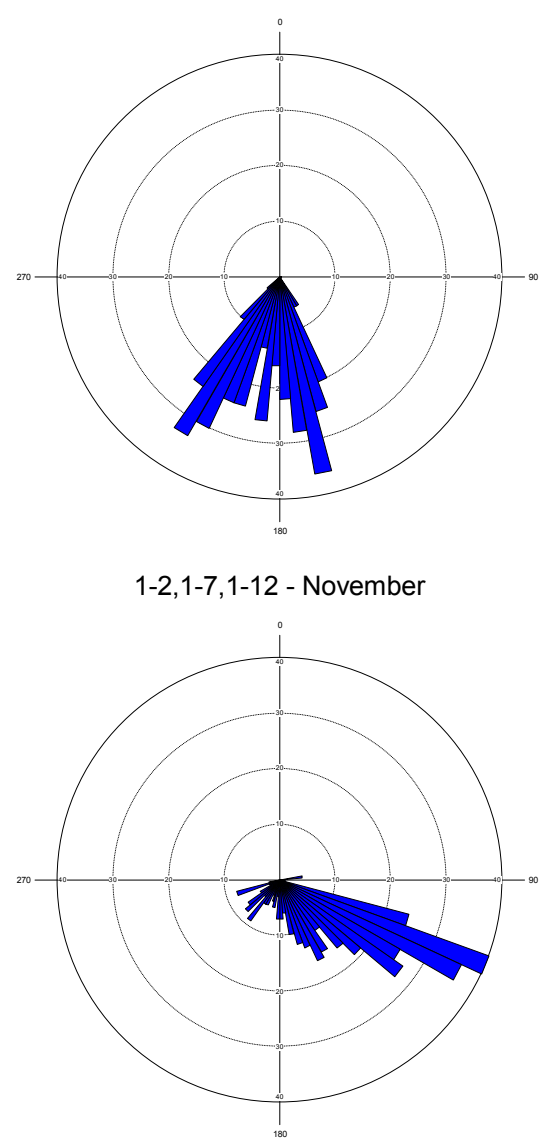

1-2,1-7,1-12 - August

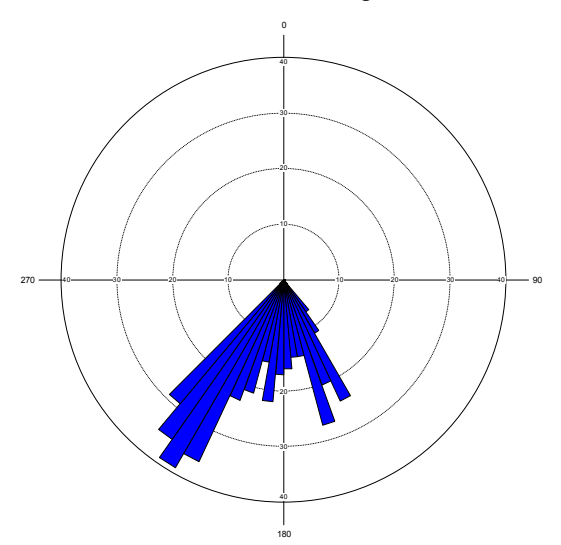

$1-2,1-7,1-12$ - October

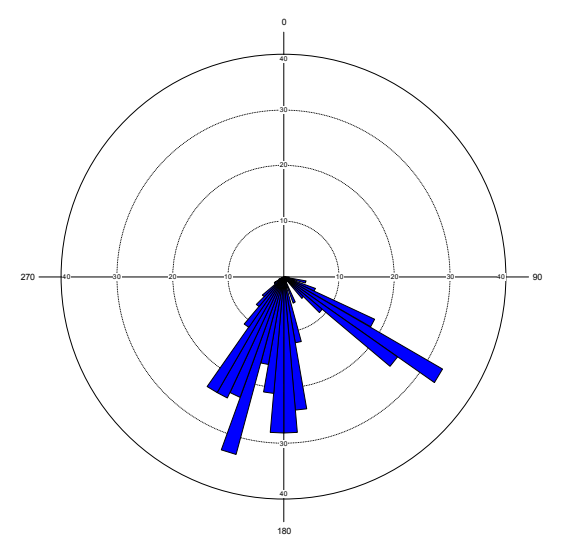

1-2,1-7,1-12 - December

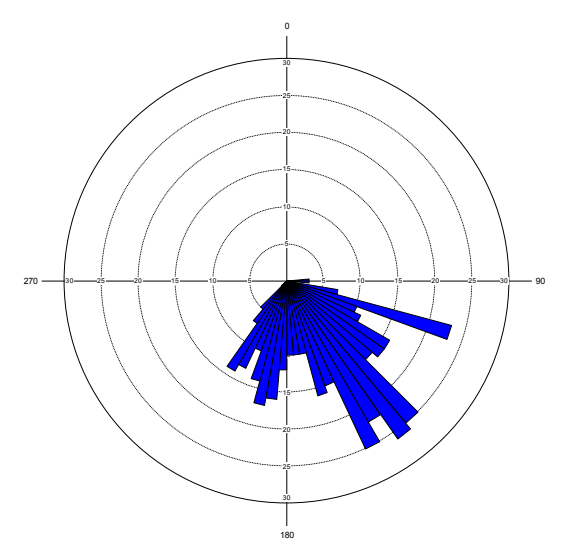

Figure 3.23. Hydraulic Gradient Directions for the Second Half of 2006 Calculated from 300 Area Automated Water-Level Network (2-hour data intervals used) for Well Cluster 399-1-2, 399-1-7, and 399-1-12. Azimuth shows direction towards flow (March 16, 2007 data). 


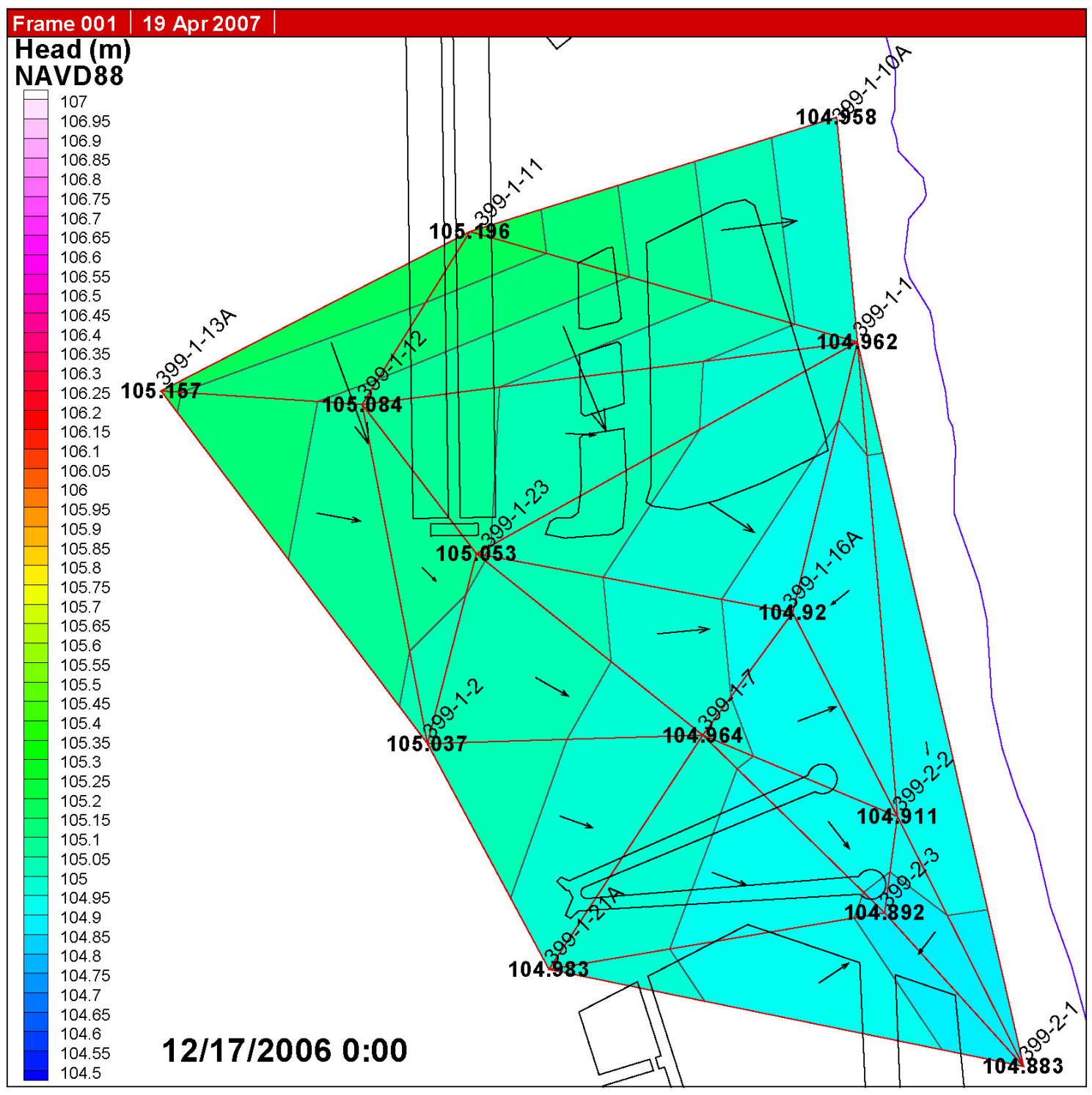

Figure 3.24. Expanded 300 Area Water-Level Monitoring Network - Low River Stage Example

Data from the automated water-level monitoring network were used to select the predominant downgradient direction for the downgradient monitoring well location (399-1-32 in Figure 3.1) for the December 2006 tracer test (predominantly southeast from the treatability test site). Results of the tracer test (discussed in Section 3.2.2) coincided with this direction during the test based on measured tracer BTCs. Additional downgradient wells were installed at the treatability test site oriented toward the southsouthwest, south, and south-southeast of the injection well, based on the predominant downgradient directions during the high river stage periods (April, May, and June). The higher-resolution water-level monitoring network that includes the polyphosphate injection well was not operational during a high river stage period, so the coarser dataset was used to guide downgradient directions during this period. The high river stage downgradient orientation was shifted southward from the predominant southwest direction seen in these rose diagrams in consideration of finer-scale water-level measurements and to also provide downgradient coverage during later parts of the year (e.g., July through October). 
Groundwater flow velocities are very high in this area given the large hydraulic conductivities. Estimated pore water velocities of $15.2 \mathrm{~m}(50 \mathrm{ft})$ per day were determined from the drift of the December 2006 tracer test (discussed in Section 3.2.2).

\subsubsection{Tracer Injection Testing}

A tracer injection test was conducted at the polyphosphate treatability test site on December 13, 2006. The objective of the tracer test was to further evaluate formation heterogeneities, to assess the downgradient transport of the tracer plume (i.e., aquifer transport properties), to refine the polyphosphate injection design, and to test operational procedures. Results from the tracer test provide information about the effective porosity of the aquifer, expected arrival times at the monitoring wells, and polyphosphate solution volume required for the targeted treatment zone thickness and radial extent.

\subsubsection{Tracer Test Description}

The tracer test was conducted by injecting a solution containing a conservative, non-reactive bromide (Br) tracer into a central injection well (399-1-23, as shown in Figure 3.11). Bromide concentrations were measured in the injection stream and the surrounding monitoring wells to determine the arrival times and extent of the tracer plume. Table 3.10 summarizes the operational parameters for the tracer test. The concentrated bromide solution was prepared in a 151-L (40-gal) plastic drum and diluted in-line during the injection to the required concentration using withdrawn groundwater from well 399-1-7, located $\sim 188.9 \mathrm{~m}(620 \mathrm{ft})$ downgradient from injection well. The concentrated bromide solution consisted of $60.8 \mathrm{~kg}(134 \mathrm{lb}) \mathrm{NaBr}$ mixed with 99.6 L (26.3 gal) of de-ionized water, for an approximate $\mathrm{NaBr}$ concentration of $610 \mathrm{~g} / \mathrm{L}$. The injection stream was maintained at a constant rate of $757 \mathrm{~L}$ (200 gal) per minute throughout the test duration (Figure 3.25). The concentrated solution was delivered to the injection stream at an average flow rate of $0.14 \mathrm{~L} / \mathrm{min}(2.2 \mathrm{gal} / \mathrm{hr})$. This resulted in an average injection concentration of around $112 \mathrm{mg} / \mathrm{L} \mathrm{NaBr}$, or $87 \mathrm{mg} / \mathrm{L} \mathrm{Br}^{-}$; however, due to mechanical problems with the tracer metering pump head, flow rates in the metering pump for the bromide solution varied some during the test (see concentration variability in Figure 3.26). The $\mathrm{NaBr}$ solution was injected into the aquifer through the injection well (399-1-23) for 11.9 hours (714 minutes), yielding a total injection volume of $541,300 \mathrm{~L}(143,000 \mathrm{gal})$. Flow rates for the injection stream during the test were monitored using in-line turbine flow meters and continuously recorded on a data logger (see Figure 3.25).

Bromide concentrations were monitored in the injection stream and monitoring wells to determine the effected radial extent of the tracer plume during the test. Downhole ISE probes continuously monitored bromide concentrations in the wells during the test. A total of 256 aqueous samples were collected from the injection stream and surrounding monitoring wells and were analyzed in the field laboratory trailer for bromide ${ }^{-}$using an ISE probe. Specific conductance, dissolved oxygen, $\mathrm{pH}$, oxidation-reduction potential, and temperature were also measured using an in-line electrode in the sampling manifold. The ion chromatography (IC) analyses were conducted on each of the 256 archive samples at an offsite laboratory as an additional method of measuring bromide concentration. 
Table 3.10. Summary of Polyphosphate Treatability Test Site Tracer Injection Test

\begin{tabular}{ll}
\hline \multicolumn{1}{c}{ Test Parameter } & \multicolumn{1}{c}{ Value } \\
\hline Tracer Mass & $60.8 \mathrm{~kg}(134.0 \mathrm{lb})$ of sodium bromide $(\mathrm{NaBr})$ \\
\hline Concentrated Tracer Solution Volume & $26.3 \mathrm{gal}(99.6 \mathrm{~L})$ \\
Total Injection Rate & $200 \mathrm{gal} / \mathrm{min}(757 \mathrm{~L} / \mathrm{min})$ \\
\hline Concentrated Tracer Injection Rate & $2.2 \mathrm{gal} / \mathrm{hr}(0.14 \mathrm{~L} / \mathrm{min})$ \\
Make-Up Water from 399-1-7 Injection Rate & $200 \mathrm{gal} / \mathrm{min}^{-}$ \\
\hline Calculated Injection Concentration & $87 \mathrm{mg} / \mathrm{L} \mathrm{Br}{ }^{-}$ \\
Averaged Measured Injection Concentration & $93 \mathrm{mg} / \mathrm{L} \mathrm{Br}{ }^{-}$ \\
Injection Duration & $714 \mathrm{~min}(11.9 \mathrm{hr})$ \\
\hline Injection Volume & $142,600 \mathrm{gal}$ \\
\hline
\end{tabular}

Unit Abbreviations: $\mathrm{kg}=$ kilogram; gal = gallon; $\mathrm{L}=$ liter; $\min =$ minute; gal $/ \mathrm{min}=$ gallon per minute; $\mathrm{L} / \mathrm{min}=$ liter per minute; gal $/ \mathrm{hr}=$ gallon per hour; $\mathrm{mg} / \mathrm{L}=$ milligrams per liter

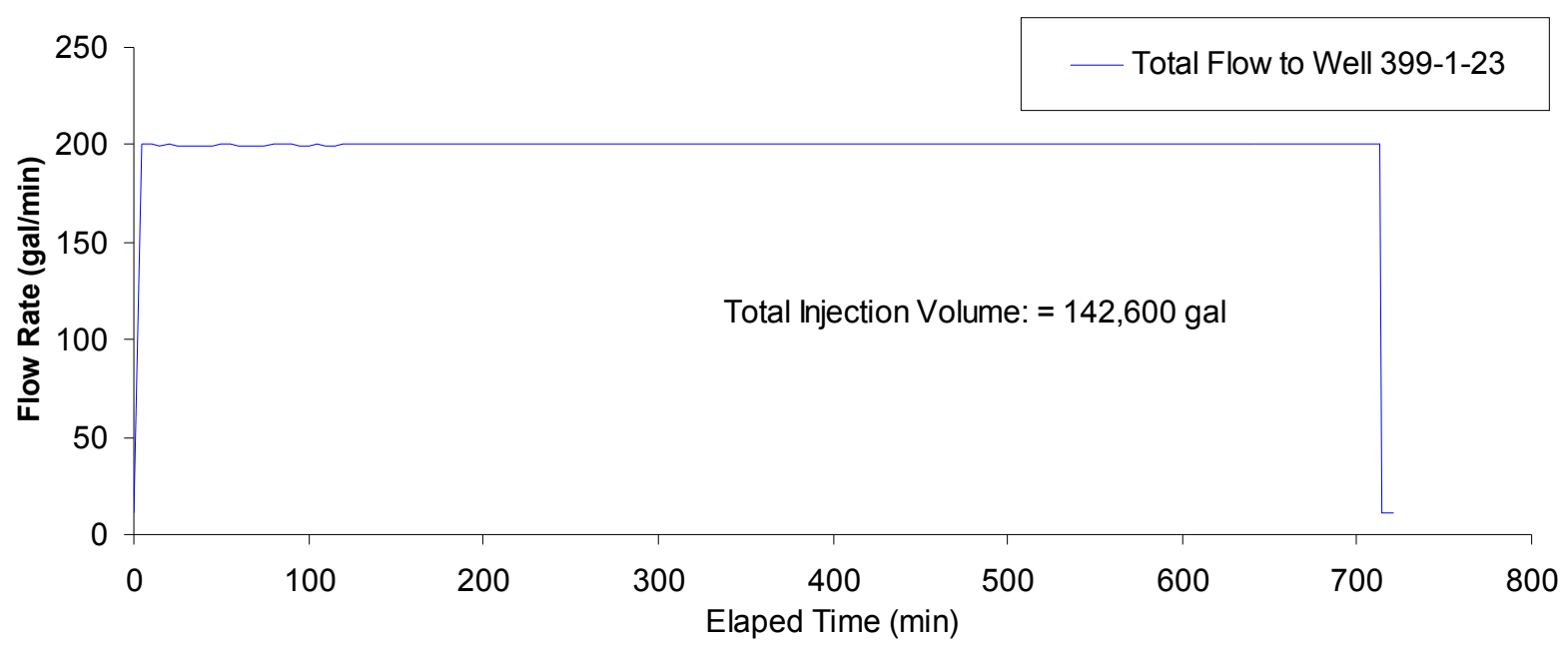

Figure 3.25. Flow Rate, Duration, and Total Injection Volume for Bromide Tracer Test at Polyphosphate Treatability Test Site on December 13, 2006 
a)

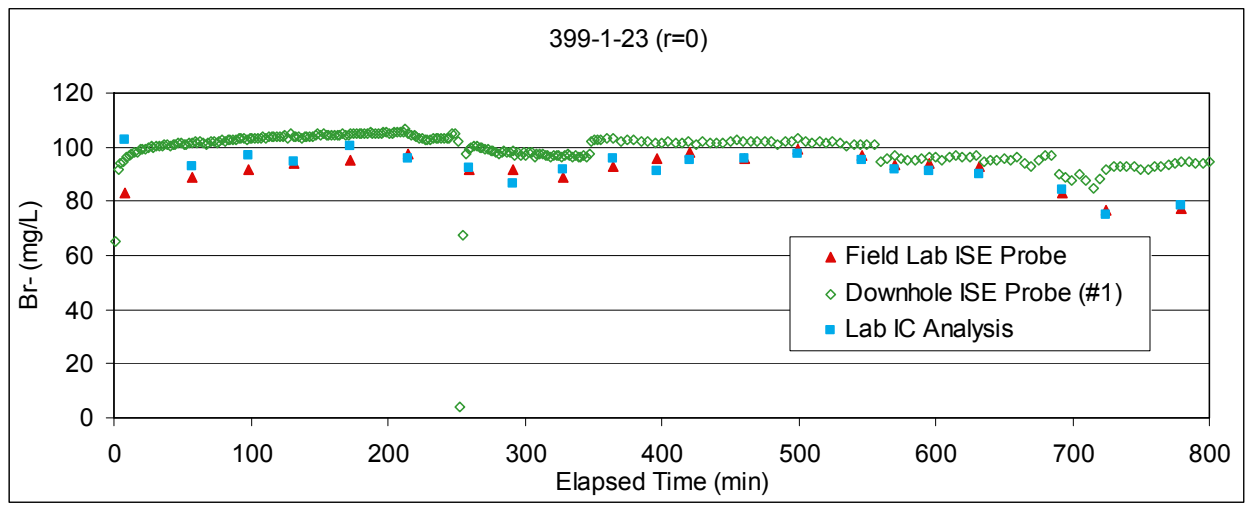

b)

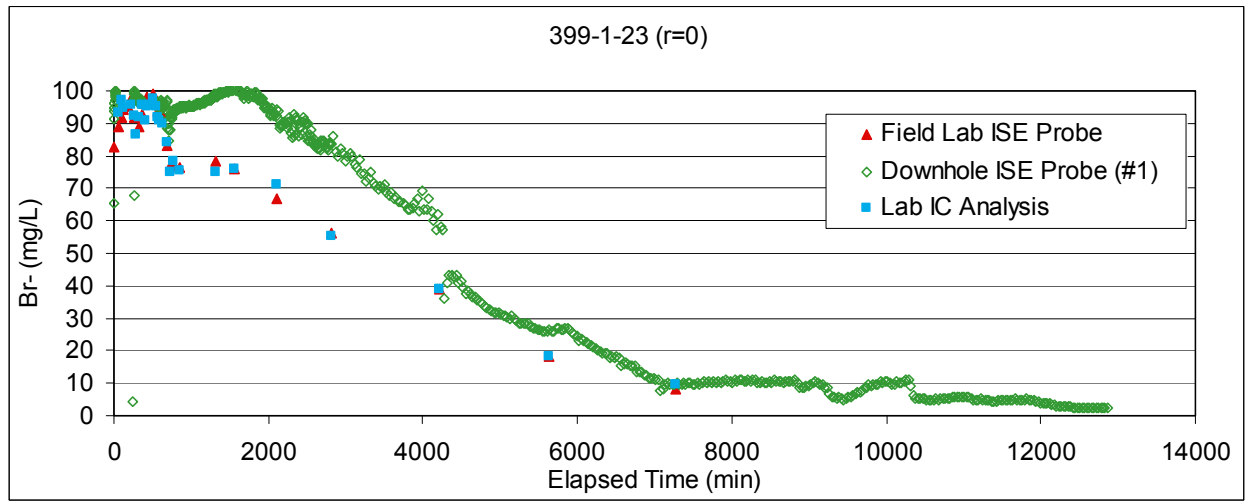

Figure 3.26. Bromide Concentrations for the Tracer Injection Stream During (a) the Injection Period of the Test ( $\mathrm{t}=0$ to $\mathrm{t}=714$ minutes) and (b) for Several Days After the Test, as Measured in the Injection Well. Bromide concentrations varied slightly during the test due to minor drift in the metering pump that required periodic adjustment.

\subsubsection{Tracer Test Results and Discussion}

The tracer injection test results provide information about aquifer heterogeneities, effective porosity, expected arrival times, and required solution volume for the polyphosphate injection. Bromide BTCs were constructed for all of the wells monitored during the test. The results will be discussed in two groups, wells within the targeted injection volume $(8.8 \mathrm{~m}[29 \mathrm{ft}]$ radial extent) and downgradient wells.

\section{Targeted Injection Volume Monitoring Wells}

Within the targeted injection volume, 50\% bromide concentration arrival times $\left(t_{50}\right)$ ranged from 16 to 428 minutes (Table 3.11). These results indicate a general correlation between tracer arrival time and radial distance from the injection well, with a few notable outliers. Four of the monitoring wells within the targeted injection volume are fully screened within the aquifer (Figure 3.11) and are useful for horizontal comparisons (Figure 3.27). Wells 399-1-26 (northwest of the injection well) and 399-1-31

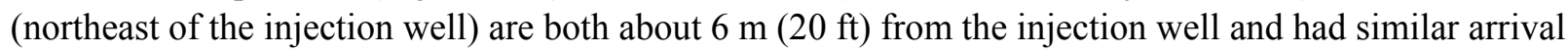
times of 111 and 90 minutes, respectively. Well 399-1-29, located on the perimeter of the targeted

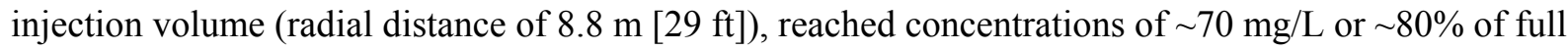
concentration, indicating that this location was near the outer extent of the injection pore volume in this radial direction. 
Well 399-1-30 is an outlier among the other fully screened wells within the targeted injection volume, showing a much quicker arrival time than the other wells ( $\mathrm{t}_{50}=16$ minutes). The observed early arrival at this location is most likely associated with formational heterogeneities resulting from a preferential flow path between the injection well and this monitoring well location.

Table 3.11. Bromide Tracer Injection Arrival Times and Porosity Results for Targeted Injection Volume Monitoring Wells

\begin{tabular}{cccccc}
\hline Well Name & $\begin{array}{c}\text { Well Screen } \\
\text { Zone }\end{array}$ & Radial Distance (ft) & $\begin{array}{c}50 \% \text { Tracer } \\
\text { Arrival (min) }\end{array}$ & $\begin{array}{c}\text { Average } \\
\text { Velocity } \\
(\mathrm{ft} / \text { day) }\end{array}$ & $\begin{array}{c}\text { Estimated Effective } \\
\text { Porosity }\end{array}$ \\
\hline $399-1-23$ & Full & 0 & - & - & - \\
$399-1-24$ & Upper & 14.9 & 124 & 168 & 0.32 \\
$399-1-25$ & Lower & 14.4 & 39 & 519 & 0.11 \\
$399-1-26$ & Full & 19.9 & 111 & 260 & 0.16 \\
$399-1-27$ & Lower & 24.5 & NA & NA & NC \\
$399-1-28$ & Upper & 24.9 & 216 & 162 & 0.20 \\
$399-1-29$ & Full & 29.6 & 165 & 254 & 0.20 \\
$399-1-30$ & Full & 14.8 & 16 & 1300 & NC \\
$399-1-31$ & Full & 19.6 & 90 & 316 & 0.13 \\
\hline & & & & Average $=0.19$ \\
\hline NC $=$ Not calculated due to uncharacteristic response. & & & \\
\hline
\end{tabular}


a)

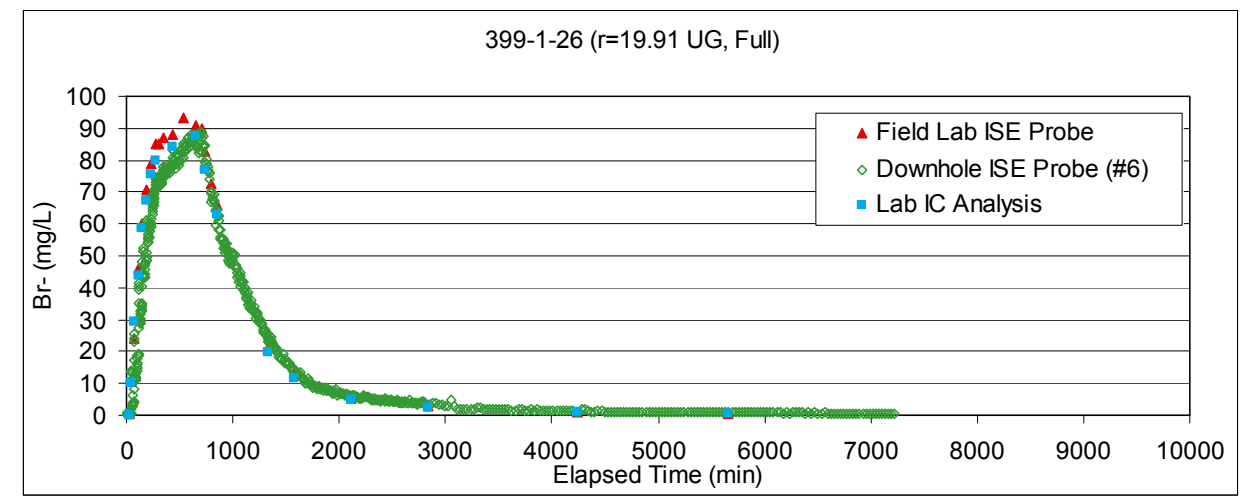

b)

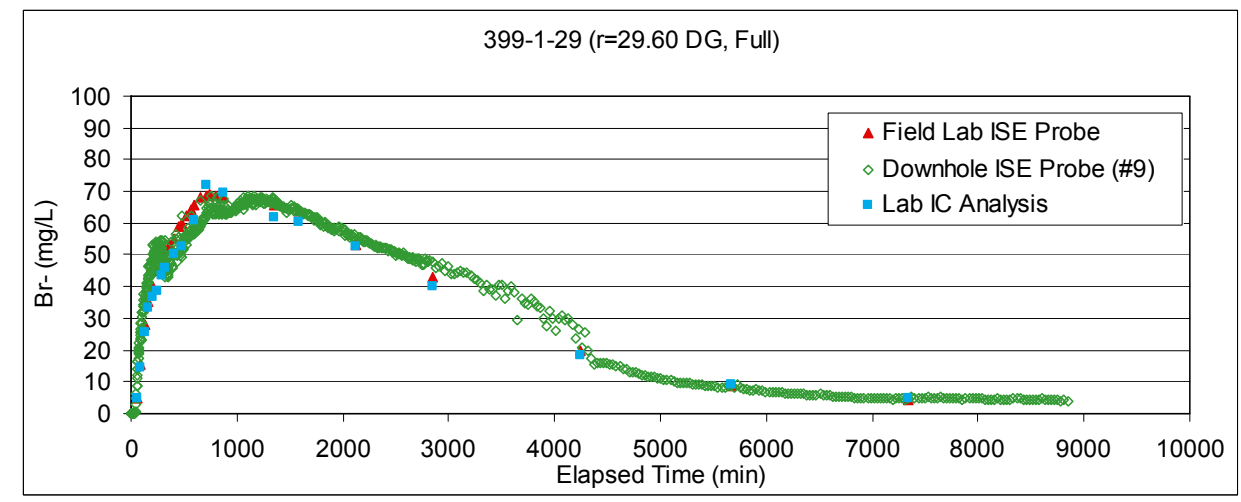

c)

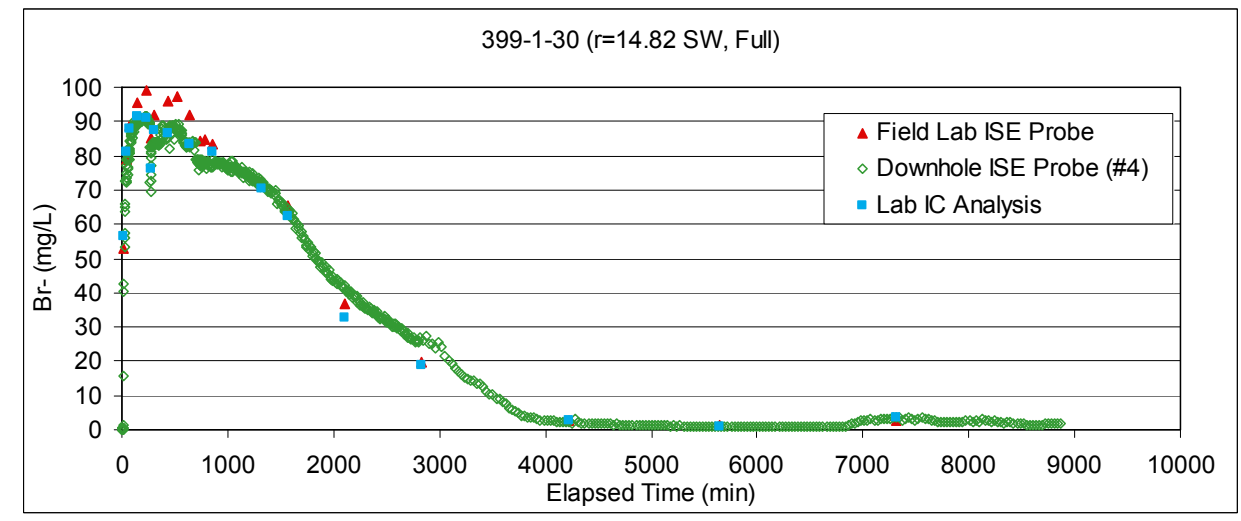

d)

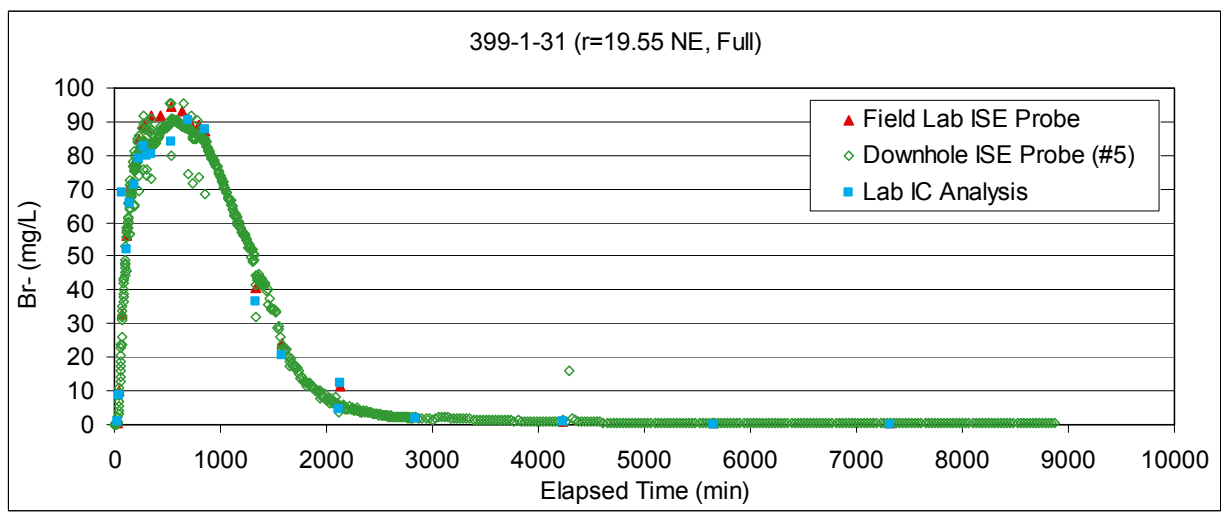

Figure 3.27. Breakthrough Curves Showing Bromide Concentrations Through Time for Fully Screened Wells Within the Targeted Injection Volume: a) 399-1-26, b) 399-1-29, c) 399-1-30, and d) 399-1-31 
Assessment of the vertical variability in bromide tracer arrival was possible by comparing the results of adjacent wells screened in upper and lower zones of the aquifer Figure 3.28). Two upper/lower screen well pairs were installed on the downgradient side of the targeted injection volume (Figure 3.11). The 399-1-24/399-1-25 well pair exhibited a similar peak concentration for both depth intervals but the 50\% tracer arrival in 399-1-25 occurred in one-third the time, indicating preferential flow within the lower portion of the aquifer between these two locations.

The other upper/lower screen well pair, 399-1-27 and 399-1-28, showed very different arrival responses for the two intervals. The tracer arrival and peak concentration for 399-1-28, screened in the upper aquifer zone, is similar to other wells within the targeted injection volume. However, bromide arrival response in well 399-1-27, which is screened in the lower zone, showed an unexpectedly slow arrival and low overall concentration at this monitoring location. The BTC shows that the peak bromide ${ }^{-}$ concentration in this well remained below $50 \%$ of the injection stream concentration over the duration of the injection (Figure 3.28). Sample purge times for well 399-1-27 were increased during the test to overcome any potential local skin effects in the well; however, this did not effectively increase tracer concentration in the samples. This response, in addition to the relatively low well yields provided by this lower zone monitoring well, suggests that the lower zone of the aquifer at this location is less transmissive than the upper zone at this location or the lower zone at the other well pair location. Although the observed variability in tracer arrival response at available upper and lower zone well pairs provides a indicator of the degree of formational heterogeneities within the wells field, no clear spatial correlations were apparent.

The tracer arrival times were used to estimate the effective porosity of the aquifer according to the following equation:

$$
n=\frac{t_{50} \cdot Q_{t o t}}{\pi \cdot r^{2} \cdot L \cdot 7.48}
$$

where $n=$ effective porosity

$t_{50}=50 \% \mathrm{Br}^{-}$concentration arrival time (minutes)

$Q_{t o t}=$ total injection rate $(200 \mathrm{gpm})$

$r=$ radial distance from the injection well (feet)

$L=$ aquifer thickness $(15 \mathrm{ft})$.

Effective porosities were calculated for each of the eight monitoring wells in the targeted injection volume, except for the two outlier wells (Table 3.11). Values ranged from 11 to $32 \%$ for the different wells, with an average effective porosity of $19 \%$. This value is consistent with porosity estimates from the LFI that were based on physical property analysis (Williams et al. 2007). 
a)

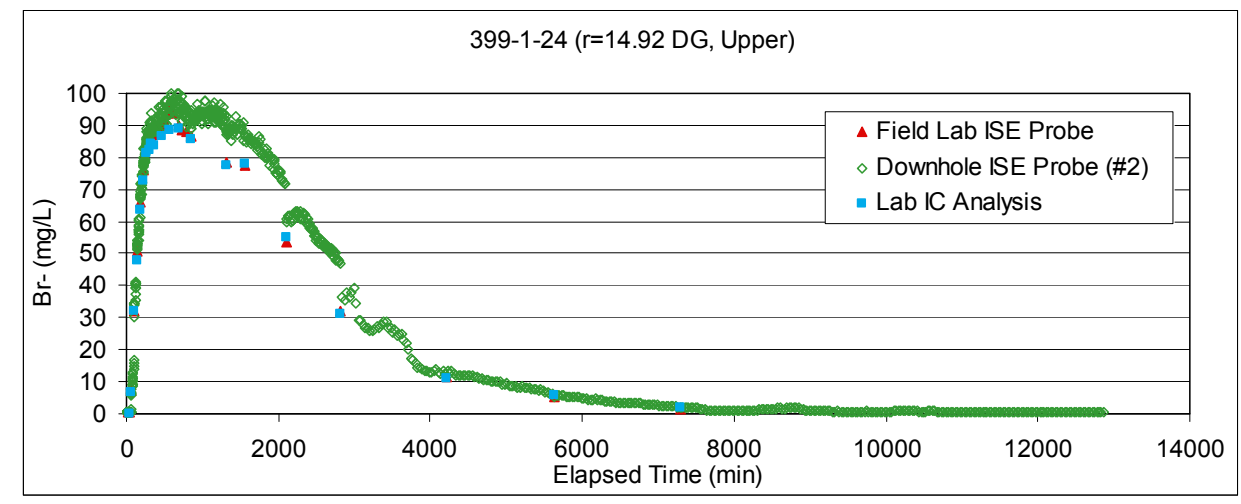

b)

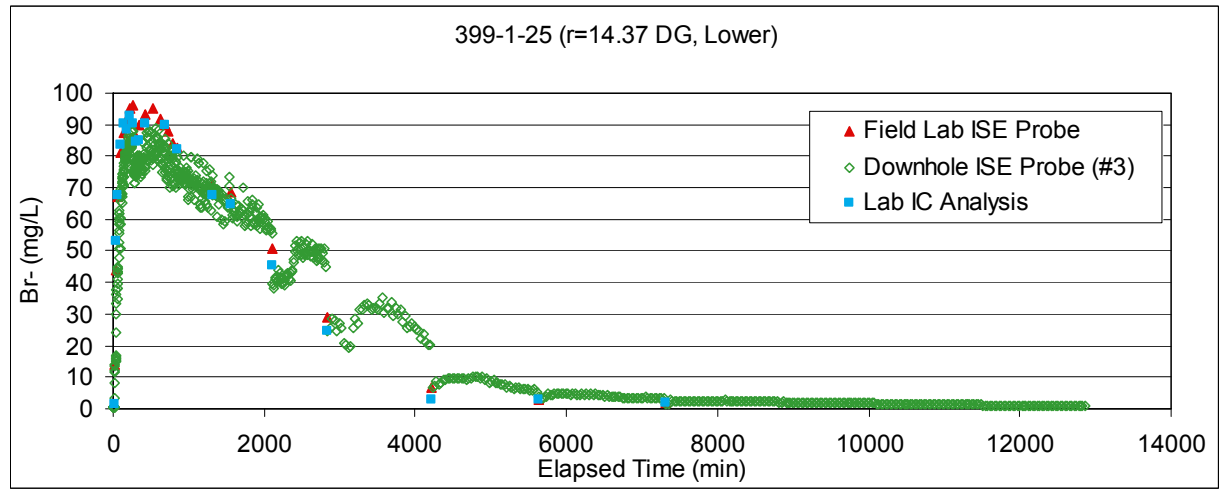

c)

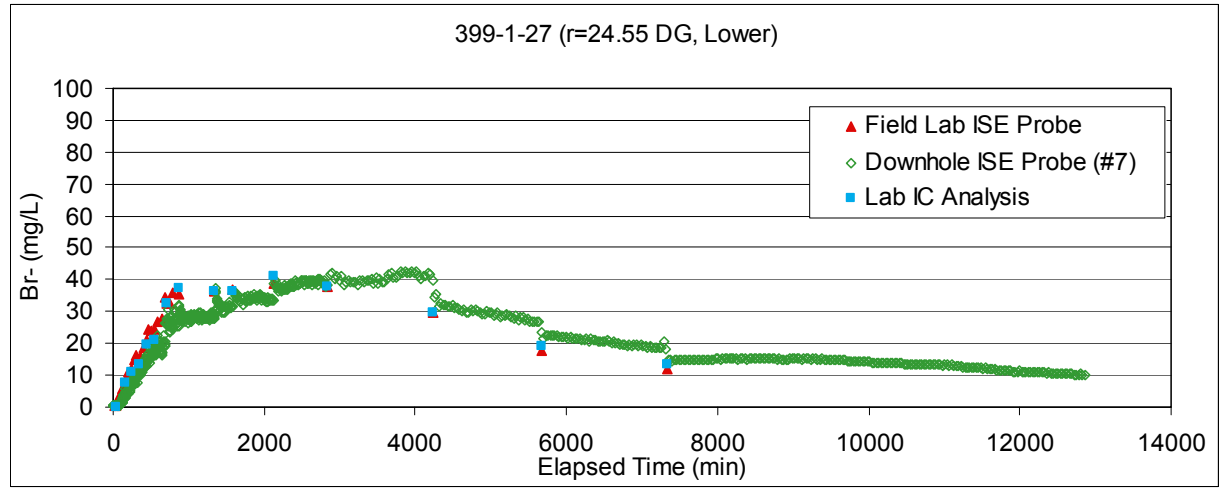

d)

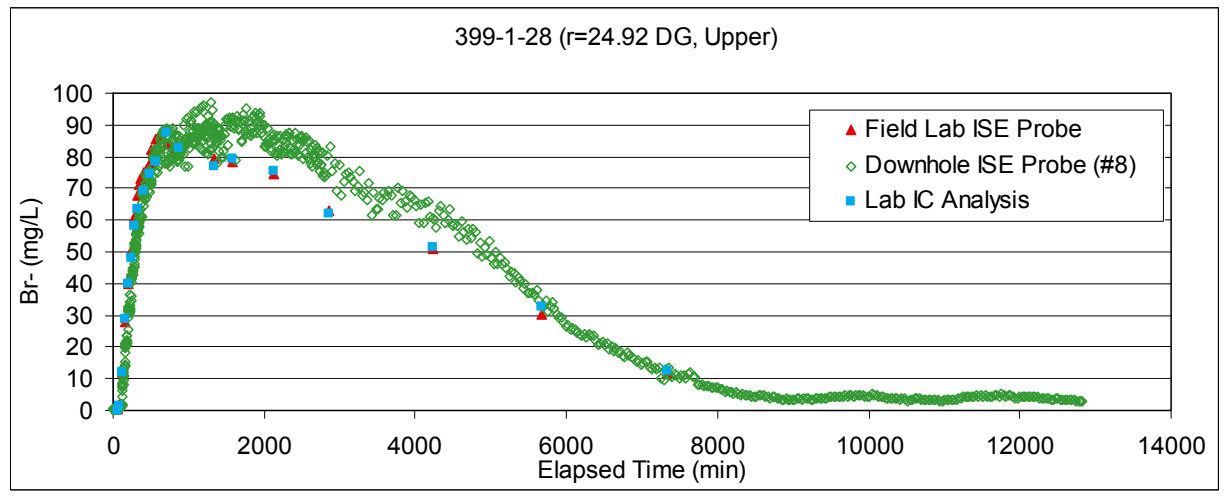

Figure 3.28. Breakthrough Curves Showing Bromide Concentrations Through Time for Wells Within the Targeted Injection Volume that Are Screened in Only the Upper or Lower Zones of the Aquifer: a) 399-1-24, b) 399-1-25, c) 399-1-27, and d) 399-1-28 


\section{Downgradient Monitoring Wells}

Several monitoring wells are located downgradient from the injection well beyond the radial extent of the targeted injection volume (Figure 3.29). These include wells 399-1-32 and 399-1-7, located 104 and 617 feet from the injection well, respectively. By combining the results from the bromide tracer drift with water-level measurements, and the resulting hydraulic gradient calculations, it is possible to estimate hydraulic conductivity $(K)$ according to Darcy's Law:

$$
\begin{gathered}
v=\frac{K}{n} \cdot \frac{d h}{d x} \\
K=\frac{v \cdot n}{\frac{d h}{d x}}
\end{gathered}
$$

where $K=$ hydraulic conductivity (ft/day)

$v=$ groundwater velocity based on the tracer arrival time (ft/day)

$n=$ average effective porosity from the tracer arrival times (19\% from above)

$\mathrm{dh} / \mathrm{dx}=$ time-weighted average hydraulic gradient during tracer transport $(\mathrm{ft} / \mathrm{ft})$.

The BTC for well 399-1-32 (Figure 3.29) shows an early arrival response in the tracer concentration data ahead of the main peak arrival, indicating the presence of formational heterogeneities that result in a faster flow path between the injection well and this location that could not be explained by transport through a homogeneous porous media. For this reason, hydraulic conductivities were estimated for both the interpreted preferential flow path resulting in an early tracer arrival and the bulk porous media attributed to transport of the main plume body.

For the main tracer plume arrival at well 399-1-32, the groundwater velocity was estimated at $\sim 15.24 \mathrm{~m}(50 \mathrm{ft})$ per day during tracer transport, based on a radial distance of $31.69 \mathrm{~m}(104 \mathrm{ft})$ and a tracer transport duration of $\sim 3000$ minutes (Table 3.12). The tracer drift duration was defined as the time period between the end of the test when the tracer plume was centered over the injection well $(t=714$ minutes $)$ and the arrival time of the center of mass at 399-1-32 $(t=\sim 3,700$ minutes $)$. The time-weighted average gradient during tracer transport between the injection well and 399-1-32, as determined from water-level measurements, was $\sim 6.5 \mathrm{E}-4 \mathrm{ft} / \mathrm{ft}$. The estimated hydraulic conductivity using these parameters is about $4300 \mathrm{~m}(14,000 \mathrm{ft})$ per day.

The fast-path hydraulic conductivity was calculated using the same equation used for the main tracer plume, but with some notable differences in the sources of the parameter values. For example, the time-weighted average hydraulic gradient was calculated using wells other than the injection well. The gradient observations between the injection well and well 399-1-32 would not be representative of the true spatially distributed gradient between the two wells because the gradient would likely be artificially high due to the inherent well inefficiencies in the injection well. To avoid this biasing, gradients were calculated using head data from wells transverse to the injection well (wells 399-1-30 and 399-1-31). Because the fast-path tracer arrival at well 399-1-32 occurred during the injection phase of the test, the transport duration was defined as the time between the beginning of the injection test $(\mathrm{t}=0)$ and the $50 \%$ tracer concentration arrival time at well 399-1-32 $(\mathrm{t}=\sim 930)$. The calculated groundwater velocity estimate based on this arrival time and the radial distance to the injection well is $\sim 48.76 \mathrm{~m}$ (160 ft) per 
day. These parameters resulted in fast-path hydraulic conductivity estimates of 6705 and $7010 \mathrm{~m}(22,000$ and 23,000 ft) per day based on gradients measured from wells 399-1-31 and 399-1-30, respectively, which is almost two times the hydraulic conductivity estimate based on transport of the bulk tracer plume.

a)

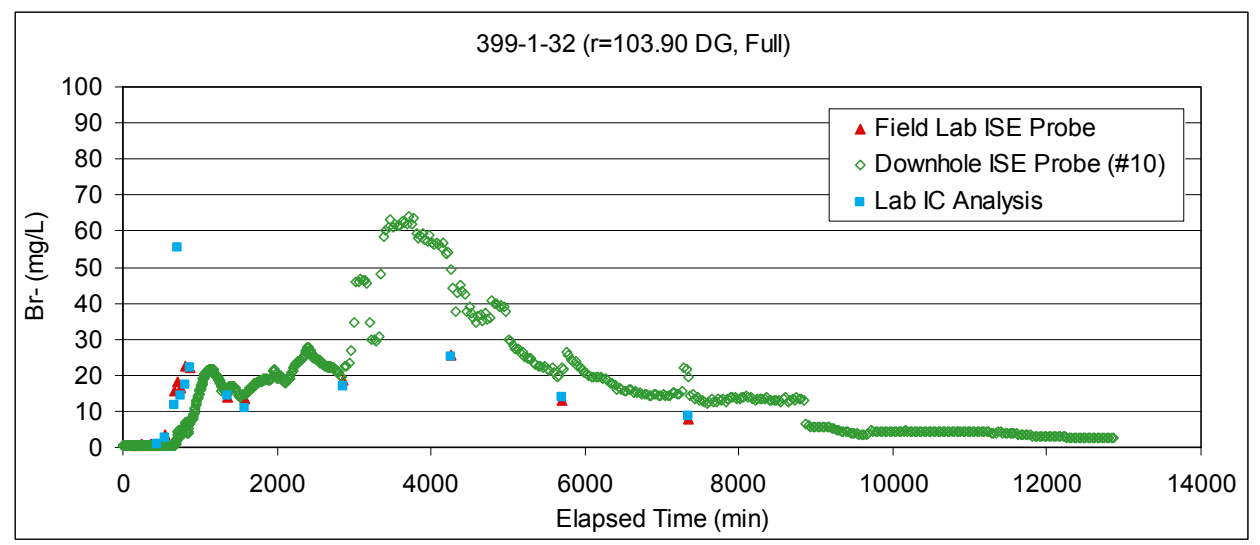

b)

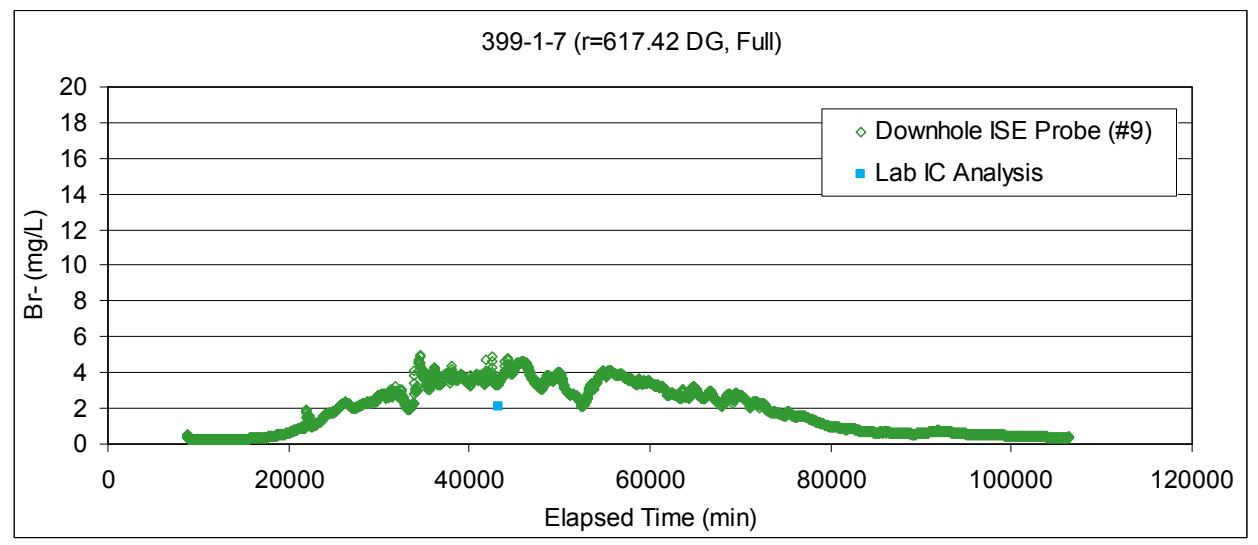

Figure 3.29. Breakthrough Curves Showing Bromide Concentrations Through Time for Downgradient Wells a) 399-1-32 and b) 399-1-7

Table 3.12. Summary of Parameters Used to Estimate Hydraulic Conductivity Between Injection Well 399-1-23 and Downgradient Well 399-1-32 for the Main Body of Tracer

\begin{tabular}{cccccc}
\hline $\begin{array}{c}\text { Time }_{\text {start }}{ }^{(\mathrm{a})} \\
\text { (elapsed } \\
\text { minutes) }\end{array}$ & $\begin{array}{c}\text { Time }_{\text {end }}{ }^{(\mathrm{b})} \\
\text { (elapsed } \\
\text { Minutes) }\end{array}$ & $\begin{array}{c}\text { Transport } \\
\text { Duration }^{(\mathrm{c})} \\
\text { (minutes) }\end{array}$ & $\begin{array}{c}\text { Groundwater } \\
\text { Velocity (ft/day) }\end{array}$ & $\begin{array}{c}\text { Time-weighted } \\
\text { Average Hydraulic } \\
\text { Gradient (ft/ft) }\end{array}$ & $\begin{array}{c}\text { Hydraulic } \\
\text { Conductivity } \\
\text { (ft/day) }\end{array}$ \\
\hline 714 & $\sim 3700$ & $\sim 3000$ & $\sim 50$ & $\sim 6.5 \mathrm{E}-4$ & $\sim 14,000$ \\
\hline
\end{tabular}

(a) Time when tracer plume was centered on injection well 399-1-23. This was the end of the test.

(b) Time when tracer plume arrives at 399-1-32.

(c) Time duration of tracer transport between injection well 399-1-23 and 399-1-32; defined as Time end $_{-}-$Time $_{\text {start }}$. Note: An effective porosity value of $18 \%$ was used in calculating the hydraulic conductivity estimate.

The BTC for well 399-1-7, the more distant downgradient monitoring well (radial distance $=188 \mathrm{~m}$ $[617 \mathrm{ft}]$ ), shows much more dispersed tracer plume arrival (Figure 3.29). The fist arrival of the tracer occurred after $\sim 12$ days $(17,280$ minutes $)$ and steadily increased in concentration to a maximum of about 
$5 \mathrm{mg} / \mathrm{L}$ around the 30-day mark (43,200 minutes). Although first arrival of the tracer plume at this location is generally consistent with the $15.24-\mathrm{m}(50-\mathrm{ft})$ per day velocity calculated from the well 399-1-32 tracer arrival data (i.e., $188 \mathrm{~m}$ [617 ft] in 12 days or $\sim 15.24 \mathrm{~m}$ [50 ft] per day), the dispersed nature of this arrival response and the variability in groundwater velocity and flow direction over the relatively long travel path preclude a quantitative velocity or hydraulic conductivity estimate using these data.

Overall, the results from the bromide tracer injection test present some important information for design of the future polyphosphate treatability test. For example, the 541,313 L (143,000 gal) injected during the tracer test appears to be a suitable volume to impact the full 9-m (30-ft) radial extent of the targeted tracer injection volume. Even well 399-1-32, located $31.69 \mathrm{~m}(104 \mathrm{ft})$ downgradient from the injection well, received over $70 \%$ tracer concentration after a two-day drift period. The test results also suggest there are heterogeneities in the aquifer that affect groundwater transport within and downgradient of the targeted treatment zone. Results from wells 399-1-27 and 399-1-29, when viewed in comparison to results from the other wells, indicate that there is a less permeable zone in the lower part of the aquifer in the vicinity of well 399-1-27. However, it is not clear from these results just how laterally extensive this zone is. The porosity estimate of $19 \%$, calculated using the arrival times in the targeted treatment zone, is consistent with other reported values (Williams et al. 2007). Lastly, the equipment and sampling methods and intervals used in the tracer test were successful and were determined to be suitable for the polyphosphate injection test.

The simplified approach for evaluation of tracer injection and transport data discussed in this section provides for a reasonable estimate of treatability test-scale transport properties and forms the basis for a more technically rigorous evaluation. Additional discussion regarding evaluation of the tracer injection data using a local-scale flow and transport model is provided in Section 3.3.

\subsubsection{Hydraulic Testing}

This section describes analysis of pressure buildup data collected during the bromide tracer injection test and slug withdrawal tests conducted in several of the site monitoring wells prior to the tracer test. As discussed in Section 6.3, operation of the tracer test involved injecting a large volume of water at a constant rate into well 399-1-23. Water levels in nearby monitoring wells responded to this injection in small but discernible buildups in pressure, which were analyzed using constant-rate pumping test analysis methods. Because water levels in monitoring wells also respond to changes in river stage, resulting in pressure changes of similar magnitude as those attributed to hydraulic test response, pressure data were first corrected to remove this effect. The correction made to the pressure buildup data is described below, followed by a discussion of the hydraulic analysis results.

\subsubsection{River Response Correction}

Given their proximity to the river, all of the wells within the polyphosphate treatability test site monitoring network respond to changes in Columbia River stage. As reported previously (Vermeul et al. 2007), distinct cycles of river stage fluctuations can be visually correlated to their resulting timelagged and attenuated pressure responses in polyphosphate wells located about 300 meters from the river (Figure 3.30). A preliminary analysis indicated that the initial well response is delayed an average of 6 hours and attenuated to about 5\% of the river fluctuation during the December 2006 tracer injection test 
period. Based on the observed visual correlation, a simplified correction method involving constant delay and attenuation factors was implemented to remove the river signal from the pressure buildup response during the bromide tracer test (Vermeul et al. 2007). This approach was less effective for the longer-duration pressure recovery response following the termination of the June 2007 polyphosphate injection, and a more robust correction method was explored. The correction method was much more effective in removing river effects, and subsequently was used on both the December 2006 and June 2007 pressure response datasets. A summary of this method is described below.

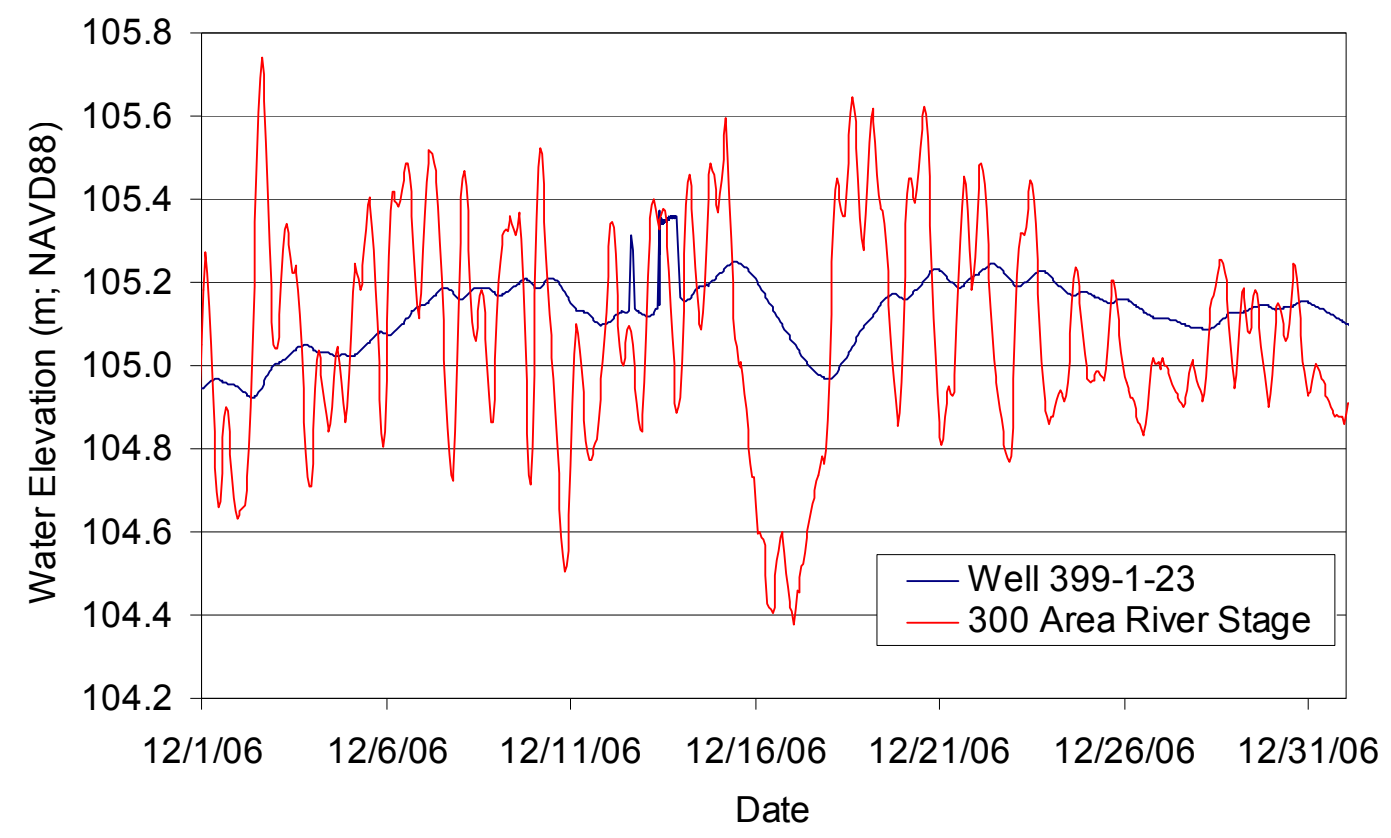

Figure 3.30. Columbia River Hydrograph and Water-Level Data for Well 399-1-23 During December 2006.

The multiple regression deconvolution (MRD) method of Rasmussen and Crawford (1997) was used to correct for river stage effects. It is a statistically based method used to remove transient barometric pressure and earth-tide effects on well water levels (e.g., Spane 1999 and 2000; Toll and Rasmussen 2007). An evaluation of this methodology indicated that it was also an effective approach for correcting river effects. The method involves regressing changes in well water-level elevations against multiple time-lagged changes in river elevations to determine a river-well response function, which is then used to correct for river stage effects.

River stage and water elevation from well 399-1-23 from August to December 2006 were used as the model "training" data for defining a representative response function that could be applied to all of the wells. Well 399-1-23 was the only well for which pre-tracer test water-level data were available, and it was assumed to have a similar river-well response as the other polyphosphate wells. This assumption was verified based on close similarities in the response functions among the polyphosphate wells for periods of time when data exist for all of the wells. Water table conditions were similar during these two time periods, both in the overall average water table elevation and the frequency and magnitude of river stage variability. The Columbia River elevation in the 300 Area, collected under the Hanford Automated Water Level Network, was used for river stage data. 
The river-well response function for well 399-1-23 displays an increase in well water-level response with increasing time lag or delay (Figure 3.31). As the Columbia River stage fluctuates up and down, a hydraulic pressure response is transmitted through the aquifer inland toward the location of the wells. For a unit step change in river elevation, the time delay and attenuation of the transmitted pressure signal is a function of multiple factors. Primary factors include inland distance from river, hydraulic properties of the aquifer between the river and the well, well construction, antecedent hydrologic conditions of the river and aquifer, and the nature of river fluctuations in the time and frequency domain. The relative role of these and other controlling factors was not explored in this analysis. The MRD method looks only at the statistical relation between two related variables, in this case the river and the well water-level elevations.

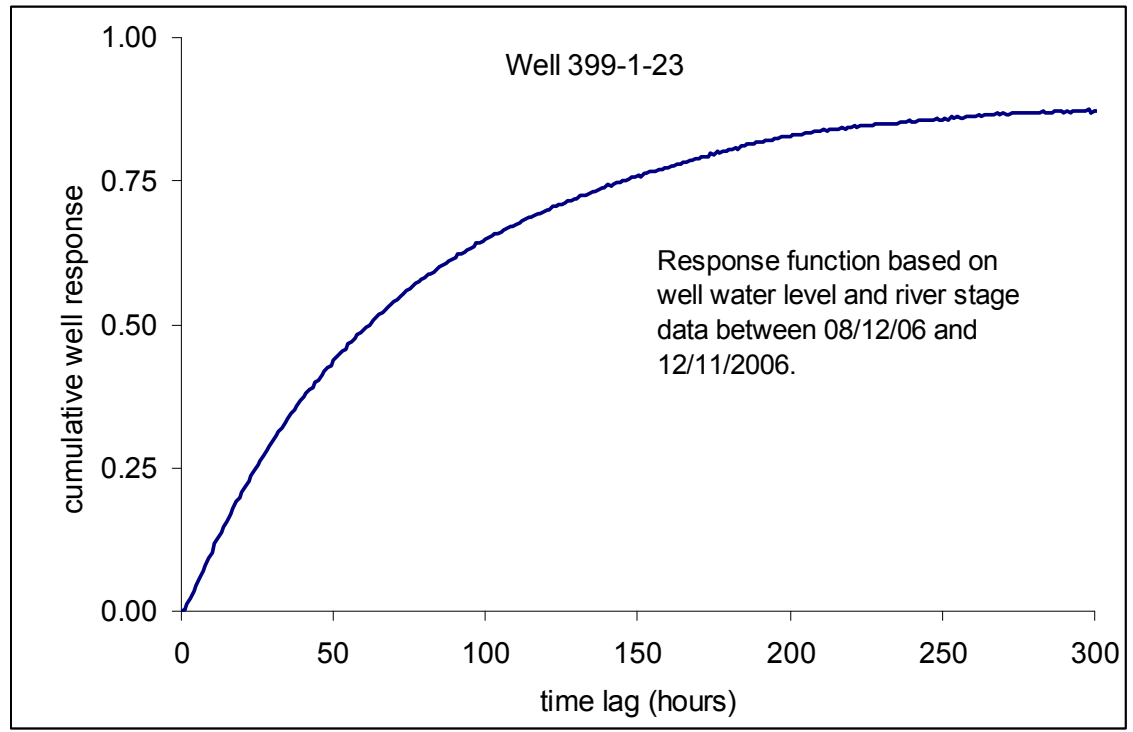

Figure 3.31. River-Well Response Function for Well 399-1-23 Based on Data Collected Between August and December 2006.

The response function for well 399-1-23 was then used to model the predicted water levels for each of the monitoring wells. The goodness-of-fit for the predicted versus the observed water levels for several weeks leading up to the tracer test is illustrated in Figure 3.32(a). In general, there was very good agreement between the predicted and the observed water levels $\left(r^{2}=0.99\right)$, and the corrected well water levels show significantly less fluctuation due to the river. Some of the high-frequency fluctuations are not fully corrected and there are periods of slight overcorrection, but despite these, it appears that the MRD correction method was very effective at removing the river signal. Figure 3.32(b) shows the observed, predicted, and corrected water levels for well 399-1-31 during the December 2006 tracer injection test, which is representative of the other wells used to analyze the pressure buildup. This figure illustrates the importance of removing river-related water-level impacts prior to analyzing hydraulic test data. The uncorrected (observed) water levels indicate a much higher apparent pressure buildup than do the river-corrected water levels. Analyzing the uncorrected data, which would effectively attribute river-induced pressure changes to the applied hydraulic stress, would in this case result in a significant underestimation of aquifer transmissivity. 
(a)
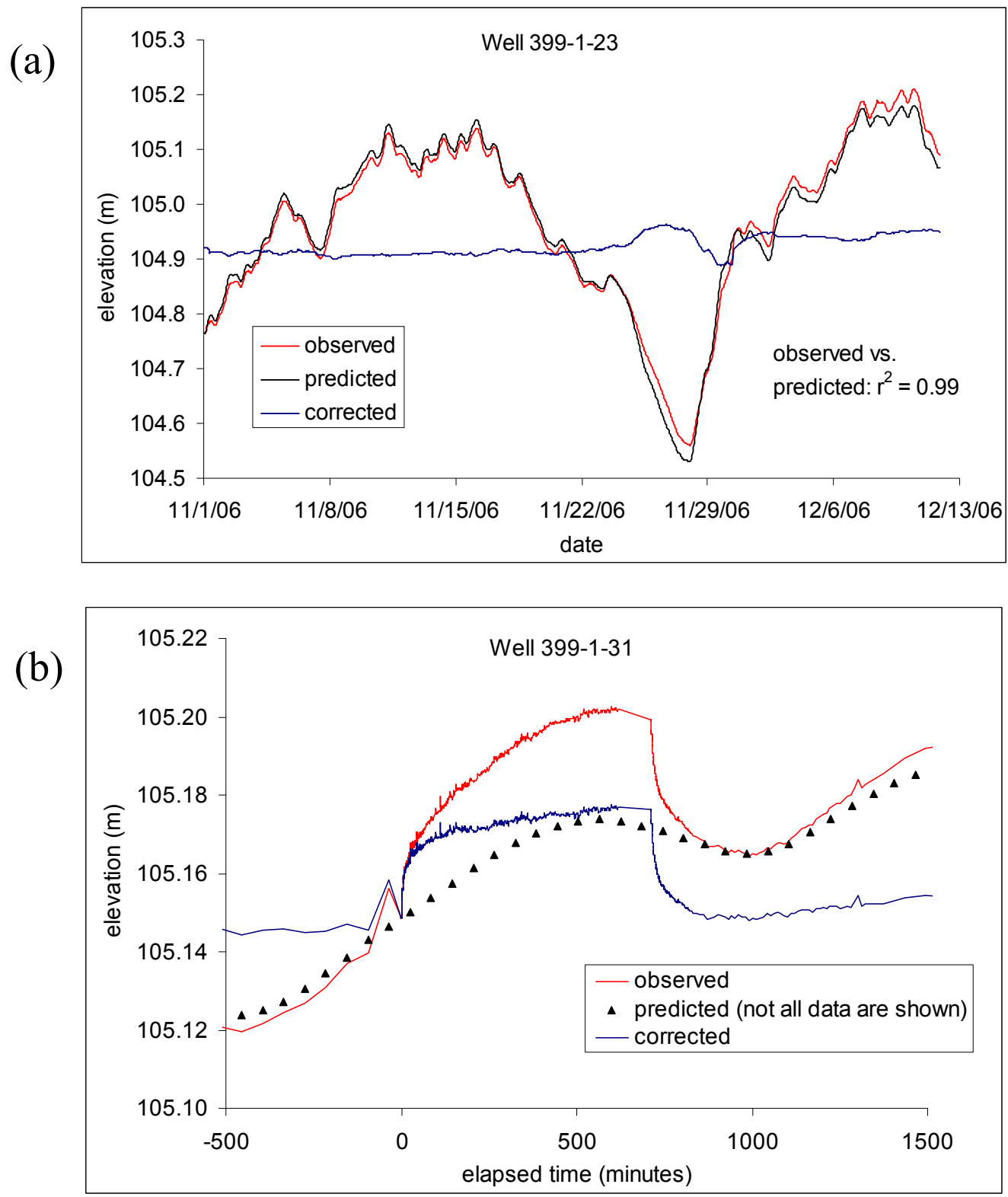

Figure 3.32. Predicted, Observed, and River-Corrected Water Levels for Well 399-1-23 Prior to the December 2006 Tracer Injection Test (a) and Well 399-1-31 During the Test (b)

\subsubsection{Hydraulic Test Analysis}

Pressure buildup data collected during the 11.9-hour tracer injection test, which was conducted at a constant rate and can be analyzed using the same analytical techniques for analyzing constant rate discharge tests (i.e., pumping tests), was used to provide local-scale estimates of hydraulic properties for the Hanford formation at this site. Test response data were analyzed using AQTESOLVE Pro, a software package developed by HydroSOLVE, Inc. The analytical approach used is a solution developed by Neuman (1975) for pumping test response in an unconfined, anisotropic aquifer, which incorporates the "delayed yield" effect associated with unconfined aquifers. The method can be used for either fully or partially penetrating wells and assumes the aquifer is homogeneous and infinite in extent. 
Although the heterogeneities observed in the tracer arrival data (Section 3.2.2) indicate that the requirements for homogeneous aquifer conditions were not fully met for the Hanford unconfined aquifer beneath the polyphosphate treatability test site, this analytical technique can still be used to provide quantitative estimates of hydraulic properties and to provide insight into the spatial variability of hydraulic properties at the site.

In general, most of the monitoring wells located within the targeted treatment zone showed relatively low pressure buildups, which is indicative of a highly transmissive aquifer (Table 3.13). The upper and lower screen well pairs had very similar responses. Hydraulic response at wells 399-1-29 and 399-1-31 were the outliers among the group. The pressure buildup responses in these two wells were considerably less than the other six monitoring wells nearby (Table 3.13 and Figure 3.33). Hydraulic response at these two wells are likely impacted by formation heterogeneities, and due to these non-ideal test conditions, were not analyzed to obtain hydraulic property estimates. The composite responses from the other six monitoring wells were used to estimate an average hydraulic conductivity within the treatment zone (Figure 3.33).

Table 3.13. Results from Pressure Buildup During the 2006 Bromide Tracer Injection Test

\begin{tabular}{cccccc}
\hline Well Name & $\begin{array}{c}\text { Well Screen } \\
\text { Zone }\end{array}$ & $\begin{array}{c}\text { Radial Distance } \\
(\mathrm{ft})\end{array}$ & $\begin{array}{c}\text { Total Pressure Buildup } \\
\left(\mathrm{ft} \mathrm{H}_{2} \mathrm{O}\right)\end{array}$ & \multicolumn{2}{c}{ Hydraulic Conductivity* } \\
\cline { 5 - 6 }$(\mathrm{ft} / \mathrm{day})$ & $(\mathrm{m} /$ day $)$ \\
\hline $399-1-24$ & Upper & 14.9 & 0.14 & $1.2 \mathrm{E}+04$ & $3.7 \mathrm{E}+03$ \\
$399-1-25$ & Lower & 14.4 & 0.14 & $1.2 \mathrm{E}+04$ & $3.7 \mathrm{E}+03$ \\
$399-1-26$ & Full & 19.9 & 0.11 & $1.4 \mathrm{E}+04$ & $4.1 \mathrm{E}+03$ \\
$399-1-27$ & Lower & 24.5 & 0.13 & $1.1 \mathrm{E}+04$ & $3.5 \mathrm{E}+03$ \\
$399-1-28$ & Upper & 24.9 & 0.10 & $1.5 \mathrm{E}+04$ & $4.5 \mathrm{E}+03$ \\
$399-1-29$ & Full & 29.6 & 0.06 & & ND \\
$399-1-30$ & Full & 14.8 & 0.13 & $1.3 \mathrm{E}+04$ & $3.9 \mathrm{E}+03$ \\
$399-1-31$ & Full & 19.6 & 0.09 & \multicolumn{2}{c}{ ND } \\
& & Average & 0.11 & $1.3 \mathrm{E}+04$ & $3.9 \mathrm{E}+03$ \\
& & S.D. & 0.03 & $1.2 \mathrm{E}+03$ & $3.7 \mathrm{E}+02$ \\
\hline
\end{tabular}

*Aquifer thickness $=14.8 \mathrm{ft}(4.5 \mathrm{~m})$

$\mathrm{ND}=$ Not determined

Representative examples of the observed pressure buildup and type-curve fits are shown in Figures 3.34 through 3.36 for a fully screened well (399-1-26) and one of the upper/lower zone well pairs (399-1-24 and 399-1-25, respectively). These plots show the pressure buildup and buildup derivative data plotted along with the Neuman (1975) type curves and include a summary of model inputs. Plots for the remaining wells are contained in Appendix A.

The Neuman type-curve analyses resulted in an average hydraulic conductivity (K) estimate of $\sim 4000 \mathrm{~m}$ $(13,000 \mathrm{ft}$ ) per day per day (Table 3.13). The specific yield was prescribed at 0.19 to be consistent with the effective porosity estimate obtained from the tracer arrival data (Table 3.11) and the anisotropy ratio was set at 0.01 , which provided an improved goodness of fit to early- to intermediate-time data. Although 
this anisotropy value is lower than is usually specified for the Hanford formation, it is within the typical range of values used for layered alluvial and glaciofluvial aquifers, and was considered appropriate given the level of heterogeneity indicated for the Hanford formation at this site. It should also be noted that the transmissivity estimate was relatively insensitive to this parameter. The storativity (S) was prescribed at 1E-06 for the final type-curve fits; however, the analysis showed identical fits when using S values as low as $1 \mathrm{E}-03$, demonstrating the insensitivity of the solution to this parameter. The aquifer thickness was $14.8 \mathrm{ft}(4.5 \mathrm{~m})$ during the tracer injection test.

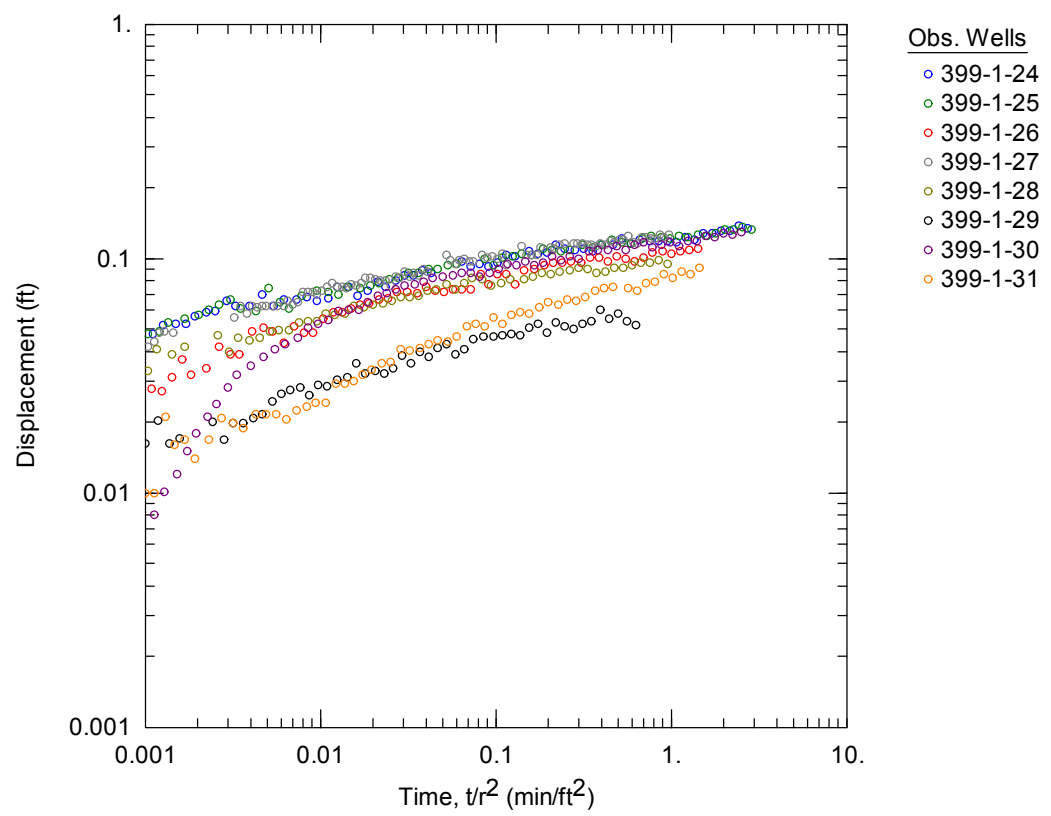

Figure 3.33. Composite Plot of Pressure Buildup Data for all Eight Monitoring Wells During the Tracer Injection Test

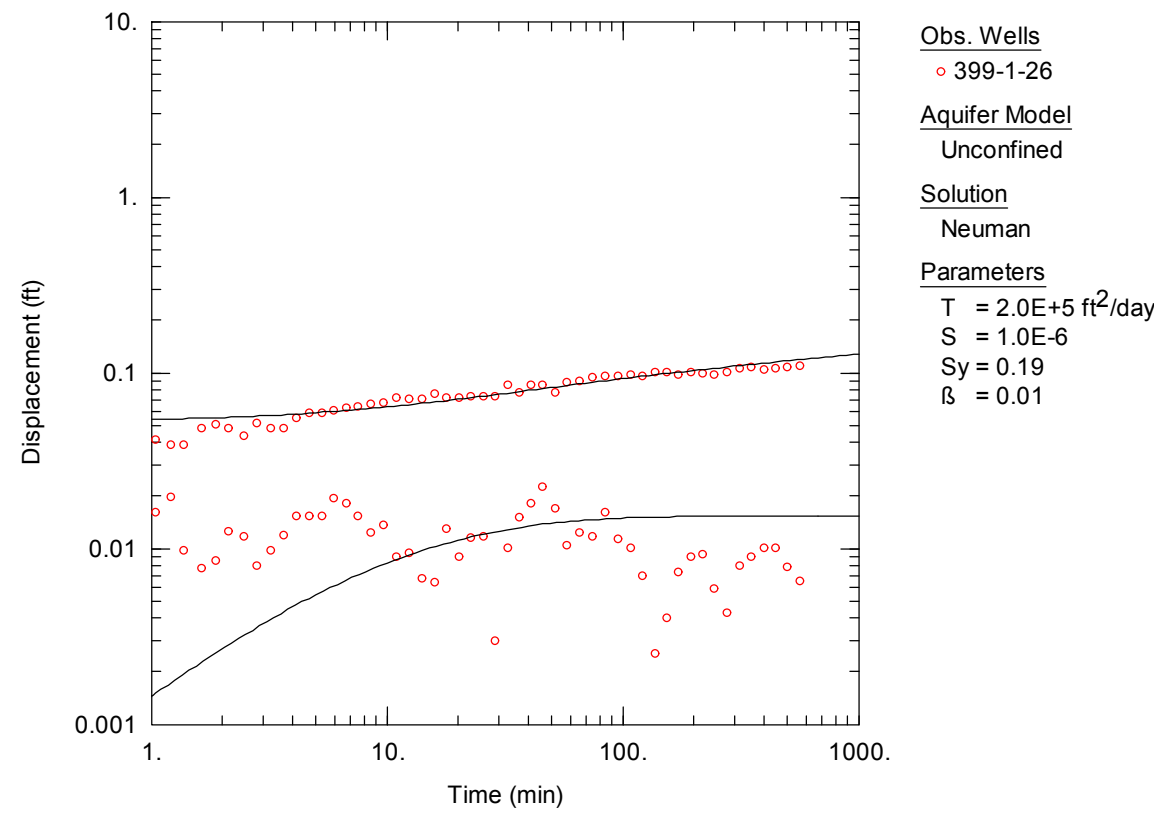

Figure 3.34. Neuman Type-Curve Analysis of Pressure Buildup Data at the Fully Screened Well 399-1-26 During the Tracer Injection Test. Note that $\mathrm{K}=\mathrm{T} /$ Aquifer Thickness. 


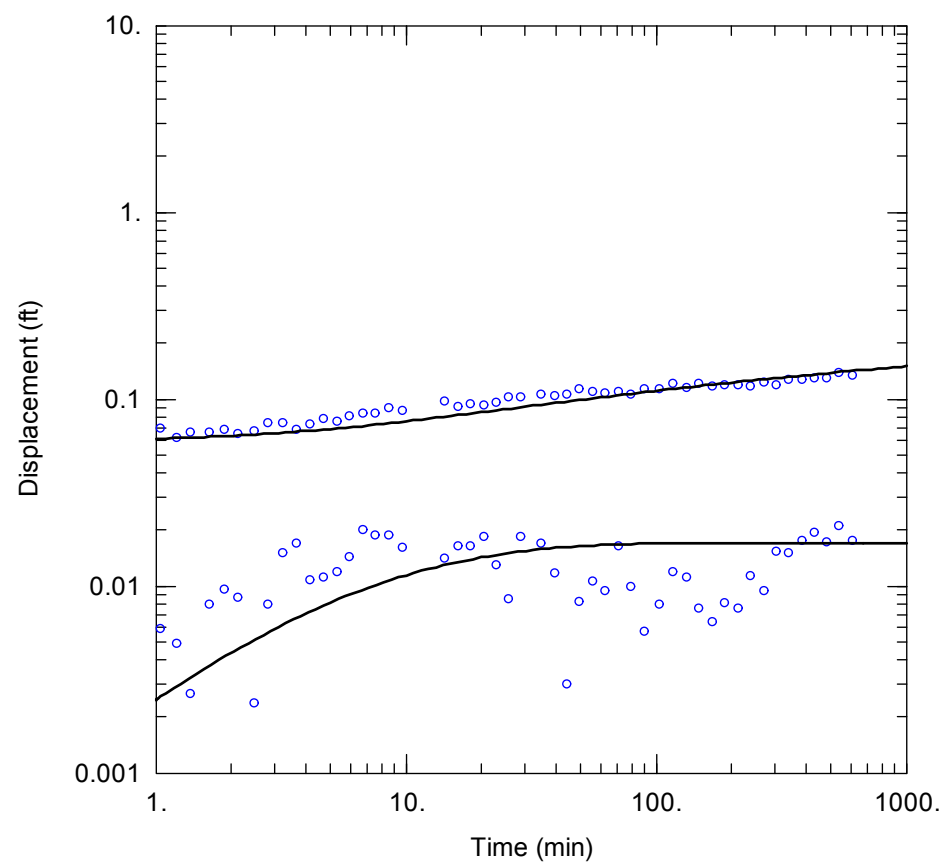

Obs. Wells

- 399-1-24

Aquifer Model

Unconfined

Solution

Neuman

Parameters

$T=1.8 \mathrm{E}+5 \mathrm{ft}^{2} /$ day

$S=1.0 \mathrm{E}-6$

Sy $=0.19$

$\beta=0.01$

Figure 3.35. Neuman Type-Curve Analysis of Pressure Buildup Data at the Upper-Screened Well 399-1-24 During the Tracer Injection Test. Note that $\mathrm{K}=\mathrm{T} /$ Aquifer Thickness.

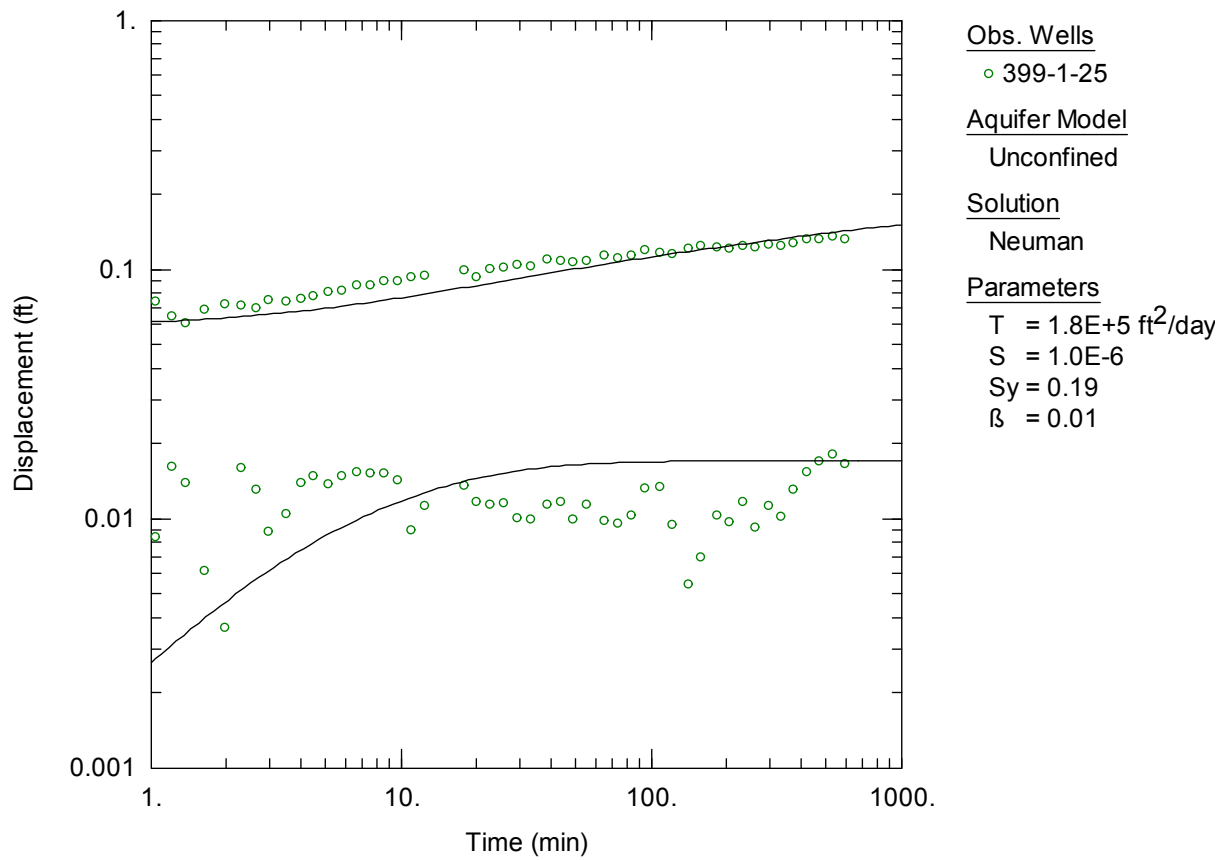

Figure 3.36. Neuman Type-Curve Analysis of Pressure Buildup Data at the Lower-Screened Well 399-1-25 
The early-time pressure buildup data did not follow the elastic or early delayed yield response predicted by the Neuman method. In this high permeability formation, the time over which this early response occurs is extremely small and would not be observable except under the most controlled of test conditions. Test response data continued to deviate from the predicted response for several minutes into the test. This early-time discrepancy is most likely associated with the non-ideal test conditions at the start of the injection (i.e., because the injection make-up waster was pumped through a $182-\mathrm{m}-(600+-\mathrm{ft}-)$ long water line from well 399-1-7, it was difficult to facilitate an instantaneous injection start), but may also be impacted by the effects of well bore storage.

In addition to analysis of the pressure buildup data during the tracer injection test, a series of slug tests was conducted prior to the tracer injection in an attempt to obtain additional hydraulic property data. Slug tests were conducted in wells 399-1-23, 399-1-25, 399-1-26, 399-1-27, and 399-1-30 on December 8,2006 . The objective of these slug tests was to obtain a preliminary estimate of hydraulic conductivity and additional information about the variability of hydraulic conductivity at different wells located within a radius of 30 feet from the injection well. However, because of the high hydraulic conductivity of the aquifer and the small diameter of the wells, slug test responses were very rapid and of very small magnitude (Figure 3.37). The magnitude of test response derived from the slug tests was insufficient to obtain quantitative estimates of hydraulic properties from the test analyses.

\subsubsection{Hydraulic Gradient Analysis}

Another analysis approach that can provide useful information with respect to the spatial distribution of aquifer transmissivity is the evaluation of hydraulic gradients. Areas with higher hydraulic gradient are indicative of less permeable regions of the aquifer whereas areas with lower hydraulic gradients indicate

more transmissive materials. This information, taken in concert with available hydrogeologic information (i.e., geologic structure, aquifer thickness) can be used to provide insights into the spatial distribution of horizontal hydraulic conductivity for an aquifer. Based on hydraulic gradient measurements made using polyphosphate treatability test site and surrounding monitoring wells, there is indication that aquifer transmissivity increases as you move southeast from injection well 399-1-23 toward well 399-1-7.

Water-level data collected for the injection and monitoring wells over several months after the tracer injection test indicate that the water table in the vicinity of the polyphosphate treatability test site has a relatively small gradient (Figure 3.38), as would be expected for such a high-permeability formation. The calculated hydraulic gradients for the three well pairs have distinctly different gradients over this period. Inter-well gradients during a period of relatively stable river stage conditions in February 2007 range from as high as 3.7E-3 near the test site injection well to as low as $1.5 \mathrm{E}-4 \mathrm{ft} / \mathrm{ft}$ over the most distal segment monitored. 


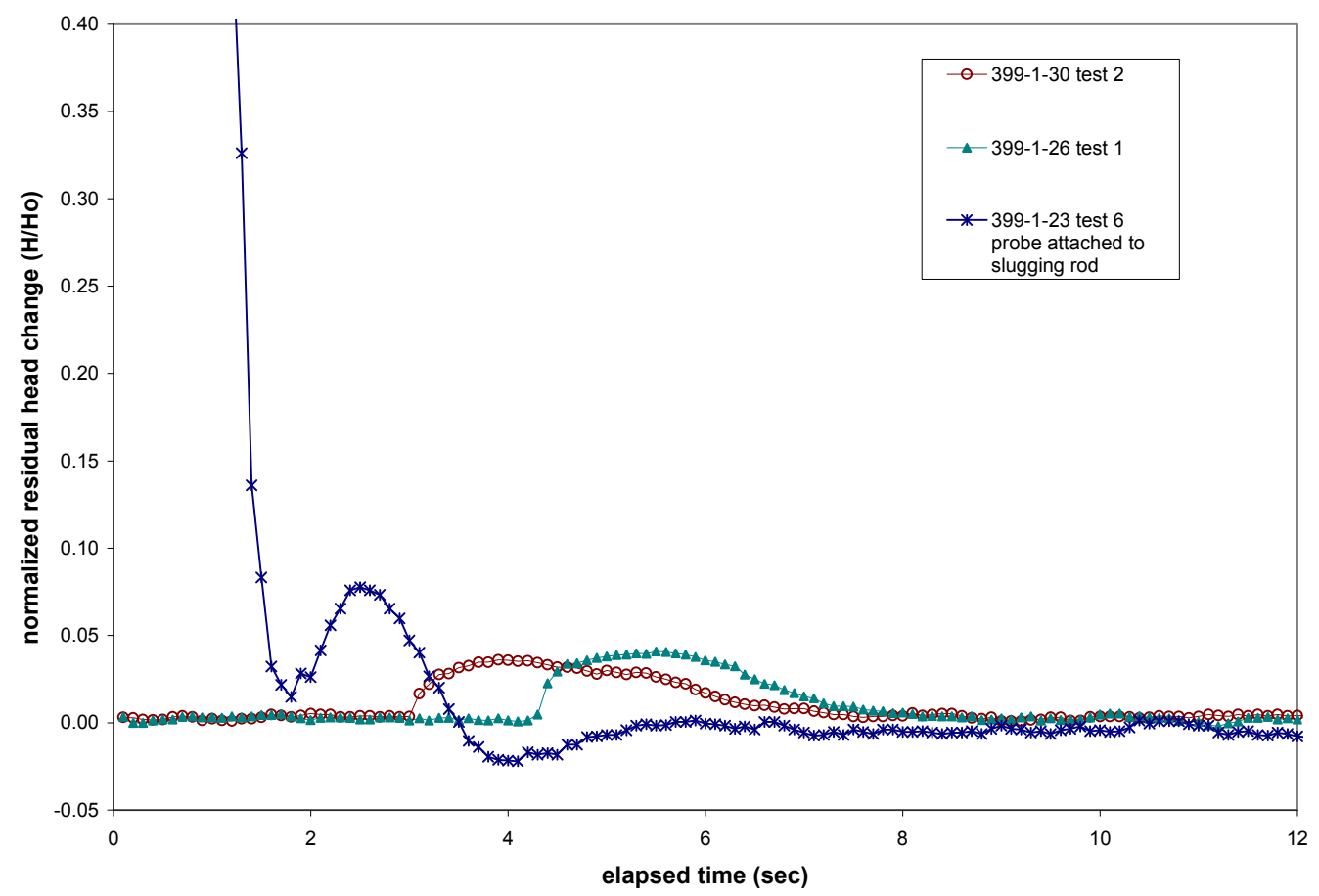

Figure 3.37. Example Slug Test Responses at Three Wells Completed over the Entire Hanford Formation Thickness (stress level calculated from slug rod volume)

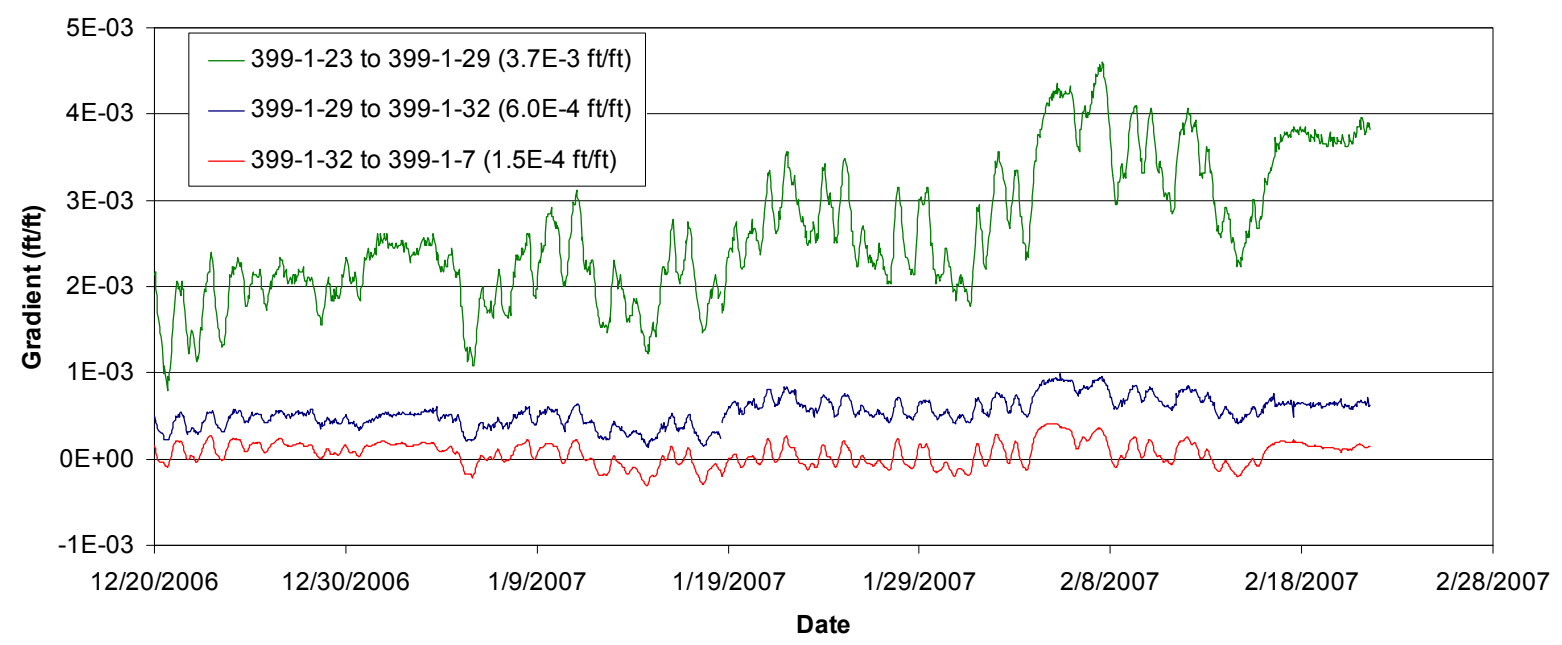

Figure 3.38. Background Water-Level Gradients for Well-Well Combinations Stepping Progressively Downgradient. Average gradients during a period of stable river stage in the middle part of February 2007 are shown in parentheses.

\subsubsection{Baseline Groundwater Monitoring}

Three baseline sampling activities were conducted prior to injection. The first baseline sampling event occurred prior to the tracer injection on December 13, 2006; the second event occurred on April 22, 2007, approximately two months prior to injection. The third baseline sampling event took place 
immediately prior to injection, on June 11,2007. Results of the baseline sampling events (Table 3.14 through Table 3.17) indicated relatively uniform analyte concentrations in the vicinity of well 399-1-23 during each sampling event.

Table 3.14. Average Anion Concentration Results for all Site Monitoring Wells During the Three Baseline Sampling Events

\begin{tabular}{cccccc}
\hline Analyte & $\begin{array}{c}\text { BL 1 Average } \\
(\mu \mathrm{g} / \mathrm{mL}, \mathrm{ppm})\end{array}$ & $\begin{array}{c}\text { BL 2 Average } \\
(\mu \mathrm{g} / \mathrm{mL}, \mathrm{ppm})\end{array}$ & $\begin{array}{c}\text { BL 3 Average } \\
(\mu \mathrm{g} / \mathrm{mL}, \mathrm{ppm})\end{array}$ & $\begin{array}{c}\text { Combined } \\
\text { Average }\end{array}$ & $\begin{array}{c}\text { Combined } \\
\text { Std. Dev. }\end{array}$ \\
\hline Bromide & $<1$ & $<1$ & $<1$ & $\mathrm{ND}$ & $\mathrm{ND}$ \\
Chloride & 19.7 & 17.8 & 18.1 & 18.4 & 1.1 \\
Nitrate & 24.1 & 23.1 & 29.7 & 26.3 & 14.5 \\
Nitrite & $<1$ & $<1$ & $<1$ & $\mathrm{ND}$ & $\mathrm{ND}$ \\
Phosphate & $<1.5$ & $<1.5$ & $<1.5$ & $\mathrm{ND}$ & $\mathrm{ND}$ \\
Sulfate & 61.8 & 54.7 & 60.2 & 59.1 & 5.4 \\
\hline
\end{tabular}

$<\#=$ Concentration below the listed detection limit

$\mathrm{ND}=$ Analyte not detectable

Table 3.15. Average Trace Metals Concentration Results for all Site Monitoring Wells During the Three Baseline Sampling Events

\begin{tabular}{cccccc}
\hline Analyte & $\begin{array}{c}\text { BL 1 Average } \\
(\mu \mathrm{g} / \mathrm{L}, \mathrm{ppb})\end{array}$ & $\begin{array}{c}\text { BL 2 Average } \\
(\mu \mathrm{g} / \mathrm{L}, \mathrm{ppb})\end{array}$ & $\begin{array}{c}\text { BL 3 Average } \\
(\mu \mathrm{g} / \mathrm{L}, \mathrm{ppb})\end{array}$ & $\begin{array}{c}\text { Combined } \\
\text { Average }\end{array}$ & $\begin{array}{c}\text { Combined Std. } \\
\text { Dev. }\end{array}$ \\
\hline $\mathrm{Cr}-52$ & 4.02 & 4.40 & 4.20 & 4.21 & 0.75 \\
$\mathrm{Cr}-53$ & 4.45 & 4.88 & $\mathrm{NA}$ & 4.67 & 0.52 \\
$\mathrm{Cu}-63$ & 7.25 & 5.08 & $<125$ & $6.16^{(\mathrm{a})}$ & $3.16^{(\mathrm{a})}$ \\
$\mathrm{Cu}-65$ & 7.26 & 4.77 & $\mathrm{NA}$ & 6.01 & 3.17 \\
$\mathrm{As}-75$ & 2.91 & 3.06 & 3.34 & 3.16 & 1.22 \\
$\mathrm{Se}-82$ & 5.00 & 3.72 & $<125$ & $4.36^{(\mathrm{a})}$ & $0.79^{(\mathrm{a})}$ \\
$\mathrm{Mo}-95$ & 6.43 & 4.85 & 5.54 & 5.59 & 2.10 \\
$\mathrm{Mo}-97$ & 6.54 & 5.05 & 5.34 & 5.57 & 2.09 \\
$\mathrm{Mo}-98$ & 6.56 & 4.64 & 4.97 & 5.29 & 2.20 \\
$\mathrm{Ru}-101$ & $<1.25$ & $<2.50$ & $<12.5$ & $\mathrm{ND}$ & $\mathrm{ND}$ \\
$\mathrm{Ru}-102$ & 0.015 & 0.027 & 0.145 & 0.081 & 0.079 \\
\hline
\end{tabular}


Table 3.15. (contd)

\begin{tabular}{cccccc}
\hline Analyte & $\begin{array}{c}\text { BL 1 Average } \\
(\mu \mathrm{g} / \mathrm{L}, \mathrm{ppb})\end{array}$ & $\begin{array}{c}\text { BL 2 Average } \\
(\mu \mathrm{g} / \mathrm{L}, \mathrm{ppb})\end{array}$ & $\begin{array}{c}\text { BL 3 Average } \\
(\mu \mathrm{g} / \mathrm{L}, \mathrm{ppb})\end{array}$ & $\begin{array}{c}\text { Combined } \\
\text { Average }\end{array}$ & $\begin{array}{c}\text { Combined Std. } \\
\text { Dev. }\end{array}$ \\
\hline Ag-107 & 0.012 & 0.052 & $<12.5$ & 0.032 & 0.024 \\
Ag-109 & $<1.25$ & $<1.25$ & $<2.5$ & $\mathrm{ND}$ & $\mathrm{ND}$ \\
Cd-111 & 0.037 & $<1.25$ & $<2.5$ & $0.037^{(\mathrm{a})}$ & $0.016^{(\mathrm{a})}$ \\
Cd-114 & 0.045 & $<2.5$ & 0.110 & 0.083 & 0.070 \\
\hline Sb-121 & 0.242 & $<0.05$ & $<6.25$ & $0.242^{(\mathrm{a})}$ & $0.053^{(\mathrm{a})}$ \\
$\mathrm{Sb}-123$ & 0.229 & 0.157 & 0.168 & 0.181 & 0.073 \\
$\mathrm{~Pb}-206$ & 0.201 & 0.148 & 0.373 & 0.253 & 0.638 \\
$\mathrm{~Pb}-208$ & 0.187 & 0.141 & $<6.25$ & $0.164^{(\mathrm{a})}$ & $0.106^{(\mathrm{a})}$ \\
\hline $\mathrm{U}-238$ & 60.3 & 72.1 & 78.5 & 72.2 & 11.1 \\
\hline
\end{tabular}

(a) Average and standard deviation of detectable results only

$<\#=$ Concentration below the listed detection limit

$\mathrm{NA}=$ Analyte not analyzed for

$\mathrm{ND}=$ Analyte not present at detectable concentrations

Table 3.16. Average Cation Concentration Results for All Site Monitoring Wells During the Three Baseline Sampling Events

\begin{tabular}{cccccc}
\hline Analyte & $\begin{array}{c}\text { BL 1 Average } \\
(\mu \mathrm{g} / \mathrm{L}, \mathrm{ppb})\end{array}$ & $\begin{array}{c}\text { BL 2 Average } \\
(\mu \mathrm{g} / \mathrm{L}, \mathrm{ppb})\end{array}$ & $\begin{array}{c}\text { BL 3 Average } \\
(\mu \mathrm{g} / \mathrm{L}, \mathrm{ppb})\end{array}$ & $\begin{array}{c}\text { Combined } \\
\text { Average }\end{array}$ & $\begin{array}{c}\text { Combined Std. } \\
\text { Dev. }\end{array}$ \\
\hline $\mathrm{Al}$ & $<125$ & $<30$ & 37.6 & $37.6^{(\mathrm{a})}$ & $127^{(\mathrm{a})}$ \\
$\mathrm{As}$ & 130 & 28.5 & $<150$ & $79.1^{(\mathrm{a})}$ & $145^{(\mathrm{a})}$ \\
$\mathrm{B}$ & 224 & 12.3 & $<150$ & $108^{(\mathrm{a})}$ & $170^{(\mathrm{a})}$ \\
$\mathrm{Ba}$ & 57.3 & 65.2 & 64.3 & 62.7 & 6.1 \\
$\mathrm{Bi}$ & 23.1 & 11.8 & 25.7 & 22.9 & 10.5 \\
$\mathrm{Ca}$ & 51,200 & 51,600 & 49,200 & 50,300 & 2,180 \\
$\mathrm{Co}$ & 1.1 & 1.9 & $<15$ & $1.5^{(\mathrm{a})}$ & $1.1^{(\mathrm{a})}$ \\
$\mathrm{Cr}$ & 3.0 & 4.7 & 2.8 & 3.4 & 1.2 \\
$\mathrm{Cu}$ & 53.7 & 5.8 & $<75$ & $29.8^{(\mathrm{a})}$ & $25.1^{(\mathrm{a})}$ \\
$\mathrm{Fe}$ & 11.8 & 52.5 & 23.1 & 27.7 & 77.4 \\
$\mathrm{~K}$ & 4,580 & 4,710 & 4,440 & 4,540 & 269 \\
$\mathrm{Mg}$ & 12,100 & 11,600 & 11,800 & 11,800 & 380 \\
$\mathrm{Mn}$ & 39.8 & 8.0 & 18.4 & 19.1 & 46.6 \\
$\mathrm{Mo}$ & 10.1 & 4.5 & 6.3 & 6.7 & 5.4 \\
\hline
\end{tabular}


Table 3.16. (contd)

\begin{tabular}{cccccc}
\hline Analyte & $\begin{array}{c}\text { BL 1 Average } \\
(\mu \mathrm{g} / \mathrm{L}, \mathrm{ppb})\end{array}$ & $\begin{array}{c}\text { BL 2 Average } \\
(\mu \mathrm{g} / \mathrm{L}, \mathrm{ppb})\end{array}$ & $\begin{array}{c}\text { BL 3 Average } \\
(\mu \mathrm{g} / \mathrm{L}, \mathrm{ppb})\end{array}$ & $\begin{array}{c}\text { Combined } \\
\text { Average }\end{array}$ & $\begin{array}{c}\text { Combined Std. } \\
\text { Dev. }\end{array}$ \\
\hline $\mathrm{Ni}$ & 17.3 & 17.8 & 9.1 & 13.4 & 10.1 \\
$\mathrm{P}$ & 160 & 216 & 241 & 214 & 38 \\
$\mathrm{~Pb}$ & $<125$ & $<75$ & $<75$ & $\mathrm{ND}$ & $\mathrm{ND}$ \\
$\mathrm{Se}$ & 485 & 408 & 389 & 418 & 73 \\
$\mathrm{Sr}$ & 240 & 237 & 239 & 238 & 7 \\
$\mathrm{Zn}$ & 186 & 105 & 85 & 116 & 86 \\
$\mathrm{Na}$ & 24,700 & 24,200 & 21,800 & 23,200 & 4,060 \\
$\mathrm{Si}$ & 13,500 & 13,100 & 13,200 & 13,300 & 510 \\
$\mathrm{~S}$ & 20,600 & 18,100 & 18,600 & 19,000 & 1,780 \\
$\mathrm{Zr}$ & 3.0 & 3.4 & 0.7 & 2.0 & 4.1 \\
$\mathrm{Ag}$ & 12.5 & $<75$ & 1.2 & $5.9^{(\mathrm{a})}$ & $5.8^{(\mathrm{a})}$ \\
$\mathrm{Sb}$ & $<250$ & 32.4 & 28.8 & $30.1^{(\mathrm{a})}$ & $14.0^{(\mathrm{a})}$ \\
\hline
\end{tabular}

(a) Average and standard deviation of detectable results only

$<\#=$ Concentration below the listed detection limit

$\mathrm{ND}=$ Analyte not present at detectable concentrations

Table 3.17. Average Field Parameter Results for All Site Monitoring Wells During the Three Baseline Sampling Events

\begin{tabular}{lccccc}
\hline \multicolumn{1}{c}{ Analyte } & $\begin{array}{c}\text { BL 1 } \\
\text { Average }\end{array}$ & $\begin{array}{c}\text { BL 2 } \\
\text { Average }\end{array}$ & $\begin{array}{c}\text { BL 3 } \\
\text { Average }\end{array}$ & $\begin{array}{c}\text { Combined } \\
\text { Average }\end{array}$ & $\begin{array}{c}\text { Combined } \\
\text { Std. Dev. }\end{array}$ \\
\hline Temperature $(\mathrm{C})$ & 16.6 & 17.5 & 17.7 & 17.3 & 0.66 \\
Specific Conductance $(\mu \mathrm{S} / \mathrm{cm})$ & 479 & 467 & 462 & 468 & 14 \\
Dissolved Oxygen $(\mathrm{mg} / \mathrm{L})$ & 8.50 & 7.02 & 5.95 & 6.95 & 1.21 \\
$\mathrm{pH}$ & 7.40 & 7.40 & 7.29 & 7.34 & 0.08 \\
Oxidation Reduction Potential $(\mathrm{mV})$ & 123 & 58 & 136 & 111 & 40 \\
\hline
\end{tabular}

During the first baseline sampling event, there were two wells where concentrations were not consistent with concentrations measured in other wells. Uranium concentration in 399-1-26, which is located on the upgradient side of the targeted treatment zone to the northwest of 399-1-23 (Figure 3.11), was lower relative to other wells in the network (see monitoring data contained in Appendix B). This result is consistent with local-scale uranium plume maps (Figure 1.2) that show the test site location near the western edge of the plume. The other well of interest during the first baseline sampling event was 399-1-27. This well was completed in a lower portion of the aquifer in what is thought to be less permeable material based on tracer test results and hydraulic response. The concentrations of uranium, molybdenum, fluoride, and sulfate were all elevated relative to the other monitoring wells. This is 
consistent with the higher specific conductance and lower dissolved oxygen measured in 399-1-27 during each sampling event (Appendix B). To a lesser extent, well 399-1-28 (the adjacent upper zone well) also showed elevated uranium concentrations, but no other analytes were elevated. It is likely that the lower permeability zone causes less dynamic changes in concentrations measured in 399-1-27 relative to the other monitoring wells.

\subsection{Injection Design Analysis}

The objective of the injection design analysis is to determine injection volumes, rates, and sampling requirements for the treatability test. These will be based on the results of the bench-scale studies (Section 2), the tracer injection test that was conducted at the site in December 2006, and the use of analytic and numerical models. The nominal design for the treatability test is described below. Additional details and changes will be documented in field test instructions that will be prepared prior to the polyphosphate injection test. The volumes and rates for the nominal injection design are based on a conservative species (i.e., bromide) as described below along with a description of the numerical model to aid in the design and interpretation of the treatability test. The injection volumes, which are based on the observed arrival of conservative species during the tracer injection test, have been increased to account for increased aquifer thickness during spring high river stage conditions. These volumes will also be increased to account for retardation associated with the reactive species used for the polyphosphate treatability test. Injection volume specifications for the polyphosphate injection are provided in Section 3.3.3.

\subsubsection{Injection Volume and Rates}

The injection volume for a conservative species at the polyphosphate treatability test site was estimated based on the results of the bromide tracer test and adjusted for the higher river stage conditions expected for the test in June. The targeted treatment volume is for $90 \%$ or greater concentrations at a $7.62-\mathrm{m}(25-\mathrm{ft})$ radial distance from the injection well.

Figure 3.39 and Figure 3.40 show the tracer BTCs during the injection period (714 minutes) of the December 13, $2006 \mathrm{Br}^{-}$tracer test at the polyphosphate treatability test site. As can be seen in these figures, there is a large variability in the tracer arrivals at the wells due to heterogeneities at the site. Also shown in Figure 3.39 and Figure 3.40 are the results of an analytic solution for advection and dispersion for wells around an injection well at different radial distances at the site (Hoopes and Harleman 1967). This analytic solution assumes a homogeneous, isotropic aquifer with constant thickness. Parameters used for the analytic solution are shown in the figures. It should be noted that the simulated arrivals assume an effective porosity of $18 \%$, which was selected based on a preliminary evaluation of the tracer arrival data (later adjusted to $19 \%$ ). Comparisons with the analytic solution are meant to show the relative differences between the measured tracer arrivals using a standard response. This allows the wells to be categorized as fast or slow relative to this measure. Based on these comparisons, most of the wells southeast of the injection well had slower tracer arrivals than wells in other directions. Well 399-1-30, to the southwest of the injection well, had a very fast arrival indicating preferential flow in that direction. Wells to the northeast and northwest had similar arrivals to the average expected at the site. Using the comparison to the analytic solution for well 399-1-29, it appears that the tracer response at this well is influenced by multiply layers within the screened zone as seen by an initial early tracer arrival to about $50 \%$ of the tracer concentration followed by a slow increase during the rest of the injection period. 

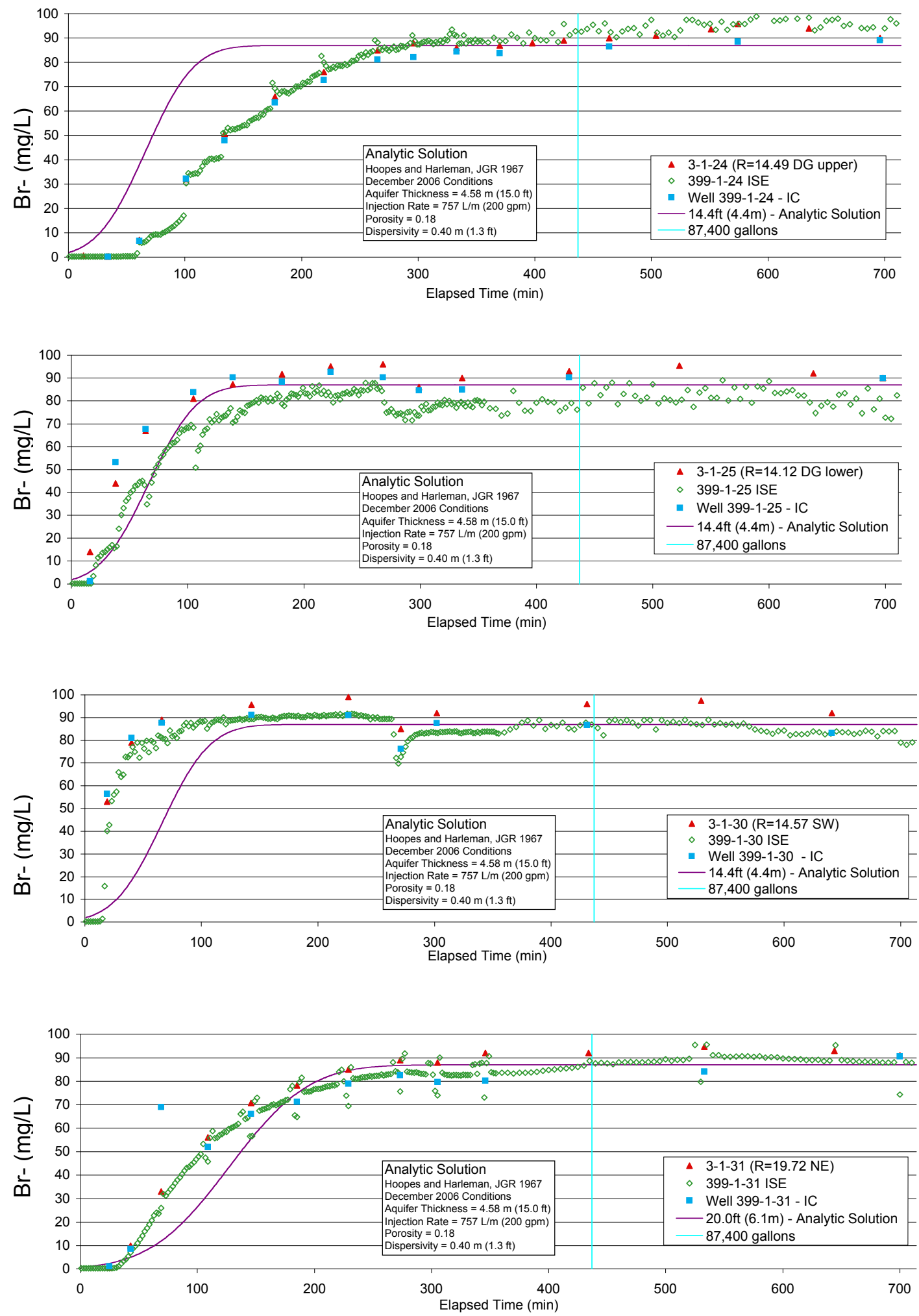

Figure 3.39. Tracer Breakthrough Curves During Injection Period of the December 13, 2006, Bromide Tracer Test 

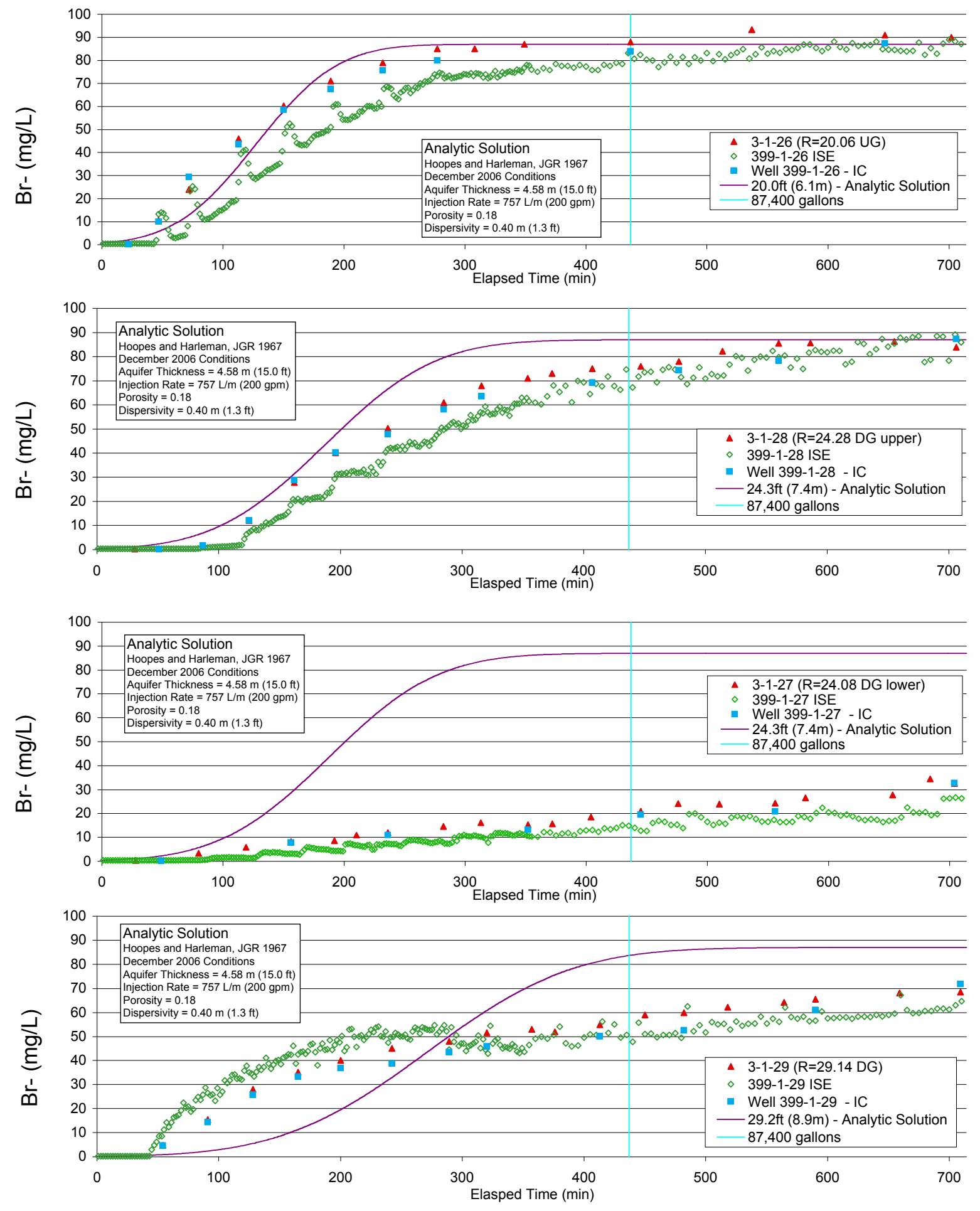

Figure 3.40. Tracer Breakthrough Curves During Injection Period of the December 13, 2006, Bromide Tracer Test

Table 3.18 summarizes the injection volumes for percentage arrivals of tracer from the BTCs at each of the wells during the December 2006 tracer test at the site. 
Table 3.19 scaled these percentage tracer volumes for each well with its radial distance adjusted to a 25 -ft radius based on cylindrical geometry. Using this scaling, the average volume from all the wells at the site for a $90 \%$ tracer arrival at $7.6 \mathrm{~m}(25 \mathrm{ft})$ is $\sim 330,800 \mathrm{~L}(87,400$ gal $)$ during the December tracer test. The volume is shown in Figure 3.39 and Figure 3.40 for comparison with the tracer arrivals during the injection. Adjusting for the $25 \%$ increase in aquifer thickness expected due to increased river stage in June, 4.58-m- (15.0-ft-) thick aquifer in December 2006 and an estimated 5.73-m- (18.8-ft-) thick aquifer based on May-June 2006300 Area water-table map, results in a 413,500 L (109,200 gal) per pore volume for a 7.6-m (25-ft) radius at high river stage in June. An analytic solution of tracer arrivals in a homogeneous, isotropic aquifer under these conditions is shown in Figure 3.41. This is the same method used for the comparison with the measured tracer BTCs in Figure 3.39 and Figure 3.40.

The injection rate of $757 \mathrm{~L}$ ( 200 gal) per minute was determined for the design of the bromide tracer test and was used for selecting pump sizes and hoses as part of the site setup. This injection rate was sustained during the tracer injection test by pumping groundwater from well 399-1-7, mixing with the concentrated tracer solution, and injecting into well 399-1-23. An injection rate of 757 L (200 gal) per minute will also used for the polyphosphate amendment injection.

Table 3.18. Estimated Volumes for Tracer Arrivals for Bromide Tracer Test Conducted in December 2006

\begin{tabular}{cccccc}
\hline Well Name & $\begin{array}{c}\text { Distance to Well } \\
399-1-23(\mathrm{ft})\end{array}$ & $\begin{array}{c}50 \% \text { Tracer } \\
\text { Arrival (gal) }\end{array}$ & $\begin{array}{c}80 \% \text { Tracer } \\
\text { Arrival (gal) }\end{array}$ & $\begin{array}{c}90 \% \text { Tracer } \\
\text { Arrival (gal) }\end{array}$ & $\begin{array}{c}100 \% \text { Tracer } \\
\text { Arrival (gal) }\end{array}$ \\
\hline $399-1-23$ & 0.0 & & & & \\
$399-1-24$ & 14.5 & 26,000 & 42,000 & 50,000 & 114,000 \\
$399-1-25$ & 14.1 & 8,000 & 16,000 & 20,000 & 44,000 \\
$399-1-26$ & 20.1 & 22,000 & 40,000 & 56,000 & 130,000 \\
$399-1-27$ & 24.1 & ---- & ---- & ---- & ---- \\
$399-1-28$ & 24.3 & 44,000 & 90,000 & 118,000 & 144,000 \\
$399-1-29$ & 29.1 & 62,000 & 150,000 & ---- & ---- \\
$399-1-30$ & 14.6 & 4,000 & 6,000 & 8,000 & 20,000 \\
$399-1-31$ & 19.7 & 18,000 & 38,000 & 48,000 & 70,000 \\
\hline
\end{tabular}


Table 3.19. Scaled Tracer Arrivals for Wells at the Treatability Test Site to a 7.6-m (25-ft) Radius

\begin{tabular}{cccccc}
\hline Well Name & $\begin{array}{c}\text { Distance to Well } \\
399-1-23(\mathrm{ft})\end{array}$ & $\begin{array}{c}50 \% \text { Tracer } \\
\text { Arrival (gal) }\end{array}$ & $\begin{array}{c}80 \% \text { Tracer } \\
\text { Arrival (gal) }\end{array}$ & $\begin{array}{c}90 \% \text { Tracer } \\
\text { Arrival (gal) }\end{array}$ & $\begin{array}{c}100 \% \text { Tracer } \\
\text { Arrival (gal) }\end{array}$ \\
\hline $399-1-23$ & 0.0 & & & & \\
\hline $399-1-24$ & 14.5 & 77,425 & 125,072 & 148,895 & 339,481 \\
\hline $399-1-25$ & 14.1 & 25,093 & 50,185 & 62,731 & 138,009 \\
\hline $399-1-26$ & 20.1 & 34,175 & 62,136 & 86,990 & 201,940 \\
$399-1-27$ & 24.1 & ---- & ---- & ---- & --- \\
\hline $399-1-28$ & 24.3 & 46,659 & 95,438 & 125,130 & 152,701 \\
$399-1-29$ & 29.1 & 45,640 & 110,420 & ---- & ---- \\
\hline $399-1-30$ & 14.6 & 11,785 & 17,677 & 23,569 & 58,923 \\
$399-1-31$ & 19.7 & 28,941 & 61,099 & 77,177 & 112,550 \\
Average & & 38,531 & 74,575 & 87,415 & 167,267 \\
Average @ & & 48,292 & 93,468 & 109,561 & 209,642 \\
June WT & & & & & \\
\hline
\end{tabular}

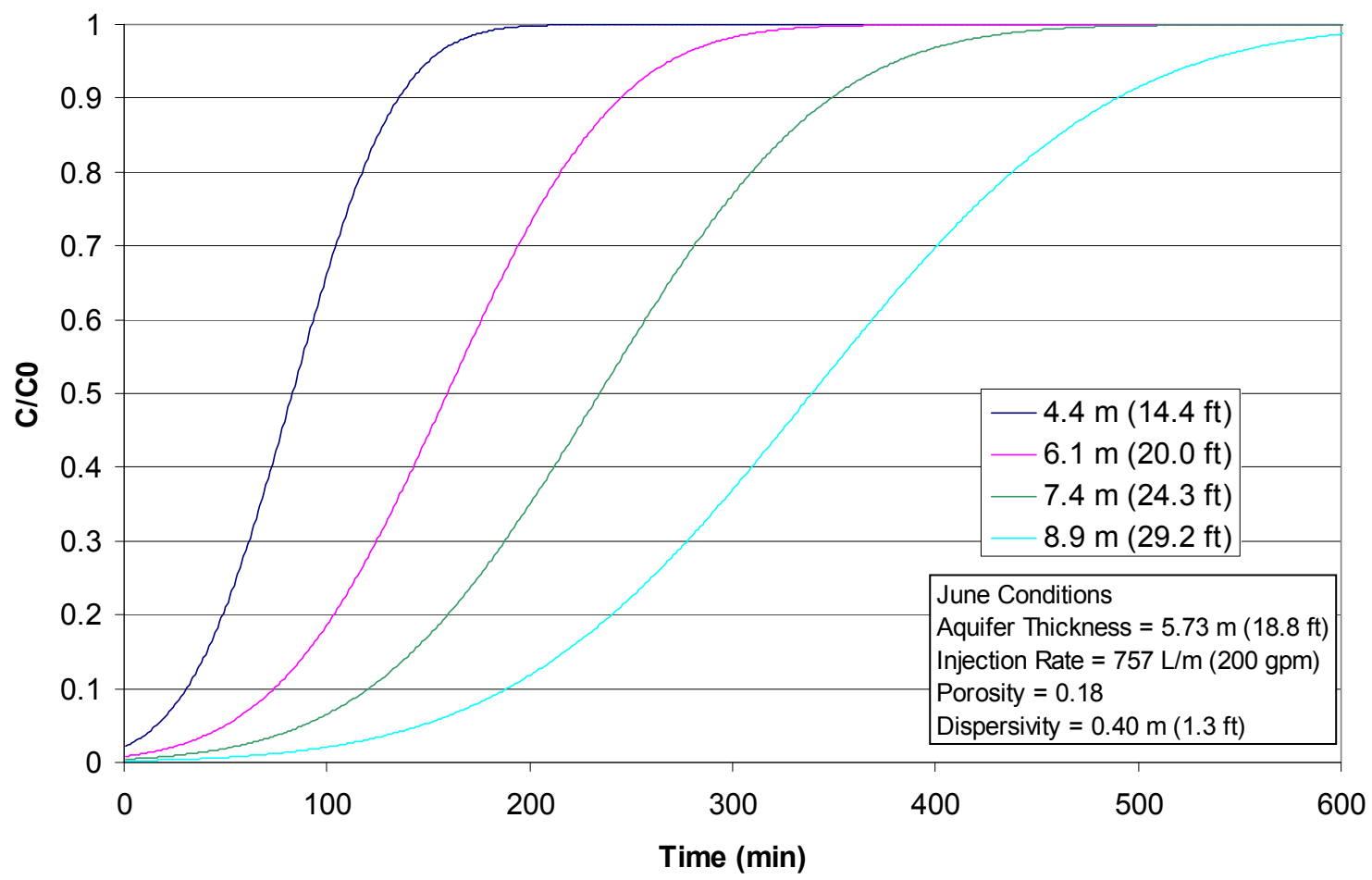

Figure 3.41. Analytic Solution (Hoopes and Harleman 1967) for Tracer Arrivals at Different Radial Distances Using Estimated June Conditions. Parameters: Injection rate is $757 \mathrm{Lpm}$ (200 gpm), 5.73-m-thick aquifer, 18\% porosity, $0.4 \mathrm{~m}$ dispersivitiy, and 454,200 L (120,000 gal) total volume. 


\subsubsection{Treatability Test Numerical Model Description}

A numerical model of the site is being developed based on the site characterization (geologic description, physical property measurement of sediment samples, aquifer tests, and tracer test) for help in the design and interpretation of the polyphosphate injection test. The model uses the Subsurface Transport Over Multiple Phases (STOMP) code, which is a multi-fluid flow finite difference code that can simulate both the vadose zone and aquifer (White and Oostrom 2000, 2006). The model domain, boundary conditions, material properties, and preliminary simulation results are described in the following sections.

\subsubsection{Model Domain and Finite Difference Grid}

A plan view of the STOMP finite difference grid for the polyphosphate treatability test model is shown in Figure 3.42. The domain is bounded by wells 399-1-1 and 399-2-2 near the river and wells 399-1-12 and 399-1-2 inland. This model domain does not extend to the Columbia River (within $\sim 50 \mathrm{~m}$ [164 ft] from the shoreline). The vertical domain of the model ranges from $90-\mathrm{m}$ (295- $\mathrm{ft})$ elevation at the bottom to $107.5 \mathrm{~m}(352.68 \mathrm{ft})$ at the top. The bottom of the domain was set below the Hanford formation in the domain and extends a few meters into the Ringold Formation gravels and sands depending on the location (see structure contour map of the top of the Ringold Formation in Figure 3.14). The focus of the treatability study is within the Hanford formation, which has hydraulic conductivities many orders of magnitude greater than the underlying Ringold Formation. The upper limit of the model domain was set to an elevation higher than the observed water levels in these wells over the past few years.

The finite difference grid is 103 by 91 nodes in the $\mathrm{x}$ and y directions and 24 nodes in the $\mathrm{z}$ direction (vertically). The total number of nodes in the domain is 224,952 with 190,896 active nodes. The nodes outside the polygon created by the four bounding wells listed above in the rectangular grid are inactive. As shown in Figure 3.42, grid spacing in the $x-y$ directions is variable and ranges from 1 to $7 \mathrm{~m} \mathrm{(3.28} \mathrm{to}$ $22.96 \mathrm{ft}$ ). The grid has the highest resolution around the treatability test site for simulating the injection and surrounding monitoring wells in the treatment zone with the grid spacing coarser away from the site. Vertical grid spacing is from 0.5 to $1.5 \mathrm{~m}$ (1.64 to $4.9 \mathrm{ft})$ with the finer resolution near the top of the aquifer.

\subsubsection{Boundary Conditions}

The lateral boundary conditions of the model are specified hydraulic heads from the four outermost wells shown in Figure 3.42 using data from the 300 Area automated water-level monitoring network that has been in operation since 2004 (see description in Section 3.2.1). Water levels for some of the wells in this network have been collected at up to 15-minute intervals; however, hourly and 2-hour data are used in the model, which is sufficient for resolving the daily, weekly, and seasonal fluctuations seen in these hydrographs. Specified heads along the boundaries between these four wells are interpolated in the x-y direction onto the finite difference grid. 


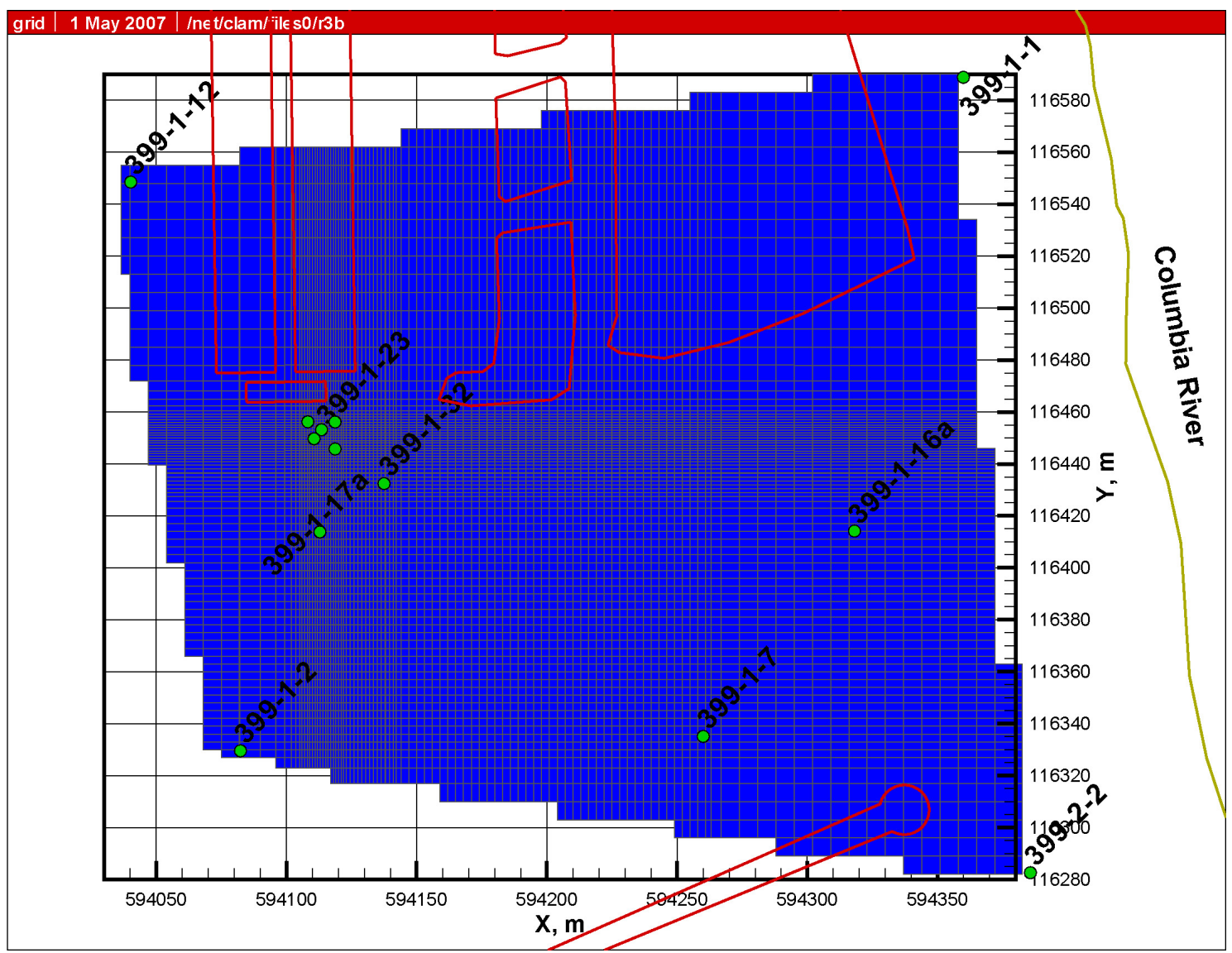

Figure 3.42. Plan View of Polyphosphate Treatability Test STOMP Model Domain and Finite Difference Grid

Fayer and Walters (1995) generated a Hanford sitewide map of natural groundwater recharge rates by combining available information on land use, vegetation, soil types, lysimeter and tracer (chloride) studies, and numerical simulation. For the 300 Area, their map indicates variable recharge rates, ranging from near zero to $\sim 100 \mathrm{~mm} / \mathrm{yr}$. The Fayer and Walters (1995) recharge map was based, in part, on data from the Buried Waste Test Facility (BWTF) lysimeter, located in the north of the 300 Area. Rockhold et al. (1995, Table 3.1) report an 8-year (1985-1993) record of drainage rates (equivalent to natural ground water recharge) from a bare (unvegetated) lysimeter at the BWTF that range from 111 to $24 \mathrm{~mm} / \mathrm{yr}$, with an average of $55 \mathrm{~mm} / \mathrm{yr}$. Average annual precipitation rates at Hanford have increased slightly since the 1985-1993 time frame, so a higher recharge rate of $60 \mathrm{~mm} / \mathrm{yr}$ was assumed for the upper surface boundary condition in the model. The bottom of the model domain, within the Ringold Formation, is a no-flow boundary.

Williams et al. (2006) used the chloride mass balance method to estimate a recharge rate of $1.8 \mathrm{~mm} / \mathrm{yr}$ for the undisturbed, vegetated area in the vicinity of well 699-S20-E10, located northwest of the 300 Area. Based on these data, and on the lysimeter data noted above, natural groundwater recharge rates in the 300 Area can be expected to range from an annual average of $<2 \mathrm{~mm} / \mathrm{yr}$ (for undisturbed, vegetated areas) up to $60 \mathrm{~mm} / \mathrm{yr}$ or more (for disturbed, unvegetated areas). Note that this range does not include locally elevated recharge rates that might occur, for example, adjacent to relatively impermeable surfaces such as buildings, roads, and parking lots. The area around the treatability test site has also been 
undergoing extensive surface remediation over the past decade with the vegetation and top layer of the soil removed and backfilled. Water has also been applied to the surface via water trucks for dust control during these activities.

\subsubsection{Material Properties}

Total and effective porosity for the Hanford formation was set at $18 \%$ based on the physical property measurements from cores as part of the LFI characterization for well 399-1-23 (see Table 3.9) and preliminary estimates from the tracer injection test (see Section 3.2.2). For unsaturated zone parameters in the STOMP code, a Brooks-Corey function is used along with a Burdine porosity distribution model for aqueous relative permeability. The air-entry pressure and lambda parameters for the Hanford formation are based on data from Rockhold et al. (1988, p. A.1), which represent the ("L-soil") sediment used in the BWTF lysimeters, located north of the 300 Area. The irreducible saturation parameter was estimated at 0.16 based on data from well 699-S20-E10 (see Figure 8 of Williams et al. 2006).

Hydraulic conductivity values for the Hanford Site are very high and variable in the area of the polyphosphate treatability test site. Initial simulations of the tracer test using the STOMP model with uniform hydraulic properties for the Hanford formation in the area of the tracer test resulted in a good agreement with the overall tracer plume from the monitoring data; however, conflicts between tracer arrivals in different wells required developing different zonations (i.e., need for faster arrivals in some wells and slower arrivals in other wells). Analytic models used for the tracer injection stage data with the monitoring wells within the treatment zone showed a similar need for hydraulic conductivity zonation.

A number of data sources were used for creating hydraulic conductivity zones within the Hanford formation aquifer for the model and are shown in Figure 3.43 for an elevation of $105 \mathrm{~m}(344.48 \mathrm{ft})$ and in Figure 3.44 for an elevation of $102.5 \mathrm{~m}(336.2 \mathrm{ft})$. These data include areas of higher hydraulic gradients in the northeast portion of the current water-level monitoring network, differences in tracer BTCs measured in monitoring wells at different orientations and depths during the injection stage of the tracer test, differences in hydraulic gradient and tracer drift downgradient from the site, and descriptions from geologic logs during drilling of the wells at the polyphosphate treatability test site (notably a clast-supported gravel that was identified in the bottom portion of the Hanford aquifer in most of the wells except in the southeast direction). Hydraulic conductivity values for these zones were varied to develop a best-fit case based on the tracer test and hydraulic test characterization results. The starting hydraulic conductivity values for these zones were specified from values determined from the field tests, where available, as discussed in the site characterization results above.

\subsubsection{Preliminary Bromide Tracer Test Simulations}

During development of the hydraulic property zonations shown in Figure 3.43 and Figure 3.44, a manual process was used for estimating parameters, primarily hydraulic conductivities, by comparing simulated tracer and hydraulic heads with measured values during the tracer test and adjusting the properties accordingly.

Preliminary results are shown in Figure 3.45 and Figure 3.46. Figure 3.45 shows the simulated tracer plumes at the end of the injection (12/23/06 10:00 pm) along with selected periods during the tracer drift at 3 days, 14 days, and 28 days. Figure 3.46 compares the simulated values at different node locations 
within the well screens (s1, s2, and s3) with the measured Br- values (both IC and in situ probe data). These preliminary results show that the simulated values have a good fit for the injection well, but are slow for the downgradient well 399-1-32. Simulated tracer arrivals at the far downgradient well (399-1-7) are within the time period of detected bromide in this well; however, the simulated pulse is too short and at slightly higher concentrations. This could be due to the need for higher dispersivity or the trajectory of the simulated plume could be shifted (i.e., off the plume centerline). In addition to changing travel times, the contrast in hydraulic properties also influences the plume trajectory.

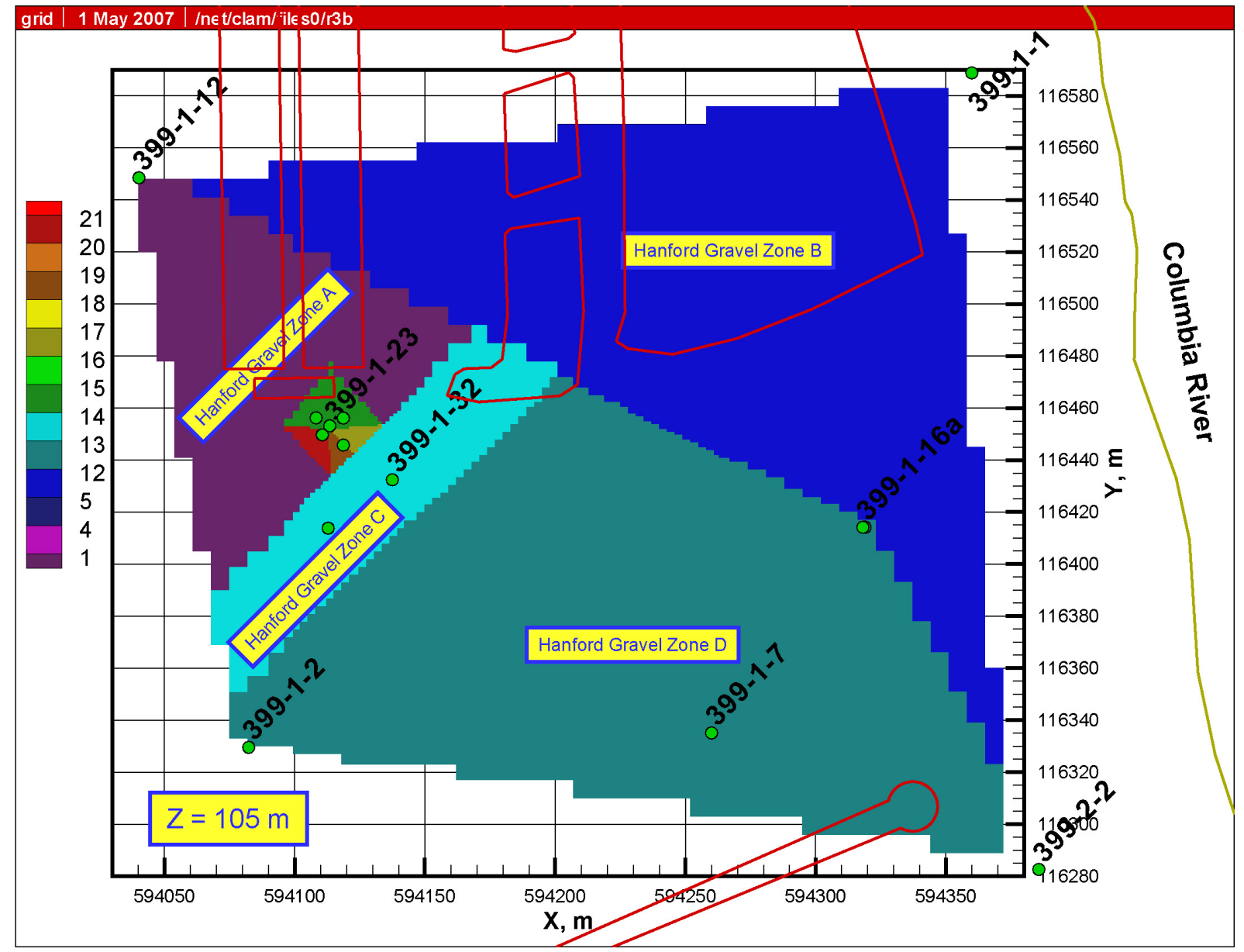

Figure 3.43. Hydrostratigraphic Zonations in Polyphosphate Site Model at 105-m Elevation

\subsubsection{Chemical Requirements}

The chemical requirements for the polyphosphate treatability test are based on the bench-scale studies described in Section 3.1 (particularly Table 3.7) and the determination of the fluid volume required for treatment out to a specific radial distance from the injection well at the field site (as discussed in Section 3.2.2). The chemicals were delivered to the site in a concentrated form in tanker trucks. The concentrated solutions from the tanker trucks were mixed inline with supply water pumped from well 399-1-7 to the specified injection concentrations and injected in well 399-1-23. 


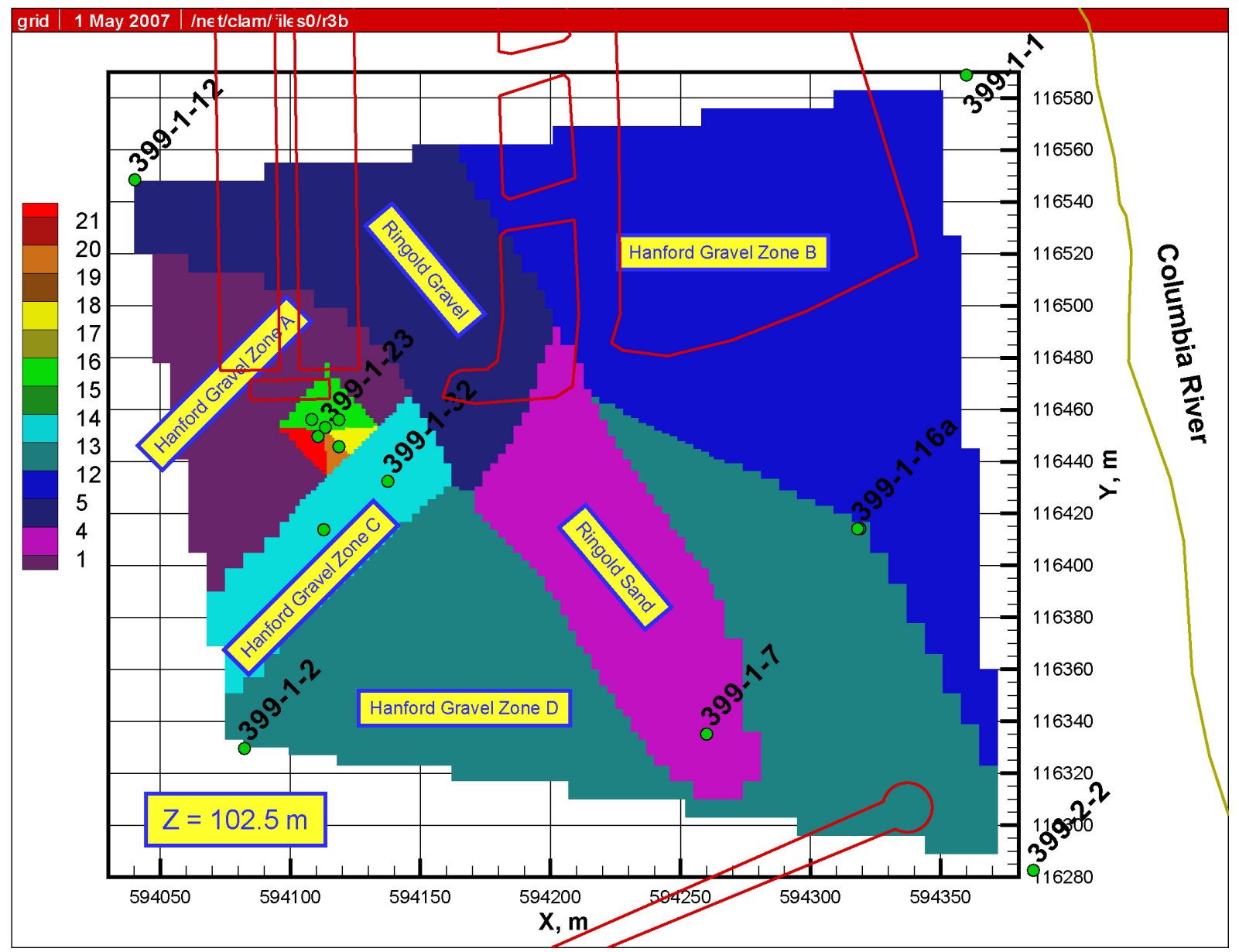

Figure 3.44. Hydrostratigraphic Zonations in Polyphosphate Site Model at 102.5-m Elevation

Based on the bromide tracer test data and adjusting for the thicker aquifer at the site during June, a volume of $\sim 412,600 \mathrm{~L}$ ( $\sim 109,000 \mathrm{gal})$ was selected for treatment of a 7.6-m (25-ft) radial distance (at least $90 \%$ concentration) from the injection well (399-1-23). This volume is for a non-reactive species; for reactive species the volumes were scaled up using the retardation factors determined from the bench-scale tests for the different mixtures used in the test (Table 3.6).

The amendment formulation and injection concentrations for the polyphosphate treatability study are shown in Table 3.7. As described in Section 2.0, the selected implementation approach for the field-scale polyphosphate injection test included three separate injection phases. The first phase consisted of a polyphosphate amendment for sequestration of the uranium in phosphate mineral phases (i.e., autunite), the second phase consisted of a calcium chloride solution for supplementing the existing calcium in the aquifer for apatite formation, and the third phase consisted of another polyphosphate amendment (same composition as the first injection) for providing phosphate for apatite formation. The injection design volumes for the first and third injection phases were scaled up from 412,600 to 990,300 L (109,000 to $262,000 \mathrm{gal}$ ) based on a retardation factor of $\sim 2.4$ for the polyphosphate amendment, which was determined in laboratory experiments using site sediments. The injection volume for the calcium chloride solution used in the second injection phase was scaled up to $1,980,000 \mathrm{~L}(523,000$ gal) based on a retardation factor of 4.8 . 

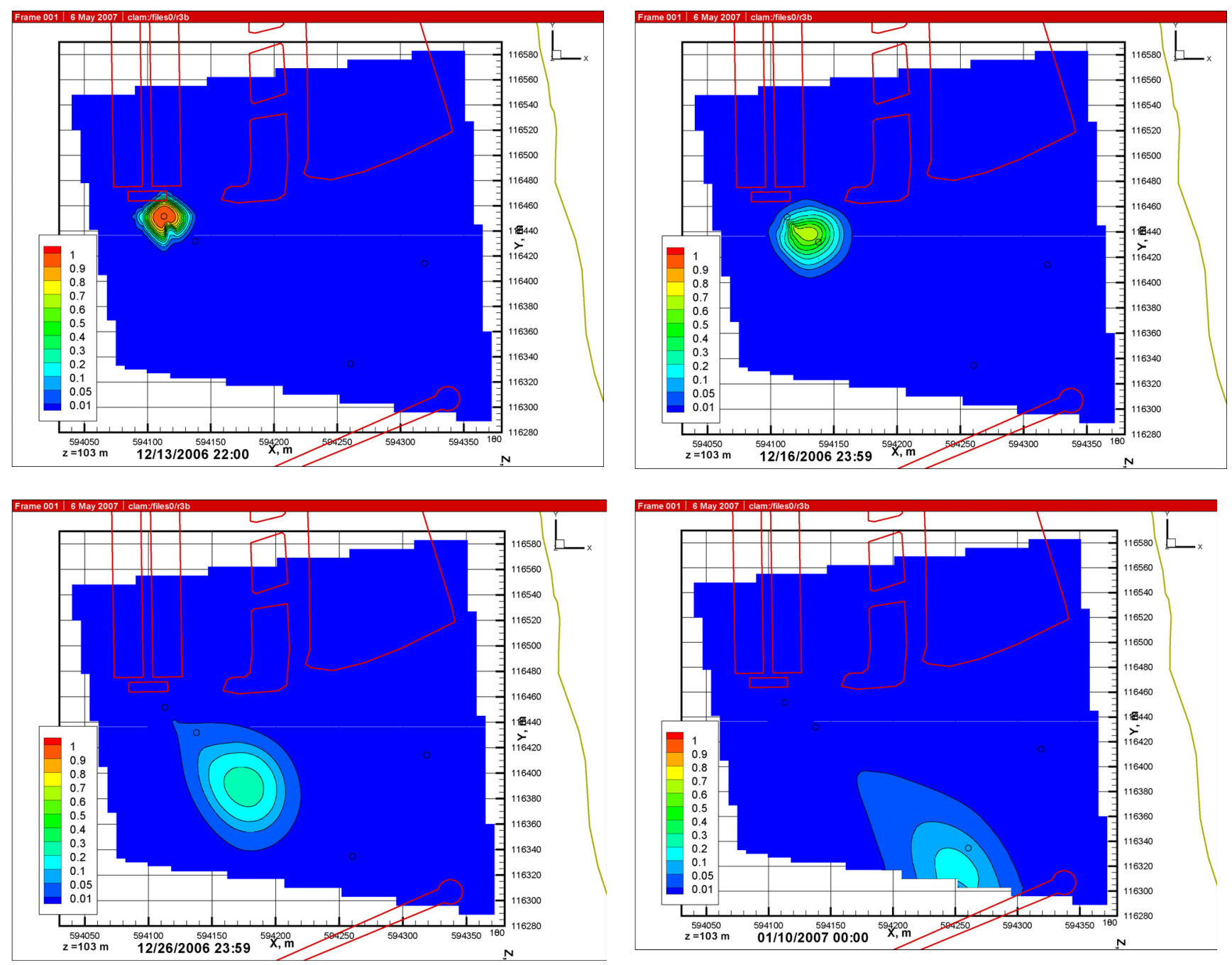

Figure 3.45. Preliminary Results of Polyphosphate Site Model of Bromide Tracer Test. Simulated tracer values at end of injection and for drift periods 3, 14, and 28 days later. Tracer concentrations are normalized $(\mathrm{C} / \mathrm{CO})$.

Sodium bromide was added to the polyphosphate amendment to provide a conservative tracer for the test $\left(\mathrm{Br}^{-}\right)$. Using bromide as the tracer for both the first and third injection phases did not cause overlap problems within the injection zone because of the large injection volume specified for the second phase of the treatment $(\mathrm{CaCl})$. The chloride that is a component of the second injection solution was used as a conservative tracer during this phase of the experiment.

\subsection{Polyphosphate Injection Test}

The polyphosphate injection test was performed over a 5-day period starting on June 11, 2007, and ending on June 15, 2007. As discussed in Sections 3.1.4 and 3.3.3, the injection design consisted of three separate injection phases; an initial phosphate solution injection was immediately followed by a calcium solution injection, which was immediately followed by a second phosphate solution injection. Each of the three solutions was premixed at a chemical plant and delivered to the field demonstration site in 
tanker trucks. Sodium bromide was included in the concentrated phosphate solutions to act as a conservative tracer during the polyphosphate injection phase. During the calcium chloride injection phase, the chloride ion was monitored as an indicator of conservative transport. During all phases of the test, field parameters were monitored and specific conductance was used as a real-time indicator of solution arrival response at surrounding monitoring wells. Test operations were performed using the injection and monitoring systems described in Section 2.3, Equipment and Material. The surrounding wells were sampled at frequent intervals to assess arrival times, phosphate and calcium interaction, uranium concentrations/mobilization, and apatite formation (see Section 2.4 for a description of sampling and analysis approach).
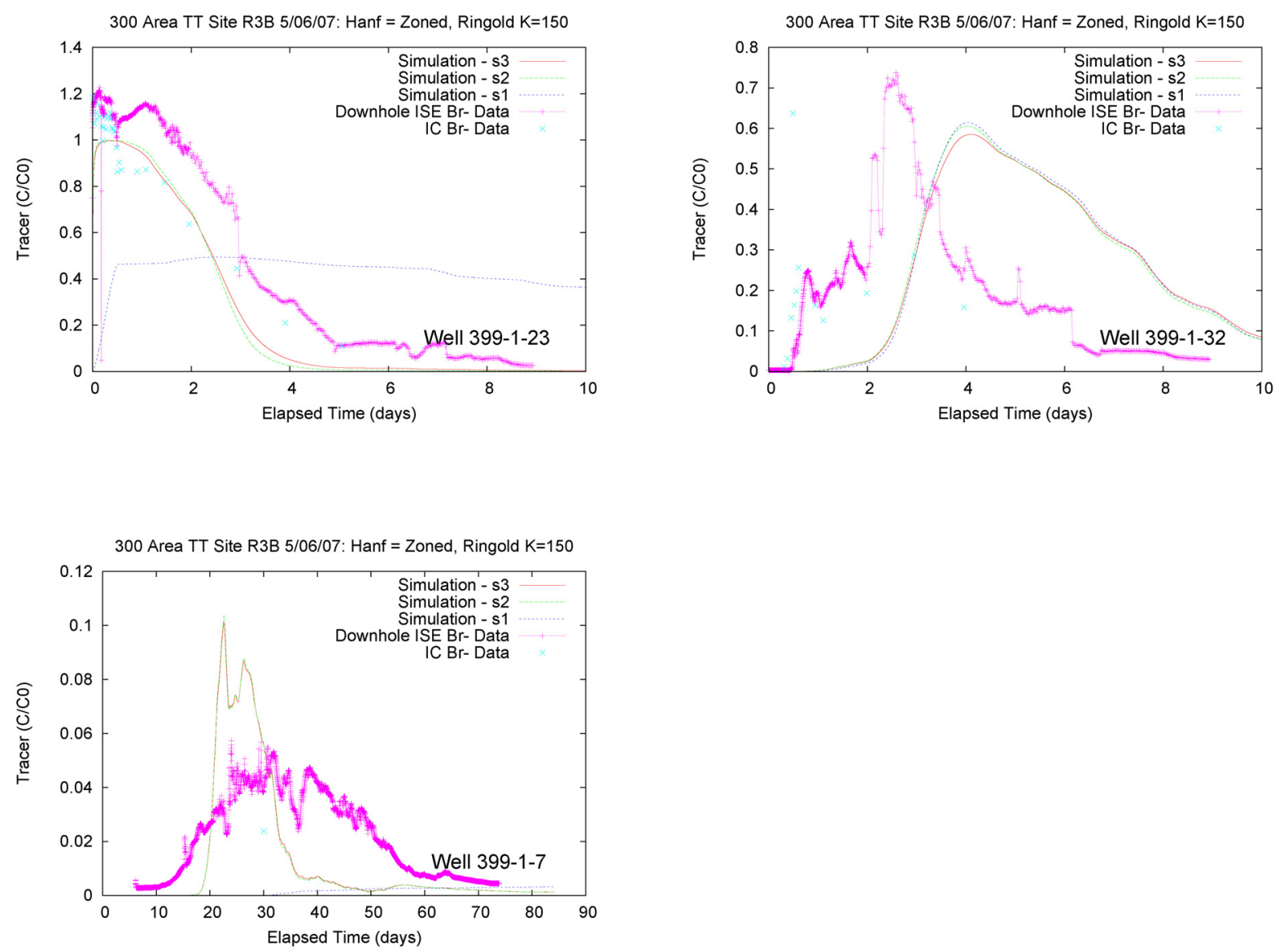

Figure 3.46. Preliminary Results of Polyphosphate Site Model of Bromide Tracer Test. Comparison of measured versus simulated tracer concentrations at wells 399-1-23, 399-1-32, and 399-1-7; $\mathrm{s} 1, \mathrm{~s} 2$, and $\mathrm{s} 3$ are simulated values at different node positions in the well screen.

During each phase of the test, amendment solutions were injected into well 399-1-23 (Figure 1.3). Groundwater extracted from well 399-1-7 (shown in Figure 1.2), which is located approximately $190 \mathrm{~m}$ (620 ft) downgradient of the injection area, was used as make-up water for preparation of the injection solutions (i.e., in-line dilution of the concentrated tanker solutions). Eight monitoring wells were located within the targeted radial extent $(7.6 \mathrm{~m}[25 \mathrm{ft}])$ of the primary treatment volume and eight additional wells 
were located downgradient of this zone to evaluate the drift of the amendments and the lateral extent of treatment. Downgradient well locations were fanned out in a southeast to southwest direction to account for changes in groundwater flow direction associated with seasonal changes in Columbia River stage.

The injection parameters for all three phases of the field test are summarized in Table 3.20. Reactive and conservative species concentrations of interest measured in the injection solutions during the test are shown for the full test duration in Figure 3.47, which provides a graphical illustration of the three-phased approach. This plot also shows concentrations monitored in the injection well for the first day after the test. As indicated, amendment concentrations were held relatively constant during each phase of the test. Phosphate concentrations were more variable during the third phase of the test due to fluctuations in the chemical feed pump, but were maintained within acceptable limits. Analysis and interpretation of the field-scale polyphosphate injection test are discussed in Section 4.1.

Table 3.20. Summary of Injection Volumes, Flow Rates, and Test Durations for Each Phase of the Test

\begin{tabular}{ccccc}
\hline Injection & $\begin{array}{c}\text { Tanker Solution } \\
\text { Volume (gal) }\end{array}$ & $\begin{array}{c}\text { Total Solution } \\
\text { Volume (gal) }\end{array}$ & $\begin{array}{c}\text { Injection Flow } \\
\text { Rate (gal/min) }\end{array}$ & Duration (hr) \\
\hline Phase 1 & 4950 & 254000 & 200 & 25 \\
Phase 2 & 4100 & 580000 & 200 & 48 \\
Phase 3 & 4900 & 244000 & 200 & 20 \\
\hline
\end{tabular}

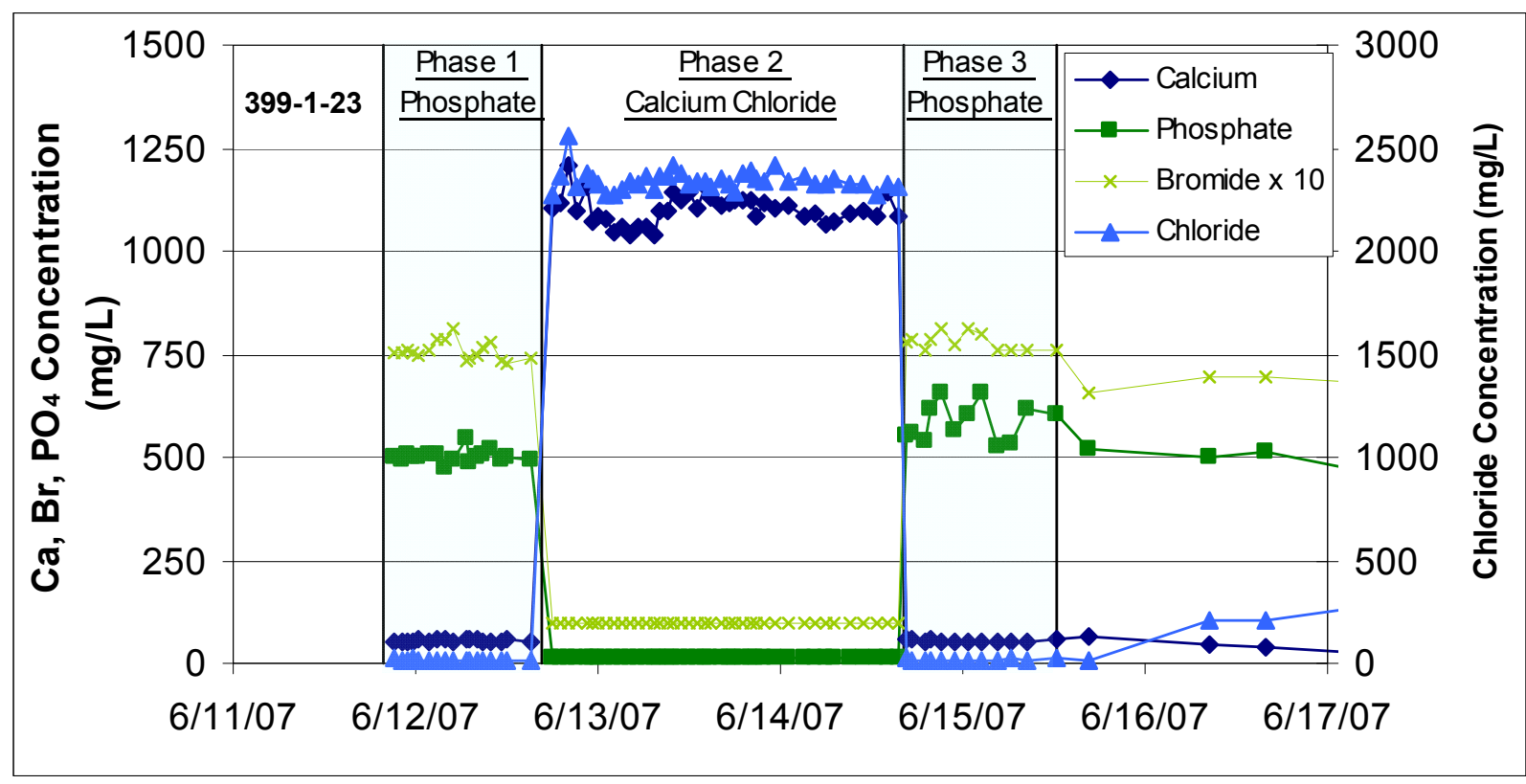

Figure 3.47. Reactive and Conservative Species of Interest Measured in the Injection Solution 


\subsection{Results and Discussion}

This section describes results and interpretation of the field-scale polyphosphate injection test, identifies implementation challenges, compares results with test objectives, and discusses the cost and schedule for performing the treatability study.

\subsection{Data Analysis and Interpretation}

Data analysis and interpretation have been separated into three sections including assessment of amendment arrival responses, impacts to formation permeability (i.e., aquifer plugging), and treatment performance based on uranium trend monitoring.

\subsubsection{Assessment of Amendment Arrivals}

Amendment arrival response data from the three phases of the injection test indicate significantly lower reactive constituent retardation than was predicted based on laboratory-scale column experiments (see discussion in Section 3.1.3). The lower effective retardations resulted in only limited overlap between the calcium and phosphate amendments during the transition between injection phases, and thus limited calcium-phosphate mineral formation. The arrival response for monitoring well 399-1-26 (Figure 4.1), which is located on the upgradient edge of the targeted primary treatment volume, provides a typical example of limited mixing between the two reactive constituents. During the initial injection phase, both phosphate and bromide (a conservative tracer) show a similar response, indicating very little retardation of the reactive species. During the transition between the first and second injection phases the phosphate concentration drops relatively rapidly as the calcium concentrations increase, providing for a limited duration of reactive species overlap at this location. During the transition between the second and third injection phases, the arrival/elution responses are even steeper, indicating even less mixing of the two reactive species had occurred. Also worth noting is the relatively high total phosphorous concentration during the third injection phase, indicating that significant concentrations of tripolyphosphate and pyrophosphate were still present (i.e., the difference between phosphate by IC and total phosphorous by ICP-OES represents the amount of tripoly- and pyro-phosphate remaining in the system), thus indicating that limited quantities of phosphate had been consumed to form calcium-phosphate mineral phases.

The arrival response for monitoring well 399-1-24 (Figure 4.2) provides an example of a location where better amendment mixing characteristics were observed. It should be noted that during the tracer injection test a delayed tracer arrival response was observed at this location, indicating that it is located within a zone of reduced permeability or along a flow path from the injection well that is impacted by lower-permeability materials. During the initial phase of the injection test, both bromide and phosphate arrival showed a similar response and only limited mixing was observed during the transition between the first and second injection phases. However, during the transition between the second and third injection phases, a significantly longer duration overlap occurs between the two reactive species. Of note is the low phosphate and total phosphorous concentrations during the third injection phase, which is an indicator of phosphate species consumption (tripolyphosphate, pyrophosphate, and orthophosphate) along the flow path between the injection well and this well location. 

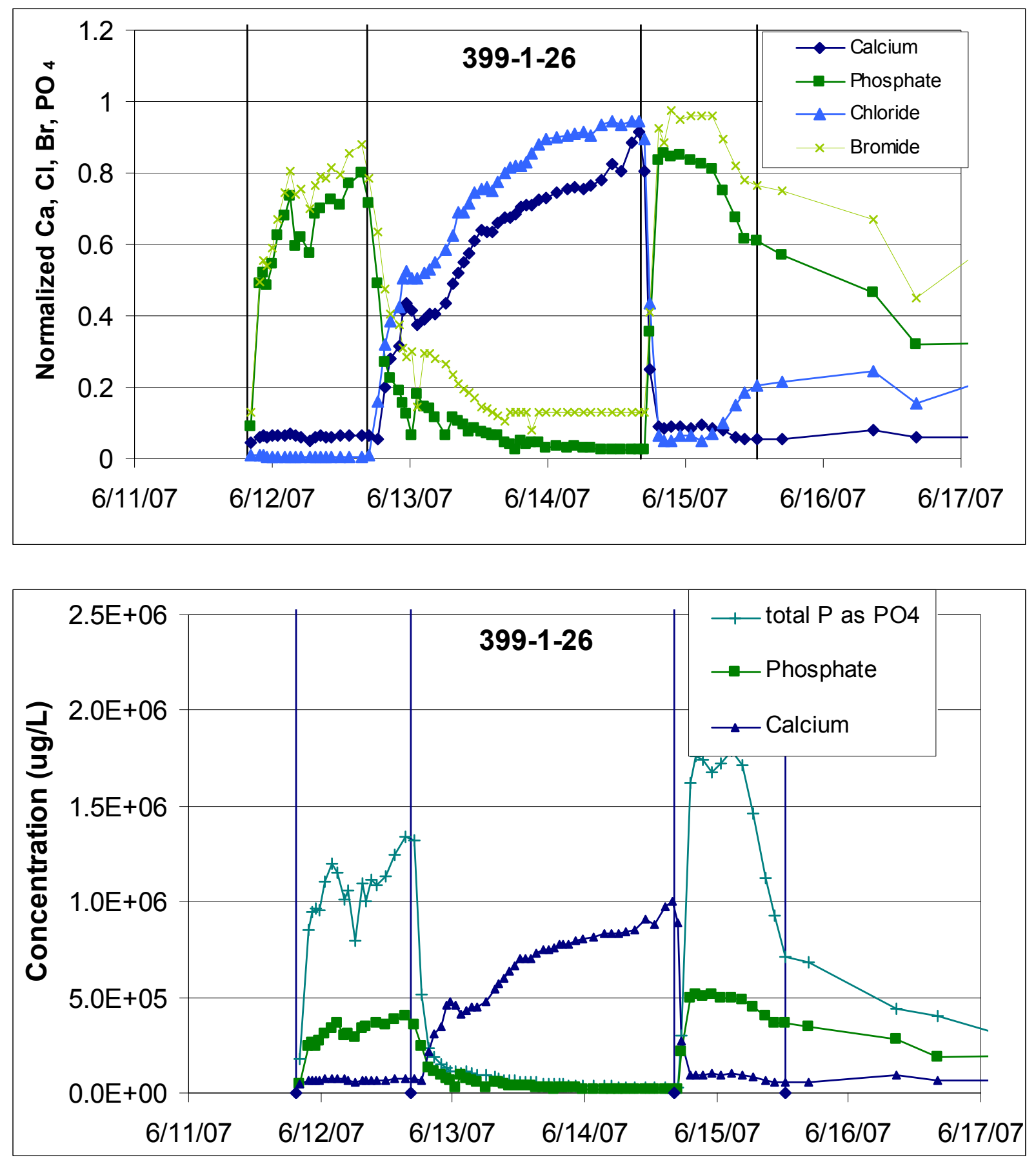

Figure 4.1. Calcium/Phosphate Amendment Arrival Response for Monitoring Well 399-1-26 

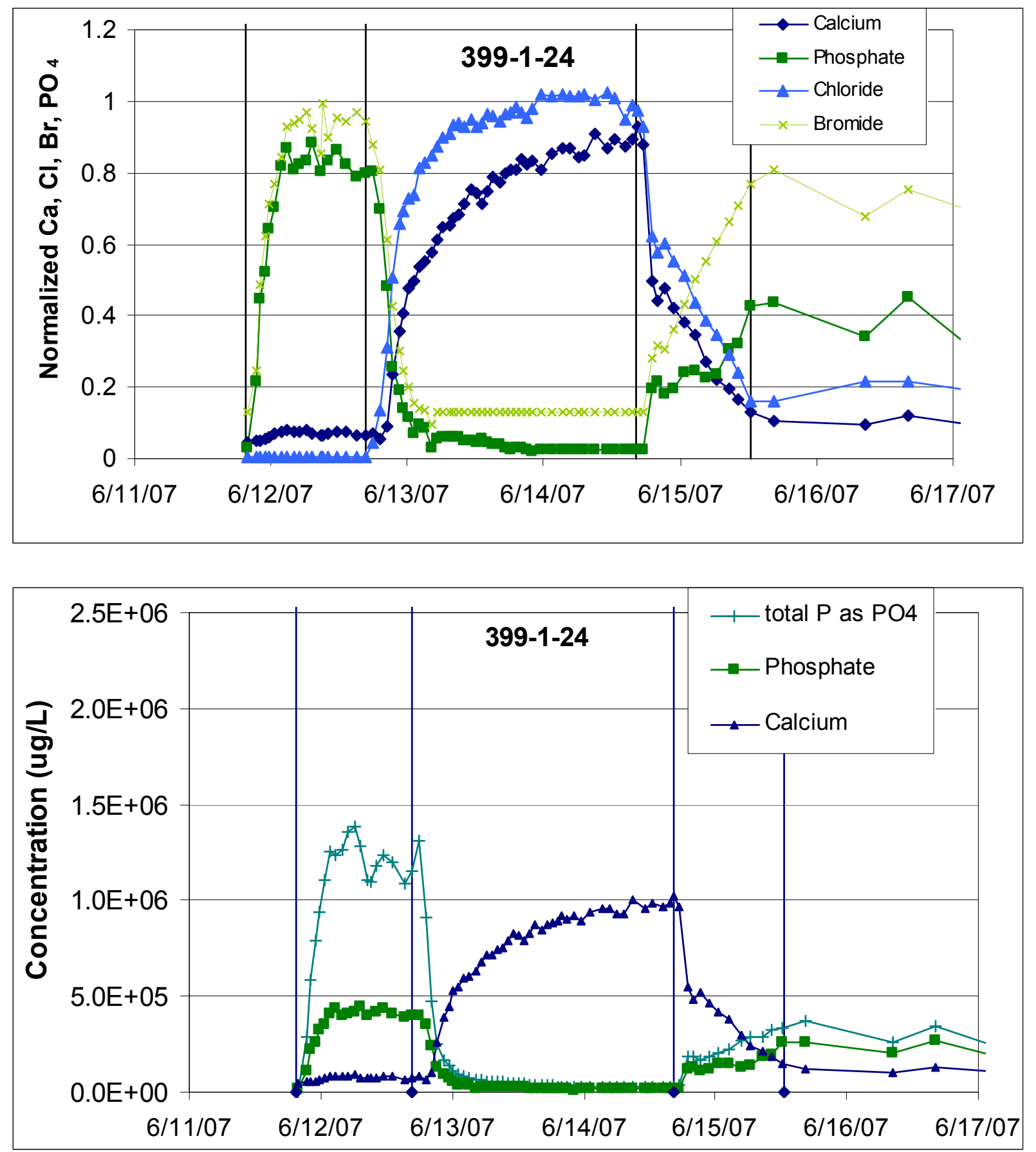

Figure 4.2. Calcium/Phosphate Amendment Arrival Response for Monitoring Well 399-1-24 
Amendment arrival for monitoring well 399-1-38 (Figure 4.3) provides a typical example of the mixing response for wells located outside the targeted primary treatment volume. Although similar arrival responses for phosphate and bromide were observed during the initial phosphate arrival, indicating limited phosphate retardation even at this radial distance, the lower pore water velocities and more dispersed arrival fronts at these more distal locations resulted in better mixing between the two reactive species.

A summary of the reactive species arrival concentrations (normalized to the injection concentration) and overlap durations (defined as the time period during which $10 \%$ or more of the injection concentration is present at the monitoring location) for all monitoring well locations are provided in Table 4.1. These data provide for a quantitative measure of the relative calcium/phosphate mixing efficiency at each well location. As indicated, total calcium/phosphate overlap ranged from 1 to 23 hours, with well 399-1-24 showing the longest duration of reactive species overlap (see Figure 4.2). At this well location, overlap between the first and second injection phases was approximately 3 hours and overlap between the second and third injection phases was approximately 20 hours. A comparison of the normalized phosphate arrival between the first and third phase of the tests shows that the phosphate concentration is two to four times lower in phase three, providing indication of the consumption of phosphate species and formation of calcium-phosphate mineral phases.

Phosphate arrival response data indicate that, under site conditions, the polyphosphate amendment could be effectively distributed over a relatively large lateral extent, with wells located at a radial distance of $23 \mathrm{~m}$ (75 ft) reaching from between $40 \%$ and $60 \%$ of the injection concentration. Given these phosphate transport characteristics, direct treatment of uranium through the formation of uranyl-phosphate mineral phases (i.e., autunite) could likely be effectively implemented at full field scale. However, formation of calcium-phosphate mineral phases using the selected three-phase approach was problematic. Although amendment arrival response data indicate some degree of overlap between the reactive species and thus potential for the formation of calcium-phosphate mineral phases (i.e., apatite formation), the efficiency of this treatment approach was relatively poor. Any future attempts at field-scale apatite formation under the hydrodynamic conditions characteristic of the Hanford 300 Area would need to account for the relatively low calcium and phosphate distribution coefficients for these coarse-grained materials during development of an injection strategy. Possible modification of the injection design include, but are not limited to, decreased injection rates and/or increased cycling frequency between the calcium and phosphate amendment solutions.

Plots showing the calcium/phosphate amendment arrival responses for all site monitoring wells are provided in Appendix C. 

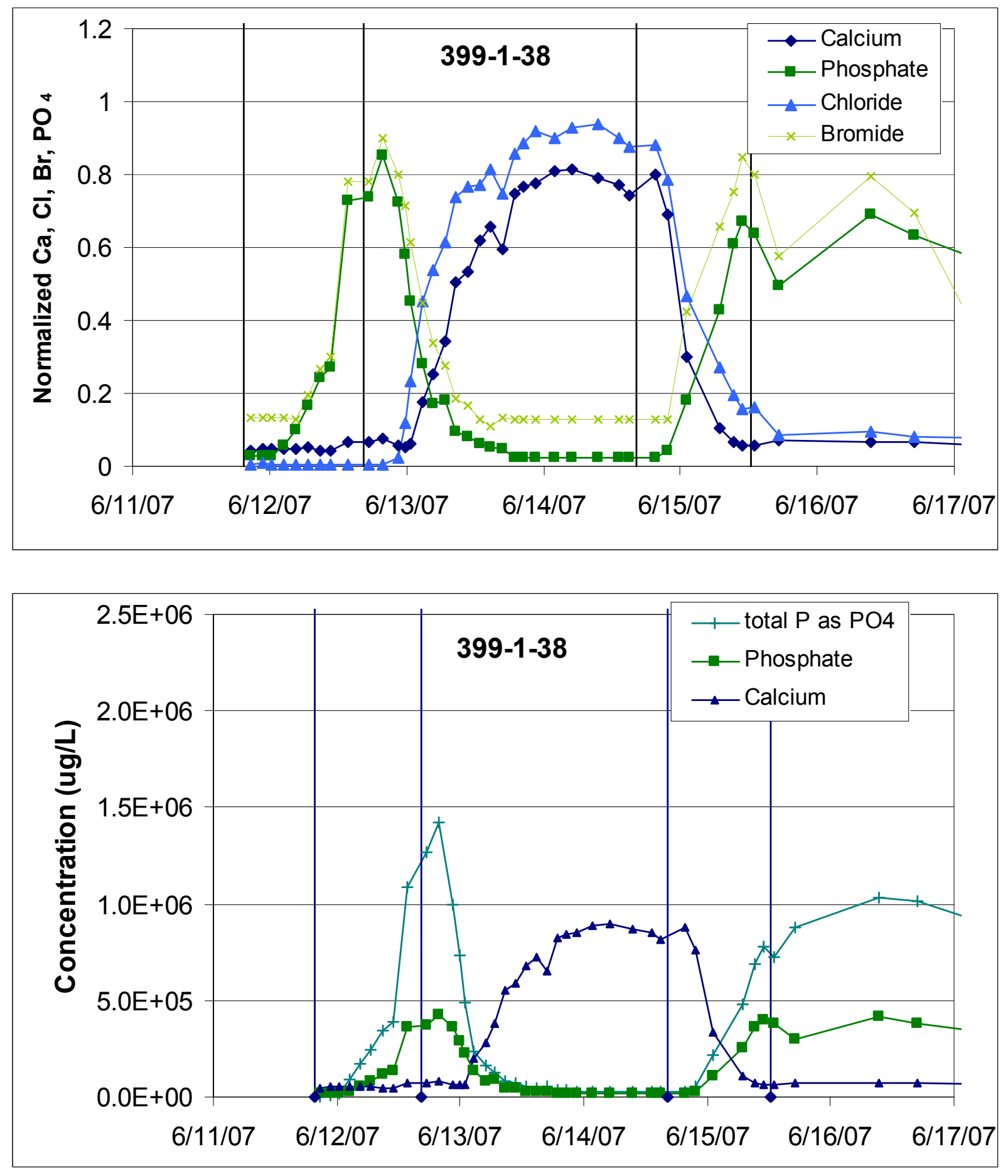

Figure 4.3. Calcium/Phosphate Amendment Arrival Response for Monitoring Well 399-1-38 
Table 4.1. Summary of Reactive Species Arrival Concentrations and Overlap Durations

\begin{tabular}{ccccccc}
\hline Well Name & $\begin{array}{c}\text { Normalized } \\
\text { Phase 1 } \\
\mathrm{PO}_{4} \text { arrival }\end{array}$ & $\begin{array}{c}\text { Normalized } \\
\text { Phase } 2 \\
\text { Ca arrival }\end{array}$ & $\begin{array}{c}\text { *Duration of } \\
\text { Phase 1-2 } \\
\text { overlap (hours) }\end{array}$ & $\begin{array}{c}\text { Normalized } \\
\text { Phase 3 } \\
\mathrm{PO}_{4} \text { arrival }\end{array}$ & $\begin{array}{c}\text { **Duration of } \\
\text { Phase 2-3 } \\
\text { overlap (hours) }\end{array}$ & $\begin{array}{c}\text { Total } \\
\text { Duration } \\
\text { of Overlap }\end{array}$ \\
\hline $399-1-23$ & 1.00 & 1.00 & -- & 1.00 & -- & -- \\
\hline $399-1-24$ & 0.78 & 0.72 & 3.0 & 0.26 & 20.0 & 23.0 \\
\hline $399-1-25$ & 0.92 & 0.94 & 2.0 & 0.89 & 0.0 & 2.0 \\
\hline $399-1-26$ & 0.65 & 0.61 & 9.0 & 0.74 & 9.0 & 18.0 \\
\hline $399-1-27$ & 0.49 & 0.62 & 2.0 & 0.29 & 7.0 & 9.0 \\
\hline $399-1-28$ & 0.16 & 0.24 & 3.5 & 0.18 & 15.0 & 18.5 \\
\hline $399-1-29$ & 0.52 & 0.64 & 8.0 & 0.74 & 3.0 & 11.0 \\
\hline $399-1-30$ & 0.97 & 0.97 & 1.0 & 1.01 & 0.0 & 1.0 \\
\hline $399-1-31$ & 0.64 & 0.85 & 0.0 & 0.70 & 4.0 & 4.0 \\
\hline $399-1-33$ & 0.37 & 0.39 & 7.5 & 0.15 & 4.0 & 11.5 \\
\hline $399-1-34$ & 0.29 & 0.34 & 10.0 & 0.11 & 0.0 & 10.0 \\
\hline $399-1-35$ & 0.45 & 0.55 & 4.0 & 0.10 & 0.0 & 4.0 \\
\hline $399-1-36$ & 0.38 & 0.44 & 6.0 & 0.10 & 3.5 & 9.5 \\
\hline $399-1-37$ & 0.68 & 0.70 & 5.5 & 0.55 & 7.0 & 12.5 \\
\hline $399-1-38$ & 0.49 & 0.63 & 6.0 & 0.50 & 6.0 & 12.0 \\
\hline 0
\end{tabular}

* Overlap of $10 \%$ or higher of both $\mathrm{PO}_{4}$ and $\mathrm{Ca}$ after phase 2 injection started.

** Overlap of $10 \%$ or higher of both $\mathrm{PO}_{4}$ and $\mathrm{Ca}$ after phase 3 injection started.

\subsubsection{Impacts on Formation Permeability}

Evaluation of pressure response (both prior to and during the polyphosphate injection test) and amendment transport behavior during the three separate phases of the injection test provided evidence of both changes in the spatial distribution of aquifer permeability and an overall reduction in the bulk permeability of the aquifer materials. Changes in the spatial distribution of permeability are evident from a comparison of amendment arrival responses at monitoring well 399-1-24 and 399-1-38 (Figure 4.2 and Figure 4.3, respectively). In the case of 399-1-38, bromide arrival during the third phase of the injection test was earlier than observed during the first phase of the test, indicating increased flow along the flow path between the injection well and this monitoring location. Conversely, tracer arrival during the third phase of the injection was delayed at well location 399-1-24, indicating decreased flow along the flow path between the injection well and this monitoring location. This redistribution of flow within the aquifer volume is indicative of permeability reduction associated with the amendment injections that varies spatially throughout the treatment zone. Reductions in permeability would result in less flux to the impacted portion of the aquifer and would tend to redirect more flux to portions of the aquifer where the permeability was not reduced. 
Changes in the spatial distribution of conservative tracer arrival over the three phases of the injection test are shown in plan view in Figure 4.4. Three snapshots of tracer distribution are shown at elapsed times of 18 hours into each injection phase. As indicated, tracer concentrations at most well locations outside the targeted primary treatment volume were successively lower during the second and third injection phase, with the exception of wells 399-1-29 and 399-1-38 where tracer concentrations increased.

Permeability reduction in the Hanford formation was investigated by comparing the pressure recovery responses associated with termination of the polyphosphate injection test (post-treatment) to the site-specific hydraulic characterization results obtained with the tracer injection test performed in December 2006 (pre-treatment). The same river correction and hydraulic analysis methods used for estimating aquifer hydraulic properties from the pre-treatment pressure buildup data were used in the analysis of the post-treatment recovery responses. Refer to Section 3.2.3 for a detailed discussion of the Rasmussen and Crawford (1997) multiple-regression deconvolution river correction and Neuman (1975) type-curve methods. Prior to the type-curve fitting, the recovery data were translated into equivalent pressure buildup responses using the method of Agarwal (1980).

Figures 4.5 through 4.8 show the pressure and pressure derivative data plotted along with the Neuman (1975) type curves and model inputs for the four monitoring wells used in the analysis. Prescribed values for specific yield, anisotropy ratio, storativity, and aquifer thickness are summarized in Table 4.2. A specific yield value of 0.15 was used in the post-treatment analysis, rather than 0.19 , which was used in the pre-treatment analysis. This resulted in improved curve fits and is consistent with the indication of permeability reduction (see discussion below). The other model input parameters were held consistent with the analysis of the pre-treatment hydraulic analysis. It should be noted that, due to the extensive nature of the river correction, the hydraulic analysis of the post-injection pressure recovery data was restricted to four selected monitoring wells, all of which were also used in the previous hydraulic characterization (Section 3.2.3.2). 


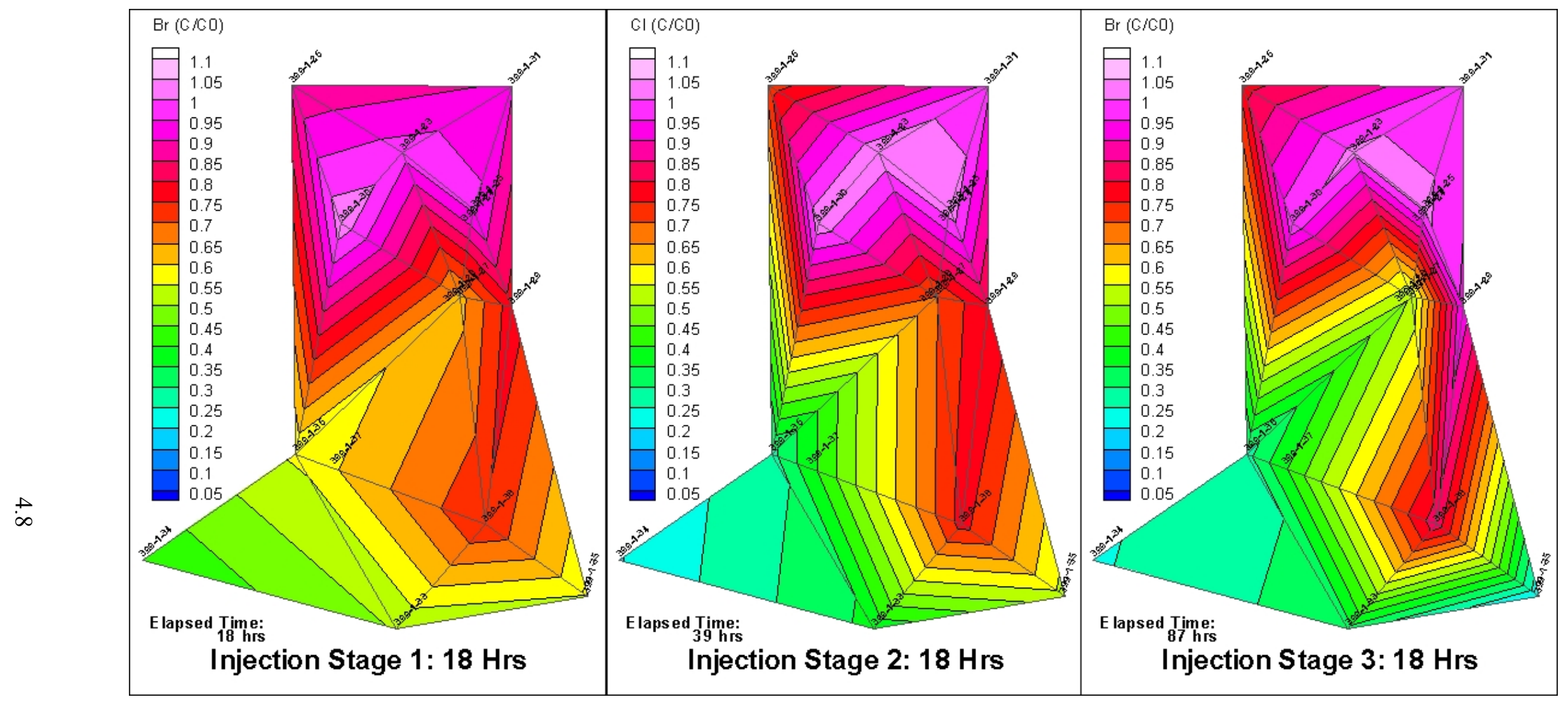

Figure 4.4. Conservative Tracer Arrival Distribution in Site Monitoring Wells 18 Hours into Each Injection Phase 


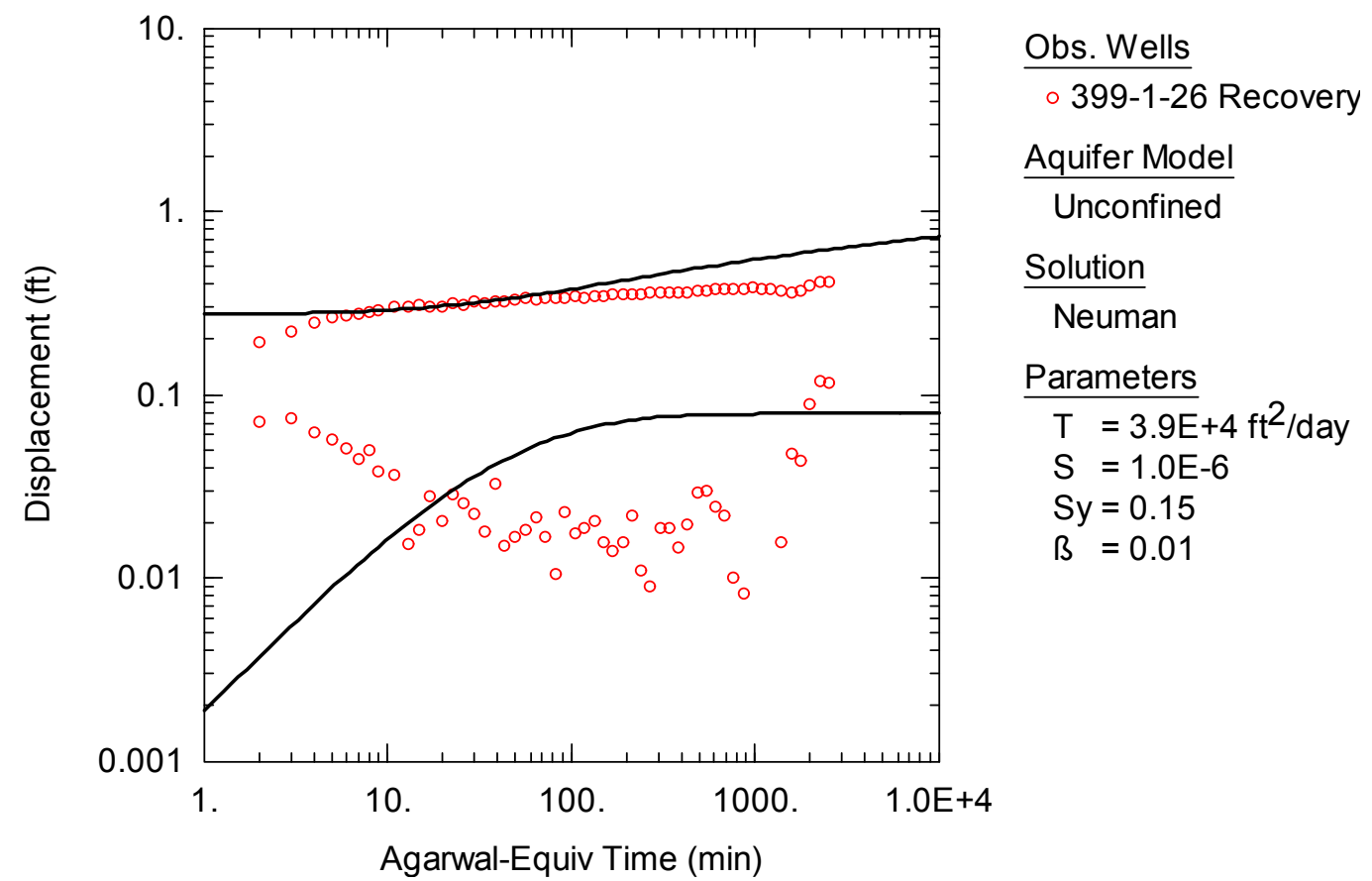

Figure 4.5. Neuman Type-Curve Analysis of Pressure Recovery Data at the Fully Screened Well 399-1-26 Following the Polyphosphate Treatability Injection Test

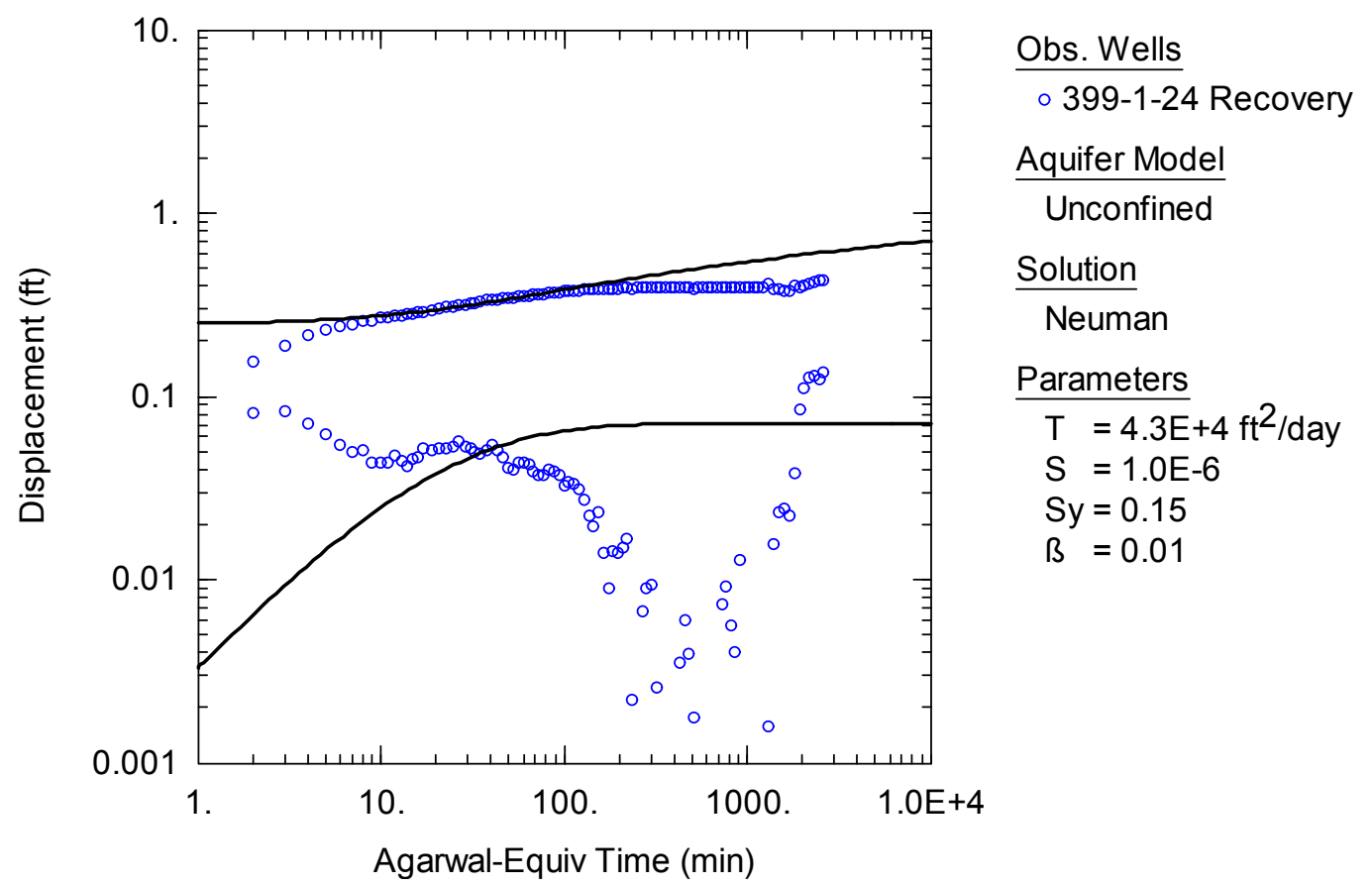

Figure 4.6. Neuman Type-Curve Analysis of Pressure Recovery Data at the Upper-Screened Well 399-1-24 Following the Polyphosphate Treatability Injection Test 


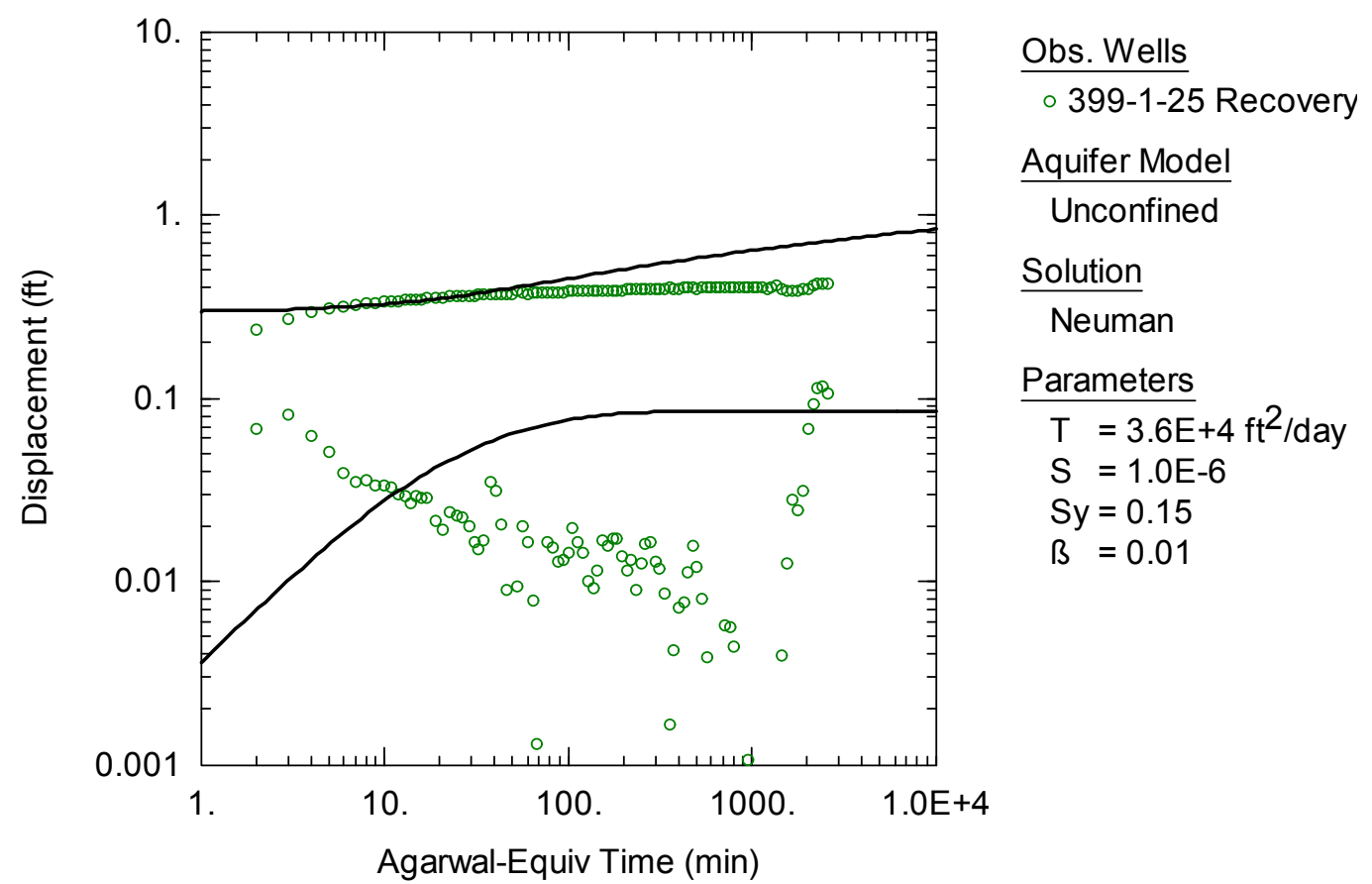

Figure 4.7. Neuman Type-Curve Analysis of Pressure Recovery Data at the Lower-Screened Well 399-1-25 Following the Polyphosphate Treatability Injection Test

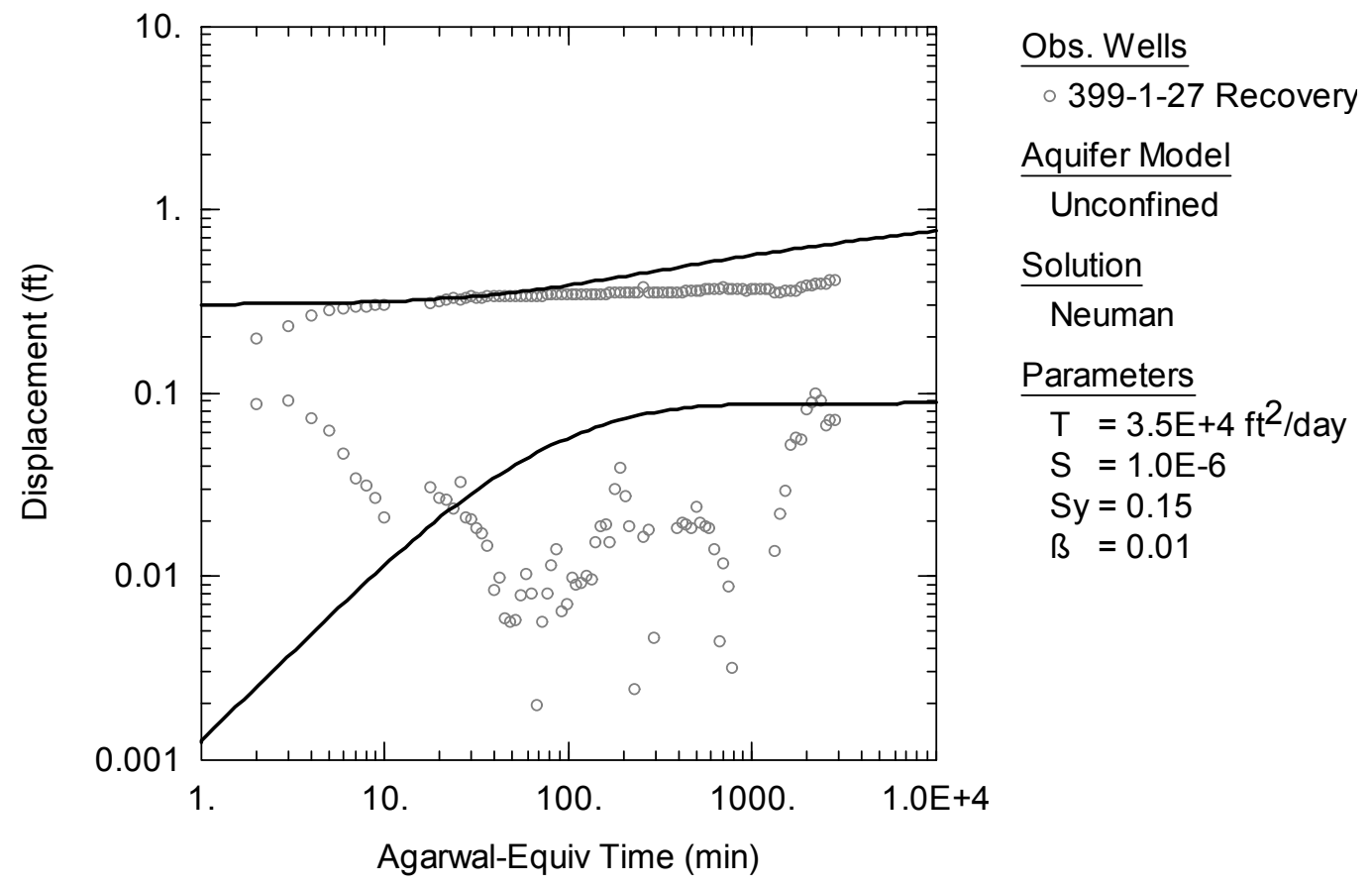

Figure 4.8. Neuman Type-Curve Analysis of Pressure Recovery Data at the Lower-Screened Well 399-1-27 Following the Polyphosphate Treatability Injection Test 
Table 4.2. Summary of Aquifer Hydraulic Property Estimates Based on Neuman (1975) Type-Curve Analyses of Pressure Recovery Responses Following the June 2007 Polyphosphate Injection Test

\begin{tabular}{|c|c|c|c|c|c|}
\hline \multirow[b]{2}{*}{ Well Name } & \multirow{2}{*}{$\begin{array}{l}\text { Well } \\
\text { Screen } \\
\text { Zone }\end{array}$} & \multirow[b]{2}{*}{$\begin{array}{l}\text { Radial Distance } \\
\quad(\mathrm{ft})\end{array}$} & \multirow[b]{2}{*}{$\begin{array}{l}\text { Transmissivity } \\
\left(\mathrm{ft}^{2} / \text { day }\right)\end{array}$} & \multicolumn{2}{|c|}{ Hydraulic Conductivity } \\
\hline & & & & $\mathrm{ft} /$ day & $\mathrm{m} /$ day \\
\hline $399-1-24$ & Upper & 14.9 & $4.3 \mathrm{E}+04$ & $2.3 \mathrm{E}+03$ & $7.0 \mathrm{E}+02$ \\
\hline $399-1-25$ & Lower & 14.4 & $3.6 \mathrm{E}+04$ & $1.9 \mathrm{E}+03$ & $5.8 \mathrm{E}+02$ \\
\hline $399-1-26$ & Full & 19.9 & $3.9 \mathrm{E}+04$ & $2.1 \mathrm{E}+03$ & $6.3 \mathrm{E}+02$ \\
\hline \multirow[t]{3}{*}{$399-1-27$} & Lower & 24.5 & $3.5 \mathrm{E}+04$ & $1.9 \mathrm{E}+03$ & $5.7 \mathrm{E}+02$ \\
\hline & & Average & $3.8 \mathrm{E}+04$ & $2.0 \mathrm{E}+03$ & $6.2 \mathrm{E}+02$ \\
\hline & & S.D. & $3.6 \mathrm{E}+03$ & $1.9 \mathrm{E}+02$ & $5.8 \mathrm{E}+01$ \\
\hline
\end{tabular}

Prescribed test parameters: specific yield $(\mathrm{Sy})=0.15$; anisotropy $(\mathrm{Kz} / \mathrm{Kr})=0.01$; storativity $(\mathrm{S})=1.0 \mathrm{E}-06$; aquifer thickness (b) $=18.8 \mathrm{ft}$

The results of the hydraulic analysis of the pressure recovery response in the four selected monitoring wells indicate an average hydraulic conductivity (K) estimate of $\sim 600 \mathrm{~m} /$ day (2000 ft/day). As discussed in Section 3.2.3.2, the average pre-treatment $\mathrm{K}$ estimate for the aquifer was $\sim 4000 \mathrm{~m} /$ day $(13,000 \mathrm{ft} /$ day [Table 3.13]), which is over six times higher than the post-treatment K. Figure 4.9 shows comparisons of pre- and post-treatment pressure responses and $\mathrm{K}$ estimates for the four wells common to both analyses. There is a significantly higher pressure response for the post-treatment data. Neuman (1975) type-curves were fit to the early-intermediate time pressure recovery data because the late-time data show a flattening out of the pressure response. Late-time departure from the expected response pattern may be due to the boundary effects of the river or a nearby zone of higher conductivity.

The goodness of fit with the Neuman (1975) type curves to the post-treatment recovery data was decreased relative to that obtained for the pre-treatment pressure buildup data. Heterogeneities and other non-ideal test conditions following the injection of the polyphosphate and calcium amendments appear to be influencing the response of the pressure recovery data, more so than for test conditions present during the tracer test. Although the hydraulic conductivity estimates from the post-treatment recovery data are susceptible to a relatively higher degree of uncertainty, the higher overall pressure response indicates that there was a notable reduction in formation permeability within the treatment zone as a result of the polyphosphate injection test (Figure 4.9). 

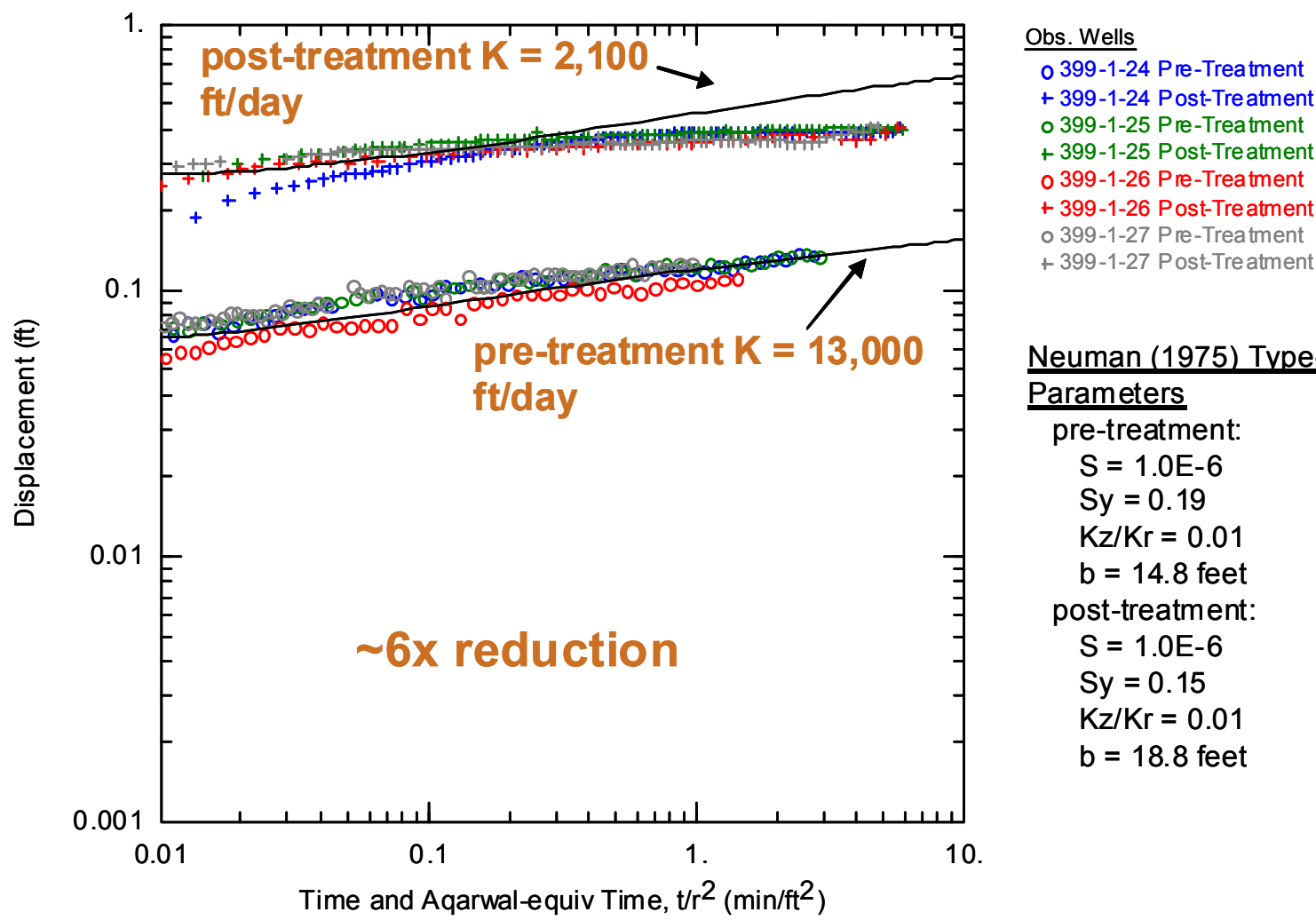

Neuman (1975) Type-Curve Parameters

pre-treatment:

$S=1.0 \mathrm{E}-6$

Sy $=0.19$

$\mathrm{Kz} / \mathrm{Kr}=0.01$

$b=14.8$ feet

post-treatment:

$S=1.0 \mathrm{E}-6$

Sy $=0.15$

$\mathrm{Kz} / \mathrm{Kr}=0.01$

$b=18.8$ feet

Figure 4.9. Composite Plot of Pre- and Post Treatment Pressure Responses Showing Permeability Reduction in the Formation as a Result of the Polyphosphate Injection Test

\subsubsection{Uranium Treatment Performance}

The baseline uranium concentration in the targeted primary treatment zone ranged from approximately 60 to $80 \mathrm{ug} / \mathrm{L}$ (see

Table 3.15) during the three pre-treatment monitoring events. Following the injection test, aqueous uranium concentrations were routinely monitored to assess treatment performance. Uranium performance data are shown in Figure 4.10 for the two wells whose amendment arrival response was discussed in Section 4.1.1. For monitoring well 399-1-26, the initial uranium performance data indicate relatively good direct treatment of uranium through the formation of uranyl-phosphate mineral phases (i.e., autunite). It should be noted that the initial low uranium concentrations could also have been partially attributed to displacement of uranium out of the treatment zone by the injection of large volumes of high ionic strength amendment solutions. Although initial post-treatment uranium concentrations decreased to below the drinking water standard of $30 \mathrm{ug} / \mathrm{L}$, a significant rebound in uranium concentration was observed approximately 2 months after treatment. 

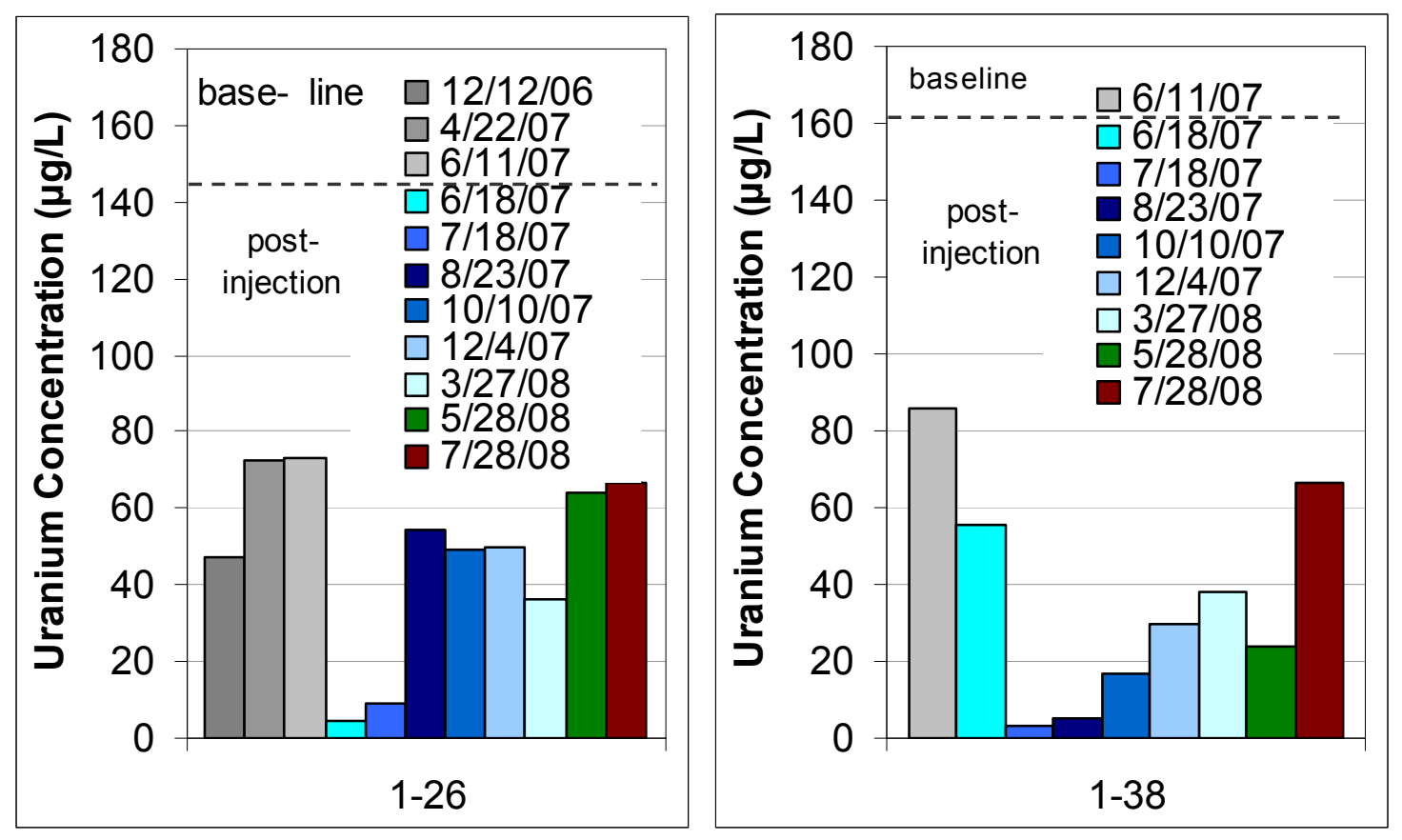

Figure 4.10. Uranium Concentration Trends in Selected Site Monitoring Wells

At well 399-1-38, uranium concentrations didn't decrease until the second sampling event one month after the injection and remained low for a longer period of time. The rebound response for these two wells is consistent with their relative locations; 399-1-26 is located on the upgradient side of the treatment zone and thus would be expected to rebound first. However, a composite evaluation of rebound response at all site monitoring wells did not identify any correlations between this response and either 1) distance downgradient from the injection well, 2) amendment concentrations observed during treatment, or 3) the duration of calcium and polyphosphate amendment overlap. In general, uranium performance monitoring results support the hypothesis that limited long-term treatment capacity (i.e., apatite formation) was established during the injection test. Concentration trend plots for all wells are provided in Appendix D.

\subsection{Implementation Challenges}

The objective of the treatability test was to evaluate the efficacy of using polyphosphate injections to treat uranium-contaminated groundwater in situ. The plan had two parts. The first was the direct formation of an insoluble uranium phosphate mineral, autunite. The second was the formation of the calcium phosphate mineral apatite to serve as a long-term source of phosphate in the aquifer. This long-term source of phosphate would result in the precipitation of further autunite as additional uranium was transported into the treatment zone by contaminated groundwater flow. The results of the treatability test indicated that while the direct formation of autunite appears to have been successful, the outcome of the apatite formation of the test was more limited. This section of the report summarizes the issues limiting the formation of apatite within the test.

Two separate overarching issues impact the efficacy of apatite remediation for uranium sequestration within the 300 Area: 1) the formation and emplacement of apatite via polyphosphate technology, which is largely affected by hydrodynamic conditions, and 2) the efficacy of apatite for sequestering uranium, which is largely affected by geochemical conditions in the aquifer. 


\subsubsection{Effect of Hydrodynamic Conditions on the Formation of Apatite}

Two hydrodynamic conditions affected the results of the treatability test: 1) the relatively high groundwater velocities that characterize the 300 Area unconfined aquifer, and 2) the lack of surface area related to the large size of the clasts in the aquifer.

\subsubsection{High Groundwater Velocities}

The Hanford formation in the 300 Area is characterized by high hydraulic conductivities. In some locations, such as the treatability test site, this has led to high groundwater flow velocities. The evidence for these velocities is discussed in detail in previous sections of this report.

Sorption of phosphate and calcium to the sedimentary matrix is relatively slow, requiring several hours. Due to kinetic considerations, flow rates resulting in more rapid transport of calcium and phosphate within the sedimentary matrix will significantly reduce the retardation, resulting in less mixing of injection phases during remedy implementation. This appears to be the case at the treatability test site.

\subsubsection{Low Surface Area}

During the pilot-scale field test, limited mixing between the calcium and phosphate that were injected resulted from a combination of factors. These include, but are not limited to, 1) the rate of injection used during remedy emplacement $(756 \mathrm{~L} / \mathrm{min}) ; 2)$ the groundwater velocity $(15.24 \mathrm{~m} /$ day $)$ within the 300 Area; 3 ) the open framework sedimentary matrix, which possesses minimal fine-textured particles; and 4) low effective retardation values for calcium and phosphate within the 300 Area subsurface. For example, Figure 4.11 is a graph of the normalized BTCs for calcium, phosphate, chloride, and bromide at monitoring well 399-1-29. The results displayed in Figure 4.11 are representative of those observed at most wells within the field test site. There was evidence of both $\mathrm{PO}_{4}$ and $\mathrm{Ca}$ mass loss, so precipitation of some apatite was likely, although not to the extent observed in laboratory experiments due to the limited mixing observed in the field. For the first injection pulse, $103.2 \%$ of the $\mathrm{Br}^{-}$was recovered and $71.7 \%$ of the $\mathrm{PO}_{4}$, indicating $30 \%$ of the $\mathrm{PO}_{4}$ was lost (likely precipitated). For the second injection pulse, $6.8 \%$ of the $\mathrm{PO}_{4}$ was lost. For the Ca injection pulse, $18 \%$ of the injected mass was lost.

Laboratory-derived effective retardation factors for the $\mathrm{PO}_{4}$ (4.76) and $\mathrm{Ca}$ (2.41) were used to design the injection strategy and create sufficient mixing between the two solutions. Much smaller retardation was observed for both $\mathrm{PO}_{4}$ and $\mathrm{Ca}$ in the field injection experiment, likely due to the high groundwater velocities that occur in these coarse-grained materials. For the adsorption limbs of the first and second $\mathrm{PO}_{4}$ pulses (Figure 4.11), the effective retardation factor was 1.0 (first pulse) or 0.93 (second pulse). The desorption limb of the first $\mathrm{PO}_{4}$ pulse had an apparent retardation much less than 1.0, but this was during $\mathrm{Ca} 2+$ injection, so it may be highly influenced by precipitation. The effective retardation factor for $\mathrm{Ca}$ appeared to be $>1$ for the adsorption limb, but again, this was likely influenced by precipitation with the $\mathrm{PO}_{4}$ present. The desorption limb of $\mathrm{Ca}$ had an effective retardation factor of 1.0. The limited retardation observed under field conditions limited the mixing of the three remedy phases. Furthermore, Wellman et al. (2007) previously noted that the ratio of calcium to phosphate needed to precipitate apatite is highly sensitive. The highly variable hydrodynamic conditions present in the 300 Area subsurface challenge the ability to control this variable. These factors limit the in situ formation of apatite to quantities that are less than the amount predicted based on the stoichiometry of the injection formulations. 


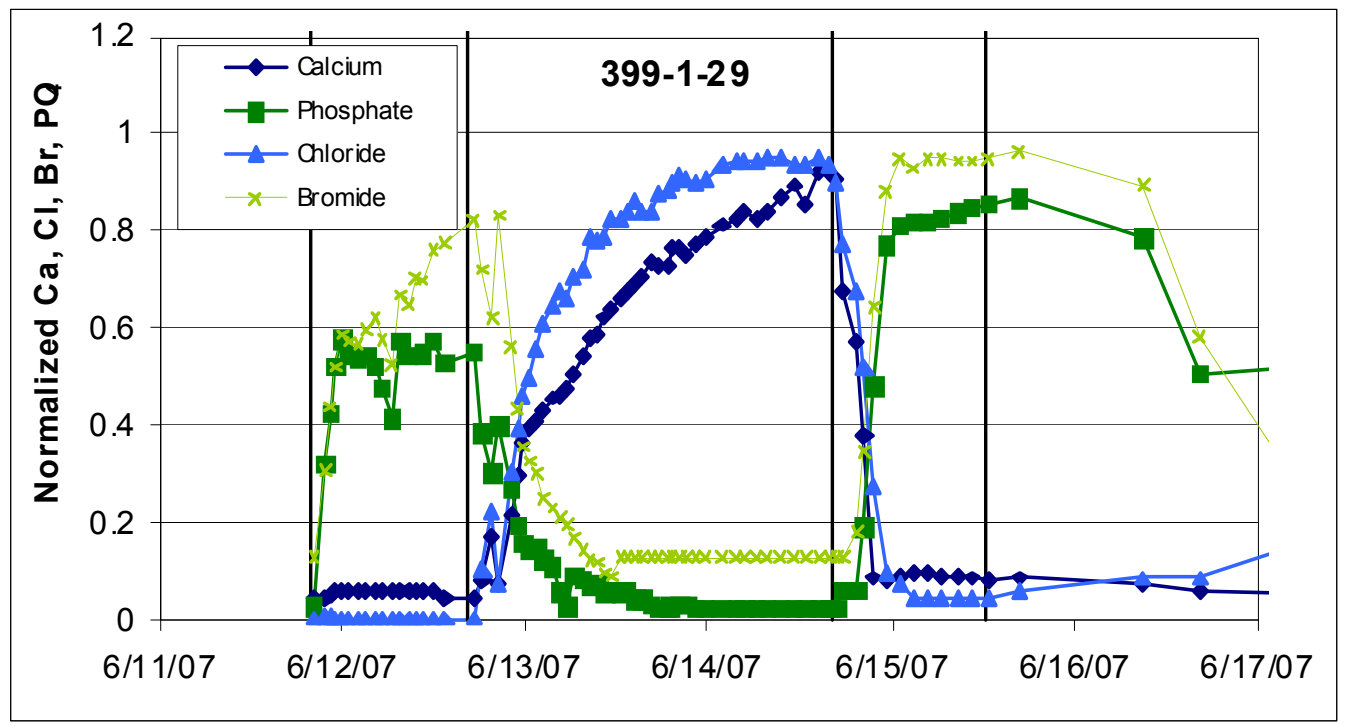

Figure 4.11. Normalized BTC for Calcium, Phosphorus, Chloride, and Bromide at Downgradient Well 399-1-29. The curve displays characteristic results with limited mixing of the calcium and phosphorus injections during the pilot-scale field test.

\subsubsection{Effect of 300 Area Geochemical Conditions on the Removal and Long- Term Retention of Uranium with Apatite}

Uranium chemistry is highly influenced by a number of geochemical variables, including $\mathrm{pH}$ and carbonate concentrations, which are particularly important. In addition, the long-term stability of uranium sequestered by apatite is dependent on the chemical speciation of uranium, the surface speciation of apatite, and the mechanism of retention, which is highly susceptible to dynamic geochemical conditions.

\subsubsection{Effects of $\mathrm{pH}$ on Adsorption of Uranium on Apatite}

Figure 4.12 displays historical $\mathrm{pH}$ values for a number of select near-river and inland wells near the 300 Area polyphosphate pilot test site. During the late 1980s and early 1990s, the pH of the groundwater within this region was strongly influenced by liquid waste disposal to process ponds and trenches. As such, the $\mathrm{pH}$ ranged from 6.7 to 8.0, with occasional spikes in $\mathrm{pH}$ being due to high river years and a reduction in the dilution from the cessation of disposal to the trenches. It was originally assumed that the groundwater $\mathrm{pH}$ would decrease in locations near the river, because of the effect of lower $\mathrm{pH}$ river water. However, as can be seen in Figure 4.12 that appears not to be the case. Over the past 10 years, the groundwater $\mathrm{pH}$ has stabilized and is generally within the range of 7.5 to 8.0.

Figure 4.13 shows the dependence of uranium uptake expressed as aqueous uranium concentration in the presence of hydroxyapatite under the $\mathrm{pH}$ range of 6 to $8,23^{\circ} \mathrm{C}$, given an aqueous uranium concentration of $100 \mathrm{ppm}$ and solution-to-solid ratio of 100 to 1 . At $\mathrm{pH} \leq 7,100 \%$ of the aqueous uranium was removed within the first 2 minutes. However, under the $\mathrm{pH}$ range of 7.5 to 8 , only $\sim 15 \%$ of the aqueous uranium was removed within the first 2 minutes. Subsequently, further removal of aqueous uranium was minimal. Thus, as the concentration of aqueous uranium increases within the treatment zone and more uranium is sequestered on the apatite surface, the rate and extent of uranium sequestration exhibits a greater dependence on $\mathrm{pH}$ and decreased performance at $\mathrm{pH}$ values $\geq 7.5$. 

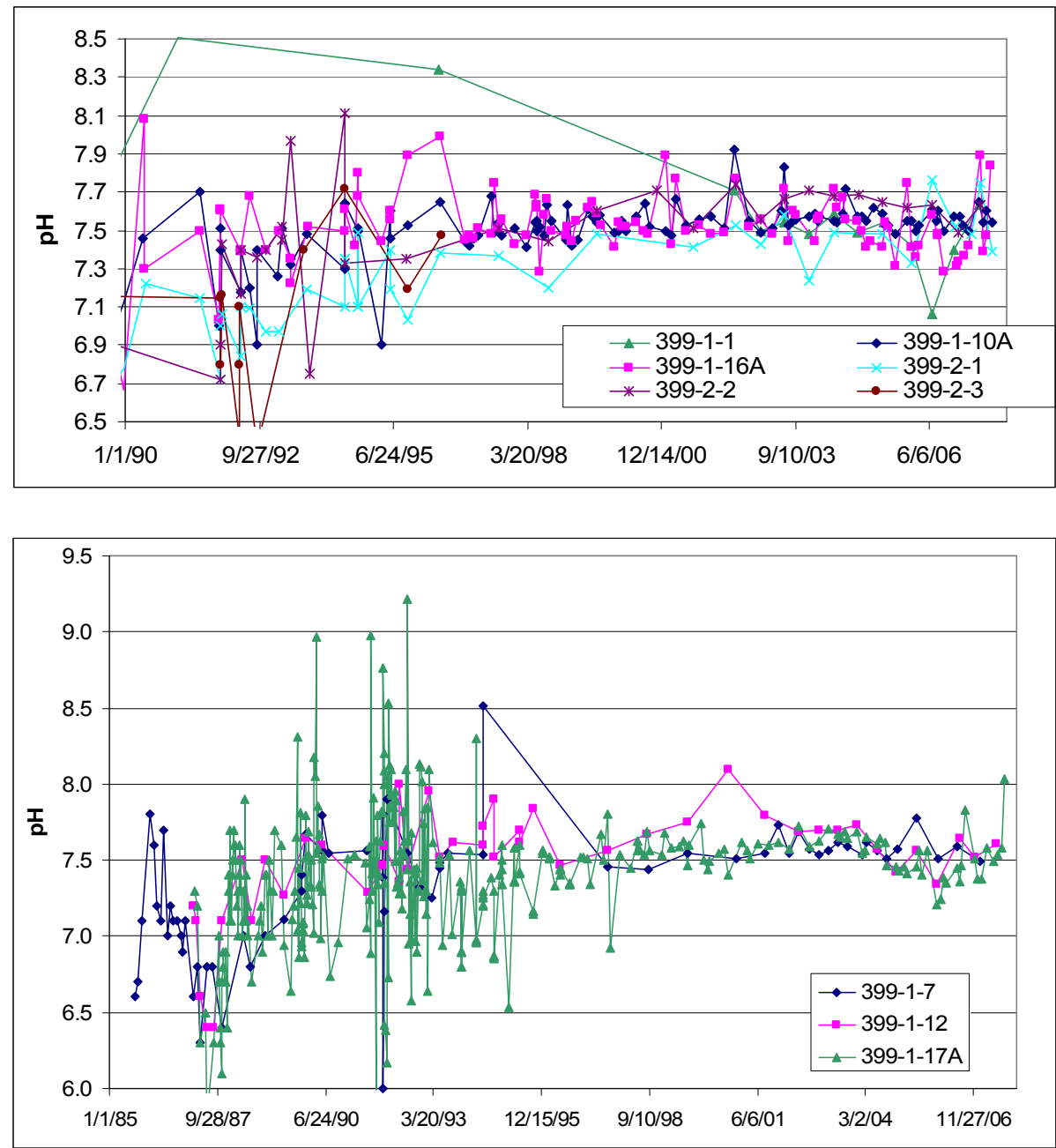

Figure 4.12. Historical $\mathrm{pH}$ Values of Selected Near-River (top graph) and Inland Wells (bottom graph) in the 300 Area (from Wellman et al. 2008)
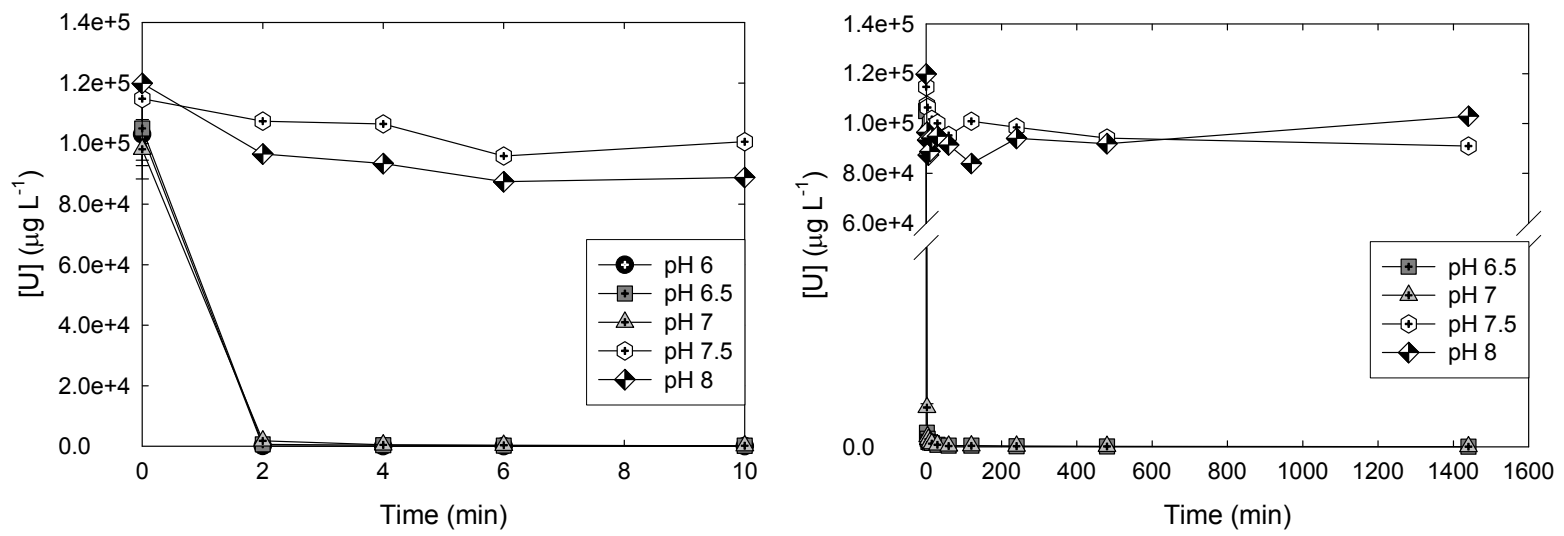

Figure 4.13. Dependence of Uranium Uptake Expressed as Aqueous Uranium Concentration as a Function of Time in Hydroxyapatite-Equilibrated Groundwater (from Wellman et al. 2008). 


\subsubsection{Effect of Speciation on the Sequestration of Uranium on Apatite}

The $\mathrm{pH}$ and concentration of $\mathrm{CO}_{2}$ have a significant influence on the speciation of aqueous uranium and the reactive sites present on the surface of hydroxyapatite. Under the $\mathrm{pH}$ range of 6 to 8 , the aqueous speciation of uranium changes from predominantly $\mathrm{UO}_{2}\left(\mathrm{CO}_{3}\right)_{2}{ }^{4-}$ and $\mathrm{UO}_{2}\left(\mathrm{CO}_{3}\right)_{2}{ }^{2-}$ to the more weakly charged species $\mathrm{Ca}_{2} \mathrm{UO}_{2} \mathrm{CO}_{3}$ and $\left(\mathrm{UO}_{2}\right)_{2}\left(\mathrm{CO}_{3}\right)(\mathrm{OH})_{3}{ }^{-}$. Additionally, hydroxyapatite surfaces are hypothesized to have two different types of surface groups: $\equiv \mathrm{Ca}-\mathrm{OH}_{2}{ }^{+}$and $\equiv \mathrm{P}-\mathrm{OH}$, affording a $\mathrm{pH}_{p z c}$ of 8.15 or 7.13 upon exposure to atmospheric $\mathrm{CO}_{2}$ (Wu et al. 1991). Below a $\mathrm{pH}$ of 4 , the phosphate sites are predicted to be fully protonated, $\equiv \mathrm{P}-\mathrm{OH}$. Above $\mathrm{pH} 4$, the phosphate sites begin to deprotonate,

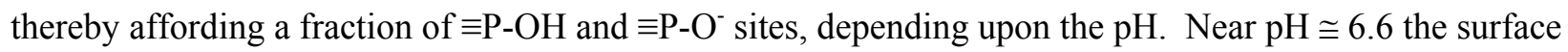
speciation is predicted to be approximately $50 \% \equiv \mathrm{P}-\mathrm{OH}$ and $50 \% \equiv \mathrm{P}-\mathrm{O}^{-}$. At a pH of $\sim 7, \equiv \mathrm{Ca}-\mathrm{OH}_{2}{ }^{+}$ surface sites begin to deprotonate, and at a $\mathrm{pH} \cong 9.7$ affords approximately $50 \% \equiv \mathrm{Ca}_{-} \mathrm{OH}_{2}{ }^{+}$and $50 \%$ $\equiv \mathrm{Ca}-\mathrm{OH}$ (Wu et al. 1991). Integrating changes in both the aqueous speciation of uranium and the speciation of reactive surface sites on hydroxyapatite can result in significant variations in the efficacy and mechanism of hydroxyapatite for sequestration of uranium under the $\mathrm{pH}$ range encountered within the 300 Area aquifer, $\mathrm{pH}=7$ to 8 . To evaluate the effects of these variables on uranium sequestration, static batch tests were conducted at a solution-to-solid ratio of $325 \mathrm{~mL} / \mathrm{g}$ apatite in the presence of $120 \mu \mathrm{g} / \mathrm{L}$ aqueous uranium at $16^{\circ}$ and $23^{\circ} \mathrm{C}$. These conditions are relevant to those that could have been encountered during the field-scale pilot test having precipitated $0.025 \mathrm{wt} \%$ apatite. Additionally, these conditions afford an excess of reactive surface sites to evaluate the subtle effects of $\mathrm{pH}$ and carbonate concentration on the sequestration of uranium on hydroxyapatite under a narrow $\mathrm{pH}$ range.

In addition to imparting significant influence on the aqueous speciation of uranium and the speciation of reactive surface sites, the high carbonate concentrations in the 300 Area subsurface also impact the mechanism of uranium retention with hydroxyapatite. Fuller et al. (2002a) previously demonstrated that in the absence of carbonate, sorbed uranium concentrations in excess of $5500 \mu \mathrm{g} \mathrm{U}(\mathrm{VI}) \mathrm{g}^{-1}$ resulted in the precipitation of chernikovite (H-autunite). However in the presence of carbonate, chernikovite formation was not observed, even with uranium loadings up to $12,300 \mu \mathrm{g} U(\mathrm{VI}) \mathrm{g}^{-1}$. Thus, it is expected that sorption and/or surface complexation of uranium could occur until all surface sites have been depleted, but the high carbonate concentrations in the 300 Area would act to inhibit the transformation of sorbed uranium to chernikovite and/or autunite. Therefore, the efficacy of uranium retention of apatite will be governed by the rates of uranium desorption and phosphate release during apatite dissolution rather than conversion of sorbed uranium to autunite, or other stable uranium phases.

\subsection{Comparison with Test Objectives}

As stated in Section 2.1, the overall objectives of the polyphosphate treatability test included the following:

1. Conduct a polyphosphate injection to evaluate reduction of aqueous uranium concentrations and to determine the longevity of the treatment zone.

2. Demonstrate field-scale application of polyphosphate injections to identify implementation challenges and evaluate whether a full-scale deployment is feasible.

3. Determine the number of wells, reagent concentrations, volumes, injection rates, operational strategy, and longevity for polyphosphate injections for remediating uranium such that costs for larger-scale application can be effectively estimated. 
The first two treatability test objectives were met. A field-scale treatability test of the technology was successfully performed that demonstrated short-term decreases in uranium concentrations and identified several implementation challenges. Due to the relatively poor longer-term performance of the technology under the hydrogeologic and geochemical conditions of the Hanford 300 Area, injection design and operational parameters for full-scale deployment were not determined.

\subsection{Cost/Schedule for Performing Treatability Study}

Cost and schedule information for the polyphosphate treatability test is summarized in Table 4.3.

Table 4.3. Cost and Schedule Summary for the Polyphosphate Treatability Test

Treatability Test Activity (Project start date of June, 2006)

Bench-scale studies

Experimental plan preparation

Bench-scale report preparation

Pilot-scale field testing

Characterization plan preparation

Site specific characterization

Treatability test plan preparation

Polyphosphate injection test

Performance assessment monitoring

Data analysis and reporting

Final report preparation

Total Treatability Study Cost
Completion Date

Cost (\$K)

September, 2006

September, 2008

1280

December, 2006

June, 2007

June, 2007

June, 2007

July, 2008

\section{5}

June, 2009 


\subsection{Summary and Conclusions}

The objective of the treatability test was to evaluate the efficacy of using polyphosphate injections to treat uranium-contaminated groundwater in situ. A test site consisting of an injection well and 15 monitoring wells was installed in the 300 Area near the process trenches that had previously received uranium-bearing effluents.

Previous laboratory tests have demonstrated that when a soluble form of polyphosphate is injected into uranium-bearing saturated porous media, immobilization of uranium occurs due to formation of an insoluble uranyl phosphate, autunite $\left[\mathrm{Ca}\left(\mathrm{UO}_{2}\right)_{2}\left(\mathrm{PO}_{4}\right)_{2} \cdot \mathrm{nH}_{2} \mathrm{O}\right]$. Based on results from the column transport experiments, a three-phase injection strategy was identified as an effective approach to attain both direct treatment of the uranium contamination in groundwater (i.e., autunite formation) and formation of the calcium-phosphate mineral apatite. The objective of apatite formation was to provide long-term treatment capacity within the amended zone to address uranium solubilized and released from the periodically re-wetted zone during future high water-table conditions. The three-part injection strategy consisted of the following:

- An initial polyphosphate amendment injection was conducted to precipitate aqueous uranium within the treatment zone as autunite.

- The initial polyphosphate injection was directly followed by injection of a calcium chloride $(\mathrm{CaCl})$ solution to provide a sufficient calcium source for apatite formation during a subsequent polyphosphate injection. Due to the higher $K_{d}$ of the $\mathrm{CaCl}$ solution as measured in bench-scale experiments with site-specific sediments, it was anticipated that a larger injection volume would be required to reach the full radial extent of the targeted treatment zone for this component of the amendment formulation. However, this same increased retardation would also help to facilitate mixing between the calcium and polyphosphate amendments during the third and final injection phase.

- The $\mathrm{CaCl}$ injection was directly followed by a final polyphosphate injection.

Amendment arrival response data from the three phases of the injection test indicated significantly lower reactive constituent retardation than was predicted based on laboratory-scale column experiments. Although amendment arrival response data indicate some degree of overlap between the reactive species and thus potential for the formation of calcium-phosphate mineral phases (i.e., apatite formation), the efficiency of this treatment approach was relatively poor.

Evaluation of pressure response (both prior to and during the polyphosphate injection test) and amendment transport behavior during the three separate phases of the injection test provided evidence of both changes in the spatial distribution of aquifer permeability and an overall reduction in the bulk permeability of the aquifer materials.

Although initial post-treatment uranium concentrations decreased to below the drinking water standard of $30 \mathrm{ug} / \mathrm{L}$, a significant rebound in uranium concentration was observed approximately two months after treatment. In general, uranium performance monitoring results support the hypothesis that limited long-term treatment capacity (i.e., apatite formation) was established during the injection test. 
Two separate overarching issues affect the efficacy of apatite remediation for uranium sequestration within the 300 Area: 1) the efficacy of apatite for sequestering uranium under the present geochemical and hydrodynamic conditions, and 2) the formation and emplacement of apatite via polyphosphate technology. It was expected that uranium sequestration in the presence of hydroxyapatite would occur by sorption and/or surface complexation until all surface sites have been depleted, but that the high carbonate concentrations in the 300 Area would act to inhibit the transformation of sorbed uranium to chernikovite and/or autunite. Adsorption of uranium by apatite was never considered a viable approach for in situ of uranium sequestration in and of itself, because by definition, this is a reversible reaction. The efficacy of uranium sequestration by apatite assumes that the adsorbed uranium would subsequently convert to autunite, or other stable uranium phases. Because this appears to not be the case in the 300 Area aquifer, even in locations near the river, apatite may have limited efficacy for the retention and long-term immobilization of uranium at the 300 Area site.

The overall objectives of the Polyphosphate Treatability Test included the following:

1. Conduct a polyphosphate injection to evaluate reduction of aqueous uranium concentrations and to determine the longevity of the treatment zone.

2. Demonstrate field-scale application of polyphosphate injections to identify implementation challenges and evaluate whether a full-scale deployment is feasible.

3. Determine the number of wells, reagent concentrations, volumes, injection rates, operational strategy, and longevity for polyphosphate injections for remediating uranium such that costs for larger-scale application can be effectively estimated.

The first two treatability test objectives were met. Due to the relatively poor longer-term performance of the technology under the hydrogeologic and geochemical conditions of the Hanford 300 Area, injection design and operational parameters for full-scale deployment were not determined

The ability to maintain low uranium concentrations in the 300 Area unconfined aquifer over long periods of time using phosphate treatment of the saturated zone alone appears to be limited. Therefore, it is recommended that treatment of the source of uranium in the vadose zone and the periodically re-wetted zone using infiltration of phosphates from above be pursued.

Any future attempts at field-scale apatite formation under the hydrodynamic conditions characteristic of the Hanford 300 Area would need to account for the relatively low calcium and phosphate distribution coefficients for these coarse-grained materials during development of an injection strategy. Possible modification of the injection design include, but are not limited to, decreased injection rates and/or increased cycling frequency between the calcium and phosphate amendment solutions. 


\subsection{References}

Agarwal RG. 1980. “A New Method to Account for Producing Time Effects when Drawdown Type Curves Are Used to Analyze Pressure Buildup and Other Test Data.” SPE Paper 9289, Society of Petroleum Engineers, Dallas, Texas.

Amjad Z, PG Koutsoukos, and GH Nancollas. 1981. "Crystallization of Fluoroapatite. A Constant Composition Study." Journal of Colloid and Interface Science 82(2), 394-400.

Arey JS, JC Seaman, and PM Bertsch. 1999. "Immobilization of Uranium in Contaminated Sediments by Hydroxyapatite Addition." Environmental Science and Technology 33:337-342.

Avrami M. 1939. "Kinetics of Phase Change, I." Journal of Chemistry and Physics 7:1103-1112.

Avrami M. 1940. “Kinetics of Phase Change, II.” Journal of Chemistry and Physics 8:212-224.

Bjornstad, BN. 2004. Sampling and Hydrogeology of the Vadose Zone Beneath the 300 Area Process Ponds. PNNL-14834, Pacific Northwest National Laboratory, Richland, Washington.

Bjornstad, BN, JA Horner, VR Vermeul, DC Lanigan, and PD Thorne. 2009. Borehole Completion and Conceptual Hdrogeologic Model for the IFRC Well Field, 300 Area, Hanford Site. PNNL-18340, Pacific Northwest National Laboratory, Richland, Washington.

Boskey AL and AS Posner. 1973. "Conversion of Amorphous Calcium Phosphate to Microcrystalline Hydroxyapatite. A pH-Dependent, Solution-Mediated, Solid-Solid Conversion." Journal of Physics and Chemistry 77:2313-2317.

Boskey AL and AS Posner. 1976. "Formation of Hydroxyapatite at Low Supersaturation." Journal of Physics and Chemistry 80:40-45.

Brown CF, W zUm, and RJ Serne. 2008. Uranium Concentration in the 300 Area: Emergent Data and Their Impact on the Source Term Conceptual Model. PNNL-17793, Pacific Northwest National Laboratory, Richland, Washington.

Brown JL. 1980. "Calcium Phosphate Precipitation in Aqueous Calcite Limestone Suspensions." Journal of Environmental Quality 9(4):641-644.

Brown JL. 1981a. "Calcium Phosphate Precipitation: Effect of Common and Foreign Ions on Hydroxyapatite Crystal Growth.” Soil Science Society of America Journal 45:482-486.

Brown JL. 1981b. "Calcium Phosphate Precipitation: Identification of Kinetic Parameters in Aqueous Limestone Suspensions.” Soil Science Society of America Journal 45:475-477.

Brown WE, JP Smith, JR Lehr, and AW Frazier. 1962. "Crystallographic and Chemical Relations between Octacalcium Phosphate and Hydroxyapatite." Nature 196(4859):1050. 
Christoffersen J and MR Christoffersen. 1982. "Kinetics of Dissolution of Calcium Hydroxyapatite: V. The Acidity Constant for the Hydrogen Phosphate Surface Complex." Journal of Crystal Growth 57:21-26.

Comprehensive Environmental Response, Compensation, and Liability Act. 1980. Public Law 96-510, as amended, 94 Stat. 2767, 42 USC 9601 et seq.

Conca JL. 1996. "Phosphate-Induced Metal Stabilization." In S.t.A.R.S. Program, National Center for Environmental Research, Office of Research and Development, U.S. Environmental Protection Agency, Washington, D.C.

Diaz OA, KR Reddy, and PA Moore, Jr. 1994. "Solubility of Inorganic Phosphorous in Stream Water as Influenced by $\mathrm{pH}$ and Calcium Concentration." Water Resources 28(8):1755-1763.

DOE. 1995. Remedial Investigation/Feasibility Study Report for the 300-FF-5 Operable Unit. DOE/RL-94-85, U.S. Department of Energy, Richland, Washington.

DOE. 2005. Work Plan for Phase III Feasibility Study, 300-FF-5 Operable Unit. DOE/RL-2005-41, Rev. 0, prepared by Pacific Northwest National Laboratory for the U.S. Department of Energy, Richland, Washington.

DOE. 2006. 300-FF-5 Operable Unit Limited Field Investigation Plan. DOE/RL-2005-47, Rev. 1, U.S. Department of Energy, Richland, Washington.

Eanes ED and JL Meyer. 1977. Maturation of Crystalline Calcium Phosphates in Aqueous Suspensions at Physiologic Ph." Calcareous Tissue Research 23(3):259.

Eanes ED and AS Posner. 1965. "Kinetics and Mechanism of Conversion of Noncrystalline Calcium Phosphate to Crystalline Hydroxyapatite." Transactions New York Academy of Sciences, pp. 233-240, New York.

Eanes ED and AS Posner. 1970. "A Note on the Crystal Growth of Hydroxyapatite Precipitated from Aqueous Solutions." Materials Research Bulletin 5(6):377-384.

Eanes ED, IH Gillessen, and AS Posner. 1965. "Intermediate States in the Precipitation of Hydroxyapatite." Nature 208:365-367.

EPA. 1991. "Method 300.0, The Determination of Inorganic Anions in Water by Ion Chromatography." U.S. Environmental Protection Agency, Washington, D.C.

EPA. 1996a. Record of Decision for USDOE Hanford 300-FF-1 and 300-FF-5 Operable Units Remedial Actions. EPA/ROD/R10-96/143, U.S. Environmental Protection Agency, Region 10, Seattle, Washington.

EPA. 1996b. "Method 6010B, Inductively Coupled Plasma-Atomic Emission Spectrometry." In Test Methods for Evaluating Solid Waste, Physical/Chemical Methods. Publication SW-846, U.S. Environmental Protection Agency, Washington, D.C. Available at http://www.epa.gov/epaoswer/hazwaste/test/sw846.htm 
EPA. 2000. "Method 6020, Inductively Coupled Plasma-Mass Spectrometry." In Test Methods for Evaluating Solid Waste, Physical/Chemical Methods. Publication SW-846, U.S. Environmental Protection Agency, Washington, D.C. Available at http://www.epa.gov/epaoswer/hazwaste/test/sw846.htm

Fayer MJ and TB Walters. 1995. Estimated Recharge Rates at the Hanford Site. PNL-10285, Pacific Northwest Laboratory, Richland, Washington.

Feenstra TP and PL de Bruyn. 1979. "Formation of Calcium Phosphates in Moderately Supersaturated Solutions." Journal of Physical Chemistry 83(4):475-479.

Ferguson JF, D Jenkins, and J Eastman. 1973. "Calcium Phosphate Precipitation at Slightly Alkaline pH Values.” Water Pollution Control Federation 45(4):620-631.

Ferguson JF, D Jenkins, and W Stumm. 1970. "Calcium Phosphate Precipitation in Wastewater Treatment.” Chemical Engineering Progress Symposium Series 107(67):279-287.

Fuller CC, JR Bargar, JA Davis, and MJ Piana. 2002a. "Mechanisms of Uranium Interactions with Hydroxyapatite: Implication for Groundwater Remediation." Environmental Science and Technology 36:158-165.

Fuller CC, MJ Piana, JR Bargar, JA Davis, and M Kohler. 2002b. "Evaluation of Apatite Materials for Use in Permeable Reactive Barriers for the Remediation of Uranium-Contaminated Groundwater." In Handbook of Groundwater Remediation Using Permeable Reactive Barriers: Applications to Radionuclides, Trace Metals, and Nutrients. DL Naftz, SJ Morrison, JA Davis and CC Fuller (eds.), Academic Press, San Diego, California.

Fuller CC, JR Bargar, and JA Davis. 2003. "Molecular-Scale Characterization of Uranium Sorption by Bone Apatite Materials for a Permeable Reactive Barrier Demonstration." Environmental Science and Technology 37:4642-4649.

Gamerdinger AP, DI Kaplan, DM Wellman, and RJ Serne. 2001a. "Two-Region Flow and Decreased Sorption of Uranium (VI) during Transport in Hanford Groundwater and Unsaturated Sands." Water Resources Research 37(12):3155-3162.

Gamerdinger AP, DI Kaplan, DM Wellman, and RJ Serne. 2001b. Two-Region Flow and Decreased Sorption of Uranium (VI) during Transport in an Unsaturated Silt Loam." Water Resources Research 37(12):3147-3153.

Gamerdinger AP, K van Rees, PSC Rao, and RE Jessup. 1994. "Evaluation of In Situ Columns for Characterizing Organic Contaminant Sorption during Transport." Environmental Science and Technology 28:376-382.

Garten VA and RB Head. 1966. "Homogeneous Nucleation and the Phenomenon of Crystalloluminescence." Philosophical. Magazine 14(132):1243.

Gauglitz R and M Holterdorf. 1992. "Immobilization of Heavy Metals by Hydroxyapatite." Radiochimica Acta 58(59):253-257. 
Gee GW and D Orr. 2002. "Particle-Size Analysis." In Methods of Soil Analysis, Part 4 - Physical Methods. JH Dane and GC Topp (eds.), Soil Sci. Am. Book Series: 5.

Griffith EJ, A Beeton, JM Spencer, and DT Mitchell. 1973. Environmental Phosphorus Handbook. John Wiley \& Sons, New York.

Hartman MJ, LF Morasch, and WD Webber (eds.). 2007. Hanford Site Groundwater Monitoring for Fiscal Year 2006. PNNL-16346, Pacific Northwest National Laboratory, Richland, Washington.

Hoopes JA and DRF Harleman. 1967. "Dispersion in Radial Flow from a Recharge Well." Journal of Geophysical Research 72:3595-3607.

Inskeep WP and JC Silvertooth. 1988. "Kinetics of Hydroxyapatite Precipitation at pH 7.4 to 8.4." Geochimica et Cosmochimica Acta 52:1883-1893.

Jenkins D, JF Ferguson, and AB Menar. 1971. "Chemical Processes for Phosphate Removal." Water Research 5:369-389.

Jensen MP, K Nash, JW Morse, EH Appelman, and MA Schmidt. 1996. Immobilization of Actinides in Geomedia by Phosphate Precipitation. ACS Symposium Series \#651, pp. 272-285.

Lee SY, CW Francis, ME Timpson, and MP Elless. 1995. Radionuclide Containment in Soil by Phosphate Treatment. Oak Ridge National Laboratory, Oak Ridge, Tennessee.

Lindberg JW and FW Bond. 1979. Geohydrology and Ground-Water Quality Beneath the 300 Area, Hanford Site, Washington. PNL-2949, Pacific Northwest Laboratory, Richland, Washington.

Lindsay WL. 1979. "Phosphates.” In Chemical Equilibria in Soils, JW Sons (ed.), pp. 163-209. The Blackburn Press, Caldwell, New Jersey.

Lindsay WL and EC Moreno. 1960. "Phosphate Phase Equilibria in Soils." Soil Science Society of America Proceedings 24:177-182.

Moore RC, C Sanchez, J Schelling, J Jones, DR Anderson, F Salas, D Lucero, and K Holt. 2001. BenchScale Testing of In-Situ Formation of Apatite in Hanford Soils for Sorption of Uranium and Technetium. Sandia National Laboratories, Albuquerque, New Mexico.

Murakami T, H Isobe, T Sato, and T Ohnuki. 1996. "Weathering of Chlorite in a Quartz-Chlorite Schist I. Mineralogical and Chemical Changes." Clays and Clay Minerals 44(2):244-256.

Nancollas GH and MS Mohan. 1970. "The Growth of Hydroxyapatite Crystals." Archieves of Oral Biology 15:731-745.

Nancollas GH and BB Tomazic. 1974. "Growth of Calcium Phosphate on Hydroxyapatite Crystals. Effect of Supersaturation and Ionic Medium.” Journal of Physics and Chemistry 78:2218-2225.

Nash K. 2000. Organophosphorous Reagents in Actinide Separations: Unique Tools for Production, Cleanup and Disposal. Argonne National Laboratory, Argonne, Illinois. 
Nash K, MP Jensen, and MA Schmidt. 1997. “Actinide Immobilization in the Subsurface Environment by In-Situ Treatment with a Hydrolytically Unstable Organophosphorous Complexant: Uranyl Uptake by Calcium Phytate.” International Conference on Actinides, Baden-Baden, Germany.

Nash K, EJ Jensen, and MA Schmidt. 1998a. "In-Situ Actinide Immobilization of Actinides for Groundwater Cleanup: Laboratory Demonstration with Soil from the Fernald Environmental Management Project." In Science and Technology for Disposal of Radioactive Tank Wastes, WW Schultz, and NJ Lombardo (eds.), pp. 507-518. Plenum Press, New York.

Nash K, MP Jensen, and MA Schmidt. 1998b. Actinide Immobilization in the Subsurface Environment by In-Situ Treatment with a Hydrolytically Unstable Organophosphorous Complexant: Uranyl Uptake by Calcium Phytate." Journal of Alloys and Compounds 271-273:257-261.

Nash K, LR Morse, MP Jensen, EH Appelman, MA Schmidt, S Friedrich, M Redko, and JJ Hines. 1999. Water-Soluble Organophosphorous Reagents for Mineralization of Heavy Metals. Argonne National Laboratory, Argonne, Illinois.

Neuman SP. 1975. "Analysis of pumping test data from anisotropic unconfined aquifers considering delayed gravity response." Water Resources Research 11(2):329-342.

Nimmons, MJ 2007. Evaluation and Screening of Remedial Technologies for Uranium at the 300-FF-5 Operable Unit, Hanford Site, Washington. PNNL-16761, Pacific Northwest National Laboratory, Richland, Washington.

Nriagu JO and PB Moore. 1984. Phosphate Minerals. Spinger-Verlag, Berlin, Germany.

Patton GP, BL Tiller, EJ Antonio, TM Poston, and SP Van Verst. 2003. Survey of Radiological and Chemical Contaminants in the Near-Shore Environment at the Hanford Site 300 Area. PNNL-13692, Rev. 1, Pacific Northwest National Laboratory, Richland, Washington.

Peterson RE (ed.), EJ Freeman, CJ Murray, RE Peterson, PD Thorne, MJ Truex, VR Vermeul, MD Williams, SB Yabusaki, JM Zachara, JL Lindberg, and JP McDonald. 2005. Contaminants of Potential Concern in the 300-FF-5 Operable Unit: Expanded Annual Groundwater Report for FY 2004. PNNL-15127, Pacific Northwest National Laboratory, Richland, Washington.

PNNL. 1994, as revised. Procedures for Ground-Water Investigations. PNL-MA-567, Pacific Northwest National Laboratory, Richland, Washington.

PNNL. 2007. The Columbia River Protection Supplemental Technologies Quality Assurance Project Plan. PNNL-16340, Pacific Northwest National Laboratory, Richland, Washington.

Rasmussen TC and LA Crawford. 1997. "Identifying and Removing Barometric Pressure Effects in Confined and Unconfined Aquifers." Ground Water 35(3):502-511.

Resource Conservation and Recovery Act. 1976. Public Law 94-580, as amended, 90 Stat. 2795, 42 USC 6901 et seq. 
Rockhold ML, MJ Fayer, and GW Gee. 1988. Characterization of Unsaturated Hydraulic Conductivity at the Hanford Site. PNL-6488, Pacific Northwest Laboratory, Richland, Washington.

Rockhold ML MJ Fayer, CT Kincaid, and GW Gee. 1995. Estimation of Natural Ground Water Recharge for the Performance Assessment of a Low-Level Waste Disposal Facility at the Hanford Site. PNL-10508, Pacific Northwest National Laboratory, Richland, Washington

Schalla R, RW Wallace, RL Aaberg, SP Airhart, DJ Bates, JVM Carlile, CS Cline, DI Dennison, MD Freshley, PR Heller, EJ Jensen, KB Olsen, RG Parkhurst, JT Rieger, and EJ Westergard. 1988. Interim Characterization Report for the 300 Area Process Trenches. PNL-6716, Pacific Northwest Laboratory, Richland, Washington.

Schmid LA and RR McKinney. 1968. Phosphate Removal by a Lime-Biological Treatment Scheme. Water Pollution Control Federation, Chicago, Illinois.

Seaman JC, JS Arey, and PM Bertsch. 2001. "Immobilization of Nickel and Other Metals in Contaminated Sediments by Hydroxyapatite Addition." Journal of Environmental Quality 30:460-469.

Serne RJ, CF Brown, HT Schaef, EM Pierce, MJ Lindberg, Z Wang, P Gassman, and J Catalano. 2002. 300 Area Uranium Leach and Adsorption Project. PNNL-14022, Pacific Northwest National Laboratory, Richland, Washington.

Shen CY and FW Morgan. 1973. "Hydrolysis of Phosphorous Compounds." In Environmental Phosphorous Handbook, EJ Griffith, A Beeton, JM Spencer, and DT Mitchell (eds.), p. 241. John Wiley \& Sons, New York.

Spane FA. 1999. Effects of Barometric Fluctuations on Well Water-Level Measurements and Aquifer Test Data. PNNL-13078, Pacific Northwest National Laboratory, Richland, Washington.

Spane FA. 2002. "Barometric Pressure in Groundwater Flow Investigations." Water Resources Research 38(6)14:1-18.

Sparks DL and S Hunger. 2002. Mechanisms of Phosphorus Stabilization in the Soil Environment: A Molecular Scale Evaluation, p. 1-20. University of Delaware, Newark, New Jersey.

Termine JD, RA Peckauskas, and AS Posner. 1970. "Calcium Phosphate Formation In Vitro II. Effects of Environment on Amorphous-Crystalline Transformation." Archives of Biochemistry and Biophysics 140:318-325.

Termine JD and AS Posner. 1970. "Calcium Phosphate Formation In Vitro I. Factors Affecting Initial Phase Separation." Archives of Biochemistry and Biophysics 140:307-317.

van Cappellen P and RA Berner. 1991. "Fluorapatite Crystal Growth from Modified Seawater Solutions." Geochimica et Cosmochimica Acta 55:1219-1234.

Vermeul VR, JS Fruchter, DM Wellman, BA Williams, and MD Williams. 2006. Site Characterization Plan: Uranium Stabilization through Polyphosphate Injection. PNNL-16008, Pacific Northwest National Laboratory, Richland, Washington. 
Vermeul VR, MD Williams, BG Fritz, RD Mackley, DP Mendoza, DR Newcomer, ML Rockhold, BA Williams, and DM Wellman. 2007. Treatability Test Plan for 300 Area Uranium Stabilization through Polyphosphate Injection. PNNL-16571, Pacific Northwest National Laboratory, Richland, Washington.

WAC 173-160. "Minimum Standards for Construction and Maintenance of Wells." Washington Administrative Code, Olympia, Washington.

Wellman DM, JS Fruchter, VR Vermeul, and MD Williams. 2008. Challenges Associated with Apatite Remediation of Uranium in the 300 Area Aquifer.. PNNL-17480, Pacific Northwest National Laboratory, Richland, Washington.

Wellman DM, EM Pierce, EL Richards, BC Butler, KE Parker, JN Glovack, SD Burton, SR Baum, ET Clayton, and EA Rodriguez. 2007. Interim Report: Uranium Stabilization Through Polyphosphate Injection - 300 Area Uranium Plume Treatability Demonstration Project... PNNL-16683, Pacific Northwest National Laboratory, Richland, Washington.

Wellman DM, JP Icenhower, and AT Owen. 2006. "Comparative Analysis of Soluble Phosphate Amendments for the Remediation of Heavy Metal Contaminants: Effect on Sediment Hydraulic Conductivity." Environmental Chemistry 3:219-224.

Wellman DM, JI Icenhower, EM Pierce, BK McNamara, SD Burton, KN Geiszler, SR Baum, and BC Butler. 2005. "Polyphosphate Amendments for In Situ Immobilization of Uranium Plumes." In Third International Conference on Remediation of Contaminated Sediments, RF Olfenbuttel and PJ White (eds.), Battelle Press, New Orleans, Louisiana.

White MD and M Oostrom. 2000. STOMP Subsurface Transport Over Multiple Phase: Theory Guide. PNNL-11216, Pacific Northwest National Laboratory, Richland, Washington.

White MD and M Oostrom. 2006. STOMP Subsurface Transport Over Multiple Phases, Version 4.0, User's Guide. PNNL-15782, Pacific Northwest National Laboratory, Richland, Washington.

Williams BA. 2007. Borehole Data Package for Nine CY 2006 Polyphosphate Treatability Testing Wells, 300-FF-5 Operable Unit, Hanford Site, Washington. PNNL-16522, Pacific Northwest National Laboratory, Richland, Washington.

Williams BA, BN Bjornstad, DC Lanigan, JM Keller, and ML Rockhold. 2006. Borehole Data Package for One CY2005 CERCLA Well 699-S20-E10, 300-FF-5 Operable Unit, Hanford Site, Washington. PNNL-15417, Pacific Northwest National Laboratory, Richland, Washington.

Williams BA, CF Brown, W Um, MJ Nimmons, RE Peterson, BN Bjornstad, RJ Serne, FA Spane, and ML Rockhold. 2007. Limited Field Investigation Report for Uranium Contamination in the 300 Area, 300-FF-5 Operable Unit, Hanford Site, Washington. PNNL-16435, Pacific Northwest National Laboratory, Richland, Washington.

Wright J, LM Peurrung, TE Moody, JL Conca, X Chen, PP Didzerekis, and E Wyse. 1995. In Situ Immobilization of Heavy Metals in Apatite Mineral Formulations. Pacific Northwest Laboratory, Richland, Washington. 
Wu L, W Forsling, and PW Schindler. 1991. "Surface Complexation of Calcium Minerals in Aqueous Solution 1. Surface Protonation a Fluorapatite-Water Interfaces." Journal of Colloid and Interface Science 147(178).

Zachara JM, JA Davis, C Liu, JP McKinley, N Qafoku, DM Wellman, and SB Yabusaki. 2005. Uranium Geochemistry in Vadose Zone and Aquifer Sediments from the 300 Area Uranium Plume. PNNL-15121, Pacific Northwest National Laboratory, Richland, Washington. 


\section{Appendix A}

\section{Hydraulic Test Results}



This appendix contains additional results for hydraulic tests that were not included in Section 3.2.3. Plots showing pressure buildup and buildup derivative data plotted along with the Neuman (1975) type curves for wells 399-1-27, 399-1-28, 399-1-29, 399-1-30, and 399-1-31 are included below. Note that the plots for wells 299-1-24, 399-1-25, and 399-1-26 are included in Section 3.2.3.

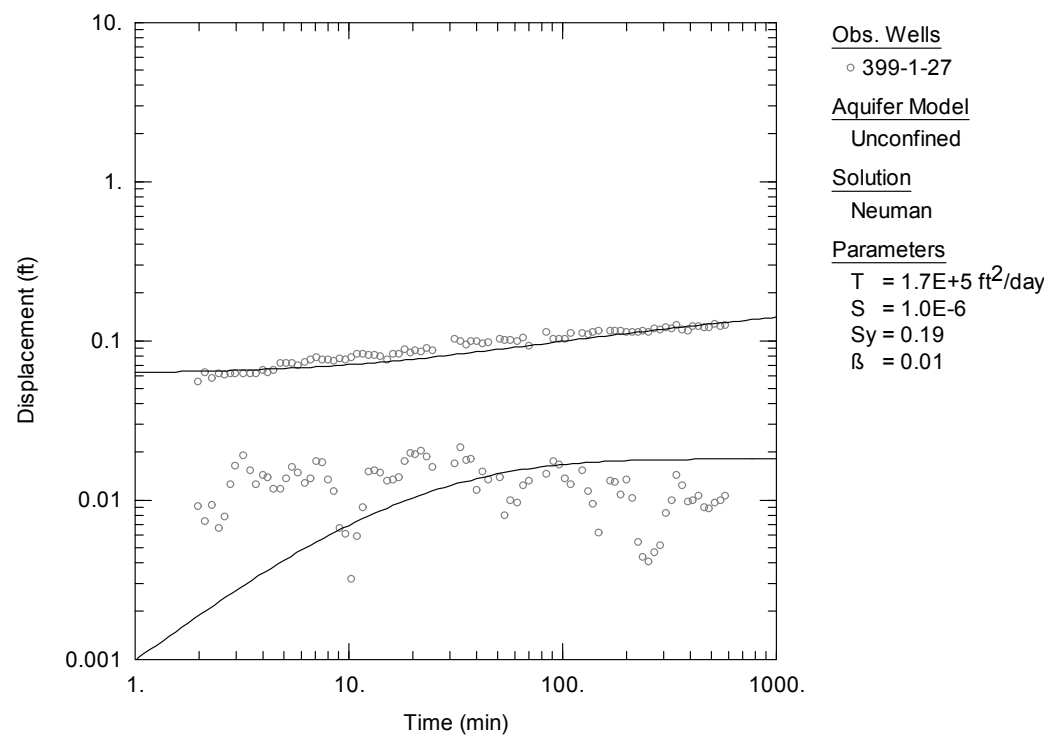

Figure A.1. Neuman Type-Curve Analysis of Pressure Buildup Data at the Lower-Screened Well 399-1-27 During the Tracer Injection Test

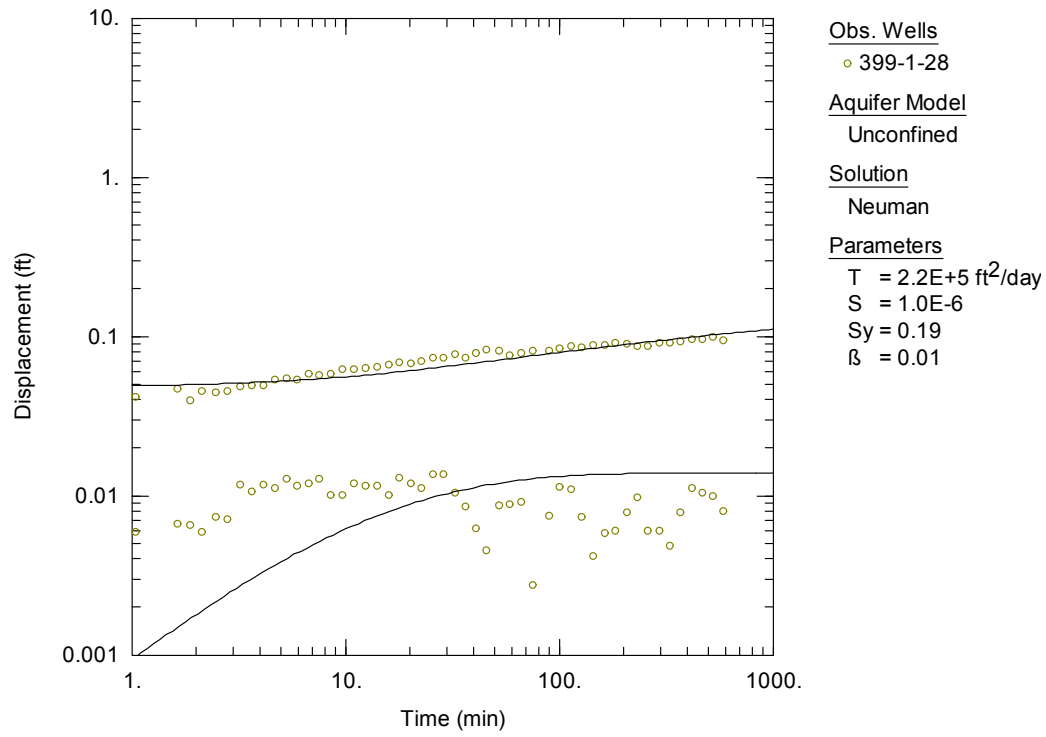

Figure A.2. Neuman Type-Curve Analysis of Pressure Buildup Data at the Upper-Screened Well 399-1-28 During the Tracer Injection Test 


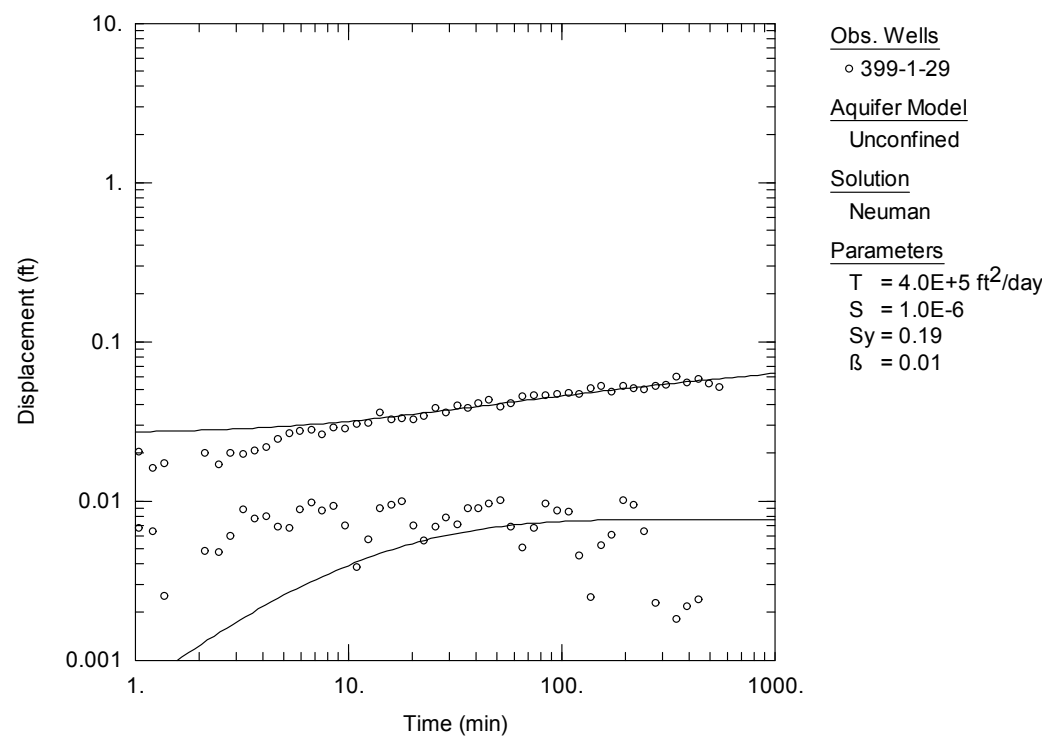

Figure A.3. Neuman Type-Curve Analysis of Pressure Buildup Data at the Fully Screened Well 399-1-29 During the Tracer Injection Test

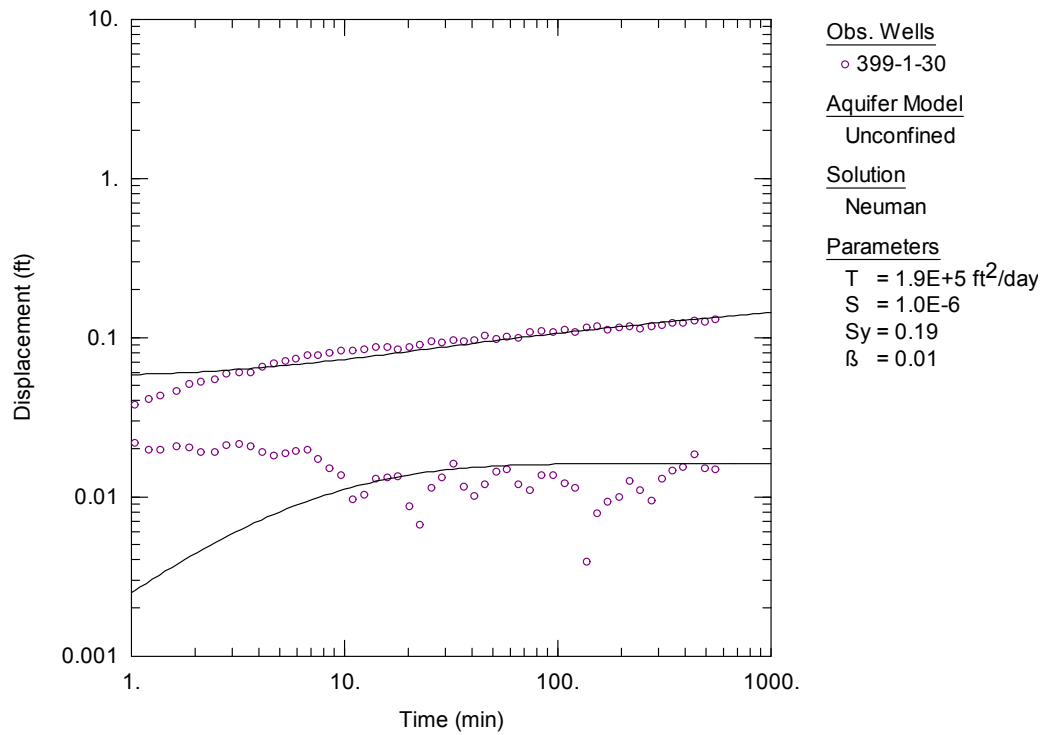

Figure A.4. Neuman Type-Curve Analysis of Pressure Buildup Data at the Fully Screened Well 399-1-30 During the Tracer Injection Test 


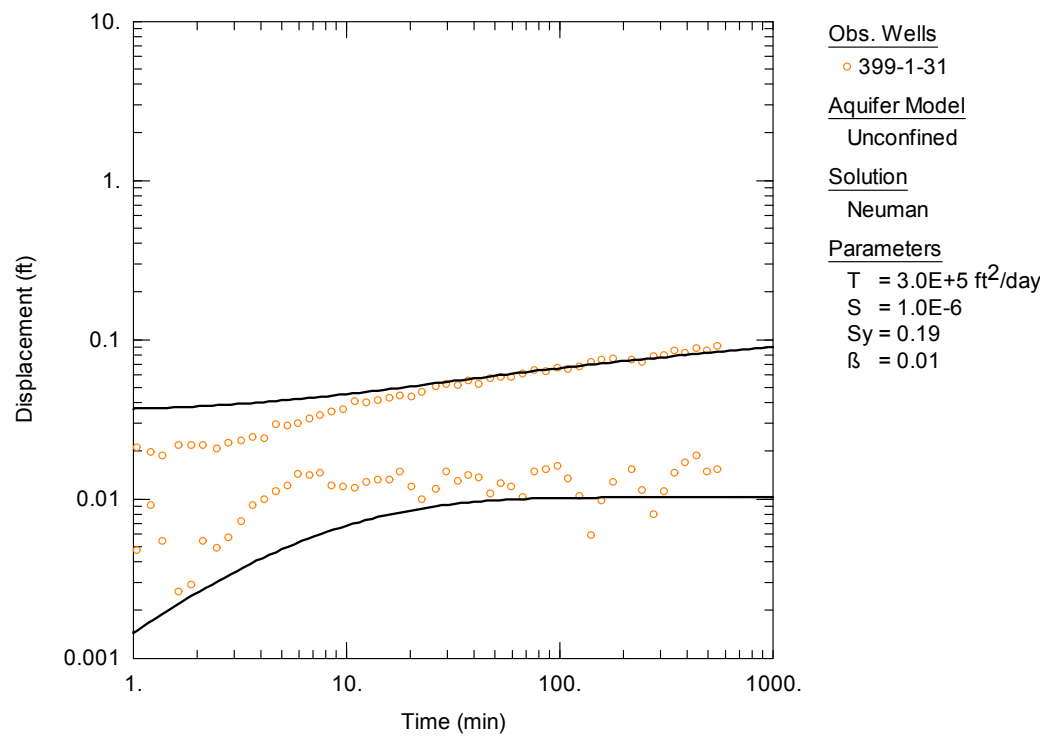

Figure A.5. Neuman Type-Curve Analysis of Pressure Buildup Data at the Fully Screened Well 399-1-31 During the Tracer Injection Test 

Appendix B

\section{Baseline Sampling Results}



Table B.1. Anion Results for Baseline Sampling (mg/L)

\begin{tabular}{|c|c|c|c|c|c|c|c|}
\hline Sample ID & Well Name & Chloride & Nitrite & Bromide & Nitrate & Sulfate & Phosphate \\
\hline \multicolumn{8}{|c|}{ Baseline sampling event \#1-1/12/2006 } \\
\hline PP-BL-A-1 & $399-1-23$ & 20.4 & $<1.0$ & $<1.0$ & 24.7 & 59.3 & $<1.5$ \\
\hline PP-BL-A-2 & $399-1-24$ & 19.6 & $<1.0$ & $<1.0$ & 24.3 & 59.3 & $<1.5$ \\
\hline PP-BL-A-3 & $399-1-27$ & 19.9 & $<1.0$ & $<1.0$ & 23.4 & 86.1 & $<1.5$ \\
\hline PP-BL-A-4 & $399-1-25$ & 19.4 & $<1.0$ & $<1.0$ & 24.0 & 59.0 & $<1.5$ \\
\hline PP-BL-A-5 & $399-1-30$ & 19.1 & $<1.0$ & $<1.0$ & 23.7 & 59.1 & $<1.5$ \\
\hline PP-BL-A-6 & $399-1-31$ & 19.6 & $<1.0$ & $<1.0$ & 24.1 & 59.2 & $<1.5$ \\
\hline PP-BL-A-7 & $399-1-26$ & 19.7 & $<1.0$ & $<1.0$ & 23.7 & 59.0 & $<1.5$ \\
\hline PP-BL-A-8 & $399-1-28$ & 19.9 & $<1.0$ & $<1.0$ & 24.1 & 58.4 & $<1.5$ \\
\hline PP-BL-A-9 & $399-1-29$ & 19.5 & $<1.0$ & $<1.0$ & 24.3 & 58.6 & $<1.5$ \\
\hline PP-BL-A-10 & $399-1-32$ & 19.7 & $<1.0$ & $<1.0$ & 24.2 & 59.7 & $<1.5$ \\
\hline \multicolumn{8}{|c|}{ Baseline sampling event \#2- 4/22/2007 } \\
\hline PP-BL-A-18 & $399-1-23$ & 17.8 & $<1.0$ & $<1.0$ & 22.6 & 53.2 & $<1.5$ \\
\hline PP-BL-A-19 & $399-1-24$ & 17.8 & $<1.0$ & $<1.0$ & 22.8 & 54.4 & $<1.5$ \\
\hline PP-BL-A-20 & $399-1-25$ & 17.4 & $<1.0$ & $<1.0$ & 23.0 & 53.7 & $<1.5$ \\
\hline PP-BL-A-21 & $399-1-30$ & 18.2 & $<1.0$ & $<1.0$ & 23.0 & 54.5 & $<1.5$ \\
\hline PP-BL-A-22 & $399-1-31$ & 16.8 & $<1.0$ & $<1.0$ & 22.2 & 53.9 & $<1.5$ \\
\hline PP-BL-A-23 & $399-1-26$ & 17.5 & $<1.0$ & $<1.0$ & 23.4 & 54.5 & $<1.5$ \\
\hline PP-BL-A-24 & $399-1-27$ & 18.3 & $<1.0$ & $<1.0$ & 23.8 & 58.3 & $<1.5$ \\
\hline PP-BL-A-25 & $399-1-28$ & 18.2 & $<1.0$ & $<1.0$ & 23.8 & 54.7 & $<1.5$ \\
\hline PP-BL-A-26 & $399-1-29$ & 17.8 & 0.9 & $<1.0$ & 22.9 & 55.1 & $<1.5$ \\
\hline PP-BL-A-27 & $399-1-32$ & 17.9 & 1.4 & $<1.0$ & 23.0 & 54.3 & $<1.5$ \\
\hline \multicolumn{8}{|c|}{ Baseline sampling event \#3- 6/11/2007 } \\
\hline PP-BL-A-28 & $399-1-23$ & 17.4 & $<1.0$ & $<1.0$ & 22.7 & 57.5 & $<1.5$ \\
\hline PP-BL-A-29 & $399-1-24$ & 17.5 & $<1.0$ & $<1.0$ & 23.8 & 58.7 & $<1.5$ \\
\hline PP-BL-A-30 & $399-1-25$ & 17.8 & $<1.0$ & $<1.0$ & 24.0 & 59.1 & $<1.5$ \\
\hline PP-BL-31A & $399-1-30$ & 17.7 & $<1.0$ & $<1.0$ & 24.6 & 59.9 & $<1.5$ \\
\hline PP-BL-33A & $399-1-31$ & 17.7 & $<1.0$ & $<1.0$ & 24.4 & 60.2 & $<1.5$ \\
\hline PP-BL-34A & $399-1-26$ & 17.9 & $<1.0$ & $<1.0$ & 24.8 & 60.3 & $<1.5$ \\
\hline PP-BL-35A & $399-1-29$ & 17.7 & $<1.0$ & $<1.0$ & 25.1 & 60.0 & $<1.5$ \\
\hline PP-BL-37A & $399-1-28$ & 17.1 & $<1.0$ & $<1.0$ & 23.9 & 57.6 & $<1.5$ \\
\hline PP-BL-38A & $399-1-27$ & 18.3 & $<1.0$ & $<1.0$ & 24.2 & 66.5 & $<1.5$ \\
\hline PP-BL-39A & $399-1-32$ & 17.1 & $<1.0$ & $<1.0$ & 25.6 & 58.4 & $<1.5$ \\
\hline PP-BL-40A & $399-1-36$ & 20.8 & 1.4 & $<1.0$ & 21.0 & 61.3 & $<1.5$ \\
\hline PP-BL-41A & $399-1-37$ & 17.8 & $<1.0$ & $<1.0$ & 25.2 & 60.7 & $<1.5$ \\
\hline PP-BL-42A & $399-1-38$ & 17.7 & $<1.0$ & $<1.0$ & 24.9 & 59.8 & $<1.5$ \\
\hline PP-BL-43A & $399-1-33$ & 19.2 & $<1.0$ & $<1.0$ & 25.4 & 60.4 & $<1.5$ \\
\hline PP-BL-44A & $399-1-34$ & 19.5 & $<1.0$ & $<1.0$ & 24.4 & 60.6 & $<1.5$ \\
\hline PP-BL-45A & $399-1-35$ & 18.2 & $<1.0$ & $<1.0$ & 110.7 & 61.5 & $<1.5$ \\
\hline
\end{tabular}


Table B.2. Cation Results for Baseline Sampling $(\mu \mathrm{g} / \mathrm{L})$

\begin{tabular}{|c|c|c|c|c|c|c|c|}
\hline Sample ID & Well Name & $\mathrm{Al}$ & As & B & $\mathrm{Ba}$ & $\mathrm{Bi}$ & $\mathrm{Ca}$ \\
\hline \multicolumn{8}{|c|}{ Baseline sampling event \#1- 1/12/2006 } \\
\hline PP-BL-C-1 & $399-1-23$ & $<1.25 \mathrm{E}+02$ & $2.18 \mathrm{E}+01$ & $1.12 \mathrm{E}+01$ & $5.83 \mathrm{E}+01$ & $1.65 \mathrm{E}+01$ & $5.18 \mathrm{E}+04$ \\
\hline PP-BL-C-2 & $399-1-24$ & $<1.25 \mathrm{E}+02$ & 6.12E-01 & $<2.5 \mathrm{E}+03$ & $5.22 \mathrm{E}+01$ & $5.00 \mathrm{E}+01$ & $5.02 E+04$ \\
\hline PP-BL-C-3 & $399-1-27$ & $<1.25 \mathrm{E}+02$ & $3.85 \mathrm{E}+01$ & $<2.5 \mathrm{E}+03$ & $5.91 \mathrm{E}+01$ & $2.95 \mathrm{E}+01$ & $5.01 \mathrm{E}+04$ \\
\hline PP-BL-C-4 & $399-1-25$ & $<1.25 \mathrm{E}+02$ & $9.04 \mathrm{E}+01$ & $<2.5 \mathrm{E}+03$ & $5.80 \mathrm{E}+01$ & $1.14 \mathrm{E}+01$ & $5.14 \mathrm{E}+04$ \\
\hline PP-BL-C-5 & $399-1-30$ & $<1.25 \mathrm{E}+02$ & $4.29 \mathrm{E}+01$ & $<2.5 \mathrm{E}+03$ & $5.70 \mathrm{E}+01$ & $1.86 \mathrm{E}+01$ & $5.15 \mathrm{E}+04$ \\
\hline PP-BL-C-6 & $399-1-31$ & $<1.25 \mathrm{E}+02$ & $<5.0 \mathrm{E}+02$ & $<2.5 \mathrm{E}+03$ & $5.88 \mathrm{E}+01$ & $8.14 \mathrm{E}+00$ & $5.13 E+04$ \\
\hline PP-BL-C-7 & $399-1-26$ & $<1.25 \mathrm{E}+02$ & $<5.0 \mathrm{E}+02$ & $1.35 \mathrm{E}+0$ & $5.56 \mathrm{E}+01$ & $2.79 \mathrm{E}+01$ & $5.10 E+04$ \\
\hline PP-BL-C-8 & $399-1-28$ & $<1.25 \mathrm{E}+02$ & $3.14 \mathrm{E}+01$ & $2.90 \mathrm{E}+02$ & $5.71 \mathrm{E}+01$ & $2.07 \mathrm{E}+01$ & $5.22 \mathrm{E}+04$ \\
\hline PP-BL-C-9 & $399-1-29$ & $<1.25 \mathrm{E}+02$ & $5.21 \mathrm{E}+01$ & $4.22 \mathrm{E}+02$ & $5.65 \mathrm{E}+01$ & $<2.5 \mathrm{E}+03$ & $5.15 E+04$ \\
\hline PP-BL-C-10 & $399-1-32$ & $<1.25 \mathrm{E}+02$ & $1.86 \mathrm{E}+01$ & $3.93 \mathrm{E}+02$ & $6.06 \mathrm{E}+01$ & $2.54 \mathrm{E}+01$ & $5.11 \mathrm{E}+04$ \\
\hline \multicolumn{8}{|c|}{ Baseline sampling event \#2- 4/22/2007 } \\
\hline PP-BL-C-18 GW & $399-1-23$ & $2.28 \mathrm{E}+00$ & $2.17 \mathrm{E}+01$ & $2.94 \mathrm{E}+01$ & $6.65 \mathrm{E}+01$ & $2.08 \mathrm{E}+01$ & $5.24 \mathrm{E}+04$ \\
\hline PP-BL-C-19 GW & $399-1-24$ & $<3.00 \mathrm{E}+01$ & $4.09 \mathrm{E}+01$ & $1.78 \mathrm{E}+01$ & $6.47 \mathrm{E}+01$ & $<1.5 \mathrm{E}+02$ & $5.04 \mathrm{E}+04$ \\
\hline PP-BL-C-20 GW & $399-1-25$ & $6.23 E-01$ & $3.54 \mathrm{E}+01$ & $1.18 \mathrm{E}+01$ & $6.49 \mathrm{E}+01$ & $<1.5 \mathrm{E}+02$ & $5.16 \mathrm{E}+04$ \\
\hline PP-BL-C-21 GW & $399-1-30$ & $7.69 \mathrm{E}-01$ & $2.70 \mathrm{E}+01$ & $3.87 \mathrm{E}+00$ & $6.51 \mathrm{E}+01$ & $<1.5 \mathrm{E}+02$ & $5.19 \mathrm{E}+04$ \\
\hline PP-BL-C-22 GW & $399-1-31$ & $<3.00 \mathrm{E}+01$ & $3.02 \mathrm{E}+01$ & $4.66 \mathrm{E}+00$ & $6.15 \mathrm{E}+01$ & $6.92 \mathrm{E}+00$ & $5.17 \mathrm{E}+04$ \\
\hline PP-BL-C-23 GW & $399-1-26$ & $<3.00 \mathrm{E}+01$ & $4.84 \mathrm{E}+01$ & $6.19 \mathrm{E}+00$ & $6.65 \mathrm{E}+01$ & $9.96 \mathrm{E}+00$ & $5.14 \mathrm{E}+04$ \\
\hline PP-BL-C-24 GW & $399-1-27$ & $<3.00 \mathrm{E}+01$ & 8.42E-01) & $<3.0 \mathrm{E}+01$ & $6.52 \mathrm{E}+01$ & $<1.5 \mathrm{E}+02$ & $5.01 E+04$ \\
\hline PP-BL-C-25 GW & $399-1-28$ & $<3.00 \mathrm{E}+01$ & $1.39 \mathrm{E}+01$ & $<3.0 \mathrm{E}+01$ & $6.51 \mathrm{E}+01$ & $<1.5 \mathrm{E}+02$ & $5.19 \mathrm{E}+04$ \\
\hline PP-BL-C-26 GW & $399-1-29$ & $<3.00 \mathrm{E}+01$ & $5.04 \mathrm{E}+00$ & $<3.0 \mathrm{E}+01$ & $6.53 E+01$ & $5.27 \mathrm{E}+00$ & $5.19 E+04$ \\
\hline PP-BL-C-27 GW & $399-1-32$ & $<3.00 \mathrm{E}+01$ & $6.16 \mathrm{E}+01$ & $<3.0 \mathrm{E}+01$ & $6.68 \mathrm{E}+01$ & $1.61 \mathrm{E}+01$ & $5.23 E+04$ \\
\hline \multicolumn{8}{|c|}{ Baseline sampling event \#3- 6/11/2007 } \\
\hline PP-BL-28C & $399-1-23$ & 1.45E-01 & $<1.5 \mathrm{E}+03$ & $<1.5 \mathrm{E}+03$ & $6.03 E+01$ & $4.06 \mathrm{E}+01$ & $5.06 \mathrm{E}+04$ \\
\hline PP-BL-29C & $399-1-24$ & $<7.50 \mathrm{E}+01$ & $2.81 \mathrm{E}+01$ & $<1.5 \mathrm{E}+03$ & $6.14 \mathrm{E}+01$ & $2.04 \mathrm{E}+01$ & $4.85 \mathrm{E}+04$ \\
\hline PP-BL-30C & $399-1-25$ & $<7.50 \mathrm{E}+01$ & $<1.5 \mathrm{E}+03$ & $<1.5 \mathrm{E}+03$ & $5.96 \mathrm{E}+01$ & $2.44 \mathrm{E}+01$ & $4.84 E+04$ \\
\hline PP-BL-31C & $399-1-30$ & $<7.50 \mathrm{E}+01$ & 8.09E-01 & $<1.5 \mathrm{E}+03$ & $7.33 \mathrm{E}+01$ & $8.90 \mathrm{E}+00$ & $4.97 E+04$ \\
\hline PP-BL-32C & $399-1-30$ & $2.86 \mathrm{E}+00$ & $<1.5 \mathrm{E}+03$ & $<1.5 \mathrm{E}+03$ & $6.09 \mathrm{E}+01$ & $2.71 \mathrm{E}+01$ & $4.75 \mathrm{E}+04$ \\
\hline PP-BL-33C & $399-1-31$ & $<7.50 \mathrm{E}+01$ & $(1.03 E+01$ & $<1.5 \mathrm{E}+03$ & $6.67 \mathrm{E}+01$ & $1.55 \mathrm{E}+01$ & $4.41 \mathrm{E}+04$ \\
\hline PP-BL-34C & $399-1-26$ & 8.78E-01 & $<1.5 \mathrm{E}+03$ & $<1.5 \mathrm{E}+03$ & $6.68 \mathrm{E}+01$ & $1.80 \mathrm{E}+01$ & $4.53 E+04$ \\
\hline PP-BL-35C & $399-1-29$ & $1.57 \mathrm{E}+00$ & $<1.5 \mathrm{E}+03$ & $3.71 \mathrm{E}+01$ & $6.59 \mathrm{E}+01$ & $2.72 \mathrm{E}+01$ & $5.03 E+04$ \\
\hline PP-BL-36C & $399-1-29$ & $4.58 \mathrm{E}+02$ & $<1.5 \mathrm{E}+03$ & $1.09 \mathrm{E}+01$ & $6.58 \mathrm{E}+01$ & $2.60 \mathrm{E}+01$ & $5.05 E+04$ \\
\hline PP-BL-37C & $399-1-28$ & $3.35 \mathrm{E}+00$ & $(9.64 \mathrm{E}+00$ & $<1.5 \mathrm{E}+03$ & $6.62 \mathrm{E}+01$ & $3.59 \mathrm{E}+01$ & $4.96 \mathrm{E}+04$ \\
\hline PP-BL-38C & $399-1-27$ & $4.48 \mathrm{E}+00$ & $<1.5 \mathrm{E}+03$ & $<1.5 \mathrm{E}+03$ & $5.31 \mathrm{E}+01$ & $3.00 \mathrm{E}+01$ & $4.27 \mathrm{E}+04$ \\
\hline PP-BL-39C & $399-1-32$ & $4.14 \mathrm{E}+00$ & $<1.5 \mathrm{E}+03$ & $<1.5 \mathrm{E}+03$ & $5.93 E+01$ & $2.67 \mathrm{E}+01$ & $4.93 E+04$ \\
\hline PP-BL-40C & $399-1-36$ & $<7.50 \mathrm{E}+01$ & $<1.5 \mathrm{E}+03$ & $<1.5 \mathrm{E}+03$ & $6.02 \mathrm{E}+01$ & $1.73 \mathrm{E}+01$ & $5.17 \mathrm{E}+04$ \\
\hline PP-BL-41C & $399-1-37$ & 2.57E-01 & $2.58 \mathrm{E}+01$ & $<1.5 \mathrm{E}+03$ & $6.53 \mathrm{E}+01$ & $2.72 \mathrm{E}+01$ & $4.99 \mathrm{E}+04$ \\
\hline PP-BL-42C & $399-1-38$ & $<7.50 \mathrm{E}+01$ & $6.13 \mathrm{E}+00$ & $<1.5 \mathrm{E}+03$ & $6.23 E+01$ & $3.66 \mathrm{E}+01$ & $5.16 \mathrm{E}+04$ \\
\hline PP-BL-43C & $399-1-33$ & 6.87E-02 & $1.90 \mathrm{E}+01$ & $<1.5 \mathrm{E}+03$ & $6.42 \mathrm{E}+01$ & $2.88 \mathrm{E}+01$ & $5.20 \mathrm{E}+04$ \\
\hline PP-BL-44C & $399-1-34$ & $9.27 \mathrm{E}-01$ & $<1.5 \mathrm{E}+03$ & $<1.5 \mathrm{E}+03$ & $8.78 \mathrm{E}+01$ & $1.03 \mathrm{E}+01$ & $5.05 E+04$ \\
\hline PP-BL-45C & $399-1-35$ & $4.42 \mathrm{E}+00$ & $1.46 \mathrm{E}+00$ & $6.64 \mathrm{E}+01$ & $6.65 E+01$ & $3.38 \mathrm{E}+01$ & $5.00 E+04$ \\
\hline PP-BL-46C & $399-1-35$ & $8.38 \mathrm{E}+00$ & $<1.5 \mathrm{E}+03$ & $3.54 \mathrm{E}+01$ & $5.59 \mathrm{E}+01$ & $3.34 \mathrm{E}+01$ & $5.20 \mathrm{E}+04$ \\
\hline
\end{tabular}


Table B.2. (contd)

\begin{tabular}{|c|c|c|c|c|c|c|c|}
\hline Sample ID & Well Name & Co & $\mathrm{Cr}$ & $\mathrm{Cu}$ & $\mathrm{Fe}$ & $\mathrm{K}$ & $\mathrm{Mg}$ \\
\hline \multicolumn{8}{|c|}{ Baseline sampling event \#1- 1/12/2006 } \\
\hline PP-BL-1 & $399-1-23$ & $1.14 \mathrm{E}+00$ & $3.33 E+00$ & $6.52 \mathrm{E}+01$ & $9.91 \mathrm{E}+00$ & $4.45 \mathrm{E}+03$ & $1.20 \mathrm{E}+04$ \\
\hline PP-BL-2 & $399-1-24$ & $1.66 \mathrm{E}+00$ & $2.73 \mathrm{E}+00$ & $6.35 \mathrm{E}+01$ & $3.93 E+00$ & $4.56 \mathrm{E}+03$ & $1.22 \mathrm{E}+04$ \\
\hline PP-BL-3 & $399-1-27$ & $<6.25 \mathrm{E}+01$ & $2.77 \mathrm{E}+00$ & $5.68 \mathrm{E}+01$ & $9.82 \mathrm{E}+00$ & $4.71 \mathrm{E}+03$ & $1.16 \mathrm{E}+04$ \\
\hline PP-BL-4 & $399-1-25$ & $<6.25 \mathrm{E}+01$ & $3.33 \mathrm{E}+00$ & $5.06 \mathrm{E}+01$ & $9.59 \mathrm{E}+00$ & $4.76 \mathrm{E}+03$ & $1.24 \mathrm{E}+04$ \\
\hline PP-BL- 5 & $399-1-30$ & $6.28 \mathrm{E}-01$ & $3.91 \mathrm{E}+00$ & $5.14 \mathrm{E}+01$ & $7.24 \mathrm{E}+00$ & $4.63 \mathrm{E}+03$ & $1.22 \mathrm{E}+04$ \\
\hline PP-BL-6 & $399-1-31$ & $5.02 \mathrm{E}-01$ & $3.34 \mathrm{E}+00$ & $4.90 \mathrm{E}+01$ & $7.24 \mathrm{E}+00$ & $4.92 \mathrm{E}+03$ & $1.23 \mathrm{E}+04$ \\
\hline PP-BL-7 & $399-1-26$ & 4.04E-01 & $3.13 \mathrm{E}+00$ & $5.53 \mathrm{E}+01$ & $7.19 \mathrm{E}+00$ & $4.62 \mathrm{E}+03$ & $1.21 \mathrm{E}+04$ \\
\hline PP-BL-8 & $399-1-28$ & $2.47 \mathrm{E}+00$ & $1.75 \mathrm{E}+00$ & $5.59 \mathrm{E}+01$ & $6.34 \mathrm{E}+00$ & $3.99 \mathrm{E}+03$ & $1.21 \mathrm{E}+04$ \\
\hline PP-BL-9 & $399-1-29$ & $<6.25 \mathrm{E}+01$ & $2.62 \mathrm{E}+00$ & $4.70 \mathrm{E}+01$ & $2.69 \mathrm{E}+00$ & $4.57 \mathrm{E}+03$ & $1.22 \mathrm{E}+04$ \\
\hline PP-BL-10 & $399-1-32$ & $6.30 \mathrm{E}-01$ & $3.17 \mathrm{E}+00$ & $4.24 \mathrm{E}+01$ & $5.36 \mathrm{E}+01$ & $4.59 \mathrm{E}+03$ & $1.22 \mathrm{E}+04$ \\
\hline \multicolumn{8}{|c|}{ Baseline sampling event \#2- 4/22/2007 } \\
\hline PP-BL-18 & $399-1-23$ & $4.38 \mathrm{E}+00$ & $5.19 E+00$ & $1.00 \mathrm{E}+01$ & $(1.62 E+01$ & $4.28 \mathrm{E}+03$ & $1.14 \mathrm{E}+04$ \\
\hline PP-BL-19 & $399-1-24$ & $2.62 \mathrm{E}+00$ & $7.15 \mathrm{E}+00$ & $1.43 \mathrm{E}+01$ & $4.41 \mathrm{E}+02$ & $4.77 \mathrm{E}+03$ & $1.16 \mathrm{E}+04$ \\
\hline PP-BL-20 & $399-1-25$ & $5.57 \mathrm{E}-01$ & $4.00 \mathrm{E}+00$ & $7.38 \mathrm{E}+00$ & 1.14E+01 & $4.82 \mathrm{E}+03$ & 1.17E+04 \\
\hline PP-BL-21 & $399-1-30$ & $2.94 \mathrm{E}+00$ & $4.31 \mathrm{E}+00$ & $4.03 \mathrm{E}+00$ & $9.69 \mathrm{E}+00$ & $4.91 \mathrm{E}+03$ & $1.18 \mathrm{E}+04$ \\
\hline PP-BL-22 & $399-1-31$ & $1.32 \mathrm{E}+00$ & $4.20 \mathrm{E}+00$ & $5.29 \mathrm{E}+00$ & $7.16 \mathrm{E}+00$ & $4.92 \mathrm{E}+03$ & $1.18 \mathrm{E}+04$ \\
\hline PP-BL-23 & $399-1-26$ & $<3.75 E+01$ & $5.32 \mathrm{E}+00$ & $3.56 \mathrm{E}+00$ & $7.67 \mathrm{E}+00$ & $5.00 \mathrm{E}+03$ & $1.19 \mathrm{E}+04$ \\
\hline PP-BL-24 & $399-1-27$ & $1.89 \mathrm{E}+00$ & $4.36 \mathrm{E}+00$ & $2.48 \mathrm{E}+00$ & $9.16 \mathrm{E}+00$ & $4.79 \mathrm{E}+03$ & $1.12 \mathrm{E}+04$ \\
\hline PP-BL-25 & $399-1-28$ & $1.35 \mathrm{E}+00$ & $4.46 \mathrm{E}+00$ & $4.18 \mathrm{E}+00$ & $7.88 \mathrm{E}+00$ & $4.25 \mathrm{E}+03$ & $1.16 \mathrm{E}+04$ \\
\hline PP-BL-26 & $399-1-29$ & 4.68E-01 & $3.61 \mathrm{E}+00$ & $2.51 \mathrm{E}+00$ & $6.33 \mathrm{E}+00$ & $4.70 \mathrm{E}+03$ & 1.17E+04 \\
\hline PP-BL-27 & $399-1-32$ & $<3.75 \mathrm{E}+01$ & $4.08 \mathrm{E}+00$ & $4.31 \mathrm{E}+00$ & $8.53 \mathrm{E}+00$ & $4.65 \mathrm{E}+03$ & $1.19 \mathrm{E}+04$ \\
\hline \multicolumn{8}{|c|}{ Baseline sampling event \#3- 6/11/2007 } \\
\hline PP-BL-28 & $399-1-23$ & $<1.50 \mathrm{E}+01$ & $3.70 \mathrm{E}+00$ & $<7.5 \mathrm{E}+01$ & $7.45 \mathrm{E}+00$ & $3.84 \mathrm{E}+03$ & $1.14 \mathrm{E}+04$ \\
\hline PP-BL-29 & $399-1-24$ & $<1.50 \mathrm{E}+01$ & $3.23 \mathrm{E}+00$ & $<7.5 \mathrm{E}+01$ & $9.53 \mathrm{E}+00$ & $4.54 \mathrm{E}+03$ & $1.18 \mathrm{E}+04$ \\
\hline PP-BL-30 & $399-1-25$ & $<1.50 \mathrm{E}+01$ & $3.56 \mathrm{E}+00$ & $<7.5 \mathrm{E}+01$ & $1.37 \mathrm{E}+01$ & $4.50 \mathrm{E}+03$ & 1.17E+04 \\
\hline PP-BL-31 & $399-1-30$ & $<1.50 \mathrm{E}+01$ & $2.14 \mathrm{E}+00$ & $<7.5 \mathrm{E}+01$ & $1.14 \mathrm{E}+01$ & $4.74 \mathrm{E}+03$ & $1.19 \mathrm{E}+04$ \\
\hline PP-BL-32 & $399-1-30$ & $<1.50 \mathrm{E}+01$ & $2.81 \mathrm{E}+00$ & $<7.5 \mathrm{E}+01$ & $2.00 \mathrm{E}+01$ & $4.76 \mathrm{E}+03$ & $1.20 \mathrm{E}+04$ \\
\hline PP-BL-33 & $399-1-31$ & $<1.50 \mathrm{E}+01$ & $2.69 \mathrm{E}+00$ & $<7.5 \mathrm{E}+01$ & $6.68 \mathrm{E}+00$ & $4.48 \mathrm{E}+03$ & $1.18 \mathrm{E}+04$ \\
\hline PP-BL-34 & $399-1-26$ & $<1.50 \mathrm{E}+01$ & $2.08 \mathrm{E}+00$ & $<7.5 \mathrm{E}+01$ & $7.47 \mathrm{E}+00$ & $4.73 E+03$ & $1.20 \mathrm{E}+04$ \\
\hline PP-BL-35 & $399-1-29$ & $<1.50 \mathrm{E}+01$ & $3.55 \mathrm{E}+00$ & $<7.5 \mathrm{E}+01$ & $9.57 \mathrm{E}+00$ & $4.50 \mathrm{E}+03$ & $1.18 \mathrm{E}+04$ \\
\hline PP-BL-36 & $399-1-29$ & $<1.50 \mathrm{E}+01$ & $3.17 \mathrm{E}+00$ & $<7.5 \mathrm{E}+01$ & $2.38 \mathrm{E}+02$ & $4.61 \mathrm{E}+03$ & $1.19 \mathrm{E}+04$ \\
\hline PP-BL-37 & $399-1-28$ & $<1.50 \mathrm{E}+01$ & $2.37 \mathrm{E}+00$ & $<7.5 \mathrm{E}+01$ & $8.41 \mathrm{E}+00$ & $4.13 \mathrm{E}+03$ & $1.15 \mathrm{E}+04$ \\
\hline PP-BL-38 & $399-1-27$ & $<1.50 \mathrm{E}+01$ & $2.70 \mathrm{E}+00$ & $<7.5 \mathrm{E}+01$ & $8.40 \mathrm{E}+00$ & $4.27 \mathrm{E}+03$ & $1.02 \mathrm{E}+04$ \\
\hline PP-BL-39 & $399-1-32$ & $<1.50 \mathrm{E}+01$ & $2.86 \mathrm{E}+00$ & $<7.5 \mathrm{E}+01$ & $1.51 \mathrm{E}+01$ & $4.02 \mathrm{E}+03$ & $1.17 \mathrm{E}+04$ \\
\hline PP-BL-40 & $399-1-36$ & $<1.50 \mathrm{E}+01$ & $1.69 \mathrm{E}+00$ & $<7.5 \mathrm{E}+01$ & $1.00 \mathrm{E}+01$ & $4.74 \mathrm{E}+03$ & $1.20 \mathrm{E}+04$ \\
\hline PP-BL-41 & $399-1-37$ & $<1.50 \mathrm{E}+01$ & $2.17 \mathrm{E}+00$ & $<7.5 \mathrm{E}+01$ & $4.75 \mathrm{E}+00$ & $4.40 \mathrm{E}+03$ & $1.20 \mathrm{E}+04$ \\
\hline PP-BL-42 & $399-1-38$ & $<1.50 \mathrm{E}+01$ & $5.74 \mathrm{E}+00$ & $<7.5 \mathrm{E}+01$ & $1.96 \mathrm{E}+01$ & $4.37 \mathrm{E}+03$ & $1.19 \mathrm{E}+04$ \\
\hline PP-BL-43 & $399-1-33$ & $<1.50 \mathrm{E}+01$ & $2.08 \mathrm{E}+00$ & $<7.5 \mathrm{E}+01$ & $9.38 \mathrm{E}+00$ & $4.35 \mathrm{E}+03$ & $1.21 \mathrm{E}+04$ \\
\hline PP-BL-44 & $399-1-34$ & $<1.50 \mathrm{E}+01$ & $2.18 \mathrm{E}+00$ & $<7.5 \mathrm{E}+01$ & $9.39 \mathrm{E}+00$ & $4.29 \mathrm{E}+03$ & $1.20 \mathrm{E}+04$ \\
\hline PP-BL-45 & $399-1-35$ & $<1.50 \mathrm{E}+01$ & $2.52 \mathrm{E}+00$ & $<7.5 \mathrm{E}+01$ & $1.07 \mathrm{E}+01$ & $4.58 \mathrm{E}+03$ & $1.21 \mathrm{E}+04$ \\
\hline PP-BL-46 & $399-1-35$ & $<1.50 \mathrm{E}+01$ & $2.55 \mathrm{E}+00$ & $<7.5 \mathrm{E}+01$ & $1.94 \mathrm{E}+01$ & $4.46 \mathrm{E}+03$ & $1.21 \mathrm{E}+04$ \\
\hline
\end{tabular}


Table B.2. (contd)

\begin{tabular}{|c|c|c|c|c|c|c|c|c|}
\hline Sample ID & Well Name & $\mathrm{Mn}$ & Mo & $\mathrm{Ni}$ & $\mathrm{P}$ & $\mathrm{Pb}$ & $\mathrm{Se}$ & $\mathrm{Sr}$ \\
\hline \multicolumn{9}{|c|}{ Baseline sampling event \#1- 1/12/2006 } \\
\hline PP-BL-1 & $399-1-23$ & $<25$ & $7.72 E+00$ & $1.78 \mathrm{E}+01$ & $1.66 \mathrm{E}+02$ & $<125$ & $4.97 \mathrm{E}+02$ & $2.43 \mathrm{E}+02$ \\
\hline PP-BL-2 & $399-1-24$ & $2.64 \mathrm{E}+01$ & $7.35 E+00$ & $1.71 \mathrm{E}+01$ & $1.45 \mathrm{E}+02$ & $<125$ & $4.25 E+02$ & $2.37 \mathrm{E}+02$ \\
\hline PP-BL-3 & $399-1-27$ & $8.68 \mathrm{E}+01$ & $2.89 E+01$ & $1.74 \mathrm{E}+01$ & $1.49 \mathrm{E}+02$ & $<125$ & $5.11 \mathrm{E}+02$ & $2.40 \mathrm{E}+02$ \\
\hline PP-BL-4 & $399-1-25$ & $7.58 \mathrm{E}+01$ & $5.22 \mathrm{E}+00$ & $1.99 \mathrm{E}+01$ & $1.75 \mathrm{E}+02$ & $<125$ & $5.87 E+02$ & $2.42 \mathrm{E}+02$ \\
\hline PP-BL- 5 & $399-1-30$ & $<25$ & $4.50 E+00$ & $2.13 \mathrm{E}+01$ & $1.76 \mathrm{E}+02$ & $<125$ & $5.43 E+02$ & $2.41 \mathrm{E}+02$ \\
\hline PP-BL-6 & $399-1-31$ & $<25$ & $1.01 \mathrm{E}+01$ & $1.66 \mathrm{E}+01$ & $1.56 \mathrm{E}+02$ & $<125$ & $5.81 \mathrm{E}+02$ & $2.39 \mathrm{E}+02$ \\
\hline PP-BL-7 & $399-1-26$ & $<25$ & $<125$ & $1.59 \mathrm{E}+01$ & 1.47E+02 & $<125$ & $3.68 \mathrm{E}+02$ & $2.38 \mathrm{E}+02$ \\
\hline PP-BL-8 & $399-1-28$ & 5.52 & $<125$ & $1.78 \mathrm{E}+01$ & $1.59 E+02$ & $<125$ & $3.60 E+02$ & $2.45 E+02$ \\
\hline PP-BL-9 & $399-1-29$ & 4.16 & $6.90 \mathrm{E}+00$ & $1.24 \mathrm{E}+01$ & $1.58 \mathrm{E}+02$ & $<125$ & $5.41 \mathrm{E}+02$ & $2.41 \mathrm{E}+02$ \\
\hline PP-BL-10 & $399-1-32$ & $4.00 \mathrm{E}+01$ & $<125$ & $1.62 \mathrm{E}+01$ & $1.70 \mathrm{E}+02$ & $<125$ & $4.39 \mathrm{E}+02$ & $2.41 \mathrm{E}+02$ \\
\hline \multicolumn{9}{|c|}{ Baseline sampling event \#2- 4/22/2007 } \\
\hline PP-BL-18 & $399-1-23$ & 2.95 & $5.28 \mathrm{E}+00$ & $2.05 \mathrm{E}+01$ & $2.24 \mathrm{E}+02$ & $<75$ & $4.36 \mathrm{E}+02$ & $2.41 \mathrm{E}+02$ \\
\hline PP-BL-19 & $399-1-24$ & $2.95 \mathrm{E}+01$ & $5.71 \mathrm{E}-01$ & $6.98 \mathrm{E}+01$ & $2.11 \mathrm{E}+02$ & $<75$ & $4.43 E+02$ & $2.34 \mathrm{E}+02$ \\
\hline PP-BL-20 & $399-1-25$ & $4.05 E+01$ & $<75$ & $1.43 \mathrm{E}+01$ & $2.21 \mathrm{E}+02$ & $<75$ & $3.95 E+02$ & $2.40 E+02$ \\
\hline PP-BL-21 & $399-1-30$ & 8.67E-01 & $8.26 \mathrm{E}+00$ & $1.16 \mathrm{E}+01$ & $2.10 \mathrm{E}+02$ & $<75$ & $4.58 \mathrm{E}+02$ & $2.34 \mathrm{E}+02$ \\
\hline PP-BL-22 & $399-1-31$ & 6.98E-01 & $1.22 \mathrm{E}+00$ & $1.14 \mathrm{E}+01$ & $2.11 \mathrm{E}+02$ & $<75$ & $4.88 E+02$ & $2.37 E+02$ \\
\hline PP-BL-23 & $399-1-26$ & 1.25 & $<75$ & $1.15 \mathrm{E}+01$ & $2.22 \mathrm{E}+02$ & $<75$ & $3.34 \mathrm{E}+02$ & $2.37 \mathrm{E}+02$ \\
\hline PP-BL-24 & $399-1-27$ & 2.16 & $9.87 E+00$ & $1.05 \mathrm{E}+01$ & $2.26 \mathrm{E}+02$ & $<75$ & $3.78 \mathrm{E}+02$ & $2.35 E+02$ \\
\hline PP-BL-25 & $399-1-28$ & 7.32E-01 & 9.19E-01 & $8.07 \mathrm{E}+00$ & $2.25 \mathrm{E}+02$ & $<75$ & $4.35 \mathrm{E}+02$ & $2.40 \mathrm{E}+02$ \\
\hline PP-BL-26 & $399-1-29$ & 8.09E-01 & $9.19 \mathrm{E}+00$ & $9.04 \mathrm{E}+00$ & $2.12 \mathrm{E}+02$ & $<75$ & $4.07 E+02$ & $2.38 \mathrm{E}+02$ \\
\hline PP-BL-27 & & $67 \mathrm{E}-01$ & 3.13E-01 & $1.13 \mathrm{E}+01$ & $2.01 \mathrm{E}+02$ & $<75$ & $3.10 E+02$ & $2.40 \mathrm{E}+02$ \\
\hline \multicolumn{9}{|c|}{ Baseline sampling event \#3- 6/11/2007 } \\
\hline PP-BL-28 & $399-1-23$ & 1.18 & $3.16 \mathrm{E}+00$ & $9.45 \mathrm{E}+00$ & $2.97 E+02$ & $<75$ & $3.98 \mathrm{E}+02$ & $2.43 E+02$ \\
\hline PP-BL-29 & $399-1-24$ & $6.50 \mathrm{E}-01$ & $6.32 \mathrm{E}+00$ & 1.10E+01 & $2.72 \mathrm{E}+02$ & $<75$ & $4.12 E+02$ & $2.44 \mathrm{E}+02$ \\
\hline PP-BL-30 & $399-1-25$ & $6.09 E-01$ & $1.19 E+00$ & $6.98 \mathrm{E}+00$ & $2.66 \mathrm{E}+02$ & $<75$ & $4.92 E+02$ & $2.42 E+02$ \\
\hline PP-BL-31 & $399-1-30$ & 4.28E-01 & $4.76 \mathrm{E}+00$ & $7.80 \mathrm{E}+00$ & $2.49 \mathrm{E}+02$ & $<75$ & $4.39 \mathrm{E}+02$ & $2.51 \mathrm{E}+02$ \\
\hline PP-BL-32 & $399-1-30$ & 7.05E-01 & $4.35 \mathrm{E}+00$ & $6.99 \mathrm{E}+00$ & $2.72 \mathrm{E}+02$ & $<75$ & $4.00 \mathrm{E}+02$ & $2.47 \mathrm{E}+02$ \\
\hline PP-BL-33 & $399-1-31$ & 5.03E-01 & $8.53 \mathrm{E}+00$ & $7.72 \mathrm{E}+00$ & $2.45 \mathrm{E}+02$ & $<75$ & $3.76 \mathrm{E}+02$ & $2.42 \mathrm{E}+02$ \\
\hline PP-BL-34 & $399-1-26$ & 3.43E-01 & 5.82E-01 & $7.25 \mathrm{E}+00$ & $2.33 E+02$ & $<75$ & $4.11 \mathrm{E}+02$ & $2.44 \mathrm{E}+02$ \\
\hline PP-BL-35 & $399-1-29$ & $1.67 \mathrm{E}+00$ & $1.22 \mathrm{E}+01$ & $1.17 \mathrm{E}+01$ & $(2.38 \mathrm{E}+02$ & $<75$ & $3.71 \mathrm{E}+02$ & $2.44 \mathrm{E}+02$ \\
\hline PP-BL-36 & $399-1-29$ & $6.34 \mathrm{E}+00$ & $6.61 \mathrm{E}+00$ & $1.08 \mathrm{E}+01$ & $(2.57 E+02$ & $<75$ & $3.52 E+02$ & $2.48 \mathrm{E}+02$ \\
\hline PP-BL-37 & $399-1-28$ & (8.40E-01) & $1.28 \mathrm{E}+00$ & $9.30 \mathrm{E}+00$ & $(2.57 E+02$ & $<75$ & $3.79 \mathrm{E}+02$ & $2.47 \mathrm{E}+02$ \\
\hline PP-BL-38 & $399-1-27$ & (8.98E-01) & $1.27 E+01$ & $9.74 \mathrm{E}+00$ & $(2.22 \mathrm{E}+02$ & $<75$ & $2.78 \mathrm{E}+02$ & $2.10 \mathrm{E}+02$ \\
\hline PP-BL-39 & $399-1-32$ & (9.95E-01) & $3.81 \mathrm{E}+00$ & $8.72 \mathrm{E}+00$ & $(2.52 E+02$ & $<75$ & $3.31 \mathrm{E}+02$ & $2.29 \mathrm{E}+02$ \\
\hline PP-BL-40 & $399-1-36$ & $2.55 \mathrm{E}+02$ & $1.04 \mathrm{E}+01$ & $8.88 \mathrm{E}+00$ & $(1.84 \mathrm{E}+02$ & $<75$ & $3.85 E+02$ & $2.34 \mathrm{E}+02$ \\
\hline PP-BL-41 & $399-1-37$ & $8.12 E+00$ & $1.19 \mathrm{E}+01$ & $7.92 \mathrm{E}+00$ & $(2.24 \mathrm{E}+02$ & $<75$ & $3.52 E+02$ & $2.31 \mathrm{E}+02$ \\
\hline PP-BL-42 & $399-1-38$ & $(9.28 \mathrm{E}-01)$ & $6.06 \mathrm{E}+00$ & $8.68 \mathrm{E}+00$ & $(2.27 E+02$ & $<75$ & $4.04 \mathrm{E}+02$ & $2.32 E+02$ \\
\hline PP-BL-43 & $399-1-33$ & $3.38 \mathrm{E}+00$ & $7.59 E+00$ & $9.01 \mathrm{E}+00$ & $(2.24 \mathrm{E}+02$ & $<75$ & $4.95 E+02$ & $2.32 E+02$ \\
\hline PP-BL-44 & $399-1-34$ & $5.87 \mathrm{E}+01$ & $1.71 \mathrm{E}+00$ & $7.84 \mathrm{E}+00$ & $(2.23 E+02$ & $<75$ & $4.26 \mathrm{E}+02$ & $2.36 \mathrm{E}+02$ \\
\hline PP-BL-45 & $399-1-35$ & $4.27 \mathrm{E}+00$ & $9.79 E+00$ & $1.18 \mathrm{E}+01$ & $(2.28 E+02$ & $<75$ & $3.34 \mathrm{E}+02$ & $2.43 E+02$ \\
\hline PP-BL-46 & $399-1-35$ & $3.80 \mathrm{E}+00$ & $6.92 E+00$ & 1.13E+01) & $(2.15 E+02$ & $<75$ & $3.61 \mathrm{E}+02$ & $2.35 \mathrm{E}+02$ \\
\hline
\end{tabular}


Table B.2. (contd)

\begin{tabular}{|c|c|c|c|c|c|c|c|c|}
\hline Sample ID & Well Name & $\mathrm{Zn}$ & $\mathrm{Na}$ & $\mathrm{Si}$ & $\mathrm{s}$ & $\mathrm{Zr}$ & $\mathrm{Ag}$ & $\mathrm{Sb}$ \\
\hline \multicolumn{9}{|c|}{ Baseline sampling event \#1-1/12/2006 } \\
\hline PP-BL-1 & $399-1-23$ & $8.28 \mathrm{E}+01$ & $2.28 \mathrm{E}+04$ & $1.34 \mathrm{E}+04$ & $1.95 \mathrm{E}+04$ & 5.99E-01 & $1.16 \mathrm{E}+01$ & $<250$ \\
\hline PP-BL-2 & $399-1-24$ & $8.52 \mathrm{E}+01$ & $2.26 \mathrm{E}+04$ & $1.35 \mathrm{E}+04$ & $1.91 \mathrm{E}+04$ & $<1.25 \mathrm{E}+01$ & $1.44 \mathrm{E}+01$ & $<250$ \\
\hline PP-BL-3 & $399-1-27$ & $2.99 \mathrm{E}+02$ & $4.04 \mathrm{E}+04$ & $1.27 \mathrm{E}+04$ & $2.89 E+04$ & $5.18 \mathrm{E}-01$ & $1.11 \mathrm{E}+01$ & 3.09 \\
\hline PP-BL-4 & $399-1-25$ & $8.30 \mathrm{E}+01$ & $2.28 \mathrm{E}+04$ & $1.40 \mathrm{E}+04$ & $1.95 \mathrm{E}+04$ & $1.11 \mathrm{E}+00$ & $1.01 \mathrm{E}+01$ & $<250$ \\
\hline PP-BL- 5 & $399-1-30$ & $3.32 E+02$ & $2.31 \mathrm{E}+04$ & $1.39 \mathrm{E}+04$ & $1.95 \mathrm{E}+04$ & $1.04 \mathrm{E}+00$ & $1.20 \mathrm{E}+01$ & $<250$ \\
\hline PP-BL-6 & $399-1-31$ & $3.75 \mathrm{E}+02$ & $2.28 \mathrm{E}+04$ & $1.40 \mathrm{E}+04$ & $2.02 E+04$ & 2.33E-01 & $1.37 \mathrm{E}+01$ & $<250$ \\
\hline PP-BL-7 & $399-1-26$ & $1.95 \mathrm{E}+02$ & $2.28 \mathrm{E}+04$ & $1.38 \mathrm{E}+04$ & 1.97E+04 & $1.03 \mathrm{E}-01$ & $1.36 \mathrm{E}+01$ & $<250$ \\
\hline PP-BL-8 & $399-1-28$ & $9.67 \mathrm{E}+01$ & $2.28 \mathrm{E}+04$ & $1.30 \mathrm{E}+04$ & $1.94 \mathrm{E}+04$ & $1.02 \mathrm{E}+00$ & $1.42 \mathrm{E}+01$ & $6.07 \mathrm{E}-01$ \\
\hline PP-BL-9 & $399-1-29$ & $8.17 \mathrm{E}+01$ & $2.28 \mathrm{E}+04$ & 1.37E+04 & $1.98 \mathrm{E}+04$ & 5.32E-01 & $1.21 \mathrm{E}+01$ & $<250$ \\
\hline PP-BL-10 & 399-1-32 & $2.33 \mathrm{E}+02$ & $2.41 \mathrm{E}+04$ & $1.34 \mathrm{E}+04$ & $2.01 \mathrm{E}+04$ & $<1.25 \mathrm{E}+01$ & $1.19 \mathrm{E}+01$ & $8.78 \mathrm{E}+00$ \\
\hline \multicolumn{9}{|c|}{ Baseline sampling event \#2- 4/22/2007 } \\
\hline PP-BL-18 & $399-1-23$ & $2.84 \mathrm{E}+02$ & $2.36 \mathrm{E}+04$ & $1.22 \mathrm{E}+04$ & $1.77 \mathrm{E}+04$ & $1.48 \mathrm{E}+00$ & $<75$ & 2.17E+01 \\
\hline PP-BL-19 & $399-1-24$ & $6.55 \mathrm{E}+01$ & $2.30 \mathrm{E}+04$ & $1.33 \mathrm{E}+04$ & $1.80 \mathrm{E}+04$ & $9.15 \mathrm{E}-01$ & $<75$ & $5.42 E+01$ \\
\hline PP-BL-20 & $399-1-25$ & $6.34 \mathrm{E}+01$ & $2.34 \mathrm{E}+04$ & $1.32 \mathrm{E}+04$ & $1.79 \mathrm{E}+04$ & 1.35E-01 & $<75$ & $2.57 \mathrm{E}+01$ \\
\hline PP-BL-21 & $399-1-30$ & $1.01 \mathrm{E}+02$ & $2.31 \mathrm{E}+04$ & $1.35 \mathrm{E}+04$ & $1.83 E+04$ & 4.19E-01 & $<75$ & 4.07E+01 \\
\hline PP-BL-22 & $399-1-31$ & $5.97 \mathrm{E}+01$ & $2.34 \mathrm{E}+04$ & $1.36 \mathrm{E}+04$ & $1.79 \mathrm{E}+04$ & 8.97E-02 & $<75$ & $4.56 \mathrm{E}+01$ \\
\hline PP-BL-23 & $399-1-26$ & $9.57 \mathrm{E}+01$ & $2.34 \mathrm{E}+04$ & $1.35 \mathrm{E}+04$ & $1.80 \mathrm{E}+04$ & $5.25 \mathrm{E}-01$ & $<75$ & $4.96 \mathrm{E}+01$ \\
\hline PP-BL-24 & $399-1-27$ & $6.28 \mathrm{E}+01$ & $3.03 E+04$ & $1.30 \mathrm{E}+04$ & $1.93 E+04$ & $<15$ & $<75$ & 3.35E+01 \\
\hline PP-BL-25 & $399-1-28$ & $1.96 \mathrm{E}+02$ & $2.38 \mathrm{E}+04$ & $1.25 \mathrm{E}+04$ & $1.80 \mathrm{E}+04$ & 3.60E-01 & $<75$ & $2.15 E+01$ \\
\hline PP-BL-26 & $399-1-29$ & $6.08 \mathrm{E}+01$ & $2.38 \mathrm{E}+04$ & $1.30 \mathrm{E}+04$ & $1.80 \mathrm{E}+04$ & 2.53E-01 & $<75$ & $1.13 E+01$ \\
\hline PP-BL-27 & $399-1-32$ & $6.17 \mathrm{E}+01$ & $2.37 \mathrm{E}+04$ & $1.31 \mathrm{E}+04$ & $1.81 \mathrm{E}+04$ & $<15$ & $<75$ & $1.98 \mathrm{E}+01$ \\
\hline \multicolumn{9}{|c|}{ Baseline sampling event \#3- 6/11/2007 } \\
\hline PP-BL-28 & $399-1-23$ & $2.35 \mathrm{E}+02$ & $2.14 \mathrm{E}+04$ & $1.24 \mathrm{E}+04$ & $1.81 \mathrm{E}+04$ & 4.65E-01 & 7.94E-01 & $1.88 \mathrm{E}+01$ \\
\hline PP-BL-29 & $399-1-24$ & $1.43 \mathrm{E}+02$ & $2.06 \mathrm{E}+04$ & $1.33 \mathrm{E}+04$ & $1.83 \mathrm{E}+04$ & 5.03E-01 & 5.82E-01 & $2.32 \mathrm{E}+01$ \\
\hline PP-BL-30 & $399-1-25$ & $6.44 \mathrm{E}+01$ & $2.04 \mathrm{E}+04$ & $1.32 \mathrm{E}+04$ & $1.83 E+04$ & 2.65E-01 & 1.11 & $3.21 \mathrm{E}+01$ \\
\hline PP-BL-31 & $399-1-30$ & $6.15 \mathrm{E}+01$ & $2.11 \mathrm{E}+04$ & $1.34 \mathrm{E}+04$ & $1.85 \mathrm{E}+04$ & $1.63 \mathrm{E}-01$ & $8.25 \mathrm{E}-01$ & $2.08 \mathrm{E}+01$ \\
\hline PP-BL-32 & $399-1-30$ & $6.13 E+01$ & $2.01 \mathrm{E}+04$ & $1.35 \mathrm{E}+04$ & $1.86 \mathrm{E}+04$ & 3.56E-01 & 1.80 & $2.55 E+01$ \\
\hline PP-BL-33 & $399-1-31$ & $7.25 \mathrm{E}+01$ & $1.86 \mathrm{E}+04$ & $1.33 E+04$ & $1.84 \mathrm{E}+04$ & 3.32E-01 & $<15$ & $<75$ \\
\hline PP-BL-34 & $399-1-26$ & $1.74 \mathrm{E}+02$ & $1.93 E+04$ & $1.34 \mathrm{E}+04$ & $1.87 \mathrm{E}+04$ & 2.89E-01 & 2.86 & 7.63 \\
\hline PP-BL-35 & $399-1-29$ & $6.55 \mathrm{E}+01$ & $2.14 \mathrm{E}+04$ & $1.32 \mathrm{E}+04$ & $1.86 \mathrm{E}+04$ & $1.90 \mathrm{E}+00$ & 2.48 & $6.04 \mathrm{E}+01$ \\
\hline PP-BL-36 & $399-1-29$ & $6.82 \mathrm{E}+01$ & $2.14 \mathrm{E}+04$ & $1.46 \mathrm{E}+04$ & $1.82 \mathrm{E}+04$ & $1.69 \mathrm{E}+00$ & 7.97E-01 & $2.98 \mathrm{E}+01$ \\
\hline PP-BL-37 & $399-1-28$ & $6.46 \mathrm{E}+01$ & $2.11 \mathrm{E}+04$ & $1.28 \mathrm{E}+04$ & $1.81 \mathrm{E}+04$ & $1.19 \mathrm{E}+00$ & $9.54 \mathrm{E}-01$ & $3.69 \mathrm{E}+01)$ \\
\hline PP-BL-38 & $399-1-27$ & $6.22 \mathrm{E}+01$ & $3.64 \mathrm{E}+04$ & $1.24 \mathrm{E}+04$ & $2.06 \mathrm{E}+04$ & $6.18 \mathrm{E}-01$ & 5.09E-01 & $1.42 \mathrm{E}+01$ \\
\hline PP-BL-39 & $399-1-32$ & $6.23 \mathrm{E}+01$ & $2.13 E+04$ & $1.29 \mathrm{E}+04$ & $1.82 \mathrm{E}+04$ & $5.78 \mathrm{E}-01$ & $<15$ & $4.12 \mathrm{E}+01$ \\
\hline PP-BL-40 & $399-1-36$ & $7.22 \mathrm{E}+01$ & $2.24 \mathrm{E}+04$ & $1.23 E+04$ & $1.92 \mathrm{E}+04$ & $5.58 \mathrm{E}-01$ & 5.36E-01 & $3.54 \mathrm{E}+01$ \\
\hline PP-BL-41 & $399-1-37$ & $6.23 \mathrm{E}+01$ & $2.10 \mathrm{E}+04$ & $1.35 \mathrm{E}+04$ & $1.89 \mathrm{E}+04$ & $3.80 \mathrm{E}-01$ & $1.75 \mathrm{E}-01$ & $2.66 \mathrm{E}+01$ \\
\hline PP-BL-42 & $399-1-38$ & $6.31 \mathrm{E}+01$ & $2.19 \mathrm{E}+04$ & $1.34 \mathrm{E}+04$ & 1.87E+04 & $1.98 \mathrm{E}-01$ & $<15$ & $3.49 \mathrm{E}+01$ \\
\hline PP-BL-43 & $399-1-33$ & 8.97E+01 & $2.18 \mathrm{E}+04$ & $1.33 \mathrm{E}+04$ & $1.86 \mathrm{E}+04$ & 3.18E-01 & $<15$ & 6.47 \\
\hline PP-BL-44 & $399-1-34$ & $6.35 \mathrm{E}+01$ & $2.13 E+04$ & $1.28 \mathrm{E}+04$ & $1.86 \mathrm{E}+04$ & 3.08E-02 & $<15$ & $2.09 E+01$ \\
\hline PP-BL-45 & $399-1-35$ & $7.05 \mathrm{E}+01$ & $2.10 \mathrm{E}+04$ & $1.35 \mathrm{E}+04$ & $1.88 \mathrm{E}+04$ & 2.01 & 2.72 & 3.19 \\
\hline PP-BL-46 & $399-1-35$ & $6.31 \mathrm{E}+01$ & $2.18 \mathrm{E}+04$ & $1.35 \mathrm{E}+04$ & $1.87 \mathrm{E}+04$ & 1.16 & $8.30 \mathrm{E}-01$ & $5.16 \mathrm{E}+01$ \\
\hline
\end{tabular}


Table B.3. Metals (ICP-MS) Results for Baseline Sampling ( $\mu \mathrm{g} / \mathrm{L})$

\begin{tabular}{|c|c|c|c|c|c|c|c|c|}
\hline Sample ID & Well Name & Cr 52 & Cr 53 & Cu 63 & Cu 65 & As 75 & Se 82 & Mo 95 \\
\hline \multicolumn{9}{|c|}{ Baseline sampling event \#1-1/12/2006 } \\
\hline PP-BL-1 & $399-1-23$ & 4.11 & 4.45 & 5.28 & 5.39 & 2.88 & 4.69 & 5.00 \\
\hline PP-BL-2 & $399-1-24$ & 4.01 & 4.48 & 8.01 & 8.04 & 2.62 & 4.93 & 5.24 \\
\hline PP-BL-3 & $399-1-27$ & 3.03 & 3.36 & 6.15 & 5.98 & 2.77 & 5.42 & 17.3 \\
\hline PP-BL-4 & $399-1-25$ & 4.09 & 4.47 & 4.14 & 4.10 & 2.88 & 5.06 & 5.66 \\
\hline PP-BL- 5 & $399-1-30$ & 4.36 & 4.72 & 10.2 & 10.3 & 3.15 & 5.38 & 5.17 \\
\hline PP-BL-6 & $399-1-31$ & 4.47 & 5.00 & 7.16 & 7.13 & 3.31 & 4.70 & 5.17 \\
\hline PP-BL-7 & $399-1-26$ & 4.61 & 5.08 & 1.57 & 15.7 & 3.34 & 5.06 & 5.18 \\
\hline PP-BL-8 & $399-1-28$ & 3.67 & 4.16 & 4.37 & 4.39 & 2.31 & 4.84 & 5.01 \\
\hline PP-BL-9 & $399-1-29$ & 3.93 & 4.39 & 4.58 & 4.59 & 2.98 & 4.87 & 5.12 \\
\hline PP-BL-10 & $399-1-32$ & 3.90 & 4.37 & 6.91 & 6.97 & 2.84 & 5.05 & 5.48 \\
\hline \multicolumn{9}{|c|}{ Baseline sampling event \#2- 4/22/2007 } \\
\hline PP-BL-18 & $399-1-23$ & 4.76 & 4.90 & 6.77 & 6.23 & 2.20 & 3.20 & 4.43 \\
\hline PP-BL-19 & $399-1-24$ & 5.76 & 6.10 & 11.0 & 10.3 & 3.03 & 3.13 & 4.81 \\
\hline PP-BL-20 & $399-1-25$ & 4.12 & 4.78 & 6.48 & 6.21 & 2.65 & 3.82 & 4.79 \\
\hline PP-BL-21 & $399-1-30$ & 4.37 & 5.36 & 3.17 & 2.95 & 3.02 & 3.34 & 4.74 \\
\hline PP-BL-22 & $399-1-31$ & 4.18 & 4.62 & 5.06 & 4.71 & 3.82 & 4.13 & 4.76 \\
\hline PP-BL-23 & $399-1-26$ & 4.54 & 4.74 & 3.26 & 3.33 & 2.82 & 2.73 & 4.62 \\
\hline PP-BL-24 & $399-1-27$ & 3.94 & 4.53 & 3.04 & 3.01 & 3.64 & 4.36 & 6.51 \\
\hline PP-BL-25 & $399-1-28$ & 4.11 & 4.68 & 4.30 & 3.84 & 2.69 & 4.05 & 4.69 \\
\hline PP-BL-26 & $399-1-29$ & 4.16 & 4.64 & 3.05 & 2.62 & 3.55 & 4.31 & 4.60 \\
\hline PP-BL-27 & $399-1-32$ & 4.10 & 4.47 & 4.70 & 4.53 & $3.16 \mathrm{E}$ & 4.12 & 4.58 \\
\hline \multicolumn{9}{|c|}{ Baseline sampling event \#3- 6/11/2007 } \\
\hline PP-BL-28 & $399-1-23$ & 4.62 & & 1.79 & & 1.92 & $<1.25$ & 5.71 \\
\hline PP-BL-29 & $399-1-24$ & 4.80 & & 3.91 & & 4.65 & $<1.25$ & 5.25 \\
\hline PP-BL-30 & $399-1-25$ & 5.42 & & 7.12 & & 2.91 & $<1.25$ & 4.95 \\
\hline PP-BL-31 & $399-1-30$ & 3.80 & & 1.01 & & 4.58 & $<1.25$ & 4.65 \\
\hline PP-BL-32 & $399-1-30$ & 3.99 & & $<1.25 \mathrm{E}+02$ & & 2.39 & $<1.25$ & 5.24 \\
\hline PP-BL-33 & $399-1-31$ & 4.69 & & $7.68 \mathrm{E}+01$ & & 5.84 & $<1.25$ & 4.50 \\
\hline PP-BL-34 & $399-1-26$ & 4.40 & & $<1.25 \mathrm{E}+02$ & & 7.03E-01 & $<1.25$ & 5.15 \\
\hline PP-BL-35 & $399-1-29$ & 3.58 & & $<1.25 \mathrm{E}+02$ & & 5.18 & $<1.25$ & 5.34 \\
\hline PP-BL-36 & $399-1-29$ & 4.32 & & 1.65E-01 & & 1.10E-01 & $<1.25$ & 5.15 \\
\hline PP-BL-37 & $399-1-28$ & 3.36 & & $<1.25 \mathrm{E}+02$ & & 1.28 & $<1.25$ & 4.56 \\
\hline PP-BL-38 & $399-1-27$ & 3.77 & & $<1.25 \mathrm{E}+02$ & & 3.77 & $<1.25$ & 7.99 \\
\hline PP-BL-39 & $399-1-32$ & 4.13 & & $6.75 \mathrm{E}-02$ & & 3.42 & $<1.25$ & 5.41 \\
\hline PP-BL-40 & $399-1-36$ & 2.42 & & $<1.25 \mathrm{E}+02$ & & 3.81 & 8.50E-01 & 6.93 \\
\hline PP-BL-41 & $399-1-37$ & 3.80 & & $<1.25 \mathrm{E}+02$ & & 1.94 & $<1.25$ & 8.08 \\
\hline PP-BL-42 & $399-1-38$ & 7.14 & & 7.75E-02 & & 5.65 & 4.94 & 4.77 \\
\hline PP-BL-43 & $399-1-33$ & 3.95 & & $<1.25 \mathrm{E}+02$ & & 3.98 & 1.43 & 5.06 \\
\hline PP-BL-44 & $399-1-34$ & 4.17 & & $<1.25 \mathrm{E}+02$ & & 3.55 & $<1.25$ & 6.27 \\
\hline PP-BL-45 & $399-1-35$ & 3.54 & & $<1.25 \mathrm{E}+02$ & & 5.62 & 5.06 & 4.67 \\
\hline PP-BL-46 & $399-1-35$ & 3.91 & & $<1.25 \mathrm{E}+02$ & & 2.24 & 1.99 & 5.58 \\
\hline
\end{tabular}


Table B.3. (contd)

\begin{tabular}{|c|c|c|c|c|c|c|c|c|}
\hline Sample ID & $\begin{array}{c}\text { Well } \\
\text { Name }\end{array}$ & Mo 97 & Mo 98 & Ru 101 & Ru 102 & Ag 107 & Ag 109 & Cd 111 \\
\hline \multicolumn{9}{|c|}{ Baseline sampling event \#1- 1/12/2006 } \\
\hline PP-BL-1 & $399-1-23$ & 5.14 & 5.07 & $<1.25$ & 2.45E-02 & 3.02E-02 & 1.05E-03 & $5.05 \mathrm{E}-02$ \\
\hline PP-BL-2 & $399-1-24$ & 5.39 & 5.43 & $<1.25$ & 1.72E-02 & $1.54 \mathrm{E}-02$ & $<1.25$ & 5.26E-02 \\
\hline PP-BL-3 & $399-1-27$ & 17.6 & 17.7 & $<1.25$ & 1.87E-02 & 1.30E-02 & $<1.25$ & 7.07E-02 \\
\hline PP-BL-4 & $399-1-25$ & 5.69 & 5.77 & $<1.25$ & 7.37E-03 & $1.22 \mathrm{E}-02$ & $<1.25$ & 3.81E-02 \\
\hline PP-BL- 5 & $399-1-30$ & 5.16 & 5.19 & $<1.25$ & 1.76E-02 & $1.04 \mathrm{E}-02$ & $<1.25$ & 1.89E-02 \\
\hline PP-BL-6 & $399-1-31$ & 5.11 & 5.16 & $<1.25$ & 1.76E-02 & 7.64E-03 & $<1.25$ & 2.64E-02 \\
\hline PP-BL-7 & $399-1-26$ & 5.39 & 5.33 & $<1.25$ & 1.29E-02 & 1.12E-02 & $<1.25$ & 2.43E-02 \\
\hline PP-BL-8 & $399-1-28$ & 5.10 & 5.04 & $<1.25$ & 1.51E-02 & 9.65E-03 & $<1.25$ & 3.26E-02 \\
\hline PP-BL-9 & $399-1-29$ & 5.33 & 5.30 & $<1.25$ & 1.27E-02 & $6.48 \mathrm{E}-03$ & $<1.25$ & 2.63E-02 \\
\hline PP-BL-10 & $399-1-32$ & 5.51 & 5.67 & $<1.25$ & 8.54E-03 & 5.15E-03 & $<1.25$ & 3.17E-02 \\
\hline \multicolumn{9}{|c|}{ Baseline sampling event \#2- 4/22/2007 } \\
\hline PP-BL-18 & $399-1-23$ & 4.93 & 4.34 & $1.40 \mathrm{E}-02$ & 3.90E-02 & 6.10E-02 & $<1.25$ & $1.50 \mathrm{E}-03$ \\
\hline PP-BL-19 & $399-1-24$ & 5.12 & 4.63 & $<2.50$ & 1.05E-02 & $4.40 \mathrm{E}-02$ & $<1.25$ & $<1.25$ \\
\hline PP-BL-20 & $399-1-25$ & 5.06 & 4.34 & $<2.50$ & $1.55 \mathrm{E}-02$ & 8.10E-02 & $<1.25$ & $<1.25$ \\
\hline PP-BL-21 & $399-1-30$ & 4.81 & 4.45 & $<2.50$ & $6.50 \mathrm{E}-03$ & $3.25 \mathrm{E}-02$ & $<1.25$ & $<1.25$ \\
\hline PP-BL-22 & $399-1-31$ & 4.94 & 4.43 & $<2.50$ & $8.00 \mathrm{E}-03$ & $5.30 \mathrm{E}-02$ & $<1.25$ & $<1.25$ \\
\hline PP-BL-23 & $399-1-26$ & 4.75 & 4.57 & $<2.50$ & 1.65E-02 & $5.10 \mathrm{E}-02$ & $<1.25$ & $<1.25$ \\
\hline PP-BL-24 & $399-1-27$ & 6.22 & 6.06 & $<2.50$ & 8.50E-03 & 6.35E-02 & $<1.25$ & $<1.25$ \\
\hline PP-BL-25 & $399-1-28$ & 5.03 & 4.76 & $<2.50$ & $2.70 \mathrm{E}-02$ & $6.50 \mathrm{E}-02$ & $<1.25$ & $<1.25$ \\
\hline PP-BL-26 & $399-1-29$ & 4.80 & 4.36 & $<2.50$ & $<1.25 \mathrm{E}-01$ & 2.20E-02 & $<1.25$ & $<1.25$ \\
\hline PP-BL-27 & $399-1-32$ & 4.84 & 4.41 & $<2.50$ & 1.05E-02 & $5.00 \mathrm{E}-02$ & $<1.25$ & $<1.25$ \\
\hline \multicolumn{9}{|c|}{ Baseline sampling event \#3- 6/11/2007 } \\
\hline PP-BL-28 & $399-1-23$ & 5.46 & 4.26 & $<12.5$ & 2.03E-01 & $<12.5$ & $<2.5$ & $<2.5$ \\
\hline PP-BL-29 & $399-1-24$ & 4.79 & 4.43 & $<12.5$ & 1.65E-01 & $<12.5$ & $<2.5$ & $<2.5$ \\
\hline PP-BL-30 & $399-1-25$ & 5.22 & 4.39 & $<12.5$ & $2.40 \mathrm{E}-01$ & $<12.5$ & $<2.5$ & $<2.5$ \\
\hline PP-BL-31 & $399-1-30$ & 4.78 & 4.84 & $<12.5$ & $1.25 \mathrm{E}-01$ & $<12.5$ & $<2.5$ & $<2.5$ \\
\hline PP-BL-32 & $399-1-30$ & 4.95 & 4.58 & $<12.5$ & $9.00 \mathrm{E}-02$ & $<12.5$ & $<2.5$ & $<2.5$ \\
\hline PP-BL-33 & $399-1-31$ & 5.55 & 4.94 & $<12.5$ & 1.40E-01 & $<12.5$ & $<2.5$ & $<2.5$ \\
\hline PP-BL-34 & $399-1-26$ & 5.40 & 4.95 & $<12.5$ & $1.30 \mathrm{E}-01$ & $<12.5$ & $<2.5$ & $<2.5$ \\
\hline PP-BL-35 & $399-1-29$ & 5.25 & 4.48 & $<12.5$ & 1.23E-01 & $<12.5$ & $<2.5$ & $<2.5$ \\
\hline PP-BL-36 & $399-1-29$ & 4.74 & 4.17 & $<12.5$ & 2.30E-01 & $<12.5$ & $<2.5$ & $<2.5$ \\
\hline PP-BL-37 & $399-1-28$ & 4.68 & 4.33 & $<12.5$ & $1.58 \mathrm{E}-01$ & $<12.5$ & $<2.5$ & $<2.5$ \\
\hline PP-BL-38 & $399-1-27$ & 7.20 & 7.93 & $<12.5$ & 2.65E-01 & $<12.5$ & $<2.5$ & $<2.5$ \\
\hline PP-BL-39 & $399-1-32$ & 4.64 & 4.71 & $<12.5$ & $1.45 \mathrm{E}-01$ & $<12.5$ & $<2.5$ & $<2.5$ \\
\hline PP-BL-40 & $399-1-36$ & 7.14 & 6.15 & $<12.5$ & 2.23E-01 & $<12.5$ & $<2.5$ & $<2.5$ \\
\hline PP-BL-41 & $399-1-37$ & 7.17 & 7.48 & $<12.5$ & $6.50 \mathrm{E}-02$ & $<12.5$ & $<2.5$ & $<2.5$ \\
\hline PP-BL-42 & $399-1-38$ & 4.93 & 4.38 & $<12.5$ & 1.60E-01 & $<12.5$ & $<2.5$ & $<2.5$ \\
\hline PP-BL-43 & $399-1-33$ & 4.26 & 4.47 & $<12.5$ & 7.50E-02 & $<12.5$ & $<2.5$ & $<2.5$ \\
\hline PP-BL-44 & $399-1-34$ & 6.04 & 5.12 & $<12.5$ & $2.00 \mathrm{E}-02$ & $<12.5$ & $<2.5$ & $<2.5$ \\
\hline PP-BL-45 & $399-1-35$ & 4.63 & 4.46 & $<12.5$ & $1.08 \mathrm{E}-01$ & $<12.5$ & $<2.5$ & $<2.5$ \\
\hline PP-BL-46 & $399-1-35$ & 4.68 & 4.35 & $<12.5$ & $8.50 \mathrm{E}-02$ & $<12.5$ & $<2.5$ & $<2.5$ \\
\hline
\end{tabular}


Table B.3. (contd)

\begin{tabular}{|c|c|c|c|c|c|c|c|}
\hline Sample ID & $\begin{array}{c}\text { Well } \\
\text { Name } \\
\end{array}$ & Cd 114 & Sb 121 & $\mathrm{Sb} 123$ & $\mathrm{~Pb} 206$ & $\mathrm{~Pb} 208$ & U 238 \\
\hline \multicolumn{8}{|c|}{ Baseline sampling event \#1-1/12/2006 } \\
\hline PP-BL-1 & $399-1-23$ & $5.26 \mathrm{E}-02$ & 2.62E-01 & 2.46E-01 & 1.77E-01 & 1.72E-01 & 60.6 \\
\hline PP-BL-2 & $399-1-24$ & $5.84 \mathrm{E}-02$ & 2.79E-01 & 2.72E-01 & $1.50 \mathrm{E}-01$ & $1.42 \mathrm{E}-01$ & 60.8 \\
\hline PP-BL-3 & $399-1-27$ & 7.10E-02 & 3.66E-01 & 3.55E-01 & 2.95E-01 & 2.66E-01 & 75.1 \\
\hline PP-BL-4 & $399-1-25$ & 4.47E-02 & 2.62E-01 & 2.59E-01 & 2.35E-01 & 2.24E-01 & 58.6 \\
\hline PP-BL- 5 & $399-1-30$ & 3.27E-02 & $2.22 \mathrm{E}-01$ & 1.81E-01 & 1.17E-01 & 1.14E-01 & 56.6 \\
\hline PP-BL-6 & $399-1-31$ & 3.32E-02 & 1.99E-01 & 1.80E-01 & 3.98E-01 & 3.67E-01 & 60.5 \\
\hline PP-BL-7 & $399-1-26$ & 3.64E-02 & 1.94E-01 & 1.91E-01 & 2.65E-01 & $2.56 \mathrm{E}-01$ & 47.5 \\
\hline PP-BL-8 & $399-1-28$ & 4.27E-02 & 2.17E-01 & $2.08 \mathrm{E}-01$ & 1.60E-01 & 1.41E-01 & 68.6 \\
\hline PP-BL-9 & $399-1-29$ & 3.68E-02 & 2.05E-01 & $1.89 \mathrm{E}-01$ & 8.37E-02 & 7.16E-02 & 57.6 \\
\hline PP-BL-10 & $399-1-32$ & 4.48E-02 & 2.16E-01 & 2.12E-01 & 1.26E-01 & 1.16E-01 & 57.1 \\
\hline \multicolumn{8}{|c|}{ Baseline sampling event \#2- 4/22/2007 } \\
\hline PP-BL-18 & $399-1-23$ & $<2.50$ & $2.40 \mathrm{E}-02$ & $1.74 \mathrm{E}-01$ & $2.56 \mathrm{E}-01$ & $2.48 \mathrm{E}-01$ & 84.2 \\
\hline PP-BL-19 & $399-1-24$ & $<2.50$ & $<5.00 \mathrm{E}-02$ & $1.51 \mathrm{E}-01$ & 3.46E-01 & $3.39 \mathrm{E}-01$ & 67.7 \\
\hline PP-BL-20 & $399-1-25$ & $<2.50$ & $<5.00 \mathrm{E}-02$ & 1.82E-01 & 2.25E-02 & $4.00 \mathrm{E}-03$ & 69.0 \\
\hline PP-BL-21 & $399-1-30$ & $<2.50$ & $4.50 \mathrm{E}-03$ & 1.43E-01 & 3.03E-01 & 3.17E-01 & 67.7 \\
\hline PP-BL-22 & $399-1-31$ & $<2.50$ & $<5.00 \mathrm{E}-02$ & 1.15E-01 & 2.40E-02 & $2.60 \mathrm{E}-02$ & 69.9 \\
\hline PP-BL-23 & $399-1-26$ & $<2.50$ & $<5.00 \mathrm{E}-02$ & 1.23E-01 & 1.39E-01 & 1.43E-01 & 64.4 \\
\hline PP-BL-24 & $399-1-27$ & $<2.50$ & $<5.00 \mathrm{E}-02$ & $2.49 \mathrm{E}-01$ & 1.11E-01 & 8.70E-02 & 72.6 \\
\hline PP-BL-25 & $399-1-28$ & $<2.50$ & $<5.00 \mathrm{E}-02$ & $1.45 \mathrm{E}-01$ & $4.75 \mathrm{E}-02$ & $3.60 \mathrm{E}-02$ & 89.4 \\
\hline PP-BL-26 & $399-1-29$ & $<2.50$ & $<5.00 \mathrm{E}-02$ & 1.31E-01 & 1.11E-01 & $8.25 \mathrm{E}-02$ & 65.2 \\
\hline PP-BL-27 & $399-1-32$ & $<2.50$ & $<5.00 \mathrm{E}-02$ & 1.62E-01 & 1.23E-01 & 1.30E-01 & 70.9 \\
\hline \multicolumn{8}{|c|}{ Baseline sampling event \#3- 6/11/2007 } \\
\hline PP-BL-28 & $399-1-23$ & $<2.50$ & $<6.25$ & 1.15E-01 & 2.28E-01 & $1.98 \mathrm{E}-01$ & 78.3 \\
\hline PP-BL-29 & $399-1-24$ & $1.70 \mathrm{E}-01$ & $<6.25$ & $1.30 \mathrm{E}-01$ & 7.75E-02 & $8.50 \mathrm{E}-02$ & 71.7 \\
\hline PP-BL-30 & $399-1-25$ & $9.50 \mathrm{E}-0$ & $<6.25$ & 1.83E-01 & 7.75E-02 & $<6.25$ & 70.3 \\
\hline PP-BL-31 & $399-1-30$ & 2.25E-02 & $<6.25$ & 1.30E-01 & $1.25 \mathrm{E}-01$ & $<6.25$ & 71.5 \\
\hline PP-BL-32 & $399-1-30$ & 1.15E-01 & $<6.25$ & 9.25E-02 & 3.00E-02 & 1.50E-02 & 72.8 \\
\hline PP-BL-33 & $399-1-31$ & 1.10E-01 & $<6.25$ & 4.18E-01 & $3.76 \mathrm{E}+00$ & $3.51 \mathrm{E}+00$ & 71.8 \\
\hline PP-BL-34 & $399-1-26$ & $<2.50$ & 1.50E-02 & $1.50 \mathrm{E}-01$ & 3.00E-02 & $<6.25$ & 73.4 \\
\hline PP-BL-35 & $399-1-29$ & $<2.50$ & $<6.25$ & 7.00E-02 & 4.00E-02 & $<6.25$ & 69.6 \\
\hline PP-BL-36 & $399-1-29$ & $<2.50$ & $<6.25$ & 1.63E-01 & 2.93E-01 & 3.23E-01 & 71.7 \\
\hline PP-BL-37 & $399-1-28$ & 3.38E-01 & $<6.25$ & 1.15E-01 & $<2.50$ & $<6.25$ & 81.4 \\
\hline PP-BL-38 & $399-1-27$ & 7.25E-02 & $<6.25$ & 3.20E-01 & $<2.50$ & $<6.25$ & 94.3 \\
\hline PP-BL-39 & $399-1-32$ & $<2.5$ & $<6.25$ & 2.00E-01 & $1.48 \mathrm{E}-01$ & $1.50 \mathrm{E}-01$ & 78.2 \\
\hline PP-BL-40 & $399-1-36$ & $1.28 \mathrm{E}-01$ & $<6.25$ & 2.13E-01 & $<2.50$ & $<6.25$ & 103.7 \\
\hline PP-BL-41 & $399-1-37$ & $6.25 \mathrm{E}-02$ & $<6.25$ & 7.25E-02 & 4.50E-02 & $<6.25$ & 75.6 \\
\hline PP-BL-42 & $399-1-38$ & $9.00 \mathrm{E}-02$ & $<6.25$ & $1.00 \mathrm{E}-01$ & $<2.50$ & $<6.25$ & 85.9 \\
\hline PP-BL-43 & $399-1-33$ & $6.75 \mathrm{E}-02$ & $<6.25$ & 1.83E-01 & $<2.50$ & $<6.25$ & 77.7 \\
\hline PP-BL-44 & $399-1-34$ & & $<6.25$ & 2.18E-01 & $<2.50$ & $<6.25$ & 86.0 \\
\hline PP-BL-45 & $399-1-35$ & $8.50 \mathrm{E}-02$ & $<6.25$ & $1.85 \mathrm{E}-01$ & $2.50 \mathrm{E}-03$ & $<6.25$ & 78.3 \\
\hline PP-BL-46 & $399-1-35$ & 1.83E-01 & $<6.25$ & $1.28 \mathrm{E}-01$ & 7.50E-03 & 3.75E-02 & 78.9 \\
\hline
\end{tabular}


Table B.4. Field Parameters Measured During Baseline Sampling Events

\begin{tabular}{|c|c|c|c|c|c|c|c|c|c|}
\hline Sample ID & Well Name & Date & Time & $\begin{array}{l}\text { Temp } \\
\text { (C ) }\end{array}$ & $\begin{array}{c}\text { Sp. } \\
\text { Cond. } \\
\text { (mS/cm) }\end{array}$ & $\begin{array}{c}\mathrm{DO} \\
(\mathrm{mg} / \mathrm{L})\end{array}$ & $\mathrm{pH}$ & $\begin{array}{l}\text { ORP } \\
(\mathrm{mV})\end{array}$ & $\begin{array}{c}\text { Bromide } \\
\text { (mg/L) }\end{array}$ \\
\hline \multicolumn{10}{|c|}{ Baseline sampling event \#1-1/12/2006 } \\
\hline PP-BL-1 & $399-1-23$ & $12 / 12 / 2006$ & $13: 27$ & 16.6 & 0.474 & 8.81 & 7.35 & 125 & \\
\hline PP-BL-2 & $399-1-24$ & $12 / 12 / 2006$ & $13: 43$ & 16.6 & 0.473 & 8.93 & 7.37 & 118 & \\
\hline PP-BL-3 & $399-1-27$ & $12 / 12 / 2006$ & $13: 48$ & 16.7 & 0.531 & 6.74 & 7.56 & 119 & \\
\hline PP-BL-4 & $399-1-25$ & $12 / 12 / 2006$ & 13:56 & 16.7 & 0.473 & 8.4 & 7.41 & 123 & \\
\hline PP-BL-5 & $399-1-30$ & $12 / 12 / 2006$ & 14:07 & 16.6 & 0.472 & 8.91 & 7.39 & 116 & \\
\hline PP-BL-6 & $399-1-31$ & $12 / 12 / 2006$ & 14:11 & 16.6 & 0.472 & 8.92 & 7.4 & 119 & \\
\hline PP-BL-7 & $399-1-26$ & $12 / 12 / 2006$ & 14:15 & 16.5 & 0.471 & 8.88 & 7.41 & 123 & \\
\hline PP-BL-8 & $399-1-28$ & $12 / 12 / 2006$ & $14: 18$ & 16.7 & 0.475 & 8.41 & 7.28 & 130 & \\
\hline PP-BL-9 & $399-1-29$ & $12 / 12 / 2006$ & $14: 25$ & 16.5 & 0.473 & 8.66 & 7.39 & 128 & \\
\hline PP-BL-10 & $399-1-32$ & $12 / 12 / 2006$ & $14: 28$ & 16.1 & 0.474 & 8.31 & 7.41 & 129 & \\
\hline \multicolumn{10}{|c|}{ Baseline sampling event \#2- 4/22/2007 } \\
\hline PP-BL-18 & $399-1-23$ & $4 / 22 / 2007$ & 15:05 & 17.7 & 0.468 & 6.44 & 7.32 & 86 & \\
\hline PP-BL-19 & $399-1-24$ & $4 / 22 / 2007$ & $15: 15$ & 17.6 & 0.463 & 6.75 & 7.29 & -46 & \\
\hline PP-BL-20 & $399-1-25$ & $4 / 22 / 2007$ & $15: 20$ & 17.9 & 0.462 & 6.68 & 7.44 & 28 & \\
\hline PP-BL-21 & $399-1-30$ & $4 / 22 / 2007$ & $15: 30$ & 17.2 & 0.465 & 7.5 & 7.4 & 59 & \\
\hline PP-BL-22 & $399-1-31$ & $4 / 22 / 2007$ & $15: 35$ & 17.4 & 0.462 & 7.46 & 7.4 & 69 & \\
\hline PP-BL-23 & $399-1-26$ & $4 / 22 / 2007$ & $15: 40$ & 17.4 & 0.469 & 7.43 & 7.42 & 77 & \\
\hline PP-BL-24 & $399-1-27$ & $4 / 22 / 2007$ & $15: 45$ & 17.2 & 0.481 & 6.3 & 7.45 & 76 & \\
\hline PP-BL-25 & $399-1-28$ & $4 / 22 / 2007$ & $15: 50$ & 17.1 & 0.468 & 7.28 & 7.34 & 73 & \\
\hline PP-BL-26 & $399-1-29$ & $4 / 22 / 2007$ & $15: 55$ & 17.2 & 0.466 & 7.36 & 7.43 & 86 & \\
\hline PP-BL-27 & $399-1-32$ & $4 / 22 / 2007$ & $15: 59$ & 18.5 & 0.467 & 7.01 & 7.44 & 73 & \\
\hline \multicolumn{10}{|c|}{ Baseline sampling event \#3- 6/11/2007 } \\
\hline PP-BL-A-28 & $399-1-23$ & $6 / 11 / 2007$ & 13:55 & 17.2 & 0.448 & 5.92 & 7.28 & 106 & 1 \\
\hline PP-BL-A-29 & $399-1-24$ & $6 / 11 / 2007$ & 13:59 & 17.2 & 0.454 & 6.13 & 7.28 & 115 & 1.1 \\
\hline PP-BL-A-30 & $399-1-25$ & $6 / 11 / 2007$ & 14:03 & 17.4 & 0.455 & 6.1 & 7.29 & 122 & 1.1 \\
\hline PP-BL-A-31 & $399-1-30$ & $6 / 11 / 2007$ & 14:06 & 17 & 0.458 & 6.32 & 7.28 & 128 & 1 \\
\hline PP-BL-A-32 & $399-1-30$ & $6 / 11 / 2007$ & 14:07 & \multicolumn{6}{|c|}{ Unfiltered Sample } \\
\hline PP-BL-A-33 & $399-1-31$ & $6 / 11 / 2007$ & 14:09 & 17.8 & 0.457 & 6.29 & 7.3 & 134 & 0.9 \\
\hline PP-BL-A-34 & $399-1-26$ & $6 / 11 / 2007$ & $14: 13$ & 17.8 & 0.462 & 6.27 & 7.27 & 138 & 1 \\
\hline PP-BL-A-35 & $399-1-29$ & $6 / 11 / 2007$ & $14: 16$ & 17.5 & 0.456 & 6.31 & 7.28 & 142 & 0.9 \\
\hline PP-BL-A-36 & $399-1-29$ & $6 / 11 / 2007$ & $14: 18$ & \multicolumn{6}{|c|}{ Unfiltered Sample } \\
\hline PP-BL-A-37 & $399-1-28$ & $6 / 11 / 2007$ & $14: 21$ & 17.1 & 0.449 & 6.46 & 7.25 & 147 & 1.1 \\
\hline PP-BL-A-38 & $399-1-27$ & $6 / 11 / 2007$ & $14: 23$ & 17.2 & 0.487 & 4.56 & 7.34 & 145 & 1.2 \\
\hline PP-BL-A-39 & $399-1-32$ & $6 / 11 / 2007$ & $14: 27$ & 19.2 & 0.456 & 6.12 & 7.28 & 143 & 1.1 \\
\hline PP-BL-A-40 & $399-1-36$ & $6 / 11 / 2007$ & $14: 30$ & 17.5 & 0.473 & 4.32 & 7.3 & 140 & 1.1 \\
\hline PP-BL-A-41 & $399-1-37$ & $6 / 11 / 2007$ & $14: 34$ & 17.5 & 0.465 & 5.96 & 7.27 & 141 & 1.2 \\
\hline PP-BL-A-42 & $399-1-38$ & $6 / 11 / 2007$ & $14: 37$ & 17.7 & 0.461 & 6.23 & 7.26 & 146 & 1.2 \\
\hline PP-BL-A-43 & $399-1-33$ & $6 / 11 / 2007$ & $14: 40$ & 18.1 & 0.47 & 6.24 & 7.26 & 147 & 1.2 \\
\hline PP-BL-A-44 & $399-1-34$ & $6 / 11 / 2007$ & $14: 44$ & 18.53 & 0.473 & 5.83 & 7.24 & 145 & 2.7 \\
\hline PP-BL-A-45 & $399-1-35$ & $6 / 11 / 2007$ & $14: 47$ & 18.1 & 0.466 & 6.13 & 7.27 & 143 & 1.5 \\
\hline
\end{tabular}



Appendix C

Amendment Arrival Plots 


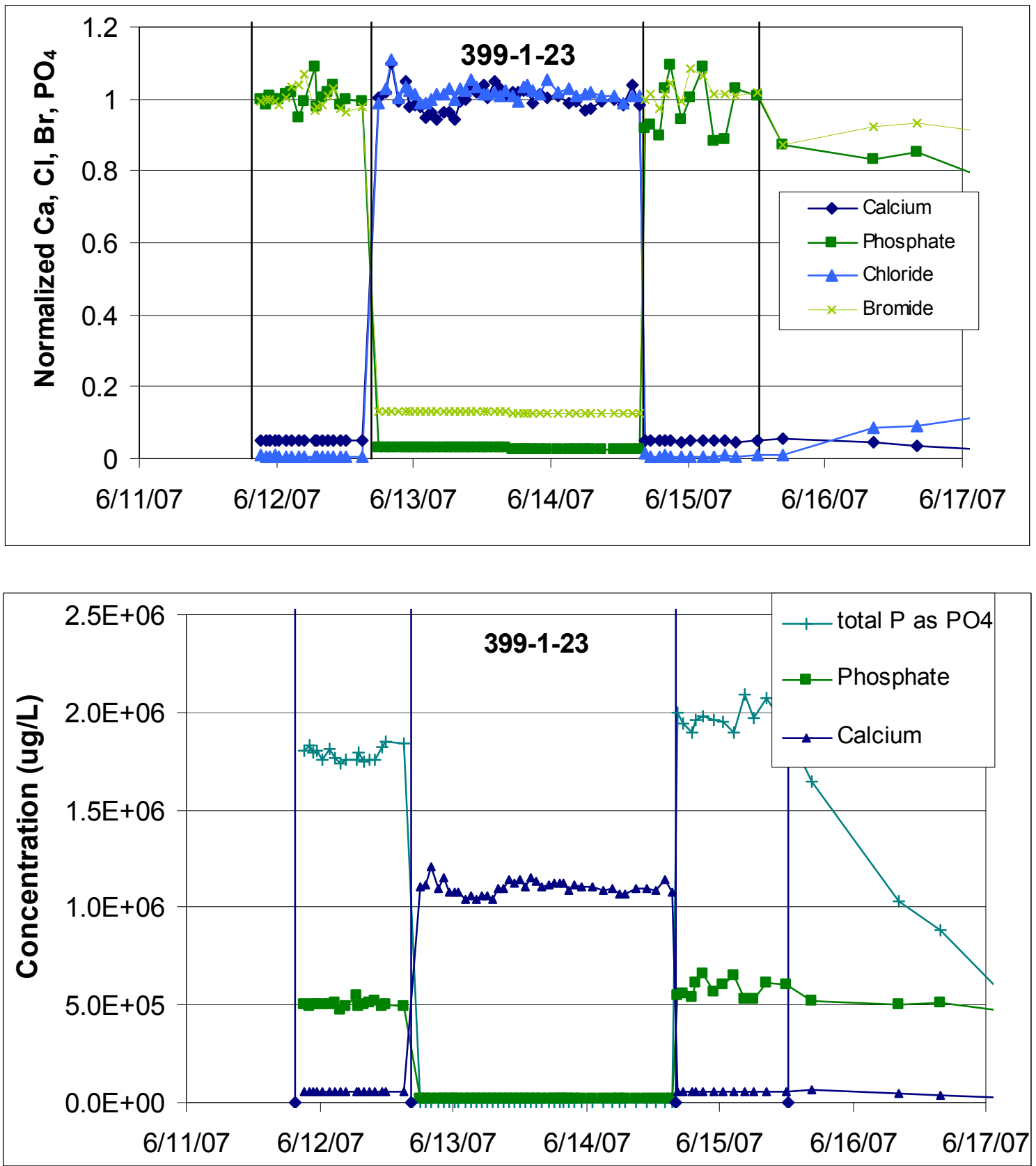

Figure C.1. Calcium/Phosphate Amendment Concentrations in Injection Well 399-1-23 

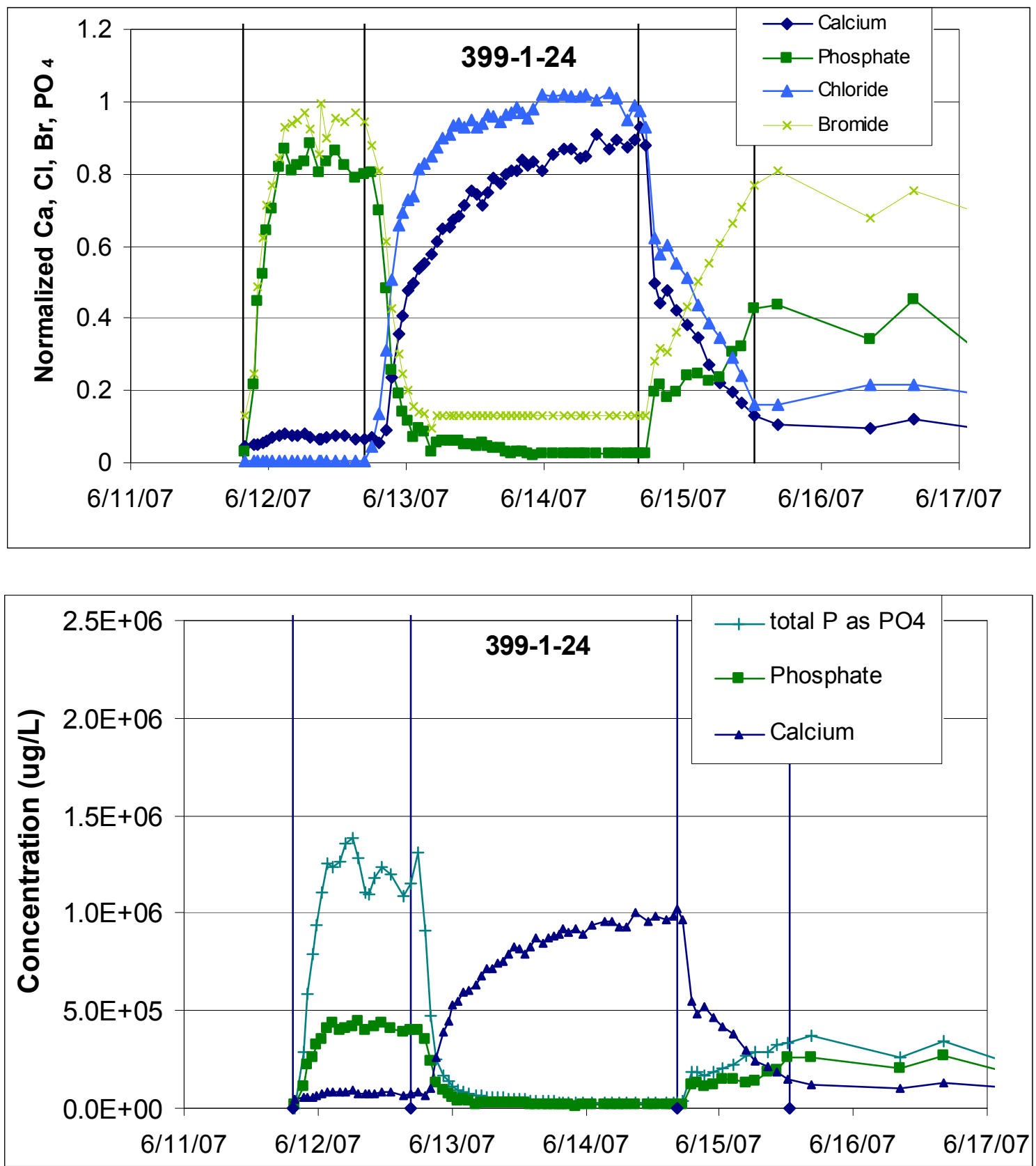

Figure C.2. Calcium/Phosphate Amendment Concentrations in Injection Well 399-1-24 

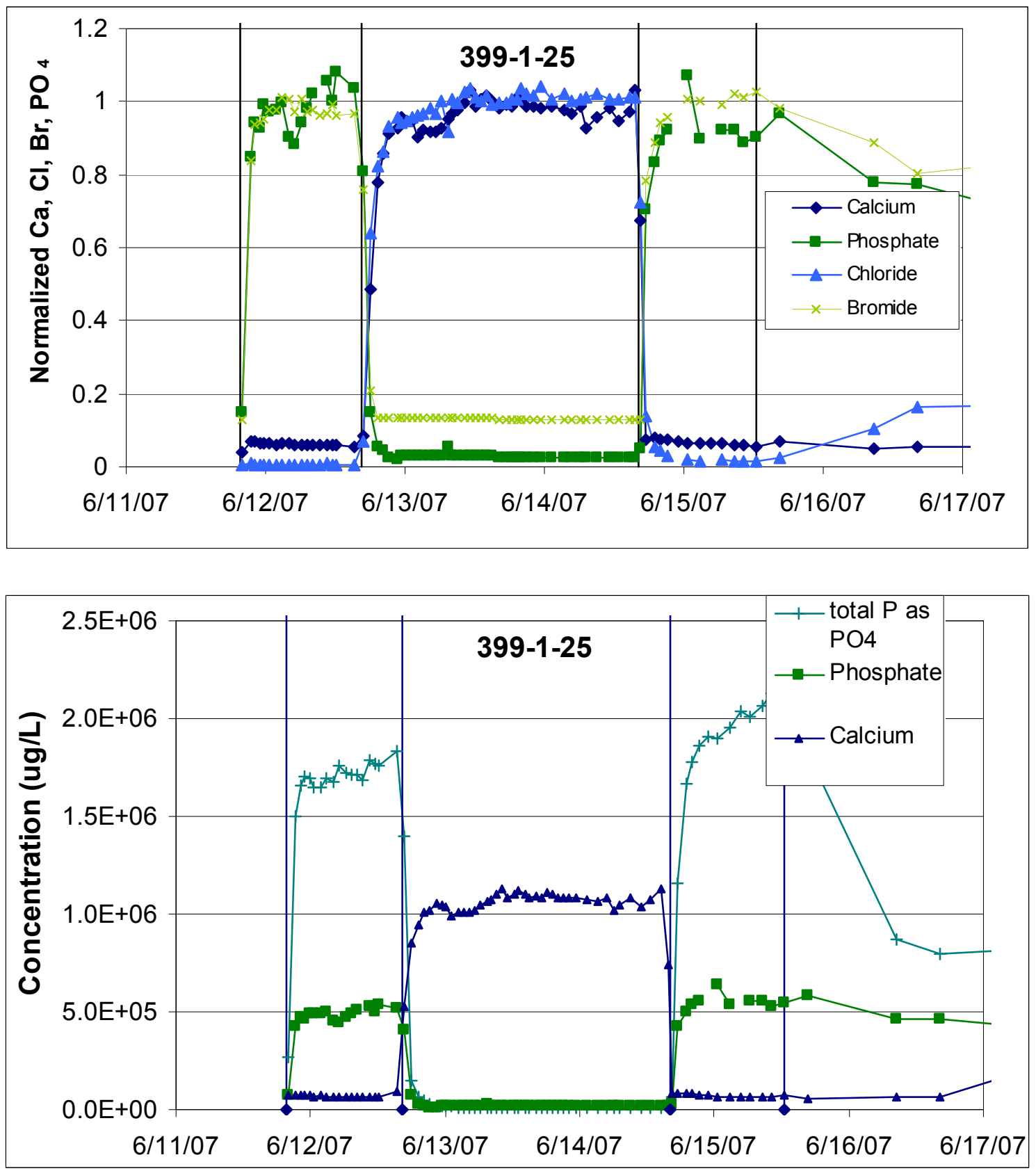

Figure C.3. Calcium/Phosphate Amendment Arrival Response for Monitoring Well 399-1-25 

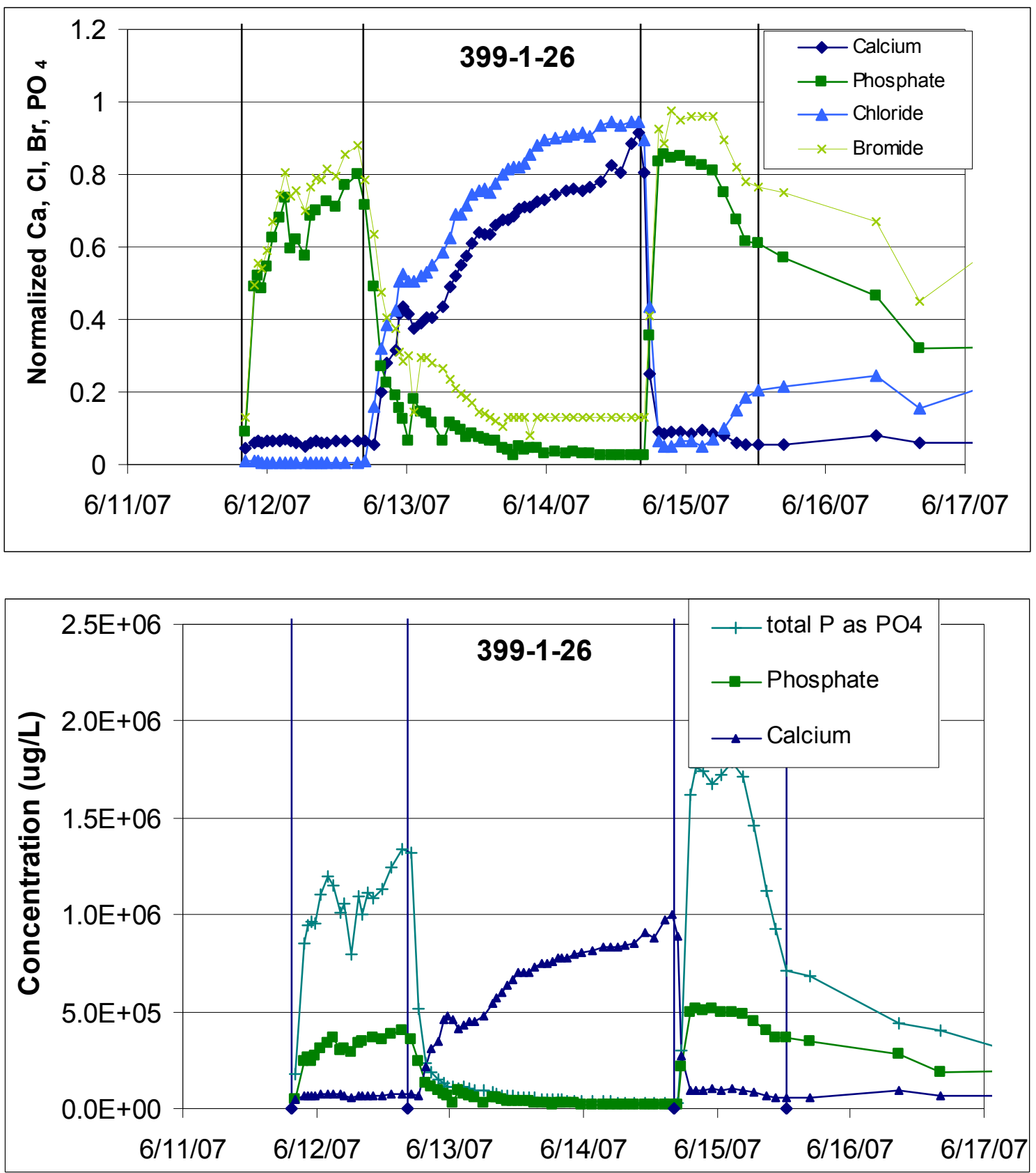

Figure C.4. Calcium/Phosphate Amendment Arrival Response for Monitoring Well 399-1-26 

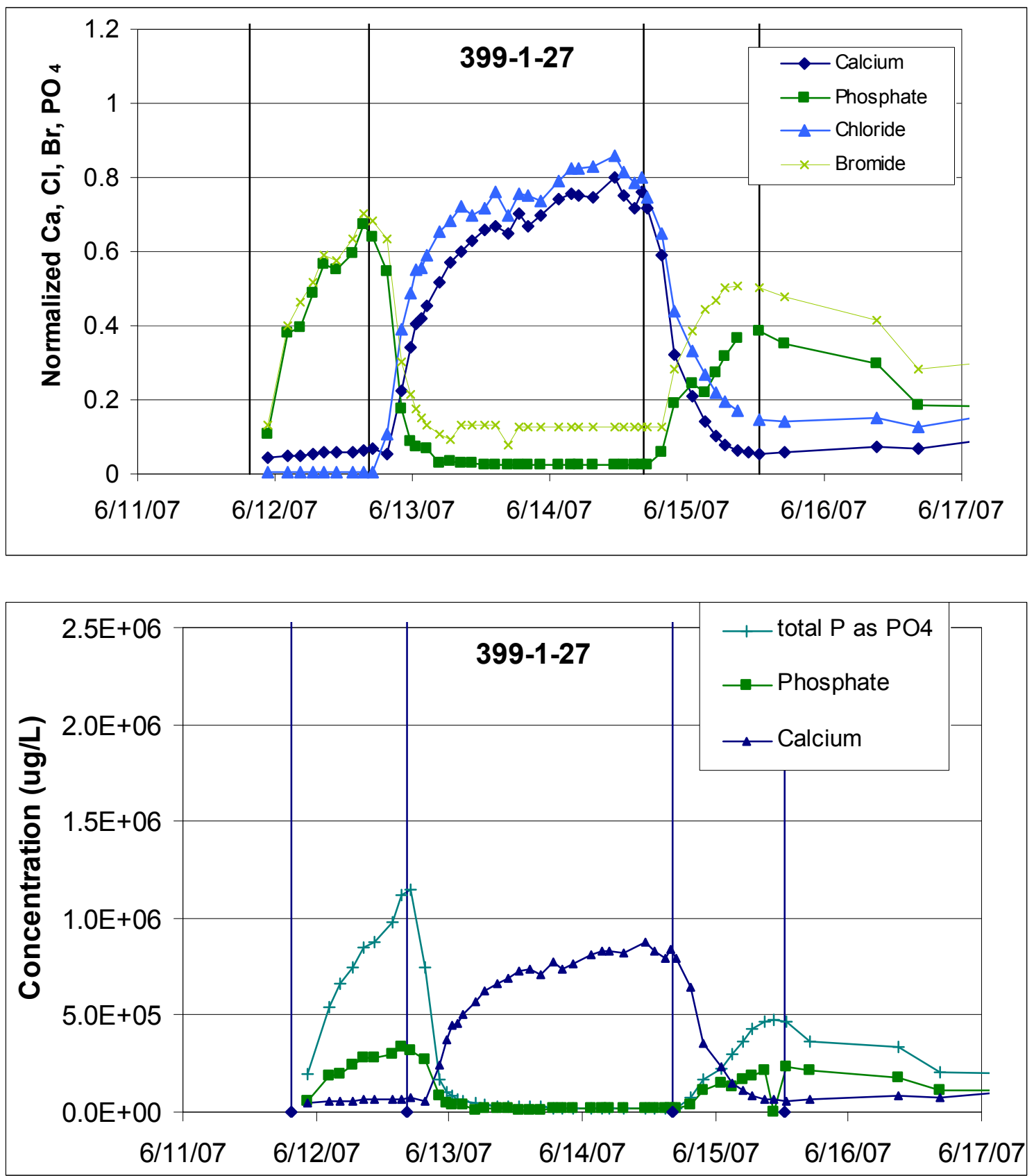

Figure C.5. Calcium/Phosphate Amendment Arrival Response for Monitoring Well 399-1-27 

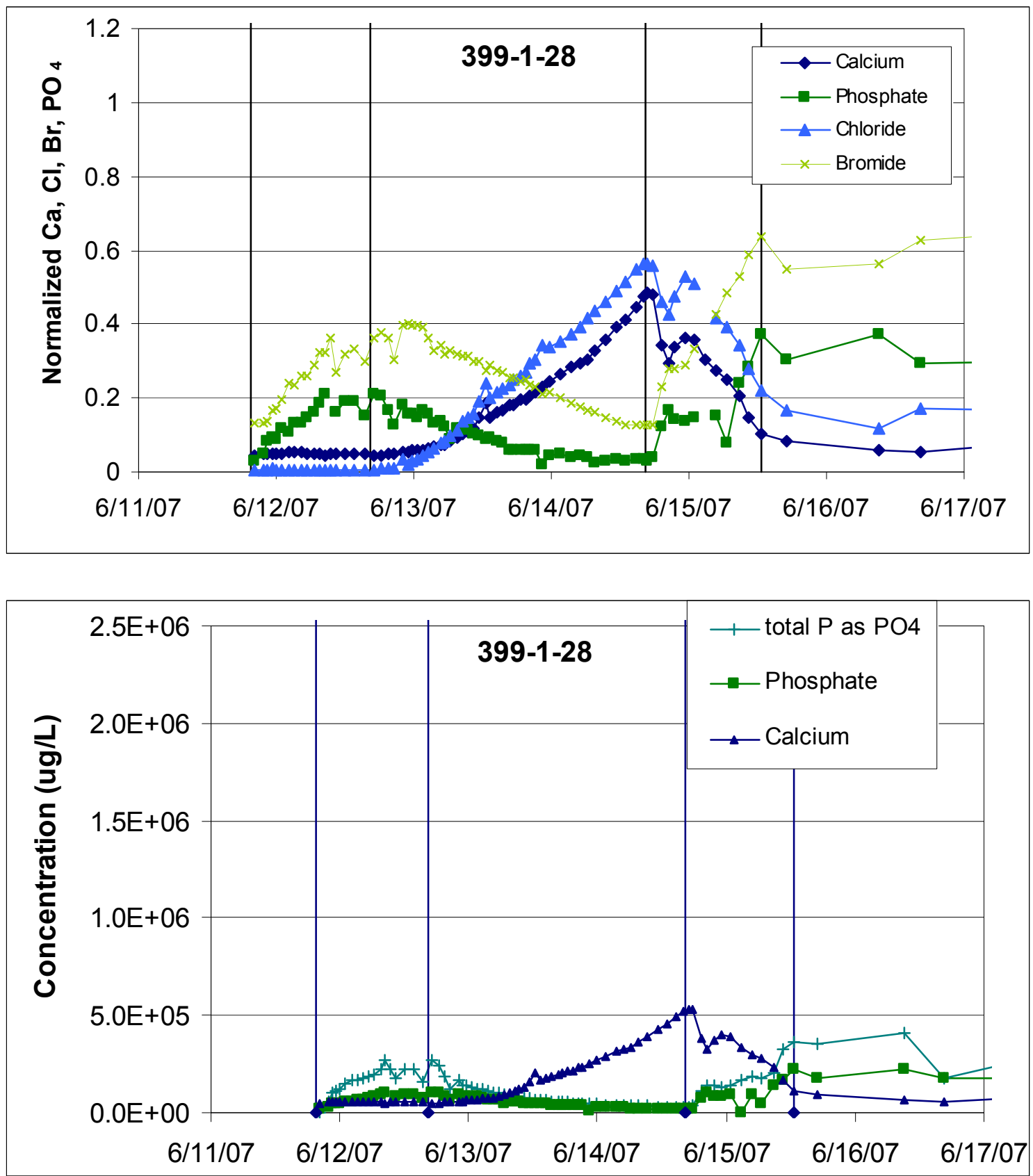

Figure C.6. Calcium/Phosphate Amendment Arrival Response for Monitoring Well 399-1-28 

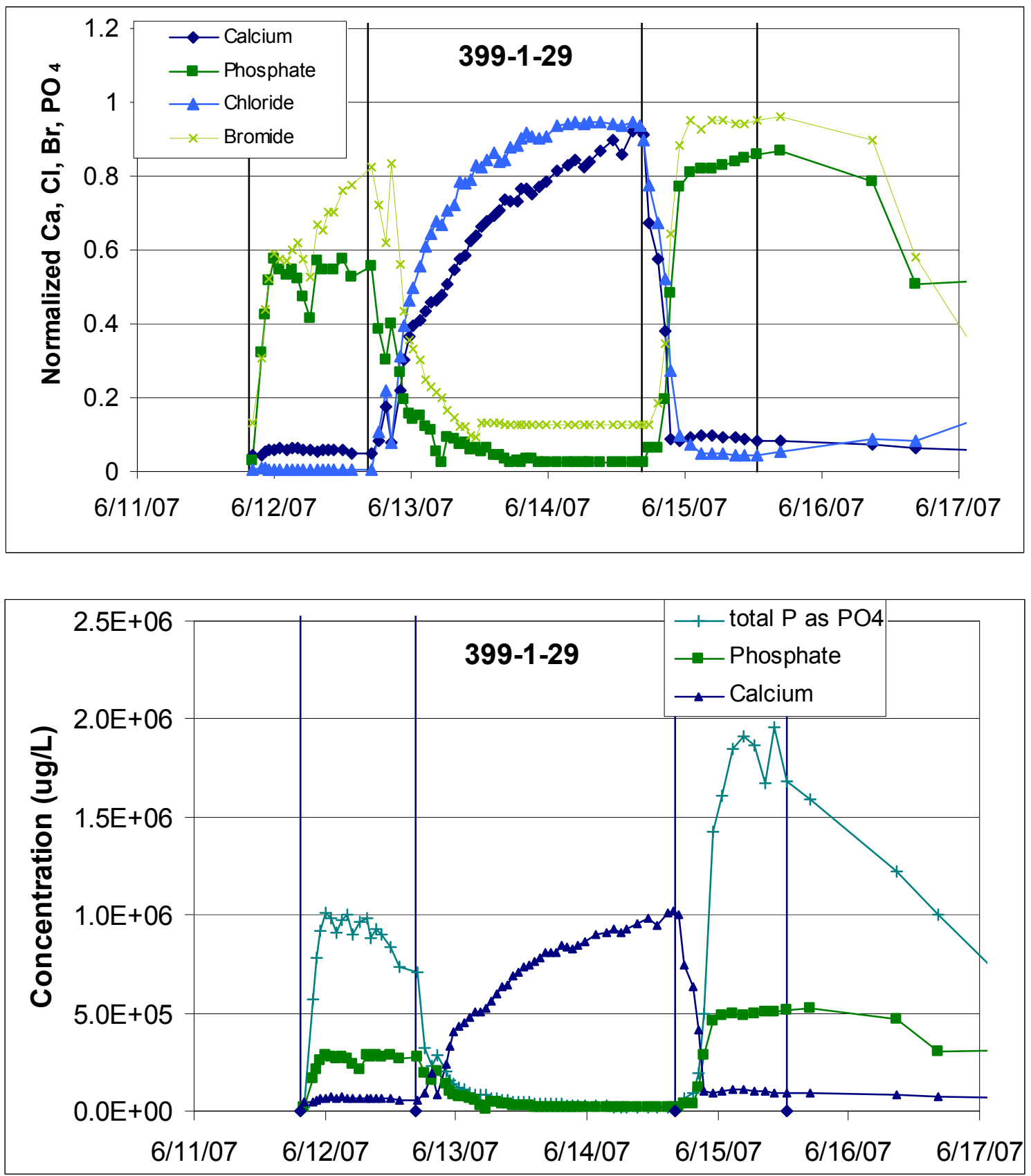

Figure C.7. Calcium/Phosphate Amendment Arrival Response for Monitoring Well 399-1-29 

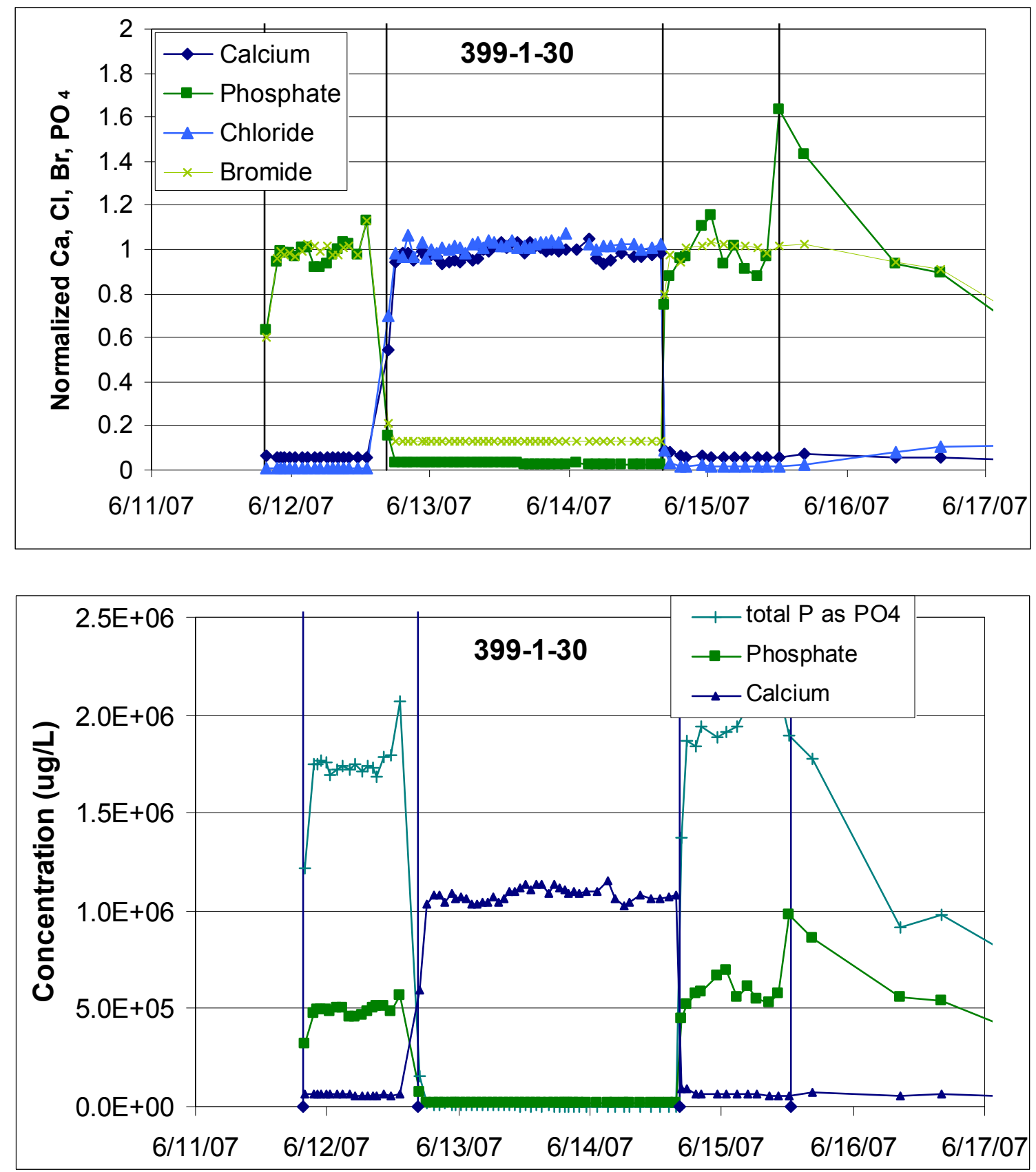

Figure C.8. Calcium/Phosphate Amendment Arrival Response for Monitoring Well 399-1-30 

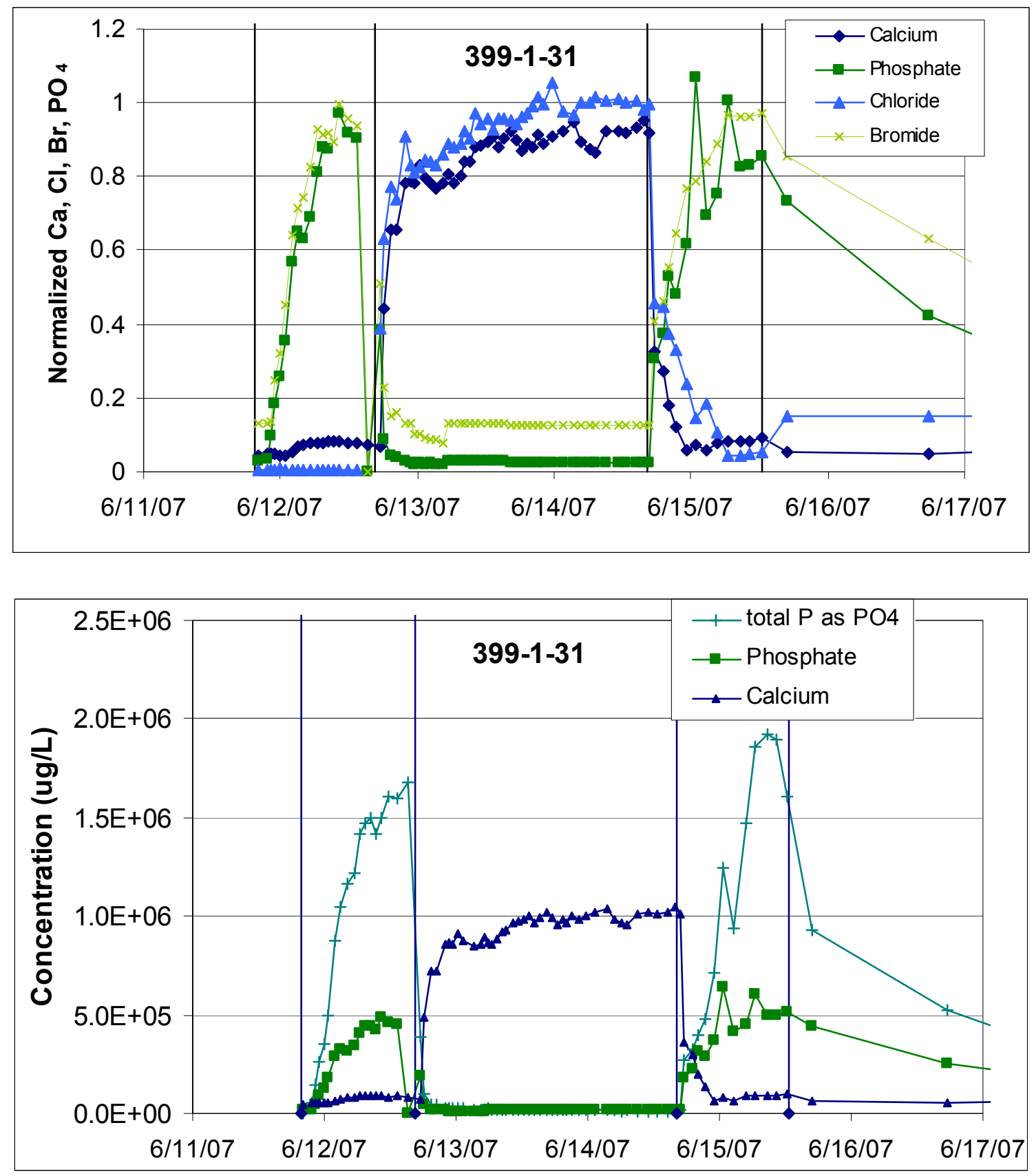

Figure C.9. Calcium/Phosphate Amendment Arrival Response for Monitoring Well 399-1-31 

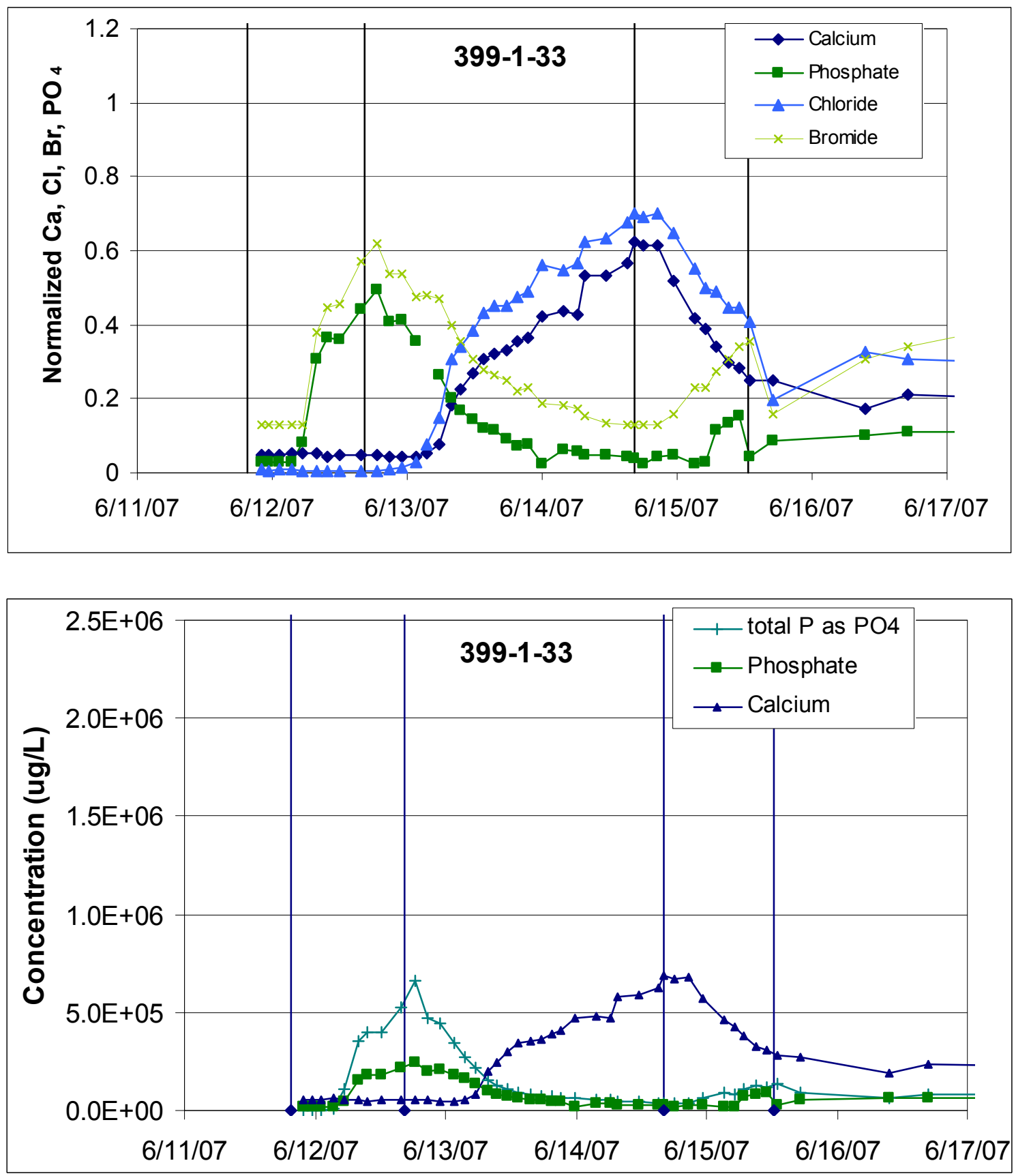

Figure C.10. Calcium/Phosphate Amendment Arrival Response for Monitoring Well 399-1-33 

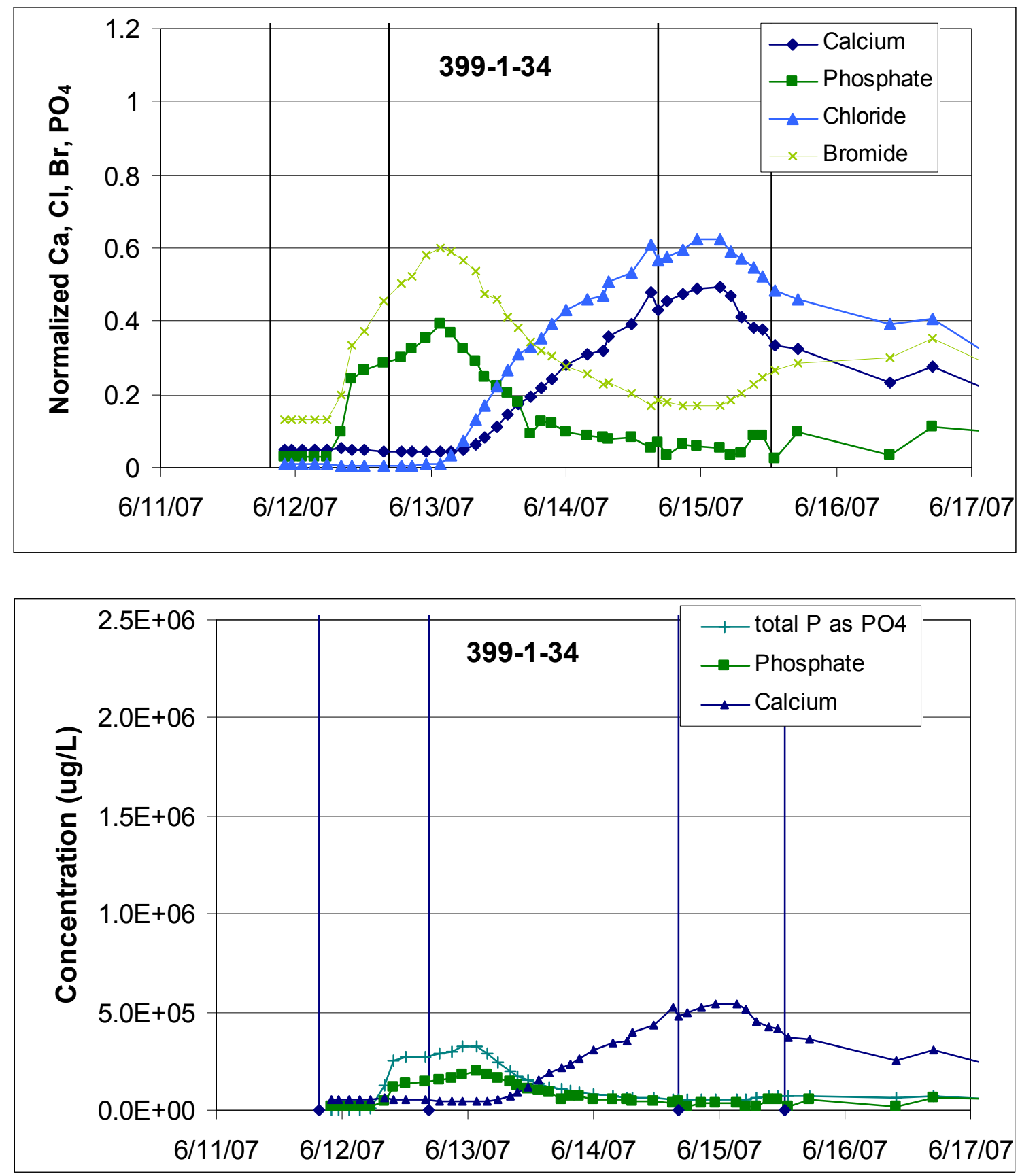

Figure C.11. Calcium/Phosphate Amendment Arrival Response for Monitoring Well 399-1-34 

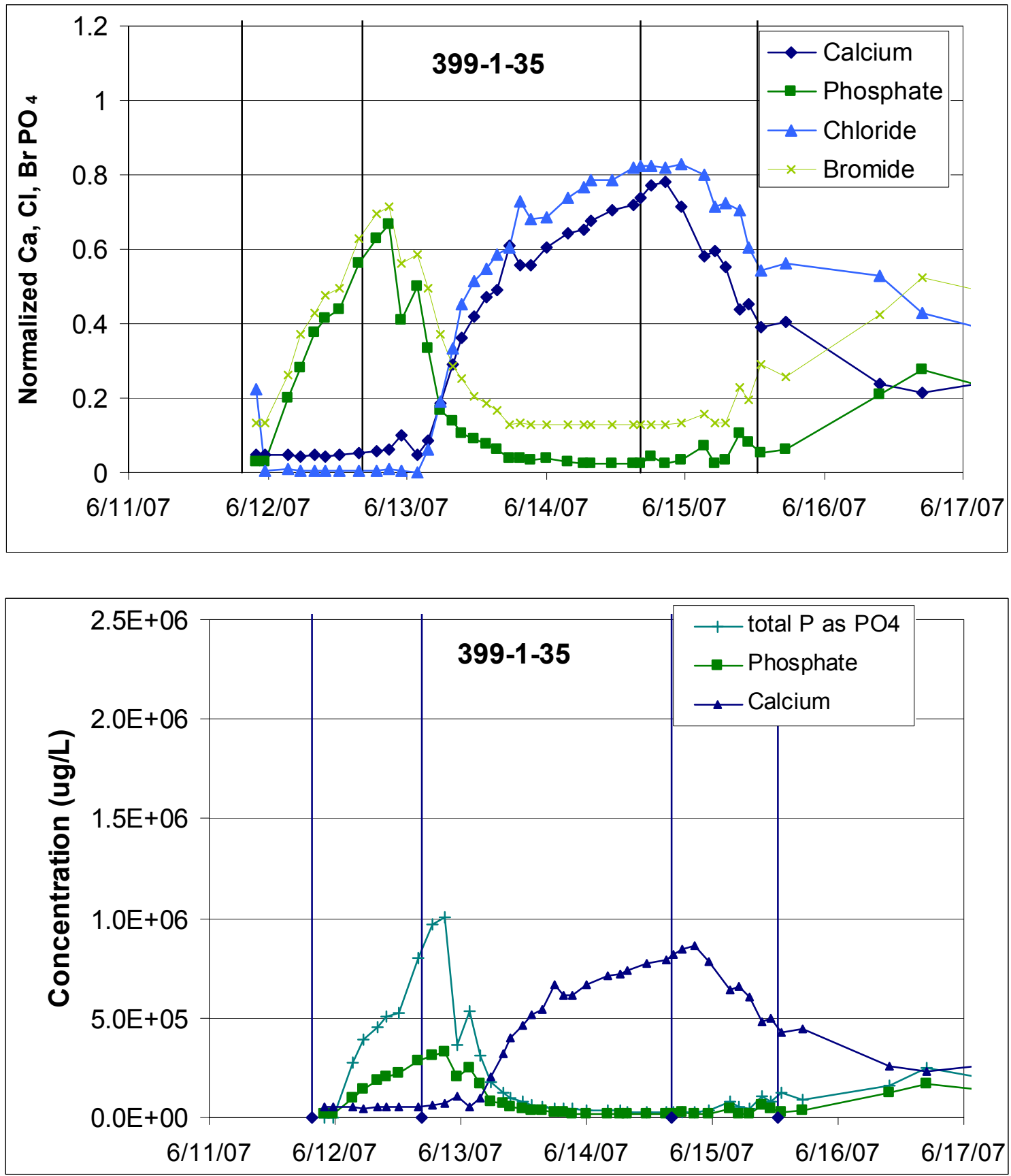

Figure C.12. Calcium/Phosphate Amendment Arrival Response for Monitoring Well 399-1-35 

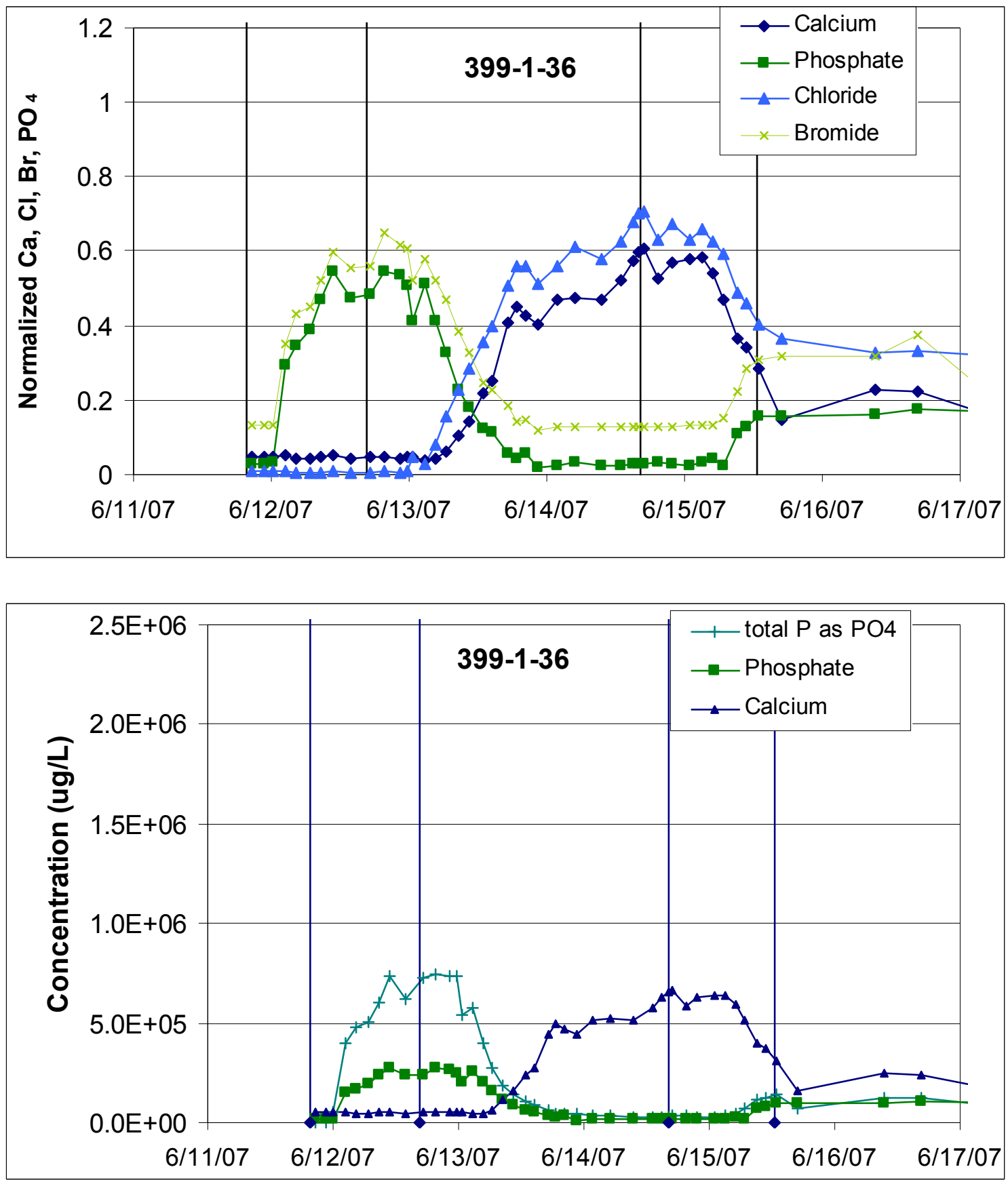

Figure C.13. Calcium/Phosphate Amendment Arrival Response for Monitoring Well 399-1-36 

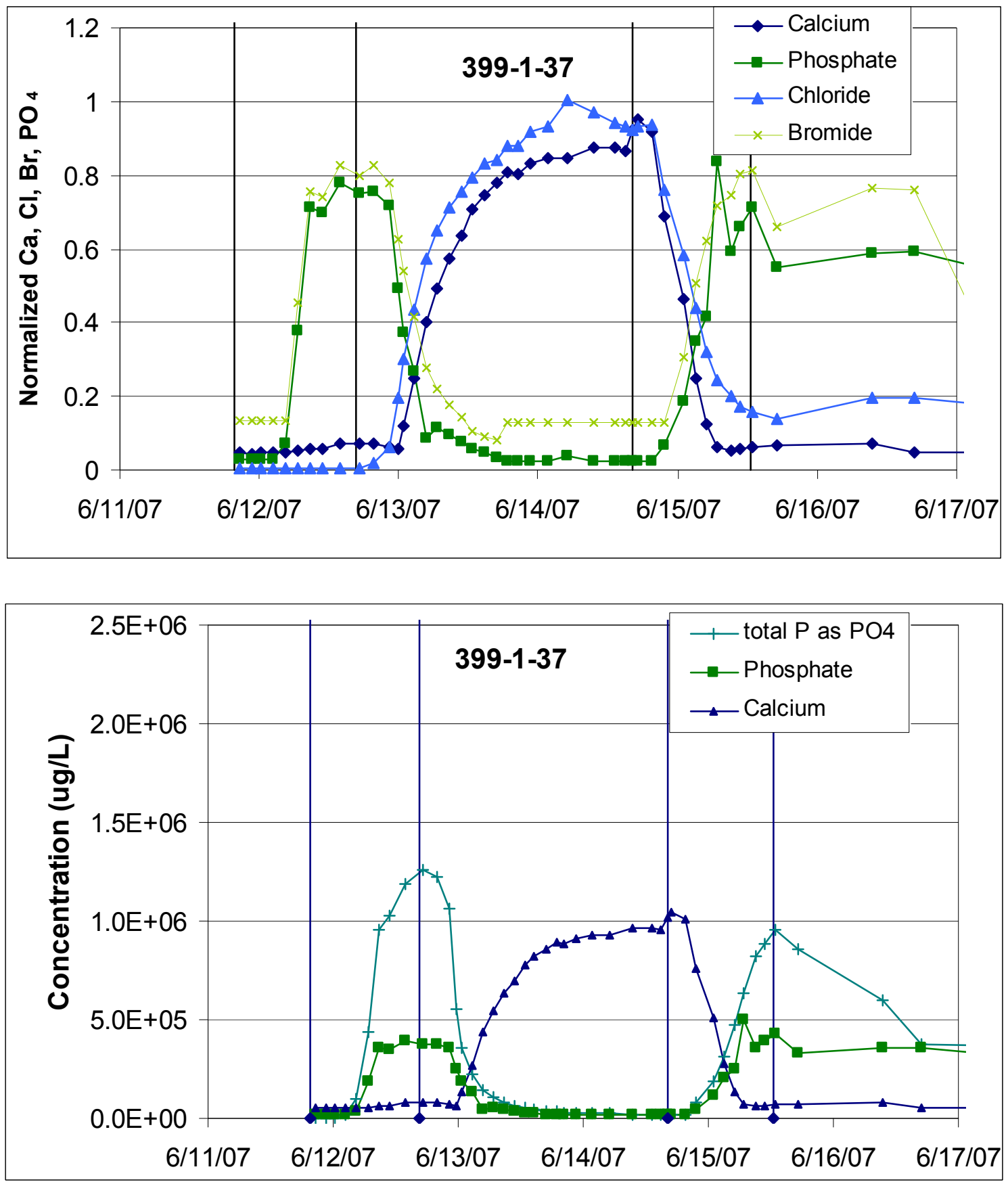

Figure C.14. Calcium/Phosphate Amendment Arrival Response for Monitoring Well 399-1-37 

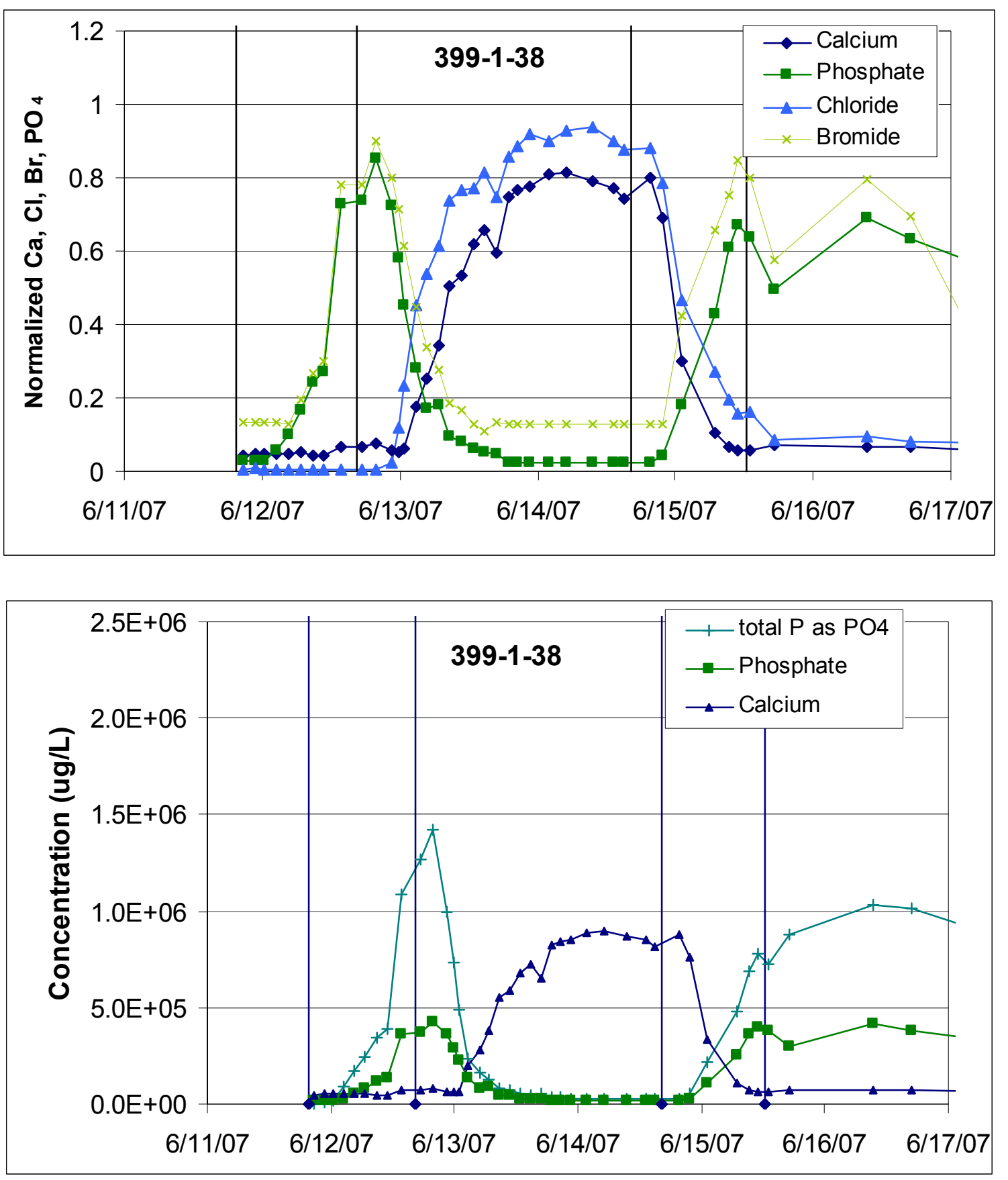

Figure C.15. Calcium/Phosphate Amendment Arrival Response for Monitoring Well 399-1-38 


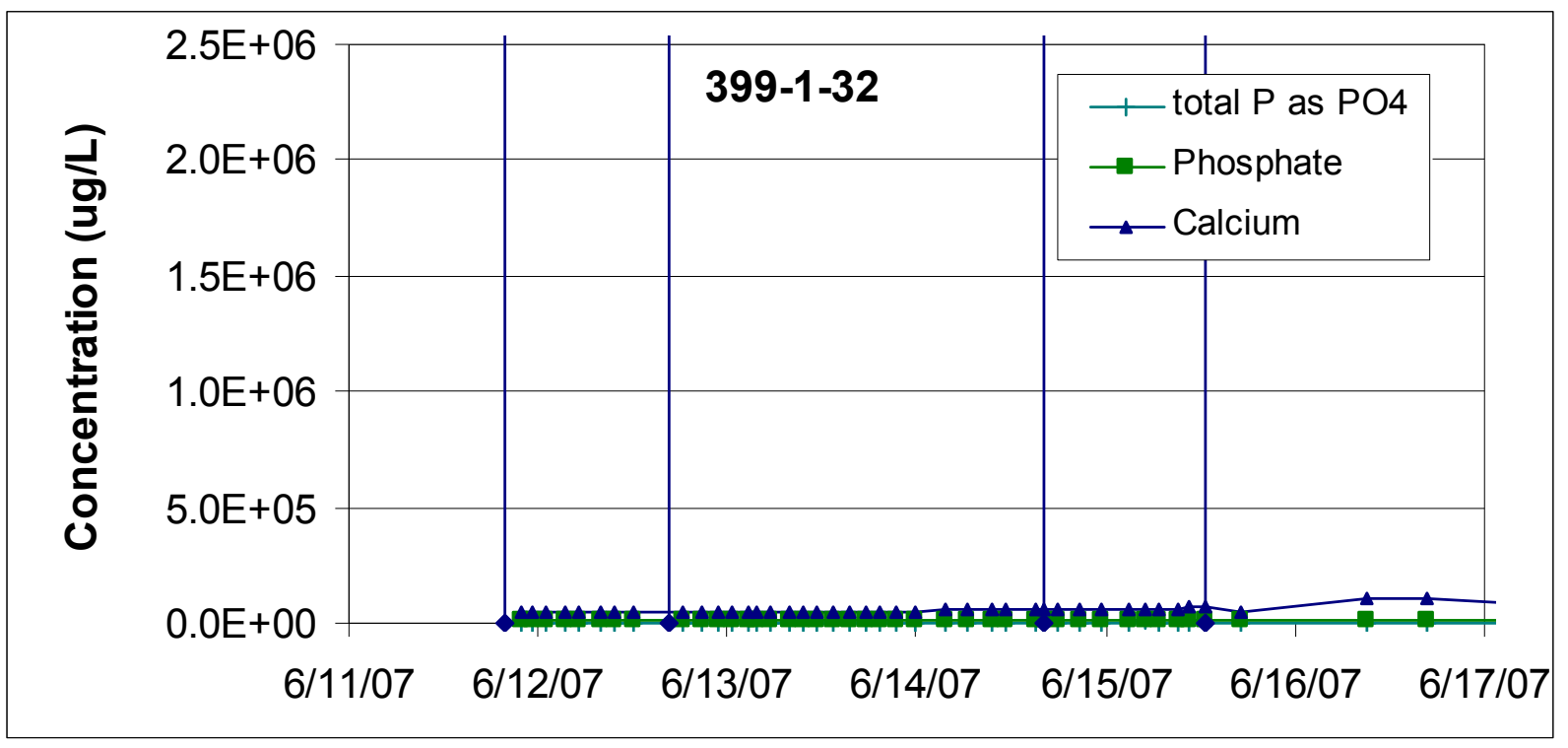

Figure C.16. Calcium/Phosphate Amendment Arrival Response for Monitoring Well 399-1-32

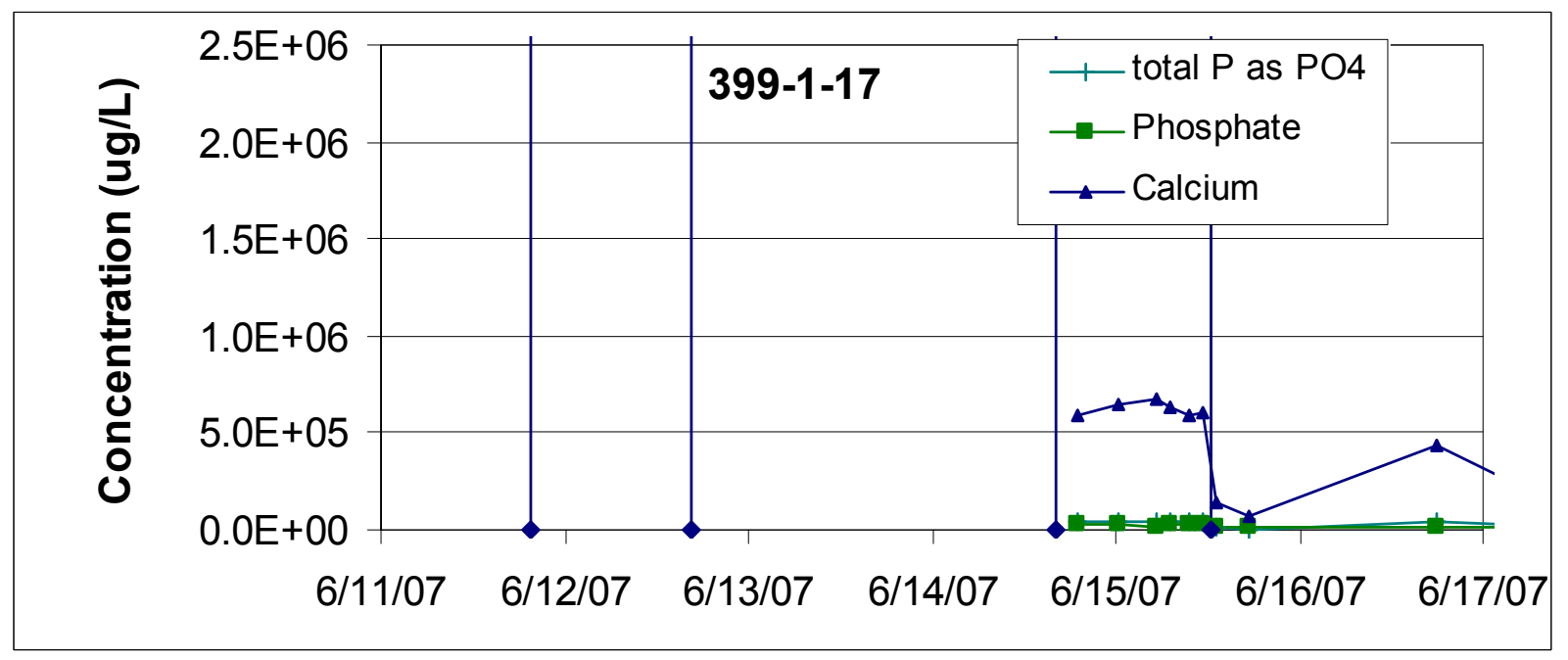

Figure C.17. Calcium/Phosphate Amendment Arrival Response for Monitoring Well 399-1-17 


\section{Appendix D}

Aqueous Uranium Performance Assessment Monitoring Data 


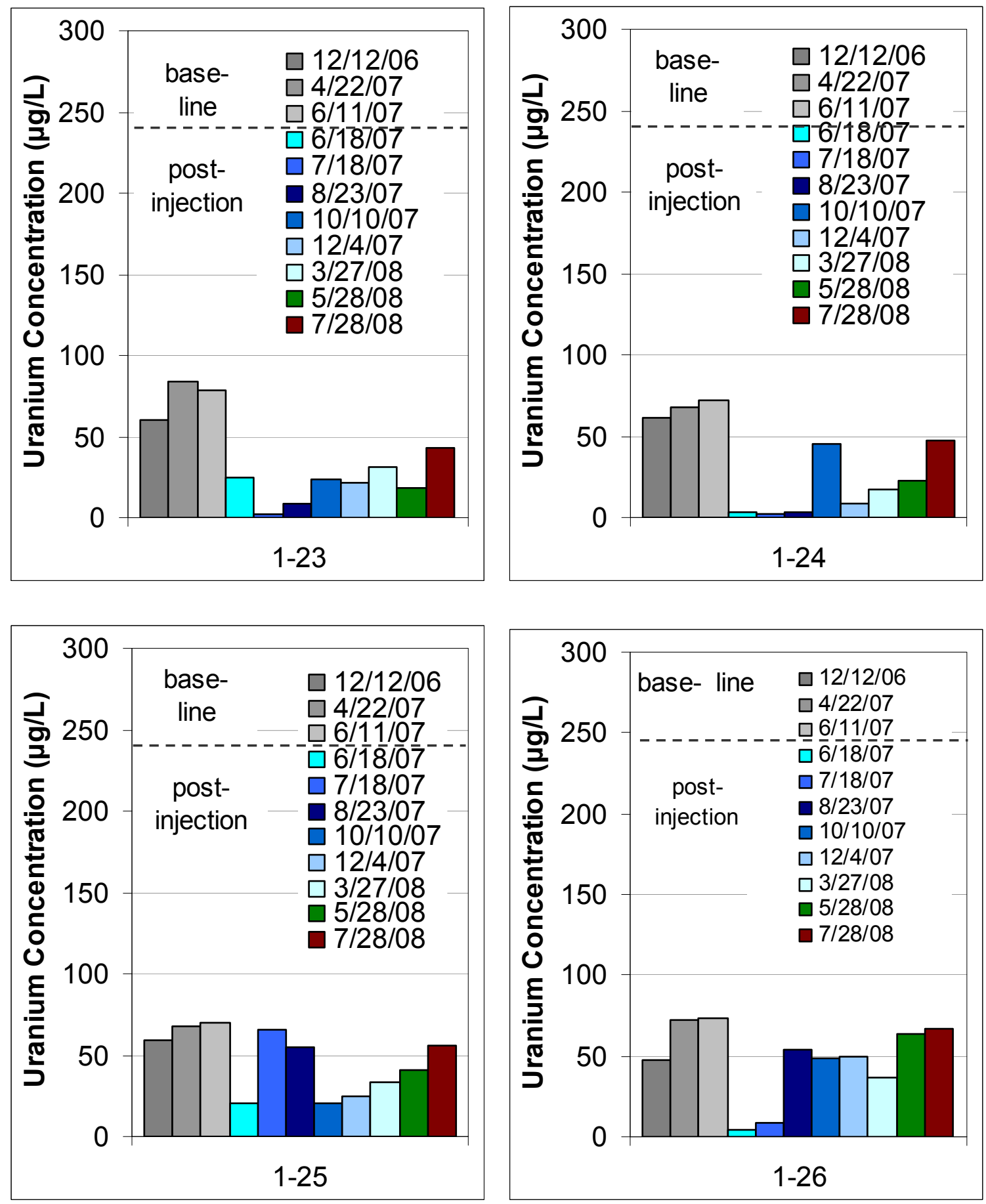

Figure D.1. Uranium Concentration Trends in Monitoring Wells 399-1-23 Through 399-1-26 

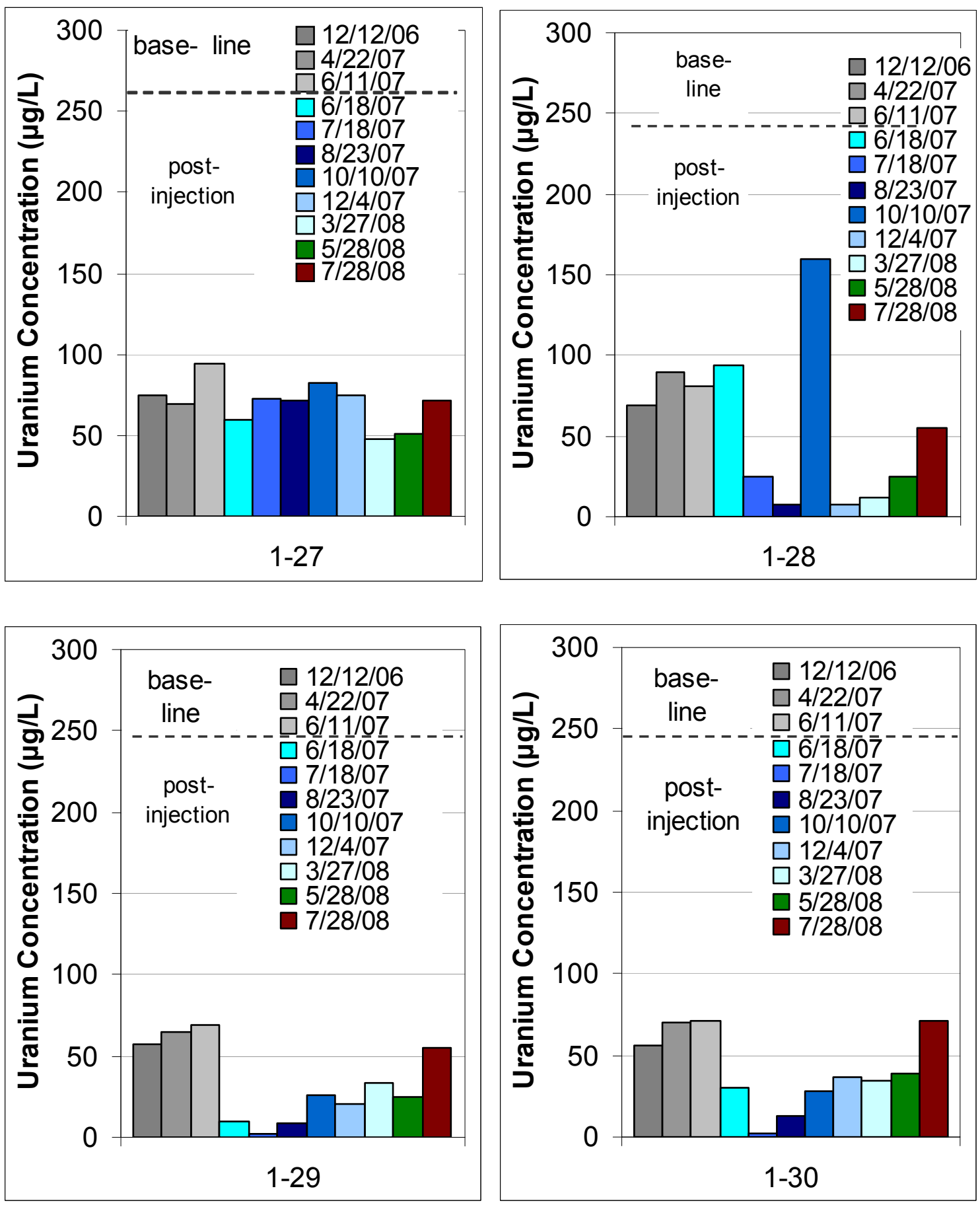

Figure D.2. Uranium Concentration Trends in Monitoring Wells 399-1-27 Through 399-1-30 

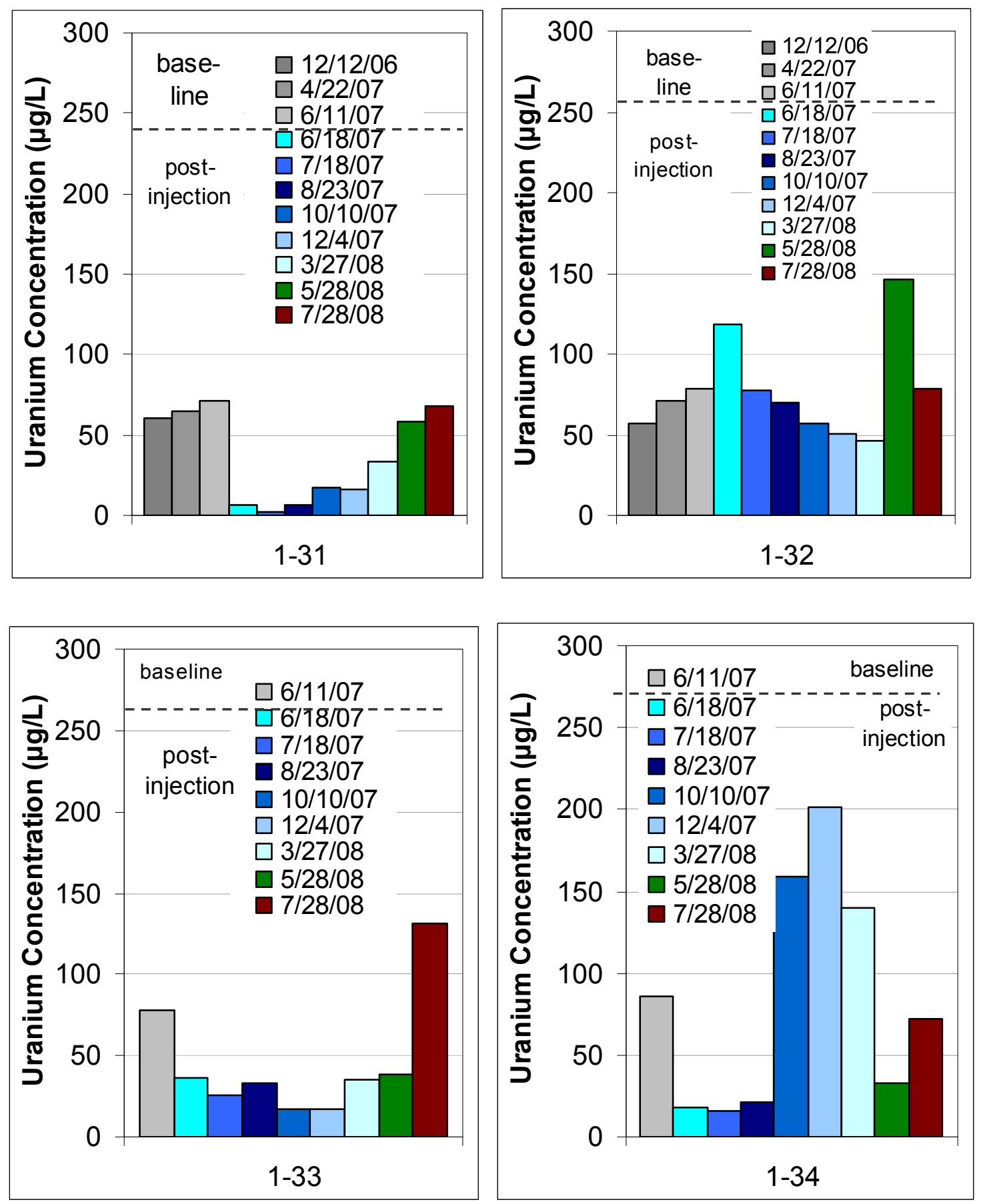

Figure D.3. Uranium Concentration Trends in Monitoring Wells 399-1-31 Through 399-1-34 

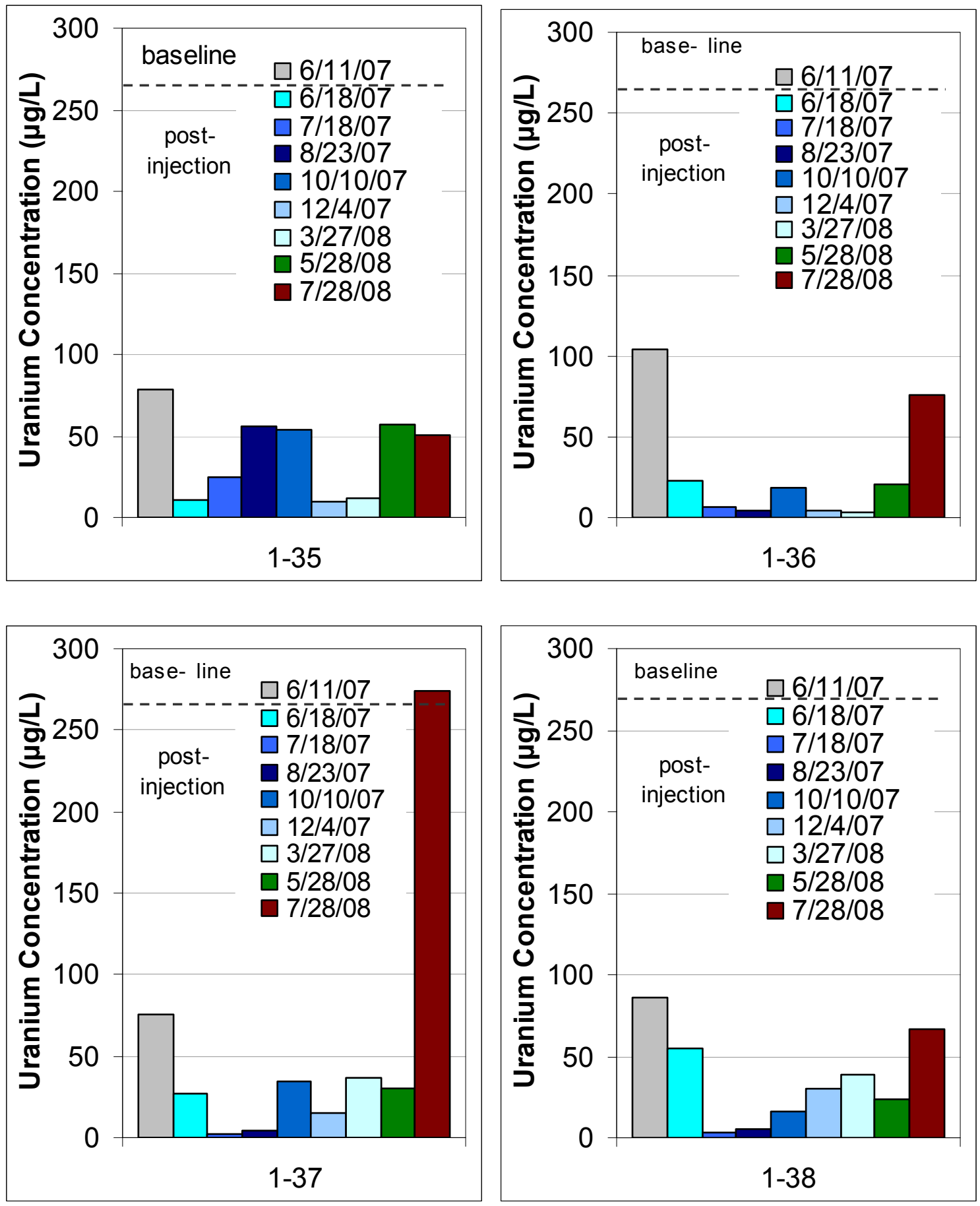

Figure D.4. Uranium Concentration Trends in Monitoring Wells 399-1-35 Through 399-1-38 


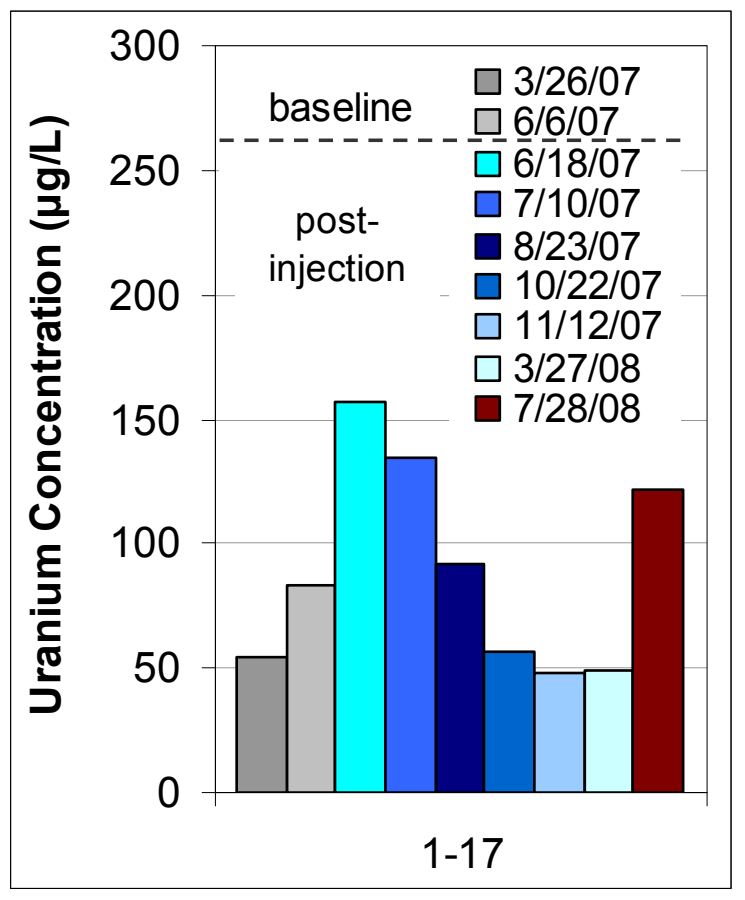

Figure D.5. Uranium Concentration Trends in Monitoring Well 399-1-17 



\section{Distribution}

No. of

Copies

2 Offsite Distribution

2 Office of Groundwater and Soil

Remediation

Em-22/Cloverleaf Building

U.S. Department of Energy

1000 Independence Avenue, SW

Washington, D.C. 20585-2040

RB Rowley

G Chamberlain
No. of

Copies
19 Onsite Distribution

14 Pacific Northwest National Laboratory

VR Vermeul (5)

K6-96

BN Bjornstad

K6-81

BG Fritz

K6-75

JS Fruchter (2)

K6-96

RD Mackley

K6-96

DP Mendoza

K6-96

DR Newcomer

K6-96

ML Rockhold

K9-36

DM Wellman

K3-62

3 U.S. Department of Energy

Richland Operations Office M Thompson (3)

1 CH2M Hill Plateau Remediation Company

JV Borghese

1 U.S. Environmental Protection Agency Hanford Projects Office

LE Gadbois

B1-46 




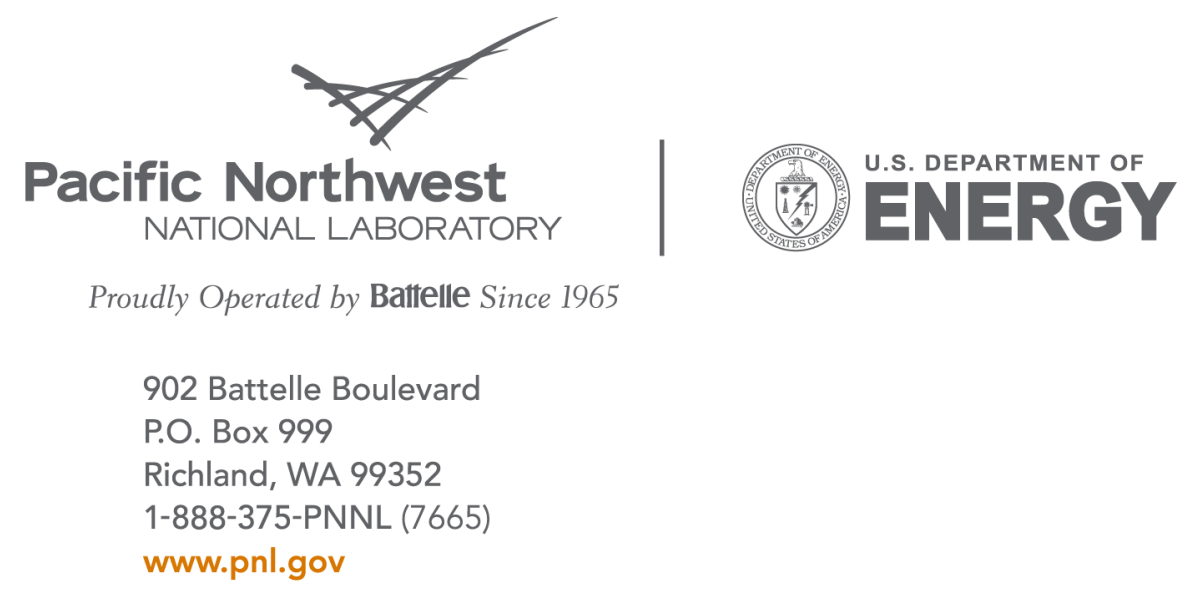

